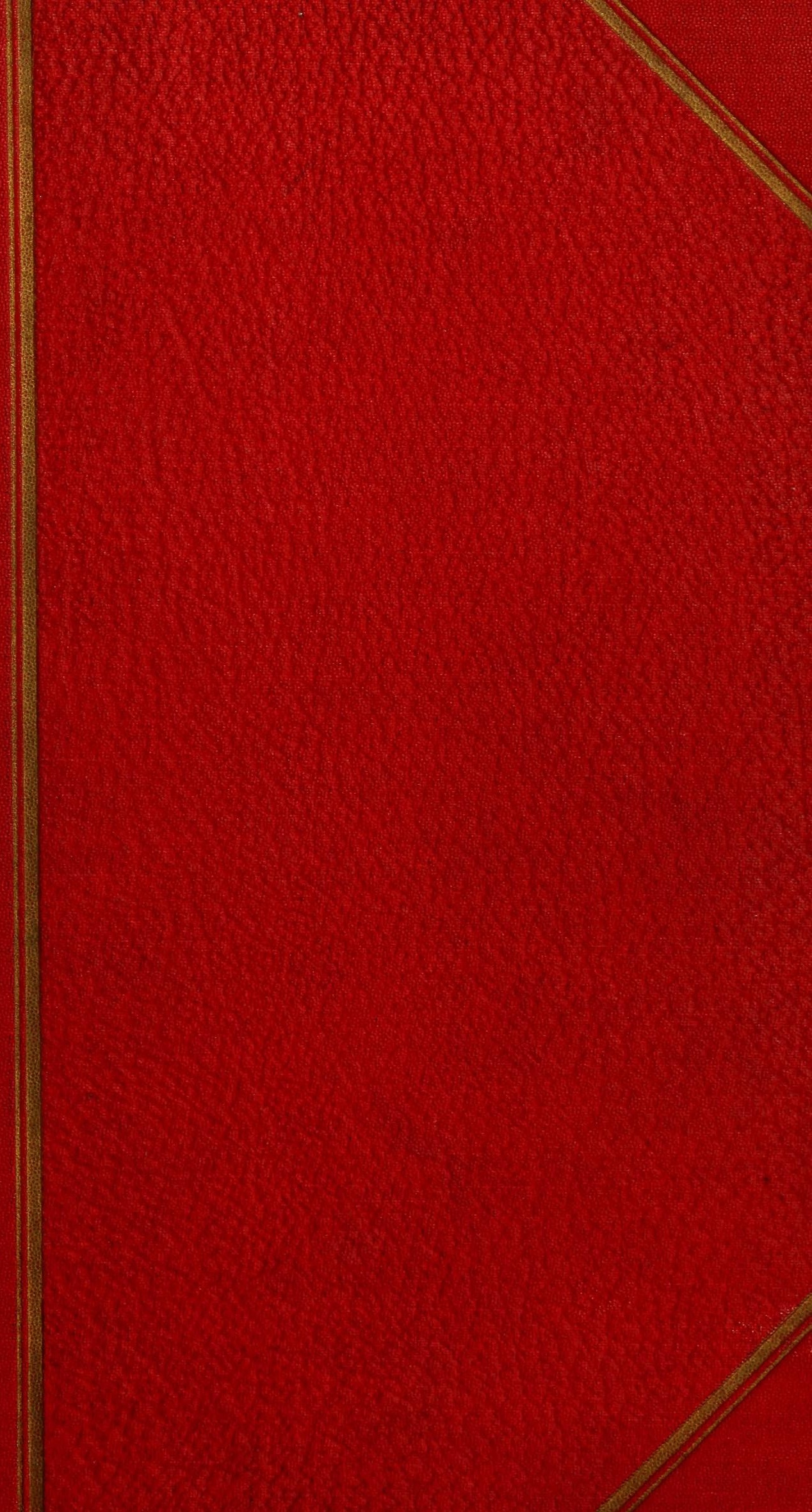





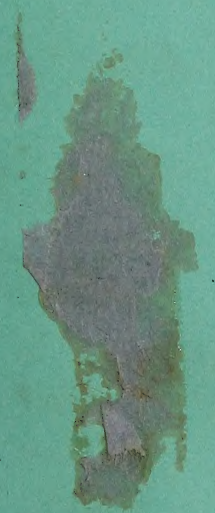





\section{LE SÉNÉGAL}

ET

LE SOUDAN FRANGAIS 



\section{PAUL GAFFAREL, $1843-1920$}

\section{LE SÉNÉGAL}

"

\section{SOUDAN FRANGAIS}

Illustrations de NESTEL, SPENER,-SPEGHT, TRAVIÈS, etc.

SIXIÈME ÉDITION

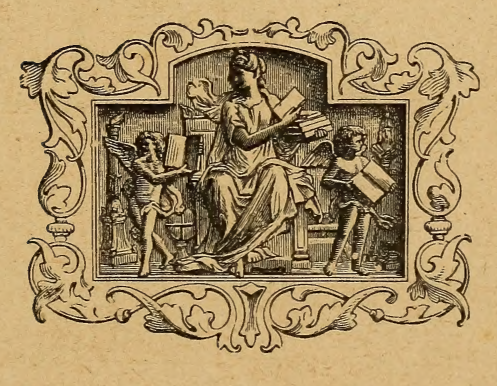

\section{PARIS}

L I B A IRIE GH. DELA GR A V E

15 , RUE SOUFFLT, 15

$\overline{1898}$ 



\title{
LE SÉNÉGAL
}

\section{ET LE SOUDAN FRANĢAIS}

\author{
I \\ GÉOGRAPHIE PHYSIQUE DU SÉNÉGAL
}

Notre colonie ${ }^{1}$ du Sénégal n’a pas de limites fixes, sauf à l'ouest, où l'Atlantique lui sert de frontière naturelle. Au sudest se dresse un massif montagneux qui n'a pas encore de nom. Jomard proposait de l'appeler les Alpes africaines. La dénomination de massif du Fouta-Djallon lui conviendrait mieux. Nous sommes arrivés au pied de ce massif; nous l'avons même franchi, mais nous n'en sommes pas encore les maîtres incontestés. Au nord s'étendent les sables brûlants et les steppes du Sahara, au sud les forêts équatoriales, à l'est le bassin du Niger, dans lequel nous commençons à nous étendre; mais nul encore ne peut déterminer avec précision où commence, où finit notre domination.

Le noyau central de la colonie a été Saint-Louis, à l'embouchure du Sénégal. Elle s'étend aujourd'hui au nord, dans la direction du Maroc, jusqu'au cap Blanc, à l'est jusqu'au Niger et à son affluent le Tankisso, au sud, par postes intermittents, jusqu'à l'embouchure de la Mellacorée. Seulement tout le territoire compris entre ces points extrêmes, SaintLouis et Bamakou, le cap Blanc et Mellacorée, ne nous appartient pas en entier. Nous y avons seulement échelonné des

1. N. Dourneaux-Dupéré, la Sénégambie française (Société de géographie de Paris); 1871. - Muiron d’Arcenart, Notice sur le Sénégal (id.); 1877. - G. Delor, le Sénégal (Congrès géographique de Lyon); 1881. - Gévêral Faidherbe, le Sénégal, la France dans l'A frique occidentale; 1889. 
postes, centres futurs de colonisation. Il est donc impossible de fixer les limites et d'évaluer la superficie du Sénégal.

Même incertitude pour la géographie physique proprement dite. Bien que traversé à diverses reprises par nos officiers ou nos négociants, le massif du Fouta-Djallon, où prennent leur source tous les grands cours d'eau de cette partie de l'Afrique, est encore bien mal connu. On en a singulièrement exagéré l'altitude. En 1850 on avait signalé à Hecquard le mont Maminia, à l'ouest du plateau de Labé, comme couvert de pluies blanches, c'est-à-dire de neiges. Or il ne lui fallut que cinq heures de marche pour arriver au sommet, et il n'y rencontra pas la moindre trace de neige. Lambert, en 1860 , évaluait à trois mille mètres l'altitude du Sondoumali, et croyait que certains pics dépassaient quatre mille mètres; mais en ce cas on les apercevrait de la basse Falémé ou de la moyenne Gambie. Or on n'aperçoit ces cimes que lorsqu'on arrive à leur pied. Autant qu'on peut le conjecturer, leur hauteur probable est seulement de deux mille mètres, et l'altitude moyenne du massif ne dépasse pas douze cents mètres.

On sait pourlant que la chaîne présente son versant abrupt du côté de l'orient, et que les contreforts et les terrasses sont au contraire tournés vers l'occident. La plus grande partic du massif est formée par des plateaux peu accidentés, les Baowals, appuyés sur des degrés extérieurs, ou plutôt des terrasses, qui se succèdent vers les plaines côtières. Tous ces plateaux sont comme séparés par les fleuves en fragments inégaux. On commence également à connaître quelques-uns de leurs contreforts. Deux de ces contreforts ont été plus souvent visités : les monts Tongue, qui séparent la Falémé de la Gambie, et les monts Tamba-Oura, jetés entre le Bafing ct la Falémé. Le Tamba-Oura est un système de montagnes à crête continue, qui paraît avoir élé coupé dans sa longueur par un plan vertical, et dont la partie antérieure s'est éboulée : aussi la montagne est-elle généralement inaccessible. Un seul défilé traverse ie Tamba-Oura; on le nomme le Kouroudabo, ou porte des Roches. Ses flancs ressemblent à des murailles construites de main d'homme; les étages supéricurs surplombent les premiers, et les blocs qui se sont 

délachés encombrent le fond de la gorge et la rendent peu praticable.

C'est dans le massif, encore si mal exploré, du FoutaDjallon que prennent leur source la plupart des rivières qui arrosent nos possessions, el tout d'abord le plus important de ces cours d'eau, le Sénégal.

De puis l'Oum-cl-Rhia, le plus méridional des fleuves marocains, jusqu'à Saint-Louis, sur une longueur de deux mille deux cents kilomètres en ligne presque droite, aucun cours d'eau ne rompt la monotonie du rivage ${ }^{1}$. Aussi le Sénégal, c'est-à-dire le premier fleuve permanent qui atteigne la mer au sud du Sahara, marque-t-il neltement la limite entre deux mondes et entre deux races, et son importance est-elle grande à la fois comme frontière elhnographique et comme voie de pénétration dans l'intérieur du continent. Les anciens, qui croyaient à l'existence d'un Nil à branches multiples traversant l'Afrique dans tous les sens, prenaient le Sénégal pour une de ces branches, et de fait, comme il existe une ligne tortueuse d'eaux courantes se prolongeant par le Niger, le lac Tchad et ses affluents, et les grands affluents du Nil, c'est sans doute la vague intuition de ce fait géographique qui avait fait croire à l'existence de ce grand fleuve. Le plus singulier, c'est que celte idée se continue au moyen âge. Ainsi Cadamosto appellera le Sénégal tantôt Gihon, tantôt Nil ou Niger. C'est seulement aux temps modernes qu'on le dégagera dans ses traits essentiels et dans son ensemble.

Le vrai nom du fleuve est l'Ovidech ${ }^{2}$. C'est Lanzarote le Génois qui, dans son voyage de 1275 , donna au fleuve le nom d'un Maure qu'il rencontra sur ses rives; mais ce nom est complèlement inconnu des indigènes. Il a longtemps été écrit Sénéga. G'est depuis une centaine d'années seulement, et sans doute pour une raison euphonique, que les Européens ont ajouté une $l$ et transformé en Sénégal le Sénéga d'autrcfois. Les anciens Ouolofs le nommaient Djalli-Balil, et sur les

1. Aube, le Fleuve du Sénégal (Revue maritime et coloniale, 1864).

2. On trouve encore les dénominations Dechgi ou la rivière, Eechundar, la rivière de Saint-Louis, Dechgogilé ou Gogilédech, c'est-à-dire la rivière même. $C f$. note du contre-amiral Vallon sur l'origine des mots Sénégal, Galam et Casamance (Bulletin de la Société de géographie de Paris, 1888, no 6). 
portulans il a longlemps été désigné par la dénomination de Vedamel, ou rivière de l'Or; mais le mot Sénégal a prévalu.

Le Sénégal ne donne pas seulement son nom à la contrée, mais aussi la vie et la fortune. Depuis sa source jusqu'à son embouchure, dans un cours de plus de dix-sept cents kilomètres, il détermine en grande partie " les caractères physiques et même les conditions sociales du pays qu'il traverse ${ }^{1}$ ". C'est lui en effet qui forme la grande ligne de séparation entre les deux races principales d'indigènes, les Maures sur la rive droite, les Noirs sur la rive gauche. Pour les Européens, il est la seule voie de transport de leurs marchandises, qui courraient de graves risques à circuler par terre. Dans celle admirable alliance des forces de la nature et des besoins de l'homme, tout vient du fleuve et s'y rattache: le sol, la culture, le commerce, les mours, la misère et la richesse, la paix et la guerre. Celte harmonie doit toujours être présente à l'esprit de quiconque veut comprendre l'histoire du Sénégal. Elle seule en donne la clef.

On a souvent écrit que le Sénégal élait formé par la réunion, à Bafoulabé, de deux cours d'eau importants, venus, l'un, le Bafing ou Rivière Noire, des monlagnes, et l'autre, le Bakoy ou Rivière Blanche, de la plaine ${ }^{2}$. Le vrai fleuve serait plutôt Je Baoulé, ruisseau qui naît à quelques kilomètres de la rive gauche du Niger, dans un pays accidenté. Ce n'est certes pas le cours d'eau le plus considérable comme masse des eaux, mais c'est le plus direct dans l'axe de la vallée. Il arrose le Bélédougou, puis, se recourbant vers l'ouest, limite les possessions françaises et le Kaarta. Les géographes l'ont traité avec la même injustice que la Saône à l'égard du Rhône ou le Missouri à l'égard du Mississipi, mais il n'en est pas moins la fulure artère de notre commerce avec l'Afrique intéricure. Ses affluents de la rive droite, c'est-à-dire du côté saharien, sont rares. Ils sont abondants au contraire au versant méridional. Le plus important est le Bafing, qui descend des montagnes du Fouta-Djallon, à sept cent cinquante mètres d'altitude, coule d'abord au sud, puis décrit une grande courbe à

1. Duval, les Colonies françaises, p. 29.

2. Delanveau, Exploration du cour's du Bakoy (Société de géographie de Bordeaux); 1 ss2. 
l'est, au nord-est et au nord. Comme il n'est alimenté que par les eaux de pluie, et seulement pendant trois mois de l'année, on pourrait s'altendre à ce que l'évaporation le tarît pendant la saison de la sécheresse; mais son lit est obstrué par de nombreux barrages de roches ou de sables, qui le parlagent en biefs où l'eau reste sans écoulement, comme dans aulant de lacs élagés. On dirait une série de réservoirs, unis par des filets d'eau qui glissent sur les rochers des seuils. Nous avons en France plusieurs rivières qui ressemblent au Bafing, l'Ain, la Durance, etc., qui ne tarissent jamais, même en temps de sécheresse, grâce à ces réservoirs naturels.

A partir de Bafoulabé, c'est-à-dire, en langue malinké, des Deux-Rivières, le Sénégal se trouve encore à cent quarantetrois mètres d'altitude. Son lit, encore encaissé entre de très hautes berges, n'est pas creusé à sa profondeur normale. Aussi les rapides et les cascades se succèdent. Les plus célèbres de ces cascades sont celles de Gouïna et du Félou. A Gouïna, sur une largeur de plus de quatre cents mètres, le fleuve s'échappe tout à coup du terrain qui manque à la masse de ses eaux, ct la nappe tombe en bouillonnant à cinquante mètres de profondeur. "Pendant les hautes eãux, la chute a une largeur double, et sa hauteur, sur la rive gauche, alleint soixante mètres. En effel, sur celte rive, de larges tablettes d'un grès très fin, d'un mètre d'épaisseur, s'avancent sur l'abîme en formant un plan horizontal élevé de dix mètres au-dessus du niveau supérieur de l'eau. Comme rien ne les soutient, il semble qu'en s'y arenturant on s'expose à rouler avec elles dans le gouffre du bassin inférieur ${ }^{1}$. " Aux abords de la cascade se trouvent des trous en forme d'entonnoirs dans lesquels l'eau s'engouffre en tourbillonnant. La cascade de Gouïna demande à ne pas être examinée $€ n$ détail; car son aspect est régulier, et d'un seul regard on peut en embrasser l'ensemble. La cascade du Félou, au contraire, est remarquable par ses bizarres découpures et ses singuliers appendices. On dirait une série de pyramides coniques, terminées par des calottes sphériques, dont la base est baignée par les eaux.

1. Tour du monde, 1861, p. 47. 
A près celte seconde chule; le Sénégal change brusquement de direction et va du sud-est au nord-ouest jusqu'à la mer, à travers un pays de plaines. A Saldé, un des bras du fleuve, le Doué ou Taouey, forme une île de cent cinquante kilomètres de longueur, l'île à Morfil ou des Éléphants. Dans la partie inférieure de son cours, à partir de Richard-Toll, il se partage en plusieurs bras, qu'on désigne sous le nom particulier de marigots (Bounoum ${ }^{1}$, Kassak, des Maringouins, etc.). Arrivé tout près de la mer, il est arrêté par une étroite digue de sable, coule alors vers le sud, se divise en bras nombreux, au milieu desquels est bâtie la ville de Saint-Louis, et finit audessous de celte ville, en étalant une barre mobile qui gêne beaucoup la navigation. Le delta du fleuve est donc tout intérieur, et forme comme un labyrinthe d'environ quinze cents kilomètres carrés, composé d'ìles et d'îlots, de bancs marécageux et de mares changeant de contenu et de profondeur à chaque inondation. Toute cette région basse, à demi lacustre, est nettement délimitée par un cordon littoral très régulier, la langue de Barbaric, à peine élevée de quatre à six mètres au-dessus des caux, large de trois cent cinquante à quatre cents mètres, constamment ébranlée du côté du large par le heurt des vagues, et ayant à soutenir du côté de l'intérieur l'assaut des eaux fluviales. Aussi la langue de Barbarie cède-t-elle tantôt d'un côté, tantôt de l'autre. En 182ว, la rasse était en face de Gandiole; en 1851, à l'extrémité méridionale ; en 1855 , à la pointe des Chameaux, tout près de Saint-Louis; en 1864, deux kilomètres plus au sud, et en 1884, de nouveau au delà de Gandiole. Nos ingénieurs se sont efforcés de régulariser l'entrée du Sénégal. Un des plus éminents d'entre cux, M. Bouquet de la Grye, proposait récemment, pour faciliter l'entrée des vaisseaux, de fixer l'entrée par unc jetée curviligne qui prolongerait la rive gauche ${ }^{2}$.

Le principal obstacle à la nạvigation est la barre mobile qui obstrue l'entrée du fleuve ${ }^{3}$. Le passage de cette barre est

1. Briouszec, Exploration du Bounoum, marigot du Sénégal, en octobre el novembre 1861 (Annales maritimes el coloniales, octobre 1862).

2. Revue scientifique du 3 juillut $18 \$ 6$.

3. Ilaurkeux, Elude de la barre du Sénégal (Société de géographie de Bordeaur); 1856. 
en effet d'une extrême difficulté pour tous les navires à roiles, et parfois des bâtiments séjournent plusicurs semaines sans pouvoir pénétrer dans le fleuve. Avant linvention des bateaux à vapeur, on aurait pu contester à l'entrée du Sénégal la qualité de port. Par bonheur. les tempètes sont rares dans colte partie de l'Allantique. Des allèges viennent alors décharger les navires et leur apporter des marchandises de retour. Il existe à Saint-Louis une corporation de pilotes ou plutôt de piroguiers chargés de ce service. Chaque matin ils vont sonder la barre, armés de longues gaffes avec lesquelles ils interrogentle terrain. Si la barre est belle, les pirogues sont lancées à l'eau; quand elle est mauvaise et quill faut rentrer à tout prix, les piroguiers ont besoin de toute leur audace et aussi de beaucoup de présence d'esprit. Ils sarent le moment précis où ils pourront confier leur esquif à une lame. Une fois engagés dans le brisant, ils font volte-face, et altendent dans le plan incliné formé par la vague qu'une nourelle chance se produise. Ils font, en se déplaçant sans cesse, contrepoids à la lame, et parriennent ainsi à se maintenir en équilibre.

Malgré ces inconvénienls, le Sénégal est une voie de pénétration de premier ordre, car elle se continue par le Niger. La navigation sur le fleure n'est pourtant pas facile, car il est sujet à des crues et à des baisses périodiques, comme presque tous les fleuves qui prennent leur source dans le voisinage de l'équateur. Arant qu'on eùt exploré complètement le pays, on sarait, comme il n'y a qu'une crue par an, que la région des sources.n'a qu'une saison de pluies, dont le maximum coïncide avec la grande chaleur de l'hémisphère septentrional, juin à octobre. La rapidité d’allures du courant démontrait en outre que le fleuve n'arait pas de réservoir lacustre. En temps de crue, les bateaux peurent remonter jusqu'à la cataracte du Félou. A Bakel, la crue atteint et dépasse quinze mètres; à Matam, neuf à dix; à Podor, six; à Dagana, quatre. Ellese fait avec une cxlrème rapidilé. En quelques semaines les parties du fleuve qui nélaient plus navigables offrent jusqu à huit et dis mèlres de fond. Comme il y a peu de couranls et que le lit du fleure présente une pente à peine sensible, le trop-plein des caux se déverse dans 
les plaines environnantes, et les transforme en lacs immenses. Le fleuve roule alors plusicurs milliers de mètres cubes d'eau par seconde, et la force du courant est telle qu'il repousse les eaux marines, pénètre dans la mer, et étale aul milieu des eaux bleues de l'Océan une nappe jaunâtre.

En novembre commence la baisse, et elle dure jusqu'en juin, où elle alteint son maximum. Le fleuve alors n'est plus, navigable qu'à deux cents kilomètres de son embouchure. Comme il est fréquemment barré par des seuils de rochers, dont aucun ne peut arrêter le courant, il est partagé en biefs successifs unis par des filels d'eau. Aussi, quand le niveau du fleuve est au plus bas, c'est à grand'peine si les barques peuvent forcer le passage. En 1860, au plus fort de la saison sèche, une expédition fut organisée de Saint-Louis à Bakel, par la voie du fleuve, pour en constater le régime ${ }^{1}$. Les chalands n'avaient qu'un tirant de soixante centimètres, et quand ils étaient déchargés, de trente-cinq. Or trente-cinq traînages sur fonds inégaux furent nécessaires, et sur un de ces seuils la couche d'eau n'élait que de cinquante centimètres. A Verma, à peu de distance en aval de Bakel, le halage dura quatorze jours, et le voyage entier réclama soixantedix-neuf jours. Jadis les Maures arrêtaient la navigation en plaçant des trones d'arbres en travers du chenal. Pendant la période de sécheresse, les eaux de l'a mer pénètrent dans toute la région du delta, et refoulent celles du fleuve. A mesure que se prolonge la sécheresse, la salinité augmente, et le flux de marée s'enfonce alors jusqu'à quinze kilomètres dans l'intérieur.

Il reste donc beaucoup à faire pour améliorer le cours du Sénégal. Nos ingénieurs y travaillent. Ils font sauter les rochers qui l'obstruent, ils brisent la force de certains remous; mais bien des années s'écouleront encore avant que le Sénégal ressemble à nos fleuves européens, si correcls, si réguliers, même dans leurs fureurs.

Le Sénégal reçoit plusieurs affluents. Les principaux sont, à droite, en aval des chules, le Kouniakari ou Tarakolé (deux cents lilomètres) et le lac Cayar ou Khomack, fosse de

1. Braouezec, Iy drographie du Sénégal; nos relations avec les populations riveraines (Revue maritime et coloniale, janvier-février 1861). 
vingt kilomètres de longueur, reliée au fleuve par le marigot de Sokam. Il se remplit à l'époque des crues, et pendant la saison sèche rend au Sénégal, commejadis le lac Mœris au Nil, le superflu de ses eaux. Sur la rive opposée, le Sénégal est grossi de la Falémé, qui vient du Fouta-Djallon, et arrose une contrée fertile. C'est là que s'établiront tôt ou tard des colonies agricoles, heurcuses de rencontrer un sol fécond et le plus admirable des climats. La Falémé, coupée par des barrages naturels ainsi que le Bafing, est divisée en biefs successifs qui l'empêchent de tarir. Pendant la saison d'hivernage, clle a trois cents mètres de largeur et huit de profondeur. Sur la même rive, le grand lac Guier ou Paniéfoul, grossi par le marigot de Bounoum, semble correspondre au lac Cayar.

Au nord du Sénégal, la rivière Saint-Jean des anciens routiers n'est qu'un estuaire entre le cap Mirik et le sud du banc d'Arguin. La rivière des Maringouins n'est qu'une coulée temporaire, à quatre-vingt-cinq kilomètres au nord de l'embouchure permanente, ne communiquant avec la mer qu'en temps de crue. Toutes les eaux pluviales du Sahara s'amassent en lagunes temporaires ou permanentes. Un de ces étangs, le lac Teniahé, a parfois quarante kilomètres de longueur et se déverse alors dans la rivière des Maringouins.

D'après la légende, le Sénégal aurait autrefois, à l'abri derrière les dunes du Cayor, continué son cours au sud-ouest, et serait tombé dans la rade de Dakar; mais on ne rencontre aujourd'hui dans le Cayor que des mares et des lagunes, qu'on désigne sous le nom de niayes, et nulle trace de lit fluvial. Le Saloum est le seul et unique fleuve qu'on rencontre au sud du Sénégal. Il a environ cent kilomètres de longueur. Quant aux autres cours d'eau qui arrosent notre colonie, ils appartiennent à la région qu'on nomme le Bas-de-Côte ou les Rivières-du-Sud, et que nous étudierons plus loin.

La côte se divise en deux grandes sections : du cap Blanc au cap Vert, du nord-est au sud-ouest, elle forme un arc de cercle rentrant, et du cap Vert aux Rivières-du-Sud elle est au contraire inclinée du nord-ouest au sud-est. Dans la première section, la côte, presque droite, bordée dans toute son étendue par une chaîne de dunes, et au large par un grand banc 
de sable, le banc d'Arguin, ne présente que deux ports, Portendick et Saint-Louis. L'aspect du. littoral est monotone. Quelques arbustes rabougris le couvrent d'une végétation que la poussière du désert rend grisâtre. Jadis les caravanes de l'Adrar et du Sahara se rendaient directement à la côte pour y échanger leurs marchandises, et des marchés temporaires s'établissaient, tantôt sur un point, tantôt sur un autre; mais ces habitudes commerciales ont disparu, et c'est à Saint-Louis ou dans les villes de l'intérieur que se rendent aujourd'hui les trailants.

A partir du cap Vert, la côte change d'aspect. Les dunes ont disparu. Des palétuviers, sur les branches desquels se développe tout un monde de zoophytes, grandissent et s'étendent en masses sombres. Bientôt les collines apparaissent. Elles sont de formation volcanique, et les laves éparses sur celle étendue de terrain prouvent que ce point de terre a été bouleversé par des feux souterrains. Les pentes des collines sont tapissées par des baobabs gigantesques, qui ne revêtent que pendant l'été leur magnifique verdure. On arrive bientôt à Gorée, rocher aride dominant une rade superbe, où les navires trouvent pendant huit mois de l'année, de novembre à juillet, une mer toujours calme. Plus au sud, et toujours en suivant la côte, de nombreux fleuves forment à leur estuaire des baies magnifiques, que l'on commence à utiliser, et qui sont appelées à un grand avenir.

Le climat du Sénégal passe pour très mauvais, et mérite sa réputation, bien qu'elle soit exagérée. On distingue deux saisons : la saison sèche et la saison pluvieuse. La première commence à la fin de novembre et se termine en juin. Les brises de terre et de mer alternent alors sur les côtes; mais en janvier, et jusqu'à la fin de mars, commence à souffler un vent de terre sec et brûlant, que l'on nomme harmattan. Ce vent est si violent que les oiseaux de terre sont fréquemment poussés au large, et cherchent un refugrc sur les mâls des navires qui ne sont pas trop éloignés. Une poussière rougeâtre couvre les voiles et le gréement des vaisseaux qui longent la côte. A terre, les écorces des arbres se fendillent, et la sève coule. C'est pourtant la saison la plus favorable aux 
Européens, qui peurent, au moins une partie de la journée, affronter sans danger les rayons du soleil, surtout dans le bas fleuve, où se font sentir les brises de mer, saines et fortifiantes.

Vers le mois de juillet commence la saison improprement appelée hivernage, car elle coïncide dordinaire avec le moment où les rayons solaires, se rapprochant de la direction perpendiculaire, rendent la température très élevée. L'hivernage correspondrait donc plutôt à notre été. C'est la saison des pluies et des orages ou tornades, la saison que chaque année les Européens du Sénégal voient revenir avec terreur, car elle leur apporte la fièrre, l'anémie et souvent la mort. Tout le pays, qui pendant sept mois a été brùlé par un soleil torride, est alors inondé. Dans un ciel immobile et plombé monte un nuage opaque et lourd. " On dirait des voûtes de pierre prètes à s'elfondrer sur le monde, et tout cela s'éclaire par en dessous de lueurs métalliques, blèmes, verdâtres ou cuivrées, et monte toujours. Puis tout à coup une grande rafale terrible, un coup de fouet formidable, couche les arbres, les herbes, les oiseaur, renverse tout sur son passage. C'est la tornade qui se déchaîne. Tout tremble et s'ébranle... Pendant vingt minutes environ, toutes les cataracles du ciel sont ouvertes sur la terre; une pluie diluvienne arrose le sol altéré d'Afrique, et le vent souffle avec furie, jonchant la terre de feuilles, de branches et de débris ${ }^{1}$. "Quoique la température moỵenne soit alors moins élevée que dans la saison sèche, l'Européen en souffre, car la chaleur est humide, l'air lourd, et le soleil pénétrant. C'est alors qu'apparaissent les fièvres ${ }^{2}$, les accès pernicieur, les maladies de la bile et du foie. Les colons qui ne quittent pas le littoral en sont, à moins d'imprudence, gé-

1. Pierre Viatd, le Spahi (Nouvelle Revue, t. IX, p. 605).

2. Taevevor, Maladies des Européens dans les pays chauds, et particulièrement au Sénégal; 1840. - Dernodus, Maladies des Européens dans les pays chauds. - M.нÉ, Étude sur les maladies endémiques au Sénégal et à la cóte occidentale d'Afrique; thése de Montpellier, 1865. - Qurrrs, Contribution à la géographie médicale; extrait d'un royage au Soudan; 1869. - GatrHIrR, les Endémies du Sénégal; thẻse de Paris, 1865. - Borrus, Recherches sur le climat du Sénégal; 1374. - Bertholor, Sénégambie et Éthiopie (Revue de géographie, 1879-1880). ID., L'Européen peut-il fonder des colonies agricoles sous les tropiques? (Méme publication, 1880.) - Rer, Géographie médicale de la cóte occideniale d'Afrique (Société de géographie de Paris); 1878. - Haxx, Klima von Senegambien (Zeitschrift der CEsterreichischer Gesellschaft fur Meteorologie, 1375. 
néralement exempts; mais leur acclimatation est néanmoins fort difficile. Ils peuvent rarement supporter deux hivernages de suite. Parfois le choléra et la fièvre jaune s'ajoutent aux maladies locales. Depuis 1830, la fièvre jaune a fait son apparition. Quatre-vingts pour cent des Européens élaient alteints, et la moitié mouraient. Parfois les médecins ont manqué aux hôpitaux. Dans ces conditions, il est difficile de croire que des colons européens puissent jamais s'établir au Sénégal. Quelques-uns d'entre eux ont essayé de le faire; ils ont même contracté des unions avec des femmes indigènes; mais l'espoir qu'on avait formé ne s'est pas réalisé de créer une race franco-africaine. Les descendants des Européens et des métis n'ont pas jusqu'à présent fourni une population stable : d'abord parce qu'ils font retour, par des croisements, avec les indigènes, et aussi parce que les enfants de sang mêlé meurent en bas âge, et que les unions des survivants sont souvent stériles. Il est peu d'exemples de familles franco-sénégalaises qui se soient perpétuées jusqu'à la quatrième génération. Le Sénégal ne sera donc jamais, grâce à son climat, une colonie de peuplement; mais il peut être une importante colonie d'exploitation, d'autant mieux que les résidents européens pourraient toujours, à la mauvaise saison de l'année, remonter jusqu'aux hauts plateaux de l'intérieur, jusqu'à Kita, par cxemple, qui peut être si facilement transformé en sanitarium. De même que les Anglais de l'Hindoustan vont chercher la santé et le repos sur les pentes de l'Himalaya, ainsi nos négociants et nos fonctionnaires peuvent trouver un climat sain ct une température normale dans le haut pays qui sépare le Niger du Sénégal.

Il est donc permis d'affirmer que tous les Européens qui débarquent au Sénégal ne se condamnent pas aux souffrances quolidiennes d'une température torride, ou aux dangers d'une insolation ou d'une intoxication paludéenne. Le Sénégal n'est certes pas un Éden, mais ce n'est pas non plus une terre maudite. 
Le Sénégal n'a longtemps été entre nos mains qu'unc pépinière d'esclaves. Nos négociants y récoltaient aussi de la gomme, de la poudre d'or, des épices et des bois précieux; mais ce qu'ils recherchaient avant tout, c'était de la marchandise noire, de la graine noire, comme ils disaient. Il est vraiment étrange que, pendant de longues années, aucun scrupule n'ait retenu ni ces trafiquants de chair humaine ni les divers gouvernements qui se sont succédé en France. Est-ce que l'habitude finit par émousser tout sentiment, ou bien la nature humaine est-elle ainsi faite qu'elle n'accepte le progrès qu'à son corps défendant? Toujours est-il que ce honleux marché s'étalait au grand jour, et sans le moindre ménagement. C'est surtout au siècle dernier, alors que la culture des plantes industrielles en Amérique prit une si grande extension, que le nombre des esclaves africains augmenta. On a calculé que deux cent mille nègres étaient chaque année transportés au nouveau monde. L'Afrique n'était plus qu'une fabrique d'hommes. Les excès de ce commerce homicide amenèrent une prompte réaction. L'Angleterrre eut la gloire d'attacher son nom à cette réforme. Elle avait pourtant pris sa part à ce déplorable trafic, et même les négriers anglais s'étaient signalés entre tous par leur âpreté au gain et leur sanguinaire activité; mais enfin ce furent des hommes d'Élat anglais qui protestèrent les premiers contre la traite des nègres. Ils réussirent même, au congrès de Vienne, en 181ร, à arracher aux parties contractantes l'expression énergique de leur répulsion, et dès lors ils ne renoncèrent plus à cette croisade abolitionniste. Dès 1815 , ils établissaient une croisière permanente sur la côte d'Afrique. En 1838, ils supprimaient résolument l'esclavage dans leurs colonies. Les unes après les autres, les puissances 
curopéennes les ont imités. La France a supprimé la traite en 1848. Celle suppression a réagi d'une manière heureuse sur les indigènes, et changé les conditions du commerce au Sćnégal. Les négociants, en effet, ne se sont plus contentés de transporter aux comptoirs sénégalais les marchandises dont les esclaves formaient le solde : ils ont demandé à la région qu'ils visitaient ses productions particulières, et lui ont apporté en échange ce qui lui manquait. A nous d'étudier ces diverses produclions.

Comme le Sénégal est situé à la limile de deux régions distinctes, le Sahara et le Soudan, il participe à ces deux régions par sa flore : au nord il ressemble aux steppes sahariennes; su sud son aspect est celui d'un pays tropical. Le nombre des formes végétales est pourtant bien restreint. Après cinq ans d'explorations botaniques, MII. Leprieur el Perrotet n'ont constalé la présence au Sénégal que de seize cents végétaux. C'est vraiment bien peu pour une aussi vaste contrée.

Pendant longtemps la gomme fut la principale, on pourrail dire la seule production du Sénégal. On nomme ainsi la substance mucilagineuse que transsude le tronc des acacias sénégalais, surlout l'Acacia Adansonia, ou goniaké, dont le bois, dur et fin, fournit à la marine des pièces courbées très résistantes. Les Acacia Arabica, Seyal et Verek, fournissent également d'abondantes récoltes. Les forêts de gommiers, ou krabas, furent longtemps des lieux sacrés. Il était interdit d'y casser une branche. Les souverains s'en disputaient la propriété et les faisaient exploiter par des captifs. C'est au dix-huitième siècle seulement que les IIollandais révélèrent l'Europe, comme un produit similaire de la gomme d'Arabie ou d'Égypte, ce produit si utile à l'art médical pour ses propriétés spéciales, et à l'industrie pour l'apprêt des étoffes ct des vernis. Ils la nommèrent d'abord gomme de l'Inde, parce qu'elle formait un article pour ceux de leurs navires qui vonaient de l'Inde. Elle ne tarda pas à compter parmi les principaux objels d'exportation de la côte. La production pourtant est restée à peu près stationnaire : en 1828 on récoltait déjà 1,491,809 lilogrammes de gomme; en 183ð, 1,464,878; en 
$18 \div 0,3,100.377$; en $18150,3,630,493$; en $18309,4,610,5006$; cn $18630,2,692,13 ั 1$; en 1871, 3,161,906.

Cette production augmenterait si les krabas étaicnt exploitées régulièrement; mais ce sont des esclaves qui sont chargés de la récolle; et comme les acacias qui produisent la gomme sont embarrassés de lianes ou hérissés d'épines, ces esclares considèrent la récolle comme une corvée. Avec un simple bâton recourbé en croc, ils détachent la gomme et détériorent les arbres. D'ailleurs les Maures se contentent de nous rendre la quantité en retour de laquelle ils reçoirent des ustensiles, des armes ou des éloffes.

Les acacias croissent tous dans le roisinage du Sahara. Quand souffle l'harmattan, qui s'est échauffé au contact des sables du désert, ses effluves brûlanls contractent et fendent l'écorce des arbres, déjà fatigués par les étreintes d'une plante parasite, le Loranthus Senegalensis, et en font couler, sous forme de larmes, la gomme, qui bientôt se coagule au grand air; en sorte que la récolte est toujours en rapport arec la durée et la violence du rent: aussi est-elle singulièrement aléatoire, et, dans de semblables conditions, on ne fondera jamais une colonie agricole qui ait quelque chance de succès. En outre, le commerce de la gomme a longtemps été comme un monopole entre les mains des Maures, qui l'araient limilé à certaines escales et à certaines saisons, et devenaient de plus en plus exigeants. Ils avaient fini par croire qu'on mangeait de la gomme en France, et que cette précieuse substance élait indispensable à notre alimentation. De là des vexations de tout genre, et peu d'empressement de la pari de nos négociants. L'arenir du Sénégal n’est donc pas dans la production de la gomme.

Les acacias ne sont pas les seuls arbres groupés en forèts qu'on rencontre au Sénégal. Les forèts sont au contraire nombreuses et abondent en essences variées, dont quelquesunes précieuses. Voici le nom des principales : le cailcedra (Caya Senegalensis) ou acajou du Sénégal, qui sert aux construclions navales et à l'ébénisterie; le detarr, le vene. le ridimb et le solum, dont on emploie les écorces pour la teinture; le baobab (Adansonia digitata) dont Cadamesto parlail 
déjà arec étonnement, et admirait les troncs "larges de dissept brasses à la base "; le fromager ou bentenier, aur troncs réguliers, aux branches symétriques, aux racines énormes laissant entre elles d'assez larges réduits pour que les roya-

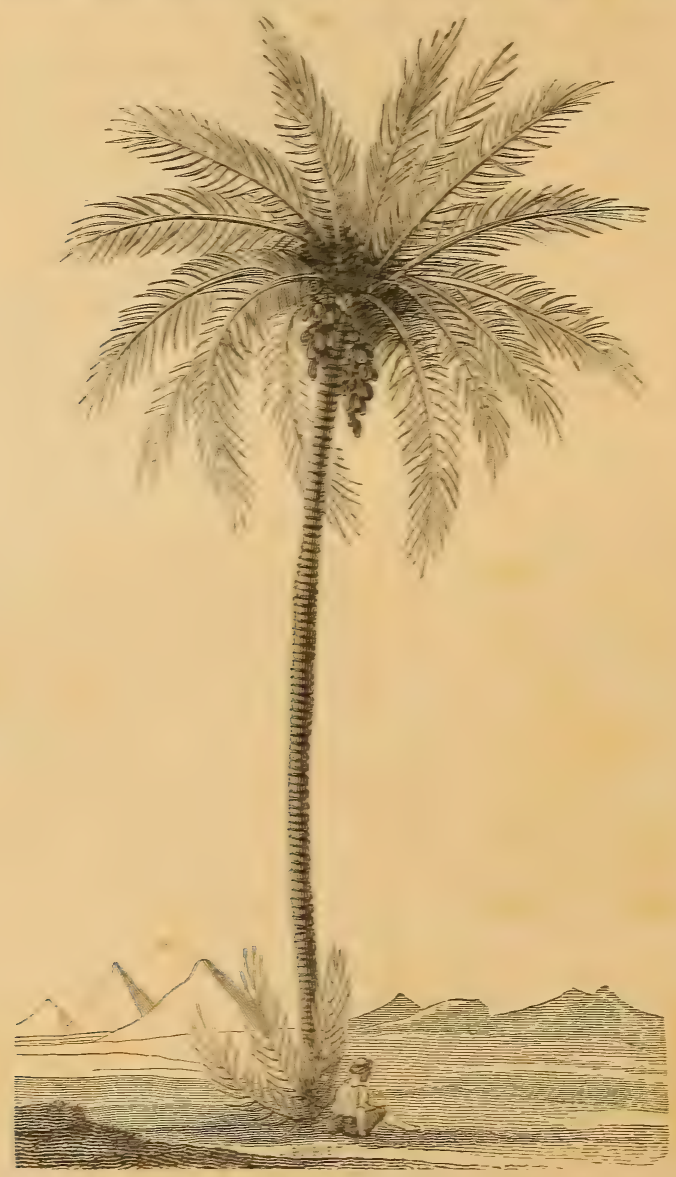

Palmier.

geurs puissent les utiliser comme magasins de dépôt ou lieus de réunion: les rôniers, dont le fruit est entouré d'une filasse juteuse d'un goût sucré très agréable, et dont le bois, très résistant, est employé pour les constructions hydrauliques; aussi le gouvernement les a-t-il pris sous sa protection, et, 
dans tous ses traités avec les Maures, s'est-il réservé la propriélé de tous les rôniers en bordure sur le fleuve; viennent ensuile les cocotiers, arbres de provenance étrangère, qui n'existaient pas encore dans la contrée à la fin du dix-septième siècle; les datliers, qui poussent aux environs de Bakel et donnent des fruits excellents; les palétuviers, très abondants sur la côte, etc. Mentionnons enfin le karité (Bassia Perliii), auquel la matière grasse de sa châtaigne a valu le nom d'arbre à beurre, et le kola ou gourou (Sterculia acuminata), dont la

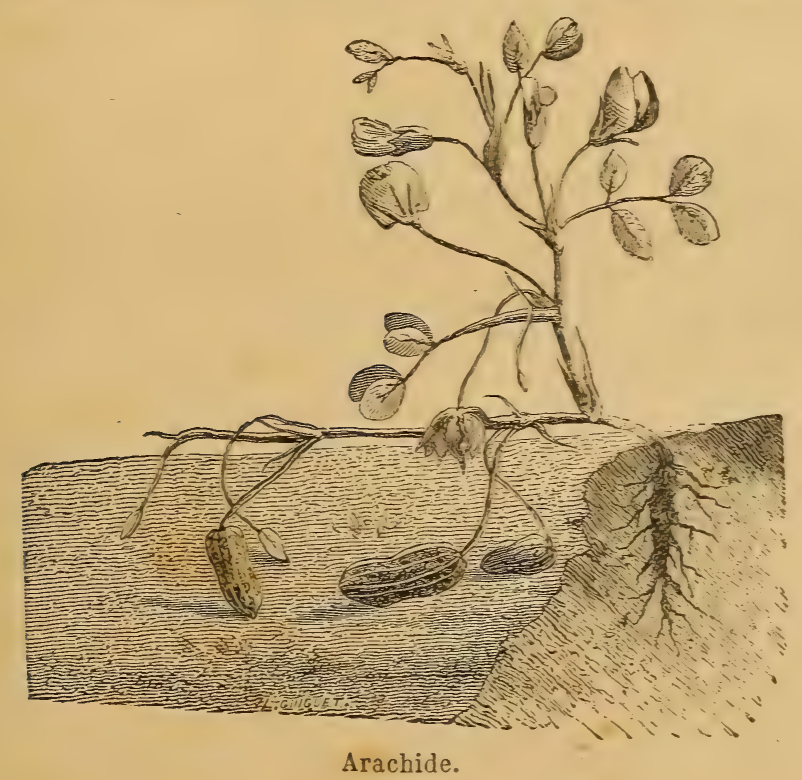

noix, apéritive et fortifiante, rend agréable au goùt jusqu'à l'eau corrompue ${ }^{1}$.

Plus encore que les forèts, ce qui constitue à l'heure actuelle la principale richesse du Sénégal, ce sont les plantes oléagineuses, et surtout l'arachide ou pistache, dont la culture, tout en procurant le bien-être aux indigènes, les fixe au sol en les accoutumant à un travail régulier, les inilie à la propriété et assure au commerce et à l'industrie un arlicle très important. L'arachide était à peine connue de nom il y a un demi-

1. Heckri, des Kolas a fricains (Société de géographie de Marseille); 1883. 
siècle. Pourtant elle croît spontanément dans tout le Sénégal. C'est une herbe annuelle, raméuse et poilue. Ses fleurs sont petites, jaunes et géminées. Le fruit se recourbe vers la terre, s'y enfonce, et accomplit sa maturation à plusieurs pouces au-dessous de sa surface. Les graines ont la grosseur d'une noiselte et une saveur assez agréable, surtoul après avoir élé torréfiées. L'arachide produit une huile grasse, qu'on prétend, mais à tort, d'aussi bonne qualité que l'huile d'olive, et qui se conserve longtemps sans rancir. Ce n'est pas le seul usage de ce précieux arbuste. Son amande sert aussi de nourriture aux bestiaux. On prétend même qu'elle remplacerait le cacao pour la fabrication du chocolat. Sa tige enfin sert de fourrage aux bestiaux quand elle est fraîche, et de combustible et d'engrais quand elle est desséchée. Les soins les plus simples suffisent à sa culture. En trois ou quatre mois la plante est semée et récoltée. Tous les terrains lui conviennent, surtout les plus secs. Ce sont autant d'admirables conditions pour faire passer de l'indolence et du vagabondage à la vie agricole des populations que rebuterait une plus longue durée de soins. En effet, les Sénégalais se sont adonnés avec empressement à une culture aussi avantageuse. L'arachide est aujourd'hui cultivée dans toute la vallée moyenne du Sénégal, dans le Cayor, dans le Saloum. Tout le long du chemin de fer de Dakar à Saint-Louis, les brousses sont défrichées et les plantations se succèdent. C'est sans doute ce qui arrivera pour chaque voie nouvelle. L'arachide commence à être fort recherchée en France, surlout dans le Midi. L'huile que la graine contient, dans une proportion de trente-trois pour cent, trouve son emploi dans la savonnerie, le graissage des laines et l'éclairage. Elle sert même comme huile comestible, pure ou mélangée à l'huile d'olive.

Il est au Sénégal une autre plante oléagineuse qui semble également appeléc à un bel avenir commercial. On la nomme le beraff. C'est la graine de deux melons d'eau ou pastèques, le Cucumis melo et le Cucurbita miroor, que les indigènes consomment crus, mais dont ils gardent la graine pour la rendre. Celle graine, moins encombrante que l'arachide, donne, assure-t-on, une huilc meilleure encore, à la fois utile 
à l'alimentation et à la saponification. Le Sénégal semble d'ailleurs la terre promise des graines oléagineuses : non seulement toutes celles qn'on récolte en France y poussent pour ainsi dire spontanément, mais on y rencontre encere des produits spéciaux : le pignon d'Inde, le pourgueire, la noix de touloucana, la noix de palme, et le modeste mais utile ricin.

Le coton ${ }^{1}$ et l'indigo méritent une mention spéciale. Le cotonnier pousse dans toule la vallée du Sénégal. Les femmes en ramassent la quantité nécessaire à chaque famille, la cardent et la filent. Un tisserand indigène en fait des tissus, qu'il teint ensuite. Les échantillons de coton sénégalais introduits en France n’ont pas été appréciés avec faveur par les manufacturiers. Il est vrai de dire que la négligence des indigènes dans le triage de la graine ou le classement des brins dépassait toule mesure. Depuis quelques années on a fait à Dakar et aux environs des plantalions modèles qui promettent de meilleurs résultats. Quant à l'indigofère, il croît, ainsi que le cotonnier, spontanément et partout. Il se passe de soins, résiste à tous les fléaux, et peut donner jusqu'à trois récoltes par an. Les noirs en obtiennent des teintures du plus bel éclat. Il pourrait faire concurrence à l'indigo du Bengale, si on cherchait à améliorer la fabrication de la pâte.

Nous ne parlerons que pour mémoire du froment, du mil et du riz, qui servent à l'alimentation générale, mais nous devons une mention spéciale au maïs, au tabac, dont on cultive deux espèces, l'une à priser, l'autre à fumer; à quatre ou cinq espèces de soies végétales; à une multitude de légumes et de fruits, dont plusieurs rappellent aux Européens les jardins de la patrie. Une plante nouvelle, un moment populaire en France, le sorgho à sucre, a fait récemment son apparition au Sénégal et y a très bien réussi. Il n'en a pas été de même pour une sorte de vigne annuelle et semée. Les tentatives pour l'introduire en France ont été infructueuses, et, même dans le pays d'origine, on n'a pas réussi à la greffer. Aussi bien il faut se défier de cette tendance à l'introduction de produits nouveaux, car les particuliers gaspil- 
lent sourent en tentatires slériles et leur lemps et leur argent. Micux vaut s'en tenir aux produclions indigènes, qui certes ne manquent ni de variété ni d’abondance.

Des végétaux, passons aux minéraux. Les richesses minérales du Sénégal sont encore mal connues et à pcine exploitées. Gorée reçoit de la Casamance environ huit cents barriques de coquilles destinées à la fabrication de la chaux et qui sont directement consommées par la colonie. Sur la lagune de Gandiole, au sud de Saint-Louis, on exploite le

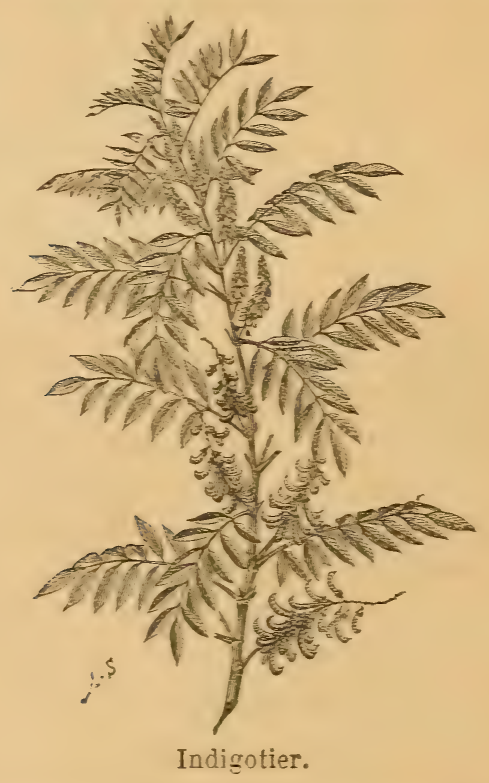

sel, denrée précieuse qui, dans l'intérieur, est avidement recherchée. Des Maures Douaichs ont apporté à Saint-Louis des échantillons de ce qu'ils appelaient des pierres noires, et qui étaient du charbon; nais on n'a fait aucune fouille, et par conséquent on ne connait pas la richesse du gisement. Les noirs de la Falémé ont encore apporté des échantillons de terre contenant du mercure à l'état natif. Le fer est abondant, on le rencontre partout à fleur de terre; il constituera quelque jour la principale richesse du haut Sénégal, car il en forme le sous-sol en rastes étendues, et la leneur 
moyenne du minerai est égale aux deux tiers de la masse. Iage raconte que, les soldats d'Ahmadou ayant manqué de balles, quelques-uns d'entre eux ramassèrent des fragments de fer qu'ils trouvèrent à ras du sol, et fabriquèrent en une nuit plusieurs milliers de projectiles. Il est vrai que les procédés d'extraclion sont encore bien rudimentaires, et que, jusquà nouvel ordre, les indigènes seuls récoltent le fer pour lcurs besoins locaux; mais il n'est pas impossible que quelque jour sur la rive du fleuve s'élèvent d'importantes usines qui utiliseront ces richesses encore à peu près inexploitées.

Restent les métaux précieux, et l'or en première ligne ${ }^{1}$. On connaît depuis longtemps l'or sénégalais. Sur les portulans du moyen âge le grand fleuve occidental est désigné sous le nom de rivière de l'Or. Dès le quatorzième siècle, nos Normands ramassaient dans leurs comptoirs de la côle de la poudre d'or. Les Portugais, qui les remplacèrent, ne négligèrent pas ces trésors. Ils pénélrèrent même dans le pays producteur, le Bambouck, mais disparurent après une occupation de peu de durée, car ils ne surent résister ni au climat, ni aux indigènes, ni à leurs propres dissensions. Ce qui prouve leur séjour, c'est la persistance de certaines dénominations locales, évidemment empruntées à la langue portugaise :ainsi le mot zapater, encore employé pour désigner les cordonniers. Les Français succédèrent aux Portugais. André Brue allait à la recherche de l'or lorsqu'il s'enfonça dans le pays, en 1698, et y fonda le fort de Saint-Joseph ou de Galam, le premier de nos établissements sur le haut Sénégal. Seize ans plus tard, en 1714, il fondait sur la Falémé le fort SaintPierre et expédiait à Paris de nouveaux échantillons d'or. Un de ses agents, Compagnon, parcourait le Bambouck, arrivait jusqu'aux monts Tamba-Oura et rapporlait de riches échantillons d'argile aurifère. Brue fut le dernier de nos gouverncurs qui s'occupa sérieusement des mines du Bambouck. Ses successeurs laissèrent dépérir nos établissements. Peu à peu on les oublia. On finit mème par croire que celte Californic africaine n'avait existé que dans l'imagination de certains

1. Geonges Rexaud, $l$ Or au Sénégal (Rerue géographique internationale, 18is). 
voyageurs. En 1843, Huart et Raffenel résolurent d'éclaircir ce mystère. Ils arrivèrent, non sans peine, à Sansandig, sur la Falémé, au seuil de la région aurifère, là où la récolte de l'or se fait par le simple lavage des sables. Quelques jours de marche les conduisirent à Kenieba, où ils furent reçus avec empressement et initiés à tous les détails d'une exploitation primitive. Ces mines sont situées dans un terrain d'alluvion, où les indigènes creusent des puits d'une profondeur de sept à quarante mètres, aboutissant à une galerie horizontale qui se prolonge rarement au delà de cinquante mètres. Le minerai, extrait par gros fragments, est jeté dans des calebasses pleines d'eau, où des femmes l'écrasent en le pétrissant, et le lavent à plusieurs reprises. Le résidu est transporté dans une valve de coquille, où il subit de nouveaux lavages. Il est réduit en poudre avec de petits cailloux. La poudre sèche au soleil; on souffle dessus, et il ne reste que l'or obtenu en paillettes ou en molécules. Le précieux mélal est alors gardé dans des cornes de gazelle, jusqu'à ce qu'on en ait ramassé une quantité suffisante pour le fondre dans un creuset. Ces procédés primitifs laissent perdre une énorme quantité de métal. D'ailleurs les terres lavées constituent la minime partie de celles qu'on pourrait exploiter. Enfin les puits et galeries sont rudimentaires et souvent détruits par des infiltrations. Parfois, surtout aux flanes des montagnes, de superstitieuses terreurs écartent toute recherche. Notons encore, comme dernier trait de mœurs, que ce sont les femmes qui exploitent les mines : les hommes ne sont admis qu'à extraire-le minerai ou à faire sentinelle à main armée.

La présence des gisements aurifères est donc constatée, mais l'exploitation n'a pas été améliorée. En 18322 le commandant Rey, en $18 a$ II. Flizes, reconnurent de nouveau le pays. En 18208 , le gouverneur Faidherbe alla en personne construire un fort à Kenieba et commencer de nouveaux travaux; mais, soit mauvaise direction, soit recherches infructueuses, l'entreprise n'a pas réussi. L'or a été mangé, disent les indigènes. D'ailleurs la région est très insalubre, car les eaux croupissantes s'amassent dans les basses vallées, et l'air est comme surchauffé par la réverbération des rayons solaircs 
sur les pentes nues. Tous les nouveaux essais entrepris par des compagnies privées n'ont pas abouti. Seuls les indigènes n’ont pas renoncé à l'industrie du lavage.

Les mines du Bambouck sont néanmoins fort riches, et il est probable qu'elles ne forment qu'une veine détachée du massif fouta-djallonais. On a encore constaté la présence de gisements aurifères dans le Bouré, sur un des hauts affluents du Bakoy, dans le voisinage du Niger; mais ils n'ont pas encore été étudiés par les Européens. Mollien écrivait au commencement du siècle: "Quand on considère quelle quantité d'or se vend chaque année sur cette partie de la côte d'Afrique, on n'hésite plus à croire que ce continent en renferme dans son sein autant que l'Amérique. "si l'on admet l'ingénieuse hypothèse d'un savant contemporain ${ }^{1}$, il ne faudrait pas aller chercher ailleurs le fameux jardin des Hespérides, qui a tant préoccupé les anciens. "Les pommes des Hespérides, écrit M. Antichan, ne sont pas des oranges, mais des pépites d'or. On allait les ramasser dans les hautes régions de la Sénégambie et de la Guinée, d'où on les rapportait à la côte pour les broyer et en extraire le précieux métal au moyen de lavages. Ces lavages se faisaient, d'après Strabon ${ }^{2}$, dans des auges ou sébiles remplies d'eau; d'après Hérodote, dans des lacs ou bassins. Les femmes qui en étaient chargées pèchaient les paillettes d'or avec des plumes enduites de poix, comme les lareurs des placers les recueillent avec du mercure. Elles égayaient leur travail de leurs chants, et, à cause de cela, elles élaient devenues les Hespérides à la voix sonore et harmonieuse. ”

Nous ne saurions admeltre sans réserve celte ingénieuse identification; mais, à en juger par la quantité d'or que, depuiś plusieurs siècles, les indigènes fournissent aux Européens sans autre manipulation que de grossiers lavages, nous croyons que les montagnes sénégalaises recèlent dans leurs lancs un vaste champ d'or. Le dernier mot n'est donc peutêtre pas encore dit sur les placers sénégalais.

Il nous reste, pour terminer celle r乞vue des produits de notre colonie, à étudier la faune.

1. Axricnax, le Jardin des Hespérides (Revue de géographie, 1SSö).

2. Strazor, III, 2-S. - НЕ́rojotв, IV, 19 J. 
Les animaux domestiques sont les mêmes qu'en Europe. Les moutons du Sénégal pourtant ne sont utiles que comme viande de boucherie. Leur laine ne peut servir, attendu que, par un effet bien connu des pays chauds, ils n'ont qu'un poil soyeux et court. Les bœufs, au contraire, sont fort recherchés. On les nomme bœufs à bosse, à cause de la tumeur graisseuse qu'ils ont sur le garrot, et bœufs porteurs, à cause de leur aptitude à porter de lourdes charges avec un pas égal à celui du cheval. Ils sont fort appréciés dans nos Antilles, surtout à la Guadeloupe, à cause de leur douceur, de leur sobriété, de leur résistance à la fatigue et de leur puissance de travail. Les fins et abondants pâturages qui couvrent surtout la rive gauche du Sénégal permettraient de les multiplier à l'infini. Le bas prix de la viande, qui varie de soixante à quatre-vingts centimes le kilogramme, témoigne d'une grande facilité d'éducation et promet des bénéfices à lout spéculateur qui découvrira des débouchés. D'ailleurs, pour un peuple qui naît à la civilisation, rien ne convient autant que l'élève du bétail.

Les chevaux du Sénégal sont de bonne race, très ardents et très résistants au travail, mais encore peu nombreux, car ils supportent avec peine les chaleurs extrêmes; mais tous ceux qui sont acclimatés, c'est-à-dire nés au Sénégal même, sont de tous points excellents.

Les animaux féroces sont assez rares, et ils n'altaquent l'homme que sous l'influence de la faim. Le plus redoutable est le lion, surtout le lion noir, mais il ne se laisse pas approcher. Les indigènes prétendent même que lorsquil rencontre une femme il lui cède le pas. Le lion aime à suivre les troupes d'antilopes, dont il fait sa principale pâture; mais il ne dédaigne pas le menu gibier, surtout les pintades. Il sait très bien observer les passes tracées dans les herbes par ces oiseaux, qui volent rarement, et d'un coup de palte il en abat des files. Le lion est souvent en compagnie de deux autres animaux avec lesquels il a, pour ainsi dire, contracté alliance. On raconte en elfet que le marabout, cclle grue sénégalaise, dont la queue orne parfois la tête de nos élégantes, forme société avec le lion. Il l'avertit du danger par ses cris aigus, et le lion, pour le remercier, lui abandonne 


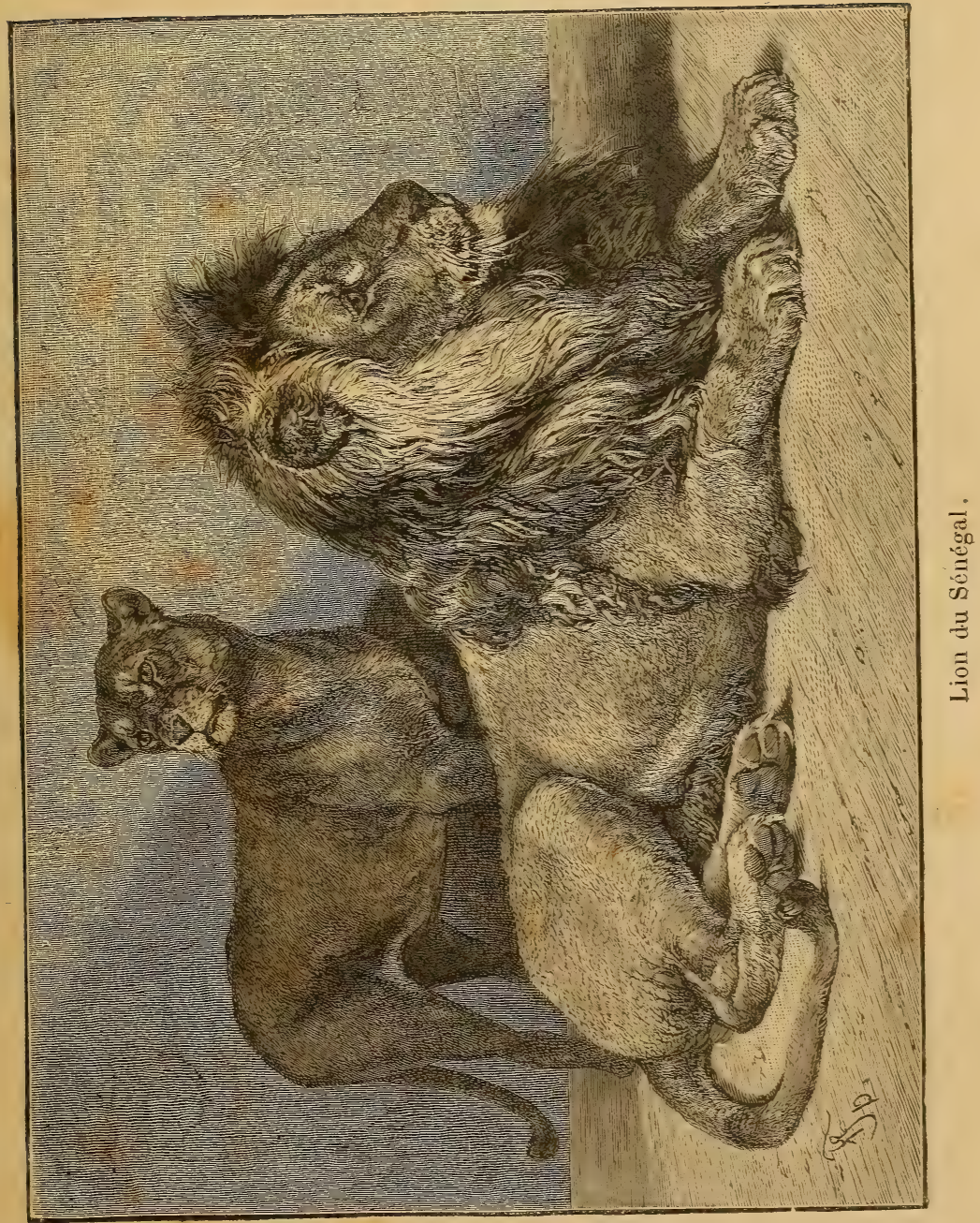

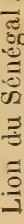



les débris de ses repas. Le chacal suit également le lion, suruel il sert de pourvoyeur. Parmi les carnassiers on cite encore la panthère, le chat-ligre, le lyns, la hyène et la genelte. $\mathrm{La}$ hyène n'est pas à eraindre pour l'homme; mais elle

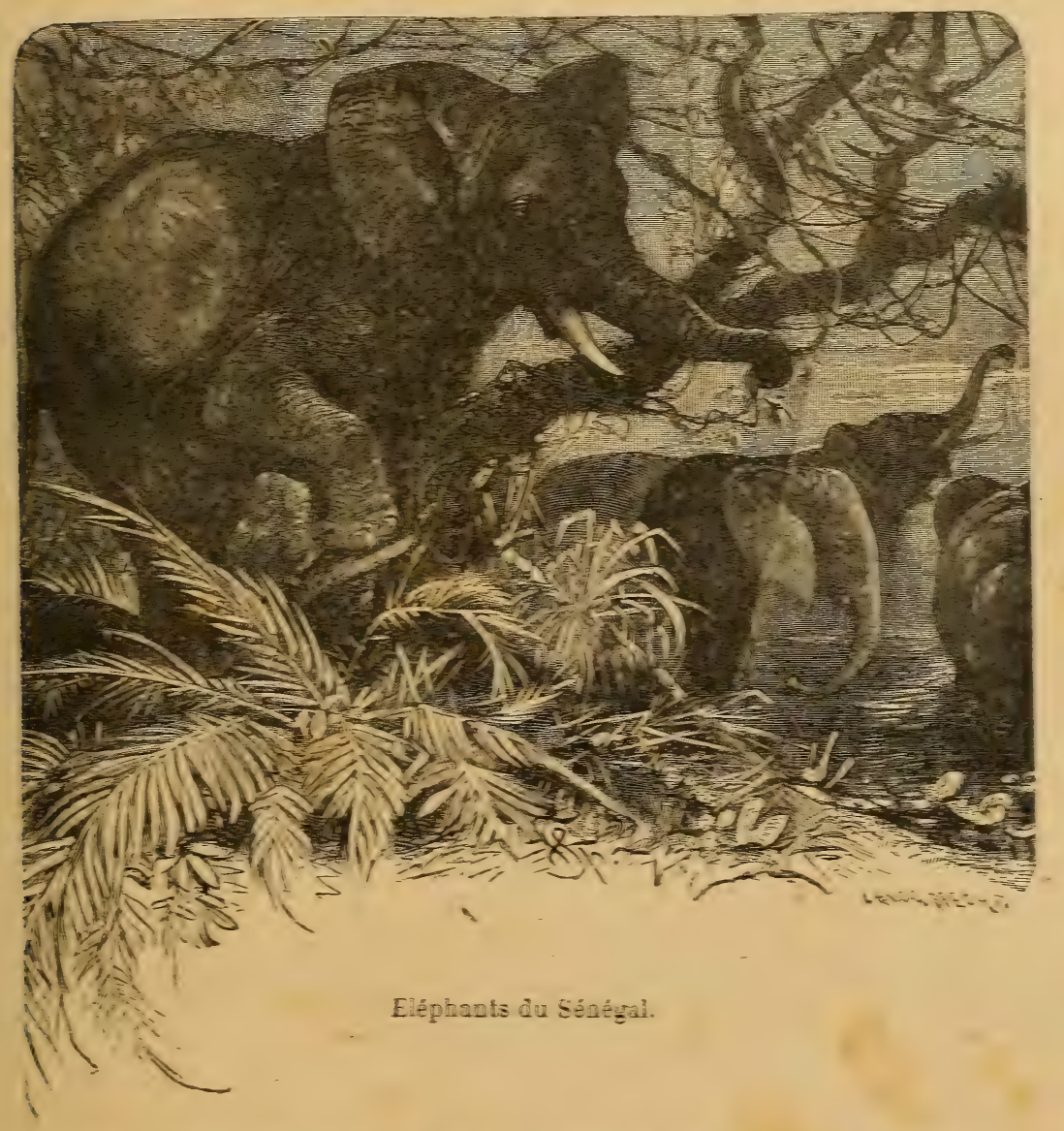

est tellement vorace, qu'il faut courrir de pierres et entourer d'épines les tombeaux. afin de protéger les restes qui $y$ sont renfermés. Quant aur genettes, elle sont grosses comme des petits chiens et fort recherchées à cause de leurs poches remplies de musc.

Les plus connus des herbivores sont les éléphants. Au 
siècle dernier on en voyait des bandes de quarante à cinquante individus qui paissaient tranquillement; mais on les a pourchassés à cause de leurs défenses, et ils sont devenus farouches et redoutables. Il y a une trentaine d'années, quelques-uns d'entre eux vivaient isolés sur les rives du Paniéfoul, et le traversaient parfois pour aller brouter les savanes du bas delta; mais on lcur a fait une guerre d'extermination. Mieux aurait valu essayer de les domestiquer, comme les Car-

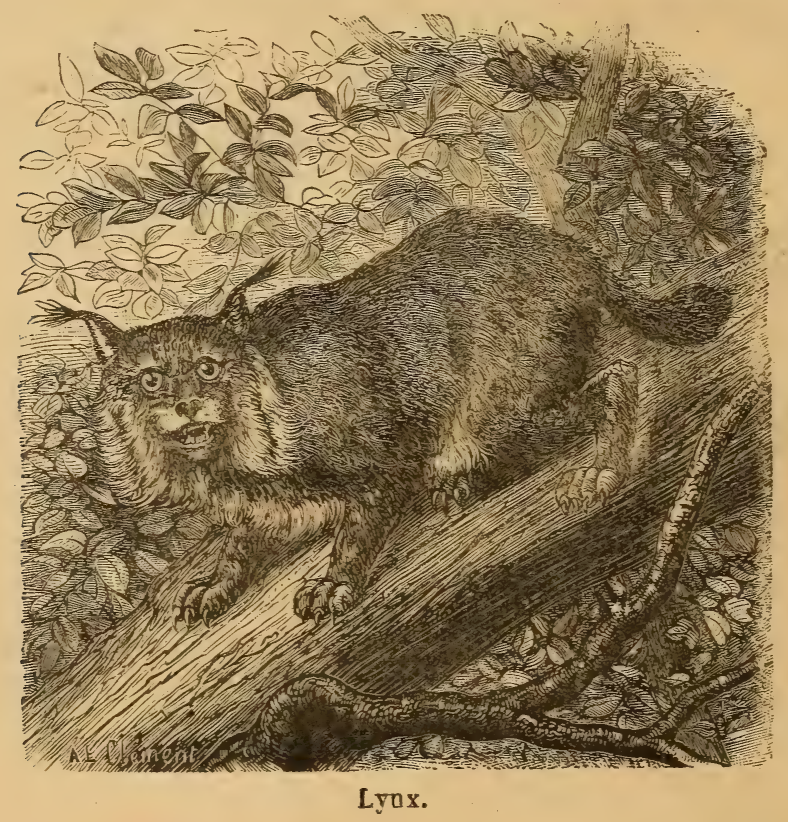

thaginois avaient jadis réussi à le faire, comme les Asıatiques le foǹt encore à l'heure actuelle. On s'est sollement privé d'utiles auxiliaires, et peut-être est-il trop tard pour réparcr celte faute.

L'hippopotame se rencontre encore en bandes assez nombreuses. Ses dents sont recherchées pour la fabrication des dentiers artificiels. Nous mentionnerons encore la girafe, l'antilope, le sanglier, l'agouti et le lièvre. Trois espèces de singes habitent la région: le singe gris à ventre blanc dans le bas fleuve, le golago ou singe de nuit près de Podor et de 


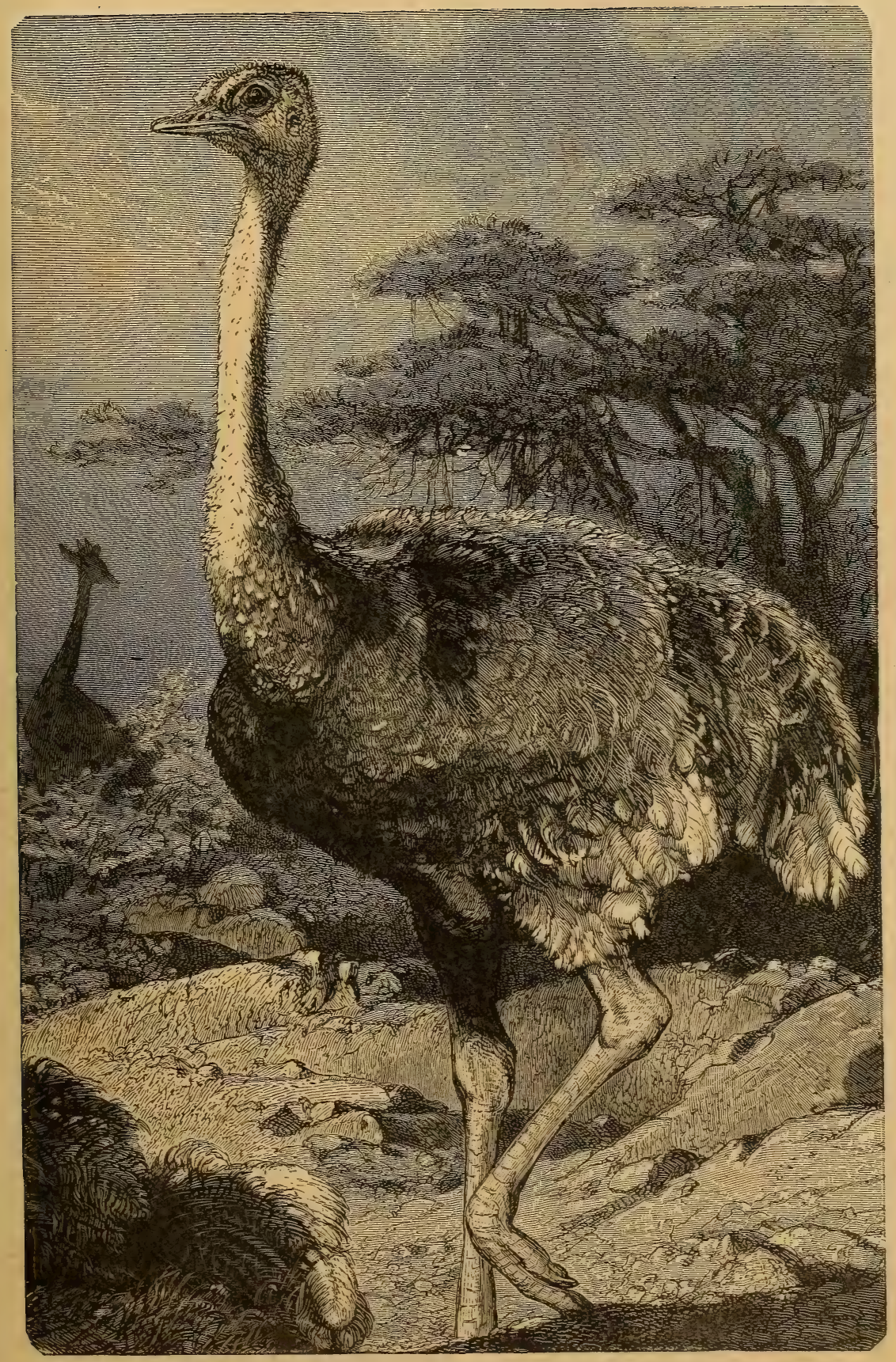

L'autruche. 

Saldé, ct le cynocéphale à poil roux, dont le museau et le cri ressemblent à ceux du chien. Les cynocéphales sont intelligents et s'apprivoisent assez vite. On les prend en leur présentant un appât dans une calebasse. Ils y passent la main et ne peuvent plus la retirer. Ils constituent, près des zones cultivées, de véritables républiques de pillards éhontés. On raconte que parfois ils se réunissent en foule contre une panthère et réussissent à la tuer. Sur les rives du haut Balioy est une montagne à degrés réguliers, immense escalier dont chaque marche fourmille de singes. Mage évaluait à six mille le nombre des cynocéphales qui le saluèrent de leurs aboiements forcenés quand il passa devant eux,

Au nombre des échassiers se place au premier rang l'autruche; dont le riche plumage est un objet de convoitise pour les nègres. Chassée à outrance, elle devient rare. Le gouvernement devra sans doute bientôt intervenir, comme l'ont fait les Anglais au Cap, afin de prévenir la disparition de l'espèce. Il faut d'ailleurs ne pas s'exposer aux convoitises de cet oiseau, altiré par tout ce qui brille, aussi bien par les bijoux que par les yeux des enfants.

Viennent ensuite, parmi les gallinacés, l'outarde, la poule de Pharaon, la pintade, la perdrix, la caille, la gelinotte, etc.; parmi les palmipèdes, l'innombrable tribu des canards; parmi les passereaux, des espèces aussi jolies que variées : sénégali, veuve, cardinal, perruche verte, qui depuis peu sont expédiées en Europe en assez grande quantité.

Les reptiles sont peu nombreux; un seul est dangereux, le 'trigonocéphale. Nous accorderons une mention spéciale au caïman qui infeste les eaux sénégalaises. Les nègres sont friands de sa chair, qui répugne aux Européens à cause de son odeur musquée. L'instinct de cet animal est très développé. A peine a-t-il noyé sa proie qu'il la cache dans des creux sous l'eau el invite ses congénères à la partager. Les noirs sont parfois enlevés par eux. La tradition est qu'il faut enfoncer les doigls dans les yeux du caïman pour lui faire lâcher prise.

Le poisson ${ }^{1}$, qui pendant l'hivernage abandonne les côtes

1. A. Merle, la Pêche sur la côte occidentale d'Afrique (Société de géographie de Bordeaux); 1879. - IIAurneux, la P'éche de la morue au Sénégal (id.); 1857. 
du Sénégal, y pullule quand arrive la saison sèche. La morue s'y rencontre fréquemment, surlout au banc d'Arguin, vaste ensemble d'écucils et de brisants, tour à tour couverts et émergés, de huit mille quatre cents kilomètres carrés. Il est même singulier que personne encore n'ait songé à tirer parti de ces richesses. Les Portugais avaient autrefois, parait-il, fondé dans ces parages des pêcheries, dont il reste des vestiges. Rien ne serait plus aisé que de les imiter. Sur ces côtes sénégalaises, les coups de vent sont rares, et la chaleur, dans celte saison, est tempérée par les brises du nord. Miême en admetlant, et rien n'est moins prouvé, l'insuffisance de la morue pour alimenter ces pêcheries, beaucoup d'autres variétés de poissons pourraient être salés et marinés, et un nombre encore plus considérable convertis en engrais.

Telles sont les principales productions du Sénégal. Variées, abondantes et riches, elles ne peuvent qu'augmenter lorsque des mains intelligentes les auront mises en valeur. Ceci nous conduit, après avoir étudié le sol et les productions du sol, ì étudier les populations qui l'habitent et l'avenir qui semble réservé à notre colonie.

Grâce à la situation du Sénégal aux confins de deux zones distinctes, les races présentent de grands contrastes de couleur et d'origine. Au sud du grand fleuve vivent les Nègres, élablis de toute antiquité dans la région qu’ils occupent; au nord sont les Maures, installés en Afrique seulement depuis les conquêtes arabes, c'est-à-dire depuis le huilième siècle environ de l'ère chrétienne. Quant aux Européens, conduits au Sénégal uniquement par les intérêts de leur commerce, ils n'y résidèrent pas d'abord à poste fixe. Ce n'est que depuis bien peu de temps que quelques-uns d'entre cux se sont déterminés à y cultiver la terre, à y fonder des industries, en 

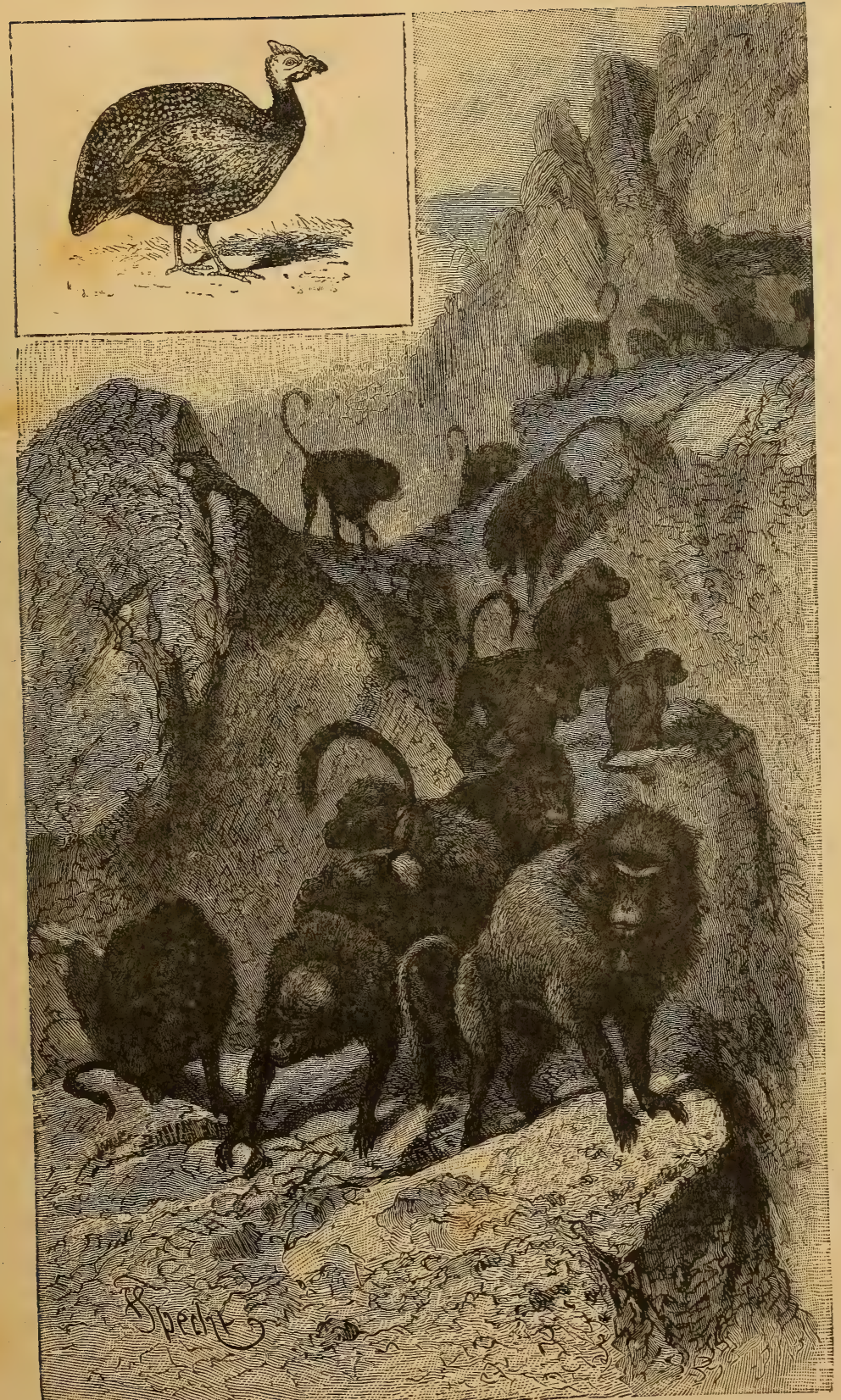

Cynocéphales. 

un mot à se considérer comme de rrais colons, atlachés au pays comme à une seconde patrie; mais leur nombre est encore très peu considérable, et il est à craindre qu ïls ne puissent s'acclimater sérieusement. Il n'y a donc à rrai dire que deux races en présence au Sénégal, et on peut leur assigner le fleure comme limile elhnograplique : les Nègres ct les Maures. Nous les étudierons successivement.

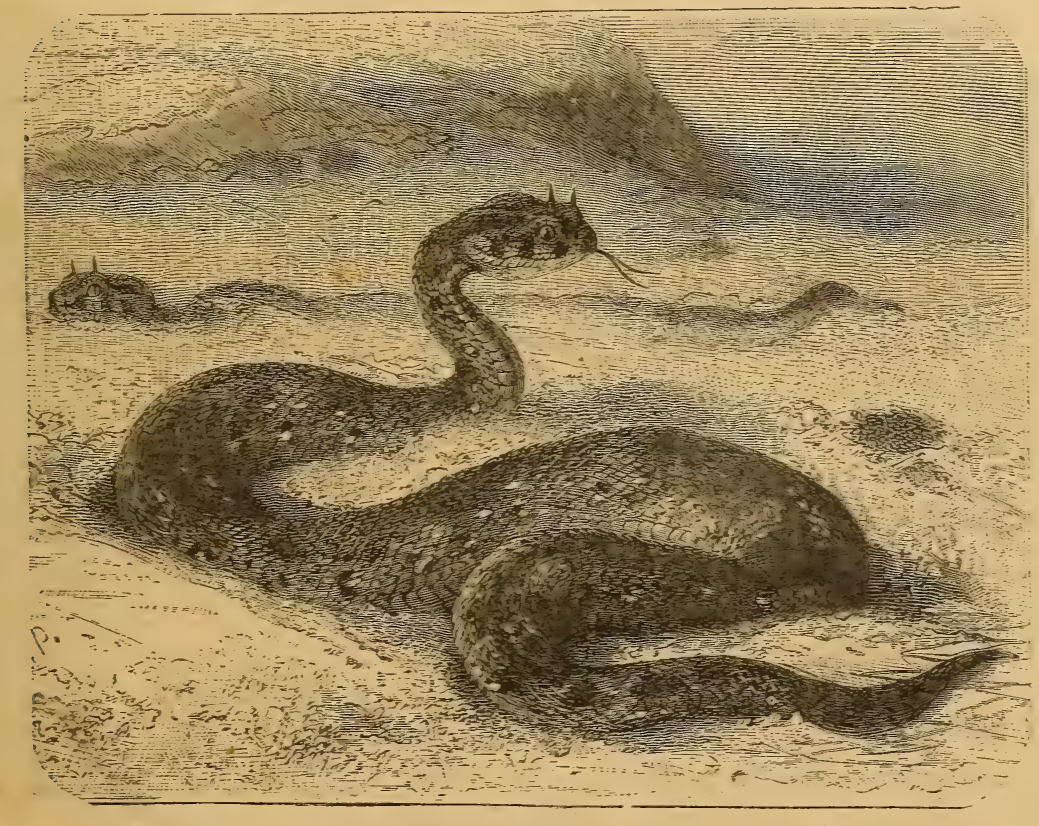

Vipères cornucs.

Race noire. - Il est peu de problèmes aussi ardus, aussi compliqués, aussi dangereux que celui de l'origine des espèces. Sans essayer de le discuter ici, il nous suffira de rappeler que. la race noire, aussi haut que remontent les souvenirs historiques, parait installée en Afrique. Elle serait donc autochtone. La majeure partie des tribus sénégalaises appartient à celle. race. Ces tribus sont divisées en une multitude de groupes, mais peurent être ramenées à cinq variétés principalês : Yolofs, Sérères, Soninkés ou Sarakolès, Mandingues ou Bambaras, Peuls ou Foulahs. 
Les Yolofs ${ }^{1}$ occupent presque tout l'espace limité par le Sénégal, la Falémé et la Gambie, c'est-à-dire les provinces sénégalaises qưon nomme le Oualo, le Cayor, le Baol et le Djolof. Ils sont noirs entre les noirs. Leurs lèvres mêmes sont noires, mais d'une teinte plus mate que le reste du visage. La peau, d'un noir de jais avec des reflets brillants, dénote la finesse du derme. Les formes sont pures et éléganies, surtout le buste, admirable de largeur et de force. Le volume de la tète est cependant trop petit pour la masse du corps; mais les Yolofs la grossissent en laissant pousser leurs cheveux crépus. Elle est attachée à un cou flexible et bien planté dans les épaules; les reins sont cambrés, la cuisse arrondie, et le genou petit. Ce sont, en un mot, de fort beaux hommes, et le type serait parfait s'il n'était déparé par une jambe un peu sèche et un pied plat.

Les Yolofs parlent une langue que l'on peut étudier comme un modèle de langue agglutinante. Les racines, toutes monosyllabiques, s'agrègent les unes aux autres, tout en restant invariables dans leurs diverses valeurs de substantifs, d'adjectifs, de verbes ou d'adverves; elles se déterminent par des suffixes qui modifient à l'infini la signification des mots. Ainsi, pour n'en citer qu'un exemple, par un simple chạgement de désinence le verbe peut se conjuguer dans le sens emphatique, interruplif, augmentatif, causatif, etc. Bien que cette langue n'ait pas de littérature proprement dite, elle est très répandue, car elle est devenue, par sa facilité même, la langue usuelle du commerce dans toute la Sénégambie ${ }^{2}$.

Les Yolofs se disent les uns musulmans, les autres catholiques; mais ils sont restés félichistes, car la principale différence entre les sectateurs des deux religions consiste en ce que les uns se servent de grisgris couverts de caractères

1. Azan, le Oualo et les pays environnants (Revue maritime et coloniale, 1864). - Bérexger-Féradd, Étude sur les Ouolofs (Revue d'anthropologie, 1873).

2. Cust, the Modern Languages of Africa. - BARThÉLEm, Guide du voyageur dans la Sénégambie française, avec une carte et un vocabulaire français-ouoloff 1885. - J. DARD, Grammaire woloffe; - Dictionnaire woloff-francais; 1826. Baron Roger, Recherches philosophiques sur la langue ouoloffe; 1829. - AвBв́ Bollat, Grammaire de la langue woloffe; 18วั8. - Descener, Recueil de douze cents phrases françaises usuelles avec traduction woloff; 1S6ł. - FaIdarabB, Vocabulaire francais-woloff (Annuaire du Sénégal, 185̌́). 
arabes, et que les autres n'accordent leur confiance qu'à des chapelels ou à des scapulaires. Ils s'accordent du reste pour la célébration de nombreuses fètes nationales ou locales, et continuent à croire à des génies domestiques, la plupart du temps représentés par une sorte de lézard gris, auquel ils scrrent arec empressement des écuelles de lait. Au fond, ma-

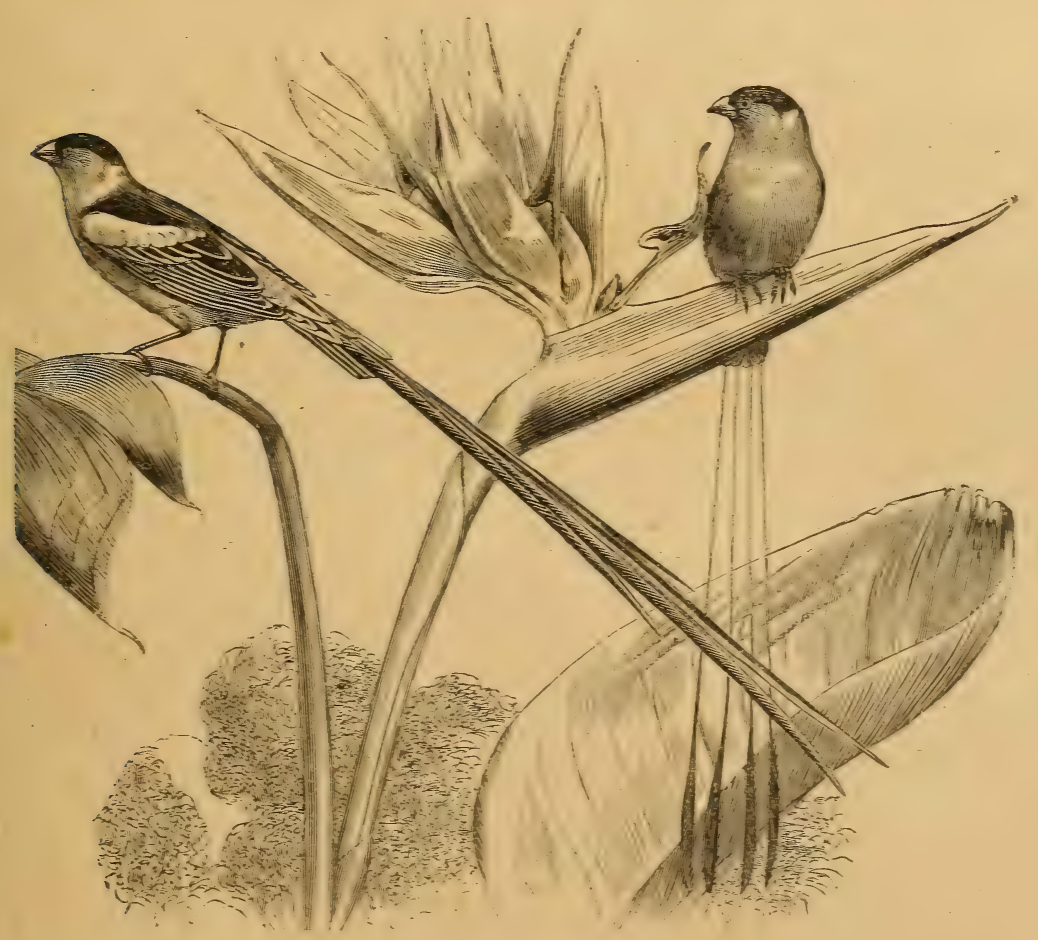

- Uiseaux sézég̨alais.

rabouls et missionnaires n'ont fait chez les Yolofs que de médiocres recrues, et leur prétendue conversion n’est le plus sourent que l'adoption de superstitions nourelles.

La société yolofe est divisée en castes. Les hommes libres forment la première. Les gens de mélier. les indigents occupés aux travaux serviles et les esclares sont répartis dans les autres. En dehors de toute classificalion sont rejelés les griots, c’est-à-dire les sorciers, méprisés, mais fort redoulés 
et très redoutables, car ils ne se contentent pas de fabriquer des talismans, et joignent à leur industrie le commerce, beaucoup plus lucratif, des poisons. La polygamie est en honneur; lorsque meurt un chef de famille, tontes ses veuves deviennent la propriété de son beau-frère. Il faut seulement qu'clles soient en quelque sorte adoplées par la sœur du défunt, qui vient les relever, et les ressuscite, pour ainsi dire, en faisant leur toilette de deuil. Les morts, ainsi que dans l'ancienne Égypte, ne reçoivent les honneurs de la sépulture qu'après avoir subi une sorte de jugement; mais la bienveillance est de rigueur envers eux, et celte épreuve n'est guère plus qu'une formalité. Le toit de la cabane du défunt est d'ordinaire enlevé et déposé sur sa tombe. Quand les parents et les amis reviennent du cimelière, ils font de nombreux détours avant de rentrer au village, car il faut éviler que le génie du mal saisisse une nouvelle proie.

Les Yolofs furent longtemps nos ennemis les plus déterminés, mais ils ont peu à peu renoncé à leurs préventions, et se sont laissé gagner par notre civilisation. Ils ont adopté notre costume; ils ont pris nos habitudes de travail et d'économie; quelques-uns d'entre eux, soit comme piroguiers, soit comme soldats, se sont même fait remarquer par de véritables traits de bravoure et de dévouement. Ce ne sont plus des sujels ou de douteux alliés, ce sont des associés; ce seront bientôt nos compatriotes. Aussi bien ils se montrent très fiers d'appartenir, même de loin, à la grande nation française. Ils se vantent d'être les enfants de la ville, et, dans leur naïf orgueil, se considèrent à l'égard des autres nègres comme constituant une véritable aristocratie. Notre règle. de conduite à leur endroit n'est-elle pas toute tracée? Ne devons-nous pas encourager ces bonnes dispositions, et ne jamais perdre de vue que les Yolofs sont appelés à créer, sans doute dans un avenir très rapproché, la nation francosénégalaise?

Les Sérères ${ }^{1}$ forment le second groupe des tribus noires

1. Phet-Laprade, Notice sur les Sérères (Revue maritime et coloniale, 1863̈). Carlus, les Sérères de la Sénégambie (Revue de géographie, 1880). - Faidrenbr, Étude sur la langue sérère (Annuaire du Sénégal, 186̈). 
sénégalaises. D’après la tradition, ils occupaient autrefois la haute vallée de la Casamance. Refoulés au quinzième siècle par les musulmans, Mandingues ou Peuls, ils franchirent la Gambie et s'établirent dans le bassin du Saloum. Lcur aire. d'habitation est assez nettement délimitée par une ligne qui suit le faite de séparation entre la Gambie et le Saloum, embrasse tout le bassin de ce fleuve, et rejoint le marigot de Tamna près du cap Vert.

Les Sérères sont de fort beaux hommes. Il n'est pas rare de rencontrer chez eux des tailles de deux mètres. Si leur jambe n'était pas grêle et leur mollet trop peu saillant, ils ressembleraient, avec leur thorax développé et leurs bras musculeux, à de vrais Hercules. Moins noirs que les Yolofs, ils ont le nez plus épaté et les lèvres plus grosses. Les jeunes filles, qui trouvent qu'elles ne sont pas encore assez grosses, se font enfler la lèvre inférieure en la perçant d'épines, et elles supportent sans crier, et par amour-propre, cette douloureuse opération.

Bien que, de temps immémorial, les Sérères pratiquent la circoncision, et que celte cérémonie, précédée par une retraite de deux mois nommée le $l c l$, et suivie de véritables scènes d'initiation, soit le prétexte de fêtẹs bruyantes, les Sérères ne sont pas musulmans. Ce n'est pas qu'ils repoussent la doctrine, mais ils n'ont pu accepter les usages et les pratiques de l'Islam. Ils croient à deux génies suprêmes, Tokhai, dieu de la justice, et Tiourack, dieu de la richesse. Ils rendent encore hommage au dieu serpent, ou Fangol, qu'ils entretiennent soigneusement dans un enclos sacré, entouré d'épines, le dianka. Jadis ils lui offraient des bœufs et des poulels, mais ils se contentent aujourd'hui de lui présenter la dépouille de ces animaux. Ils croient enfin aux génies de l'air et de la nuit, surtout aux mauvais génies, ou scytanes. Comme on ne saurait trop les implorer pour se meltre à l'abri de leur malice, c'est surtout à ces scytanes qu'ils adressent leurs prières, et c'est contre leurs maléfices qu'ils essayent de se garantir, en se couvrant de grisgris, ou térés. Les enterrements sont célébrés en grande pompe. Après le repas des funérailles ou $d e d$, le cadavre est déposé dans une enceinte 
circulaire surmontée du toit de la case du défunt. On y laisse scs armes et ses instruments, et on plante tout autour une haie d'épines, pour le protéger contre la dent des animaux carnassiers.

Le chef suprême des Sérères se nomme le bour. Jamais souverain n'a exercé avec moins d'entraves un pouroir plus absolu : à tel point que certaines classes de la société se glorifient comme d'un honneur des mauvais traitements dont il les accable. Sa personne est sacrée. Tout ce qui émane de lui l'est également. Ainsi, manifeste-t-il l'intention de cracher, il faut se jeter à terre, ramasser précipitamment une molle de terre, la présenter avec respect au souverain, et garder avec soin la salive royale. Toute une hiérarchie de fonctionnaires entoure le bour. Les plus importants se nomment le daraf et le farbo. Ils s'accordent toujours pour faire peser sur le peuple un joug écrasant; mais ils ont si bien conscience des haines soulevées contre leur intolérable tyrannie, qu'au premier symptôme de maladie chez le bour, i's s'empressent d'enlever tout ce qui leur apparlient en propre dans le palais royal. Ils savent trop bien que le palais sera pillé tout aussitôt après la mort du bour. Le daraf est une sorte de maire du palais, qui assume sur sa tête toute la responsabilité des actes royaux. C'est lui qui est chargé de l'éducation du boumi ou de l'héritier présomplif. A la mort du bour, il propose le bourni à l'acceptation du peuple. Si aucune protestation ne s'élève, le bourni est élevé à la dignité de bour. Si, au contraire, le choix n'est pas ratifié, on désigne séance tenante un compétileur, et les partis opposés se séparent pour se préparer, chacun de leur côté, à la guerre civile. Le jour même du couronnement du nouveau bour, le daraf prend mesure d'un cercueil en bois, destiné à recevoir sa dépouille mortelle. Quant au farbo, c'est à proprement parler l'intendant du palais, le fonctionnaire spécialement chargé de fournir au bour la sangara, ou cau-de-vie. Cette charge n'est pas une sinécure, car la sangara, affreux mélange d'alcool, de tabac, de poudre en grains et de piment rouge, est distribuée avec une dépłrable prodigalité. L'ivresse est en quelque sorte l'état normal du bour et des 
principaux fonclionnaires. Le fameux proverbe : " $\mathrm{Quand} A \mathrm{~A}$ guste avait bu, la Pologne était ivre, " est ici d'une application journalière. Le mauvais exemple donné par le souverain n'est en effet que trop suivi par le peuple. Il est difficile de trouver ailleurs une population aussi adonnée à l'ivrognerie. Les enfants suçent l'eau-de-vie en même temps que le lait de leur mère. Aussi les malheureux demeurent-ils comme hébétés. On ne peut demander plus tard à ces intelligences endormies que de mauvais coups ou mème des crimes à exécuter. Ils deviennent tiédos, c'est-à-dire les âmes damnées des chefs, des instruments passifs entre leurs mains. Ils ont abdiqué toute volonté. Ils ne savent plus que boire, et ne demandent plus qu'à boire cette odieuse sangara. C'est alors que les atteint un mal mystérieux, la nélouane ${ }^{1}$ ou maladie du sommeil. Portés au sommeil d'une façon invincible, on les voit manger, boire et accomplir les fonctions ordinaires de la vie sous l'influence d'une torpeur qui les accable et qui ne les abandonnera plus.

Au-dessous du bour et de ses principaux lieutenants, le daraf et le farbo, les Sérères sont répartis en dix classes, soigneusement superposées les unes aux autres. La première est celle des guélévares, ou princes du royaume, issus des princesses du sang. Ils composent l'entourage immédiat du roi et sont très puissants. Le peuple ne prononce leur nom qu'avec respect, car il redoute leur vengeance. C'est parmi eux que le bour choisit son bourni ou héritier présomplif; mais ce choix est toujours chose délicate, car les guélévares évincés rassemblent les tiédos en quête de sangara ou même les bandits qui tiennent la campagne, et se préparent à la guerre civile, pour la prochaine mort du roi. Si même celte mort tarde trop au gré de leur impatience, ils protestent contre le choix du bourni et font appel aux armes.

La seconde classe est celle des domibours, ou descendants du roi et d'une femme libre. C'est parmi cux que l'on choisit les chefs de village ou même de province. Les diamibour's, ou hommes libres, constituent la troisième classe. Ils sont

1. Max Astrié et Streab, la Nélouane (Société de géograpfie de Marseille). 
spécialement chargés de la perception des impôts. Le système de perception en bloc est pour eux l'idéal. Ils so rendent chez un propriétaire, et prennent tout ce qui est à leur convenance jusqu'à concurrence de la somme qu'on leur réclame. Le volé n'a d'autre ressource que de s'adresser au bour, mais il préfère garder le silence. Viennent ensuite les guévels o: griots, et aussi tisserands; les môbos et les bombâdos, ou agriculteurs; les tegas, ou fabricants d'armes, d'instruments et de bijoux; les udés, ou fabricants de sandales, de selles et de brides; les bissètes, charlatans ou saltimbanques, voleurs de profession, très habiles pour entever des troupeaux ou faire disparaître des enfants, et enfin, au dernier rang de celte sociélé si divisée, les laobès. Ce sont les Tziganes des Sérères : vrais nomades, sans résidence fixe, s'installant dans les forèts, où ils se livrent à toutes sortes de métiers, surlout de métiers peu avouables. Peut-être, comme les parias de l'Inde, sont-ils les vrais aborigènes, foulés et opprimés par toutes les invasions, et qui n'ont survécu à leur ruine que par leur abaissement même. Ces laobès méritent du reste lo mépris dont on les abreuve. Sales, gourmands, débauchés, ils sont entre eux d'une férocité inouie; mais les autres classes de la population les laissent se déchirer entre eux, sans accorder à leurs querelles plus d'altention que nous n'en accordons aux disputes des chiens dans les rues de nos villes.

En dehors de ces dix castes vivent à part les sorciers. On en distingue trois catégories: les boroms-hamans, qui ressemblent à nos somnambules et prédisent l'avenir; les boroms. tours, qui ont pour mission de punir les voleurs et de démasquer les sorciers dangereux, et enfin les denias, qui sont précisément ces dangereux sorciers. Un noir a-t-il des enriemis qui veulent l'expédier sans trop de danger dans l'autre monde, on l'accuse d'être denia. Le prétendu denia est alors conduit près de l'arbre fétiche, tenant un coq entre ses bras. On lui fait boire une potion. S'il est réellement sorcier, il ne romira pas la potion et le coq restera muet, et en ce cas il scra aussitôt mis à mort; s'il n'est pas coupable, il rendra la potion et le coq chantera.

La polygamie est en honneur chez les Sérères. On achète 
une femme en payant au fulur beau-père le diour, c'est-à-dire / des esclaves, des chevaux, des boufs, etc. Quand le jour fixé pour le mariage est arrivé, les amis du futur enlèvent la jeune fille, qui résiste, mais finit par être amenée au pentia ou lieu de réunion du viliage. Elle en fait le tour, et reçoit alors des félicitations et des cadeaux. Elle est ensuite enfermée pendant huit jours dans la maison d'un chef de famille, et ce n'est qu'au neuvièm'e jour qu'est célébré le mariage, par un grand festin auquel tout le monde peut prendre part. La têle de la mariée est aussitôt couverte d'un voile blanc, le maláne,

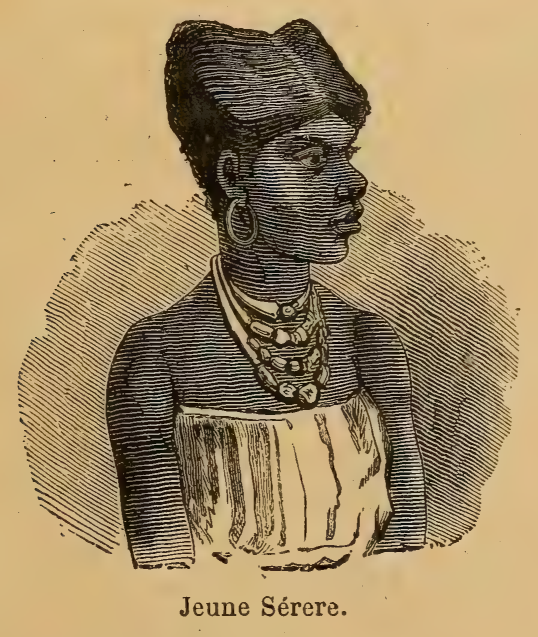

qu'elle ne pourra quitler pendant un mois, et auquel tout le monde a le droit d'essuyer ses mains. IIuit jours après le mariage commence une lessive générale, sauf pour le malâne, à laquelle chacun peut apporter son linge sale. Si l'union n'est pas heureuse, la femme se sauve chez ses parents, qui peuvent la rendre à l'époux moyennant réparation, ou la vendre à un autre fiancé. Les femmes stériles ont un singulier moyen de se créer une famille. Elles achètent une jeune fille, lui donnent un mari, et tous les enfants issus de cette union deviendront leurs héritiers légitimes et porteront leur nom.

Les Sérères sont braves. Arant de se décider à entrer en campagne, ils convoquent le conseil des "barbes blanches" 
et immolent soit un lomme, soit un bœuf. En outre, deux sorciers, deux boroms-tours, s'enferment dans une case, le demun-fangol, et passent tout leur temps à fabriquer et à expédier des grisgris aux combatlants. Comme armes offensives, ils ont des sabres, des lances et des fusils. Leurs seules armes défensives sont les grisgris. Ils sont assez habiles en castramétation, et savent improviser un camp défendu par un fossé et des palissades en bois. Au milieu se dresse une sorte de donjon, le ñdogtal, réservé au roi. On ne peut les prendre que par la famine, et il arrive souvent que, réduits au désespoir, ils s'ouvrent un chemin sanglant.

Comme les Sérères, malgré leur penchant à l'ivrognerie, sont au fond honnêtes et laborieux, il est à croire que le travail les moralisera, et qu'à l'exemple des Yolofs, ils deviendront bientôt les propagateurs de la civilisation française dans l'Afrique occidentale.

Les Soninkés ${ }^{1}$ ou Sarakolès sont également susceptibles de progrès. D'après la tradition, ils auraient autrefois fondé de grands empires dans la vallée du Niger; mais, aussi loin que remontent les souvenirs historiques, c'est en Sénégambie, sur les bords du Sénégal, entre Bafoulabé el Bakel, qu'on les trouve établis. Ils sont plus petits que les Yolofs et les Sérères. Leur teint n'est plus noir, mais marron foncé, tirant sur le rouge. Leur front est fuyant, leurs pommeltes peu saillantes, leur nez épaté; leurs lèvres très grosses et repoussées en dehors par l'inclinaison des gencives; leur menton fuyant, mais fourni d'une barbe assez épaisse; leur chevelure laineuse, sans être crépue. Les femmes portent leurs cheveux tressés en forme de casque, entremêlés de verroteries et de grains d'ambre, et sous un voile flotlant de gaze.

Les Sarakolès habilent des villages bien construits et aménagés avec goût, très rarement entourés de palissades. Au centre s'élève un grand arbre autour duquel a élé construite une estrade. C'est un véritable forum où les indigènes s'assemblent pour causer des affaires publiques. Doux de caractère el conciliants, se bornant à une résislance passive, sou- 
vent plus efficace que la violence, ils ont réussi à se maintenir en pelits États, monarchics ou aristocraties, et, sous le flot des invasions qui a traversé la région, mais sans l'anéantir, ils ont réussi à maintenir leur indépendance. Depuis longtemps convertis à l'Islam, ils sont demeurés tolérants. Ce n'est que par accès, et sous l'excitation d'une fureur passagère, que la fièvre religieuse leur met les armes à la main.

Le trait distinctif de leur caractère est une extrème curiosité. Ainsi que nos ancêtres les Gaulois, ils sont avides de nouveautés. Le désir de voir des pays inconnus les entraine au

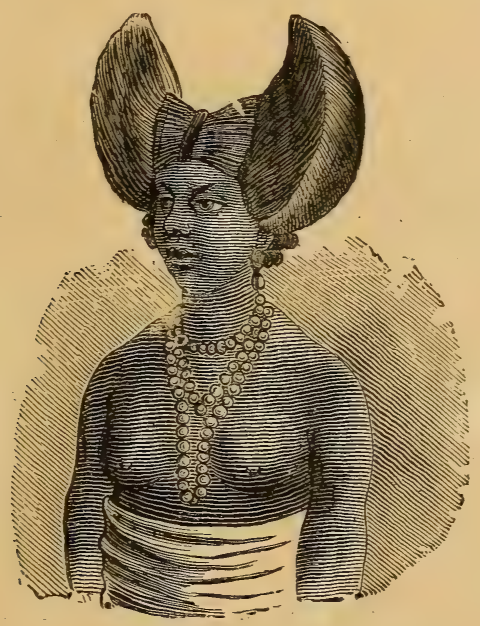

Femme soninkée.

loin. Aussi s'engagent-ils volontiers, soit comme matelots, et ils sont alors de très bons piroguiers, - soit comme guides ou porteurs, - et ils excellent à débroussailler une forêt ou à tracer des sentiers et des routes. Le commerce est leur occupation favorite, mais ils ne négligent pas pourtant l'agriculture et écoutent volontiers les conseils de nos négociants. On peut compter sur eúx. Il est probable qu'ils deviendront pour le haut fleuve ce que les Yolofs sont déjà pour le bas fleuve, et que d'ici à quelques années, sous l'influence moralisatrice de la paix, de la civilisalion et du travail, ils contribueront à la grandeur et à la prospérité de la France africaine. 
Les Mandingues ou Bambaras sont moins avancés. Ils habitent la région occupée par les hauls affluents du fleuve et tout le pays compris entre le Sénégal et le Niger. Ce sont les provinces que l'on désigne sous le nom de Khasso, de Guidimakha, Nadioga, Kaarla, Bondou, Bambouck, etc. Les Bambaras ${ }^{1}$ et Malinkés sont des noirs de haute taille, aux cheveux crépus. Leur vêtement est des plus primilifs : il se compose d'un pantalon relenu à la ceinture par une sorte de cordelière, d'un boubou assez court, laissant les bras nus, et d'un bonnet relevé par des pointes vers le sommet de la tête. Les femmes ne sont le plus souvent vêtues que d'un pagne, qu'elles enroulent autour des reins. Des fusils à silex, à un seul canon, de provenance anglaise, des sabres dont les lames sont protégées par des fourreaux de cuir fabriqués par les cordonniers du pays, quelques lances et un petit nombre d'arcs, telles sont leurs armes. Leur principale occupation est l'agriculture; mais, comme ils sont très paresseux, ils n'emploient que des procédés tout à fait rudimentaires. On rencontre dans les villages de la région des forgerons qui fabriquent les armes et les instruments d'agriculture, des cordonniers qui confectionnent d'assez jolis objets en cuir, des tisserands et des vanniers; mais toutes ces industries sont locales et n'ont aucune importance commerciale. Bambaras cl Malinkés ont pourtant l'inslinct commercial très développé : ce sera sans doute pour eux, tôt ou tard, l'occasion de mettre en œuvre leurs ressources agricoles et métallurgıques, pour se procurer en échange les objets de traite que leur apporteront nos négociants.

Entre les Yolofs et les Sérères sur le bas Sénégal et le long de l'Allantique, et les Sarakolès, Mandingues et Bambaras sur le haut fleuve, est jetée une population fort curieuse, qui ne possède pas à vrai dire de domaine propre, mais s'est en quelque sorte infiltrée parmi les noirs, et a usurpé à leurs dépens d'importants domaines. Ce sont les Peuls ou Foulahs, que l'on désigne encore, d'après divers auteurs, sous les noms de Fullos, Foulis, Fellans, Fellatahs, Pouls ou Peules. Il y a 
moins d'un siècle, les Peuls n'avaient pas d'histoire; on constatait seulement leur présence en Sénégambic. C'est en 1533 que Barros parlait pour la première fois du rey doi Fullos. lls ont joué tout à coup un rôle prépondérant, et de nomades à peu près ignorés sont devenus dominateurs. De l'anarchie ils ont subitement passé à l'organisation politique. De pareils changements ont toujours leur raison d'être. C'est l'ardeur religieuse, c'est la fièvre de propagande qui les a emportés vers ces glorieuses destinées. De même que les Arabes, ils se sont faits les apôtres d'une religion à laquelle ils se sont dévoués, et paraissent devoir jouer dans le continent noir le même rôle que jadis les premiers disciples de Mahomet dans les bassins de la Méditerranée et de la mer Rouge.

Quelle est l'origine des Peuls ${ }^{1}$ ? Ils ne sont pas autochtones, car on les trouve disséminés sur d'immenses espaces, depuis le Darfour jusqu'aux rivières du Bas-de-Côte, c'est-à-dire dans une zone de quatre mille cinq cents kilomètres de longueur, sur une largeur de mille kilomètres. Sauf en Sénégambie et dans le Fouta-Djallon, ils sont partout clairsemés. Souvent même ils sont comme noyés au milieu des tribus nègres; mais ils conservent toujours l'originalité du type et la pureté de la race. Aussi bien ils se vantent de ne pas appartenir à la race noire. Ils se prétendent même parents des blancs. Leurs savants se croient d'origine himyarite ou arabe, et leurs marabouts nomment comme leur ancêtre un certain Feolah ben Himier, c'est-à-dire le Fils du Rouge .

La couleur rouge est en effet comme la caracléristique du type peul; mais c'est un rouge d'une espèce particulière, qu'il est très difficile de définir, car les auteurs varient singulièrement dans leurs appréciations. D'après Golberry, les Peuls seraient d'un noir tirant sur le rouge; d'après MungoPark, d'un noir peu foncé, plutôt basané que noir. Mollien les a trouvés presque blancs; Gray et Dochard, cuivre clair. Caillié leur attribue un teint marron un peu clair; Raffenel, brun

1. Gustave d’Eichtal, Histoire et origine des Foulahs ou Fellans (Mémoires de la Société ethnologique). - BARTH, Reisen und Entdeckungen in nord und central Africa, 1857; - Sammlung und Bearbeitung central Afrikanischer Vocatularien, 1S62. - De Crozals, Peulhs et Foulahs (Revue de géographie, 1882). 
teinté de rouge; Boilat, bronzé rouge; Denham, bronze foncé; Barth, chocolat au lait, et Rohlf, basané. Quelles que soient ces diversilés, le fait indiscutable c'est qu'ils ne sont pas noirs. Sans doute quelques-uns d'entre eux se sont rapprochés, par des croisements, de la race noire, mais la grande masse de la nation a conservé le teint rouge foncé. Comme forme de risage, les Peuls ressemblent aux Berbères. Ils ont la figure ovale, encadrée de cheveux lisses ou bouclés, le nez droit et les lèrres fines. Leurs femmes sont véritablement belles. Elles ont la douceur du regard, la grâce des mouvements, la noblesse du maintien, un goût exquis dans le costume et les ornements.

A cette beauté extérieure les Peuls joignent une intclligence très développée. Ils ont de la noblesse dans les idées, et même de l'élération dans le langage. Certains de leurs contes populaires ${ }^{1}$ renferment des sentiments trop délicats pour être compris par les autres peuples de la Sénégambie. Ils furent d'abord pasteurs, et c'est en suivant leurs troupeaux de bœufs zébus qu'ils se répandirent dans l'A frique occidentale. Ils commencent aujourd hui à se fixer et deviennent de bons agriculteurs. Ce sont également d'habiles ouvriers. Ils savent purifier, fondre et forger la roche ferrugineuse qu'ils rencontrent en abondance. Leurs maçons construisent des cases solides et commodes, leurs tisserands et leurs corroyeurs déploient dans leur industrie un véritable talent.

La religion primitive des Peuls paraît avoir été la boolâtrie. Dans leur culle actuel se sont maintenues des pratiques qui rappellent l'ancien culte. Ainsi les étables à bœufs sont l'objet de soins minutieux; ct, quand ils reulent faire honneur à un étranger, ils le reçoirent dans leurs parcs à bestiaux. Depuis qu'ils ont adopté le mahométisme, il sont devenus zélés propagateurs de la doctrine: ainsi, ils n'aiment pas l'eau-de-vie, et montrent une grande exactitude pour les prières réglementaires. Néanmoins ils paraissent tenir à l'esprit plutôt qu'à la lettre de Coran, car leurs marabouts ne se font aucun scrupule de corriger les passages du livre sacré

1. Dérexger-Féracd, Recueil de contes populaires de la Sénégambie. 
quils ne comprennent pas. Bien que la polygamie soit aulorisée, elle n'est pas en honneur, car les femmes crercent un grand empire et n'aiment pas le parlage des affections. L'esclavage nest pas non plus en honneur. Il existe sans doute des captifs de case ou des champs, mais ils sont assez doucemênt menés, et, mème à l'époque de la traite, les Peuls n'en ont jamais fail le trafic.

Le gouvernement est une espèce de république théocratique, dont le chef, ou almamy, n'exerce le pouroir qu'après avoir pris l'avis des anciens el des nolables. Dans chaque villagre est un chef nommé par les habitants. En réalité, ce sont les familles nobles qui gouvernent. Le chef suprême, celui que les Porlugais nommaient autrefois le grdo fulo, le siratique ou cheiratic des Français, résidait dans le district des Falahos, dont Bakel est aujourd hui le chef-lieu.

Les Peuls du Fouta, c'est-à-dire des quatre provinces riveraines du Sénégal entre la bouçıe de la Falémé et le lac Paniéfoul, le Damga, le Foula. le Toro et le Diman, sont désignés sous le nom de Toucouleurs. On a prétendu que ce motétait d'origine anglaise, two colours, "les deux couleurs", parce que les indigènes de ces qualre provinces seraient des métis de Maures ou de Nègres avec les Peuls; mais rien ne juslifie celle bizarre élymologie. Dès le seizième siècle, les Portugais les désignaient sous le nom de Tacurores, et il est probable que ce mot rappelle lantique appellation de la contréc Toukoural, déjà signalée par Cadamosto. Les Toucouleurs peurent être considérés comme les représentants de la race peule. Intelligents et ambilieur, très redoutés de leurs roisins, fanatiques et même enthousiasles, ils auraient pu, suils s'étaient entendus avec leurs voisins de la rive droile du SéIégal, avec les Maures, arrèter la navigation du fleuve. Aussi bien, ils se sont longlemps opposés à nos progrès. Naguère on ne pénélrait sur leur territoire que comme en paysennemi. Bien des expéditions ont été nécessaires pour mater leur lur-

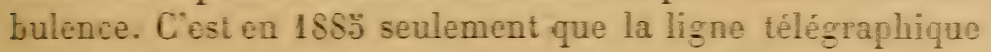
a pu fonctionner sur leur territoire. Même à l'heure actuelle, les agitatcurs ou les bandils recrulent chez eux leurs plus dangereux el leurs plus nombreux auxiliaires; mais ils n en 
sont pas moins très utiles, pour leur esprit d'initialıve et leur amour du travail. Ils émigrent facilement et vont jusque sur la rive de la Gambie planter des arachides. Aussi renoncerontils probablement à leurs préventions religieuses ou nationales, le jour où ils comprendront le rôle civilisateur de la France.

Les Toucouleurs du Toro sont répartis en six castes : les. diavandous ou nobles, les torodos, juges et savants, les bailos, artisans du fer, les tiapatos ou guerriers, les koliabes ou chasseurs, les tioubalous ou pêcheurs. En dehors de toute classification, on rencontre les laobès, que nous avons déjà signalés chez les Sérères. Ces láobès vivent à l'aventure, sans lien politique, sans organisation sociale. Négociantśs sans scrupule et colporteurs infatigables, ils élèvent des huttes de branchages à la lisière des bois, et se déplacent sans motif. Ils ne se marient qu'entre eux, et ne pratiquent aucune religion. Ce sont les bohémiens de l'Afrique.

Les Peuls ont une langue ${ }^{1}$ à eux, très variée comme dialectes, mais possédant une grammaire et un vocabulaire identiques. On trouve dans celte langue deux genres, l'humain et le non humain. Les adjectifs s'accordent par une sorte de rime avec les substantifs, et les mots se modifient euphoniquement les uns les autres. La langue peule ressemble par quelques trails aux idiomes nègres, et aux langues sémiliques par l'emploi des suffixes. C'est un instrument commode, car elle est parlée ou du moins comprise. sur une immẹnse étendue de territoire, presque d'un océan à l'autre.

Telle est, dans ses traits essentiels, cette race peule, sur laquelle doit se porter plus spécialement l'attention de la France, car elle la rencontre échelonnée partout sur sa route ; et, comme les affinités sont plus grandes entre les Peuls et les Européens qu'avec les Nègres, c'est avec eux que se fera quelque jour l'assimilation, si toutefois elle est possible.

Si différentes que soient à maints égards les tribus sénégalaises, qu'il s'agisse de Yolofs ou de Soninkés, de Peuls ou de Sérères et de Mandingues, elles se ressemblent par le développement historique et par l'organisation sociale. Ainsi que

1. Gévéral. Famnerbe, Grammarre et vocabulaire de la langue peul; 1875 el 1882. 
l'a remarqué arec ingéniosité un des maîlres de la science contemporaine, Élisée Reclus ${ }^{1}$, elles sont dans une période qui rappelle le moyen âge européen. "La division du sol en de nombreux États aux limites incessamment changeantes, l'état normal de guerre qui règne entre les tribus et qu'interrompent parfois des trêves religieuses, les brusques péripélies de la fortune entre le brigandage et la royauté, les migrations en masse, les transformations soudaines de pays cultivés en déserts, la constitution de la société en castes ennemies ou du moins en corporations fermées, la cohabitation dans chaque village d'hommes libres et d'esclaves, diversement trailés suivant leur origine et leur genre de travail, les mœurs des cours où les affranchis disposent de la fortune et de la vie des sujets, où les fous décident parfois de la paix et de la guerre par une plaisanterie, les banquels que les griols viennent égayer de leurs chants obscènes, les cérémonies terribles où les sorciers tendent aux victimes la coupe dụ poison, tout cela n'est-ce pas l'image de la société d'Europe il y a mille années? "

Plus encore peut-être que les Nègres, les Waures ${ }^{2}$ du Sénégal rappellent, par leurs mœurs et leur organisation, celle période troublée de notre histoire. Ils sont aujourd'hui campés sur la rive droite du Sénégal, qu'ils bordent depuis son embouchure jusqu'aux environs de Bakel. Ces Maures sont formés par un mélange de tribus arabes et berbères qui, poussées en avant par les grandes migrations du septième et du onzième siècle, franchirent la barrière, réputée à tort infran- . chissable, du Sahara, et envahirent les vastes solitudes qui se prolongent jusqu'au Sénégal. Comme ils sont fortement mélissés de nègres, on peut suivre chez eux toute la série des types, depuis l'Européen au front large et au nez droit jusqu'au Nègre à cheveux crépus, à nez épaté et à lèvres lippues. Ces différences tiennent surtout à celles des conditions et des castes. Les blancs se retrouvent surtout dans les rangs supérieur's de la société, les hassan ou gens de cheral et les

1. Eussér Reclus, Afrique occidentale, p. 229.

7. FaIdHERBe, Considerations sur les populations de lafrique septentrionale (Annales des voyages, 1839); - les Berbers et les Arabes des bords du Sénégal (Société de géographie de Paris'; 193̈4́. - E. Fallot, Nole sur les l'alures du Sénégal (Société de géographie de .Mrsiille); 1 SS8. 
marabouts, vivant les uns et les autres aux dépens des vaincus, qu'il nomment d'un nom caractéristique, les lahmés, ou " viandes ". Il sont remarquables par leur tête bien développée, lour front bombé, leurs yeux à fleur de tête, leur nez aquilin, leur bouche large, leurs lèvres minces, leurs dents fortes el acérées, leur menton prononcé et leur cou dégagé. Ils portent fièrement la tête et marchent en général le crâne nu. Les femmes ont une grande délicatesse de formes et les attaches fines et gracieuses; le modelé des pieds et des mains ne laisse rien à désirer. Par malheur, ces grâces naturelles disparaissent sous les couches d'un embonpoint aussi précoce qu'anormal. En outre, dans cerlaines tribus, on considère comme une beauté la lèvre supérieure rejetée en avant par les incisives, en sorte que, lors de la seconde dentition, les fillettes prennent l'habitude de donner à leur mâchoire supérieure la direction voulue par une conlinuelle action des doigts et de la langue. Le costume est le même que celui des noirs. śculement, comme ils ne lavent jamais leurs vêtements et ne connaissent pas l'usage des bains, ils exhalent des senteurs peu aromatiques. En marche ou en guerre, ils relèvent leurs boubous, et vont jambes et pieds nus. Quant aux lahmés ou tributaires, ils se rapprochent du type nègre.

Les Maures, plus rusés et plus intelligents que les Noirs, poussent à l'extrême leurs défauts et regardent cependant ces derniers comme leur élant de beaucoup inférieurs. Nomades et pasteurs, ils vivent sous la tente, et se déplacent avec facilité. Leur nourriture diffère peu de celle des Noirs, sauf qu'ils consomment plus de lait et plus de viande. Ils supportent aisément la faim et la soif. Ils ont quelques petites industries, dont ils vendent les produits aux Européens. Leurs mœurs sont efféminées et dépravées. Les maladies vénériennes sont répandues parmi eux. Ainsi que les Noirs, ils ignorent la médecine, et n'usent que des remèdes et des incantations de leurs marabouls.

C'est la nature qui a nettement établi les divisions ethnofraphiques parmi les Maures. On les distingue, en effet, en [laures septentrionaux, qui ne quiltent jamais les plateaux imitrophes du Sahara, et en Maures du Sud ou Guéblas, qui 


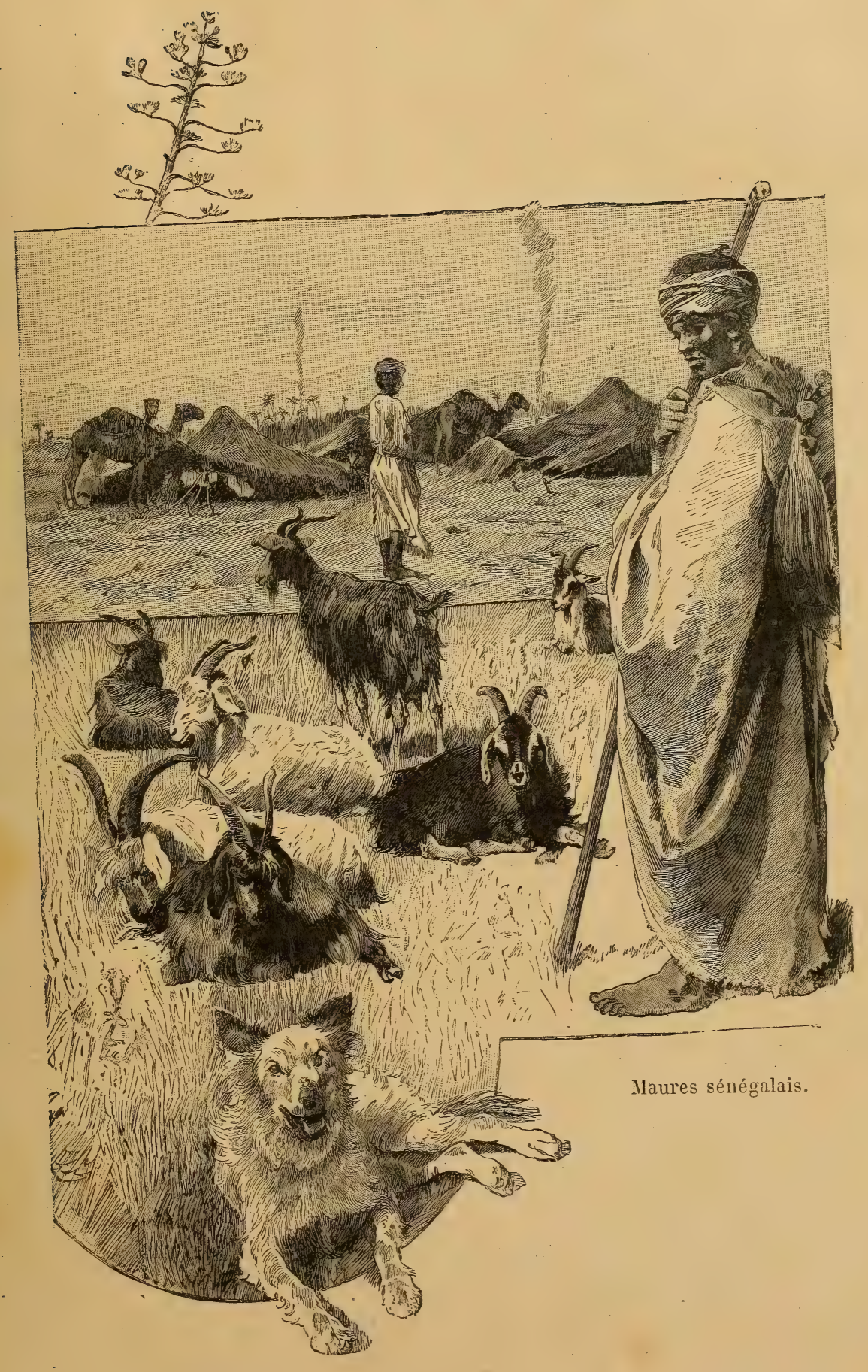



ront et viennent entre les escales du fleuve et les campements de l'intérieur. Parmi les premiers on distingue les Oulad-el-Hadj, qui étaient jadis en relations fréquentes arec les traitants français; les Oulad-Embarek et les Sidi-Mahmoud, éloignés du Sénégal par la jalousie commerciale de leurs frères d'origine, les Maures Douaichs. Ces Maures sont de très habiles chasseurs d'autruches. Ils les altrapent à la course et les assomment arec des balles de plomb suspendues à des courroies, évitant ainsi de gâter leur plumage par une goutte de sang.

Quant aux Guéblas ou Maures du Sud, ils se subdivisent en trois grandes tribus, réparties en une multilude de fractions commandées par des cheicks. Ces cheiclis obéissent à un cheick suprème, que les Européens qualifient un peu légèrement de roi. La plus importante de ces tribus maures est celle des Trarzas, qui occupe le bas du fleuve au roisinage immédiat de Saint-Louis. Les Trarzas s'appellent encore Abencerarzas, et quelques étymologisles prétendent reconnaître en eux les Abencerages de chevaleresque mémoire. La seconde tribu est celle des Bralinas, dans la région moyenne du fleuve, et la troisième celle des Douaichs, dans la région supéricure. Chez ces derniers se rencontrent les débris de la tribu Sénaga ${ }^{1}$, qui a donné son nom au fleuve.

Entre Maures et Nègres, bien que séparés par le Sénégal, la haine est profonde et l'hostilité pour ainsi dire perpétuelle. Les Nègres avaient pour eux le droit du premier occupant et la supériorité du nombre; aussi ont-ils longtemps relégué les Maures dans le désert. Ils ne les supportaient qu'en leur imposant de lourds tributs; mais la race sémitique est entreprenante, et surtout persévérante. Elle attend tout du temps et de l'occasion. Fidèles à cet esprit d'expansion qui jadis conduisit leurs ancêtres depuis la Iecque jusqu'à Tours et jusqu'en Chine, les Maures ont fini par s'avancer de proche en proche et par franchir le Sénégal. Dès lors, enhardis par le succès, ils commencèrent contre les Nègres une véritable guerre d'extermination. Arant 18304 , toutes les foires se termi- 
naient par des razzias que les Maures allaient faire sur la rive des Noirs. Impitoyables et cruels, n'épargnant après la victoire que les femmes et les enfants, maltraitant les captifs, en vertu du principe qu'il faut fouler le pəuple et l'appauvrir afin qu'il soit soumis et respectueux, ils ont soulevé contre eux des haines farouches. "Une tente n'abrite rien d'honnête, disent volontiers les Nègres, si ce n'est le cheval qui la porte. " - "Si tu rencontres sur ton chemin un Maure et une vipère, ajoutent-ils plus volontiers cncore, tue le Maure. "

Nous avons eu longtemps, nous autres Français, le grave tort de permettre et presque d'encourager les invasions et les razzias des Maures au delà du Sénégal. Cetle impolitique faiblesse nous aliéna les Nègres, qui nous détestaient, sans nous altacher les Maures, qui nous méprisaient. Nous avons fini par mieux comprendre nos intérèts. Le Sénégal est redevenu la limite des deux races, et les Maures, refoulés et contenus par nos soldals, respeclent aujourd'hui les Nègres, qui, de leur côlé, nous savent gré de notre intervention.

Quelle est donc au Sénégal la situation des Européens visà-vis des Nègres el des Maures? Les premiers d'entre eux qui abordèrent au Sénégal ne cherchèrent d'abord qu'à y fonder des comploirs d'échange. Si, par hasard, l'un d'entre eux s'enfonçait dans l'intérieur du pays et y résidait quelques années, ce colon improvisé ne songeait qu'à revenir au plus tôt au pays natal. En 1817, sous la Restauration, on essaya de créer une colonie agricole dans le Oualo, mais celte tentative avorta misérablement. Aucun autre essai n'a réussi. Sans doute, les Européens ne manquent pas au Sénégal; mais comme aucun d'eux n'ignore qu'il ne pourra s'y acclimater, ils partent tous avec l'arrière-pensée d'un prompt retour. Ce sont des soldats et des fonctionnaires, cesont des négociants qui constituent la population blanche au Sénégal. On n'y rencontre ni cultivateurs, ni propriétaires, ni même industriels. Le Sénégal ne sera donc jamais une colonie de peuplement, comme l'Algérie ou la Réunion; mais les Européens à résidence temporaire n'y manquent pas non plus. Leur nombre augmentera même, car de jour en jour on apprécie 
et on connaît micux les ressources de la colonie. Il est donc nécessaire d'indiquer dès à présent les principaux points. occupés par nos compatrioles, et qui sont appelés à devenir d'importantes cités dans un avenir plus ou moins éloigné.

Saint-Louis est la capitale officielle du Sénégal, et la plus ancienne ville fondée par les Français dans ces parages. Elle est bâtie sur une île formée par les alluvions du fleuve. Rien d'étonnant si nos compatriotes s'établirent dans une île de préférence au continent. C'est une vieille habitude commerciale. Les Phéniciens, par exemple, ne s'aventuraient jamais dans une contrée nouvelle sans s'installer au préalable dans une île voisine de la côte, car- une île est de facile défense. Les Européens se conformèrent à cet usage, sans se douter qu'ils continuaient une tradilion anlique. Depuis 1667, époque de sa fondation, Saint-Louis est restée comme la clef de voûte de nos établissements à la côte occidentale d'Afrique. L'ancien fort, qui est situé dans l'île du même nom, et qui est aujourd'hui converti en casernes et en magasins, servit de noyau à la ville. Bien que l'édilité ait fait depuis quelques. années de grands progrès à Saint-Louis, que l'île ait été bordée de quais en briques, et que le niveau des rues ait été relevé afin de les exhausser au-dessus des crues du fleuve, il reste beaucoup à faire pour que la ville ressemble à une capitale. On a construit le long des quais de vastes docks. Les. navires de commerce mouillés en face de ces docks ont ainsi toute facilité pour exéculer leur chargement et déchargement. A l'est, un pont de bateaux de six cent cinquante mètres traverse le grand bras du Sénégal et réunit Saint=Louis aux deux faubourgs de Sor et de Bouëtville. Dans ce dernier se trouve la gare du chemin de fer de Dakar. A l'ouest et au nord-ouest, trois ponts d'une centaine de mètres joignent Saint-Louis aux quartiers nègres, parfois envahis par les eaux de marée, de Gnet'Ndaz, de N'dartout et de Gokhom-Laye. Çà et là sont dispersées des cases de nègres ou quelques villas de négociants. Saint-Louis a beaucoup grandi dans ces dernières années. Elle compte aujourd'hui près de vingt mille âmes; mais ce n'est pas une ville salubre. Une des principales. causes d'insalubrité doit être altribuée aux citernes, où s'en- 
tassent des herbes visqueuses. Quand on cure les citernes, les miasmes paludéens se répandent au loin. En outre, toutes les impuretés de la ville sont jetées dans le fleuve, qui les porte à la mer; mais le flux les ramène, et c'est ainsi que se forment des amas monstrueux d'immondices. Un puits artésien qu'on a creusé n'a donné que de l'eau saumâtre. Un aqueduc a été construit; il amène au réservoir de Sor deux mille mètres cubes d'eau puisés dans le marigot de Kassak. Il a fallu, par un puissant barrage, empêcher l'eau saumâtre de refluer dans le marigot lors de la saison sèche.

En remontant le fleuve, les principaux points occupés par nos troupes et dans lesquels a commencé la colonisation sont Richard-Toll, établissement fondé pour servir de jardin d'acclimatation, mais dont on détruisit en 1840 les plantations, sous prétexte qu'elles pouvaient servir de retraite à l'ennemi. Ce n'est plus aujourd'hui qu'un village de nègres pêcheurs, à la bouche du marigot de Taoucy, émissaire du Paniéfoul. Dägana vient ensuite. Ce poste, fondé en 1821, commande le Oualo et le Fouta. Il est fréquenté par les Maures Trarzas. Les Maures Braknas se rendent de préférence à Podor. Une pelite ville s'est fondée non loin de ce point stratégique, qui commande l'ìle à Morfil. Les promenades et les maisons à terrasse de Podor démontrent que la civilisation pénètre peu à peu dans le fleuve. Un pont a même été jeté pour faciliter l'entrée de la ville aux caravanes maures.

Après Podor, nos établissements sont bien clairsemés. Ce ne sont pas les deux garnisons de Saldé et de Matam qui suffiraient à maintenir notre prestige dans la région. Le poste de Bakel est plus important. Bakel commande le haut fleuve, cette région qu'on nommait autrefois le Galam. Le fort, bâli en 1820, a été complété par trois grosses tours sur les collines voisines. Au pied des remparts ont été construites quelques maisons européennes. Les Ouolofs, les Soninkés, les Kassonkés et les Maures Douaichs vivent dans des quartiers différents. Comme Bakel est au point de contact entre plusieurs races, il a pris, surtout dans ces derniers temps, une grande importance stralégique. Il a seulement fallu, à diverses reprises, plus particulièrement en 1859 et en 1886, dégager la 
garnison française, en prenant d'assaut, dans le voisinage, la forte place indigène de Guemou.

Mentionnons encore dans le haut pays Médine, illustrée par son héroïque défense; Kayes, d'où part le chemin de fer du Soudan. Sabouciré, Konniakari, Diala, Nioro, Djala, Sénoudébou sur la Falémé, et Kenieba dans le Bambouck. Telle de ces villes deviendra sans doute une importante cité, car elle se trouve dans une région fertile et populeuse, que l'industrie métallurgique et les travaux agricoles enrichiront bien vite.

A partir de Bafoulabé, et dans la direction de Kita, Kondou, Niagassola, Dabo, Bamakou, etc., commence le Soudan français. Bien que ces villes, récemment annexées, dépendent administrativement du Sénégal, nous nous réservons de les étudier plus loin, quand nous exposerons l'histoire de nos dernières acquisitions.

En revenant sur la côte, et en descendant le rivage du nord au sud, nous trouvons, dans la province de Cayor, de gros villages échelonnés le long de la voie ferrée de Saint-Louis à Dakar : Mpal, entouré de champs d'arachides, et d'où partira sans doute quelque jour le chemin de fer qui reliera la côte au Fouta et au haut Sénégal; Longa; N'daud, l'ancienne capitale de la contrée; Thiès, qui appartenait autrefois au roi de Baol : c'est probablement de Thiès que partira la voie ferrée qui desservira la vallée du Saloum. On admire dans cette ville un baobab ayant à sa base trente-cinq mètres de tour. Non loin du cap Vert, et dans une rade qu'elle protège contre les vents du nord et de l'est, se trouve une île célèbre dans l'histoire militaire de la France, Gorée ${ }^{1}$. Occupée d'abord par les Hollandais, qui lui donnèrent le nom, soit de Goeree, l'île hollandaise qui borde au sud l'entrée du Haringvliet, soit de Goede Reede, ou la "bonne rade ". Gorée a été parfois appelée, mais bien à tort, le Gibraltar africain. Elle ne commande en effet qu'à un beau golfe, et nullement à une mer intérieure. Une jolie ville a été bâtie dans cette île, longue seulement de neuf cents mètres, et n'occupe que trente-six hectares de superficie. C'est un roc de basalte qui se dresse à trente-cinq

1. Bérenger-Féraud, Description lopographique de l'ile de Gorée (Revue maritime et coloniale, 1873). 
mètres au-dessus de la falaise méridionale, et se continue aı nord par une plage basse. Gorée ne progresse que lentement. Elle a même perdu, de 1878 à 1882, dix-sept cent quatreringts habitants, près du tiers de sa population. Elle est, en effet, dislancée et en partie ruinée par deux autres villes, en face d'elle, sur le continent, dont les progrès au contraire n'ont jamais été interrompus : ce sont les deux villes de Rufisque et de Dakar.

Dakar ${ }^{1}$, ou le Tamarinier, n'a été fondée qu'en 18ว9. Deux jetées artilicielles, défendues par de fortes balteries qui croisent leurs feux avec la citadelle de Gorée, défendent l'entrée de la rade, d'une profondeur moyenne de douze à vingt mètres. Des phares et des balises permettent d'y entrer à toute heure, avantage inappréciable sur une côte encore mal connue. Aussi les Messageries nationales ont-elles choisi Dakar comme escale. La marine de l'État y a construit un petit arsenal pour l'entretien et la réparation de ses vaisseaux. Il y a sans doute encore bcaucoup à faire pour terminer le port et achever les bassins, les quais et les fortifications, mais Dakar a pris unc grande importance. C'est une véritable ville européenne. Rufisque, le Rio-Fresco des Porlugais, le Tangueleth des Ouolofs, la Baie-de-France des Dieppois, est au contraire restée plus africaine. C'est une ville mal située, au milieu de marais et de dunes, sans eau potable; mais toutes les roules du Cayor, du Baol et du Saloum y convergent, et c'est là que sc tiennent de grands marchés d'approvisionnement très fréquentés par les indigènes.

En suivant la côte dans la même direction, nous signalerons Portudal, Niannig et Joal, fréquentées autrefois par les négricrs, qui y faisaient trop facilement d'excellents marchés; Saint-Joseph-de-Ngasobil, centre des missions calholiques de Sénégambie; Kaolack et Foundiou, dans le Saloum; Fatiko, l'ancienne résidence du bour de Sine. Au delà commencent les élablissements de la Casamance et les rivières du Bas-deCôte, que nous étudierons ailleurs.

La scule ville à mentionner sur la côte au nord de Saint-

2. Paul Vigré, le Port de Dakar (Société de géographie de Bordeaur); 1887. 
Louis est Portendick, jadis Addi, cédé par les Anglais en 18ä7, en échange d'Albréda. Ce petit port prendra de l'importance si le banc d'Arguin devient un second banc de Terre-Neuve. Jadis, au temps de la domination portugaise, les caravanes de l'Adrar et du Soudan se rendaient directement à la côte. En 144ว̆, les Portugais araient mème construit un fort sur la petite île d'Arguin, pour assurer la liberté des transactions et protéger leurs nationaux. Ce fort passa de main en main et finit par être détruit. En 1860, lors de la visite du capitaine Fulcrand, un petit village de pêcheurs s'élevait sur ses ruines, mais, depuis de longues années, les caravanes du désert avaient désappris le chemin de la côte. Peut-être serait-ce un acte de haute politique que de réoccuper Arguin, qui nous apparlient sans conteste et dont la possession nous a encore été confirmée par des trailés conclus avec l'Angleterre en 1783 et en 1882. Arguin pourrait devenir la première élape d'une route sûre vers Tombouctou. Ainsi que l'a écrit un des hommes qui connaissent le micux les intérèts sénégalais, II. A. Merle ${ }^{1}$ : " Expansion de notre influence dans des pays d'où elle a disparu depuis un siècle, échange des produits soudaniens qui se dirigent actuellement vers la ville de Noun el qui sont accaparés par le commerce anglais; extension de notre marine marchande causée par de nouveaux transports à effectuer ainsi que par la création de pècheries, ") telles seraient les utiles conséquences de cette nouvelle apparition du drapeau national à Arguin.

En résumé, des trois races qui occupent le Sénégal, la promière et la plus nombreuse, la race noire, occupe la région comprise entre la rive gauche du Sénégal, la Gambie ct l'Atlantique; la seconde, la race des Maures, occupe la région comprise entre la rive droite du Sénégal, le Sahara ct l'Océan; la troisième, la race blanche, est campée le long du Sénégal et sur le rivage de la mer, spécialement à l'embouchure des fleuves et aux environs du cap Vert.

Ils est difficile, pour ne pas dire impossible, de fixer le chiffre de la population; car, en pays musulman, les femmes

1. A. Jrerte, l'Angleterre, l'Espagne et la France à propos de l'íle d'Arguin (Ferue de géographic, 18S.); - le Quarlier du cap Blanc (ilid., 1S56). 
vivent à l'écart et ne peuvent être comptées qu'approximativenient. Quant au reste du pays, il est encore trop peu civilisé, les voies de communication et les moyens d'information sont encore trop imparfaits pour qu'on se risque à donner un chilfre précis. D'après les évaluations officielles de 1879, la population immédiatement soumise à la France serait de 192,924 âmes; mais il est difficile d'affirmer l'authenticité de ces chiffres. Quant aux indigènes qui commercent avec nous ou qui reconnaissent notre influence et paraissent disposés à convertir cette vassalité en sujétion, voici comment ils se répartiraient : Maures, 225,000; Kaarta et Guidimakha, 300,000 ; Fouta, 250,000; Khasso et Bambouck, 280,000. En y joignant le Soudan et les Rivières-du-Sud, récemment annexés, on arrive à un total de 2,594,080 habitants.

Au point de vue administratif, et sans tenir compte de la différence des races, le gouvernement a divisé le Sénégal en trois arrondissements : $1^{\circ}$ celui de Saint-Louis, avec les quatre cercles de Saint-Louis, Podor, Dagana et Mérinaghen; $2^{\circ}$ celui de Gorée, avec les quatres cercles de Gorée, Mébidgen, Kaolack et Sedbiou; $3^{\circ}$ celui de Bakel, avec les quatre cercles de Bakel, Médine, Matam et SaIdé. Ce sont là les germes futurs de trois beaux déparlements.

Nous connaissons les trois races qui vivent côle à côte au Sénégal. Essayons, sans nous targuer du don de prophétic, de deviner les destinées et l'avenir qui leur sont réservés.

Nous avons à lulter dans notre colonie contre trois ennemis dangereux; mais la lutte est engagée, et tout permet de prédire qu'elle se terminera à notre avantage. Ces trois ennemis sont l'ignorance des populations africaines, le fanatisme musulman et les fautes administratives.

L’ignorance des Sénégalais est fabuleuse. Nègres et Maures croient volontiers aux absurdités les plus révoltantes, si clles leur sont débitées avec autorité. Or, l'instruction publique est à peine organisée dans notre colonie. Faidherbe avait bien décrélé l'instruction obligatoire; mais, si les élèves ne manquaient pas, les maîtres faisaient défaut. Quelques écoles primaires de garçons, dirigées par des congréganistes, ont été ouvertes dans les principales villes; mais rien n'existe 
pour l'instruction secondaire, moins que rien pour l'instruction supérieure. Aussi nos ennemis ne manquent-ils pas d'exploiter contre nous cette indifférence. Instruisons donc, créons des écoles, répandons à flots la lumière, car, le jour où les indigènes sauront le français, ils deviendront les propagateurs inconscients de nos idées et de notre civilisation.

Notre second ennemi est le fanatisme musulman. Deux religions se partagent les peuples du Sénégal : le fétichisme, pratiqué par la majorité des Nègres, et le mahométisme, suivi par tous les Maures et la minorité des Nègres. Or le mahomélisme, avec ses principes politiques et son énergie active, est pour nous autrement dangereux que le fétichisme, que du reste il absorbe rapidement. Il est vrai que les convertisseurs musulmans s'imposent par le fer et le feu tout aussi bien que par la prédication. Étant donnés d'un côté lé fanatisme musulman, et de l'autre la ferveur qui a de tout temps caractérisé les néophytes, il n'est pas étonnant que les musulmans sénégalais soient nos ennemis les plus acharnés. C'est donc contre les musulmans qu'il nous faut concentrer nos efforts, et, si nous voulons rester les maîtres du Sénégal, nos auxiliaires les plus utiles seront les missionnaires. On a remarqué que les Nègres fétichistes se convertissaient volonliers au christianisme et devenaient par le fait nos parlisans, tandis que jamais un Nègre converti au mahométisme ou un musulman d'ancienne date ne devenait chrétien, et, par cela même, restait notre ennemi. A la prédication musulmane il nous faut donc opposer la prédication chrétienne, aux marabouts les missionnaires. C'est la condition de notre succès final.

Nous avons à luller contre un troișième ennemi, plus dangereux que l'ignorance ou que le fanatisme : contre nousmêmes, contre nos fautes administratives. Il nous faudrait surtout renoncer à ces perpéluels changements de gouverneurs qui déconsidèrent l'administration et empêchent tout progrès sérieux. Pourquoi ne pas nommer des gouverneurs civils, qui prendraient racine dans le pays? ou, si l'on tient à conserver des militaires ou des marins, pourquoi ne pas établir que ce poste, dans leur carrière, constituera une ćtape 
qui pourra être pour eux l'occasion d'avancement sérieux, et d'avancement sur place.

Parmi les plus graves fautes qui aient été commises au Sénégal, nous signalerons encore la conduite maladroite de nos négociants. Uniquement préoccupés de leurs intérêts actuels, ils ont trop souvent gêné l'action du pouvoir central par des alliances intempestives avec les indigènes, ou par leur profond dédain de ces mêmes indigènes. Ils se sont, en outre, opposés avec une énergie regretlable à l'abolition de l'esclavage. Heureusement pour l'avenir de la colonie, le gouvernement a pris deux mesures d'une grande portée. Il a proclamé la liberté du commerce et aboli l'esclavage. Du jour où nos négociants ont compris qu'ils ne pouvaient plus compter que sur eux-mêmes et qu'ils ont eu à lutter contre la concurrence étrangère, ils se sont déterminés à de sérieux efforts pour maintenir leur vieille supériorité.

Signaler le mal, n'est-ce pas en triompher à demi? Aussi, bien des progrès multiples se sont accomplis, et ils s'accentuent chaque jour davantage. Nous commençons à acquérir les sympathies des indigènes, et surtout des Nègres. Déjà plusieurs provinces se sont volontairement annexées. Le Cayor, qui nous fut si longtemps hostile, semble avoir renoncé à ses haines. Le Fouta ne remue plus. En remontant le Sénégal, vers le Bambouck, des perspectives indéfinies s'ouvrent à l'activité européenne. Dans le bassin du Niger pénètre notre influence, et nous nous acheminons pas à pas vers l'Afrique centrale. Les Maures eux-mêmes, si réfractaires à notre civilisation, se rapprochent peu à peu. Au point de vue agricole, mêmes espérances de progrès. L'introduction de la culture des plantes oléagineuses a été pour le Sénégal un coup de fortune. La culture maraîchère a également progressé. A notre exemple, et d'après nos conseils, les roitelets indigènes, au lieu de s'exterminer réciproquement, s'occupent de faire cultiver leurs immenses propriétés. La population s'accroît, la sécurité grandit, et le Sénégal se transforme.

C'est surtout par le commerce que notre colonie est pleine d'avenir. Les chiffres d'importation et d'exportation grandissent d'année en année. Dans la période décennale 1826- 
1836. le commerce du Sénégal n'était que de sept millions de francs. De 1836 à 1846 , il atteignait quatorze millions; de $18\{6$ à $185 \% 6$, ringt millions. Il s'éleva brusquement en 1859 , après la proclamation de la liberté du commerce, à trentetrois millions. La progression a été depuis plus lente, mais continue. En 1883, le chiffre total des affaires était de quarante-huit millions, et rien n'indique un arrèt. Voici que nos négociants songent à faire du Soudan comme un Hindoustan français. Ils sont arrirés à Bamakou. Ils viennent de débarquer à Tombouctou. De là sans doute ils se répandront dans ces contrées vierges, qui leur réservent plus d'une surprise.

Ainsi se trourent réunies dans une colonie trop longtemps méconnue toutes les causes de prospérité : sol fertile, facilité des échanges, territoire considérable et susceptible d'une grande extension, populations nombreuses et qui s'attacheront à nous par la reconnaissance aussi bien que par lintérèt. Peut-ètre n'est-il pas dans le domaine colonial de la France, à l'exception de l'Algérie et de la Tunisie, une province dont l'arenir autorise de plus brillantes espérances.

\author{
IV \\ HISTOIRE DE SÉxÉgal DEPCIS LES ORIGIYES \\ JUSQU'A L'AYYKÉE 181 כ̈
}

L'histoire de la colonie française du Sénégal ${ }^{1}$ peut ètre divisée en trois périodes distincles. La première, la plus longue, mais la moins remplie, s'étend des origines à l'année

1. On peut consuiter, sur l'histoire du Sénégal : Cearles Corro, le Sénégal (Revue des Deux Mondes, 1845); - Maridal, le Sénégal, son état présent et son atenir; 1862; - FAidherbe, Nolice sur la colonie du Sénégal et sur les pays qui sont en relation avec elle; 1858 ; - Ricand, le Sénégal, étude intime; 1805 ; Carrèrr et Holle, la Sénégambie française; - Barthélrur, Notice hislorique sur les établissements français des cótes occidentales de l'A frique; - S. HAcriGor, Quinze Mois en Sénégambie (Annales des voyages, 1869); - FAllor, Histoire de la colonie française du Sénégal (Société de géographie de Marseille); 1883; - I., Annales sénégalaises de 183 ́̀ à 1885 ; - Arcelle, les Explorations au Sénégal et dans les contrées voisines depuis l'anliquité jusqu'à nos jours; 1897 ; Bérexger-Fératd, le Sénégal de 1818 à 187.4 (Revue maritime el coloniale, 1875). 
181วّ. Le Sénégal n’est qu'un comptoir d'échange, et le gourernement ne prend part aux affaires du pays que pour nommer ses gourerneurs ou tenter quelques essais de culture qui ne réussissent jamais. A partir de $181 \%$, quelques progrès sont accomplis; mais c'est en 183 ł́ que, grâce à la féconde impulsion donnée par un administrateur éminent, Faidherbe, le Sénégal subit une transformation totale. Ce n'est plus un marché d'esclaves ou de gommes; ce n'est plus une terre maudite, où les fonctionnaires se considèrent comme envoyés en disgrâce, et dont les négociants ne s'approchent qu'à contre-cœur; il devient au contraire un foyer d'influence d'où rayonnent au loin, et dans toutes les directions, notre civilisation et notre prépondérance, et chaque jour est marqué par un progrès ou par une conquête.

On ne saurait dire arec précision à quelle époque a été fondé le premier poste français au Sénégal, ni mème à quelle époque a été exécuté le premier roỵage dans cette direction. En effet, le Marseillais Euthymenes, qui passe pour aroir visité les rives du fleure africain, virait, à ce que l'on conjecture, vers l'an 300 arant Jésus-Christ; mais on ne possède aucun détail sur son expédition, el sa présence aux bords du Sénégal n’est mème qu'une hypothèse. "J'ai navigué dans la mer Atlantique, aurait-il écrit ${ }^{1}$; elle cause le débordement du Nil tant que les rents étésiens se soutiennent, car c'est leur souffle qui pousse alors cette mer hors de son lit. Dès qu'ils tombent, la mer redevient calme, et le Nil rencontre moins d'obstacles à son embouchure. Du reste, l'eau de cetle mer est douce et nourrit des animaux semblables à ceux du Nil. "A quel fleuve correspond ce Nil occidental? est-ce au Niger, à la Gambie, au Sénégal? Faute de renseignement plus précis, toutes les suppositions sont autorisées. Un seul fait se dégage, c'est que trois siècles arant l'ère chrétienne les Marseillais avaient déjà franchi les colonnes d Hercule, et avaient ouvert des relations commerciales arec la côle d'Afrique. On a encore prétendu ${ }^{2}$ qu'en témoignage de ces relations les Marseillais avaient fondu des monnaies portant'l'empreinte d'hippopotames et de

1. SÉxÈQCe, Questions naturelles, IV, 2.

2. A, Bocdir, Histoire de Mar'seille; in-1S. 
girafes; mais la collection des monnaies marseillaises est aussi complète que possible, et nos recherches à la bibliothèque de cette ville ne nous ont rien fait découvrir de semblable. Ce n'est certes pas une raison pour nier l'authenticité du royage d'Euthymenes; mais ce voyage ou bien fut isolé ou bien fut oublié.

C'est en plein moyen âge et seulement à l'année 140 o̊ que

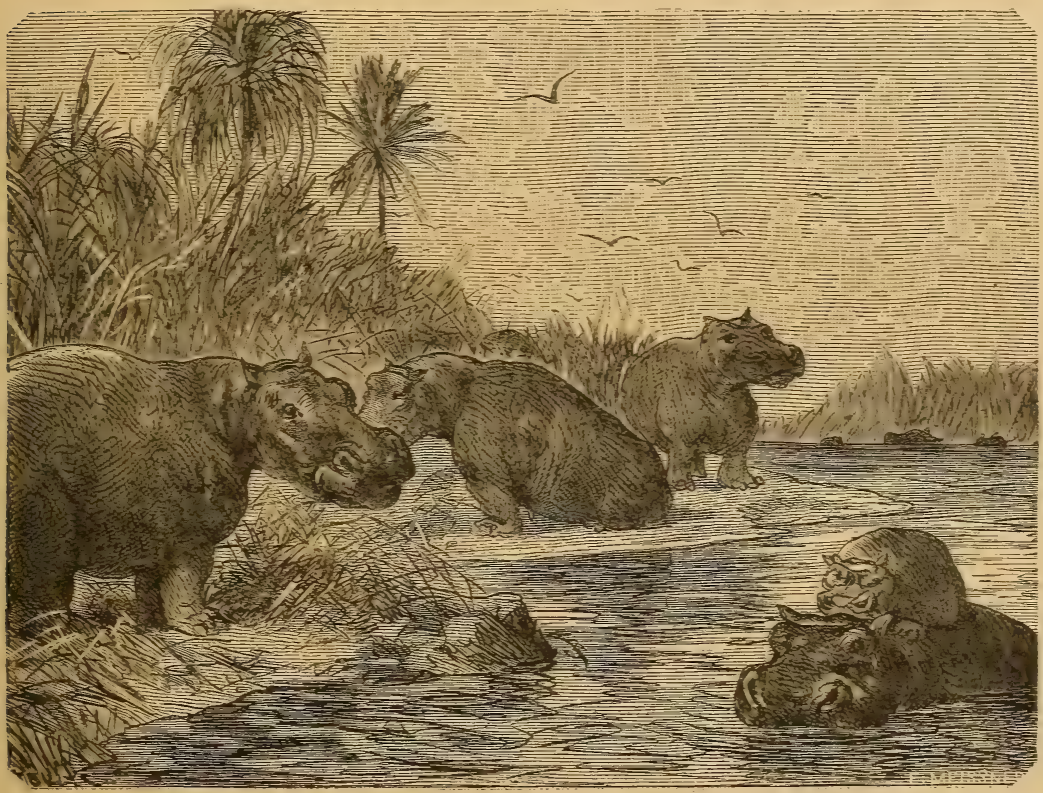

Hippopotames du Sénégal.

remonte la première mention certaine de l'arrivée des Français à la côte occidentale d'Afrique. Nous lisons en effet dans la relation des voyages et aventures de Jean de Bélhencourt, le conquérant des Canaries ${ }^{1}$ : "Fortune vint dessus la mer que les barges furent departies et vindrent touls trois près des terres sarazines, bien près du port de Bugeder. Et là dessendit monsgr de Bethencourt et ses gens, et furent bien huit lieues dedens le pais, et prindrent homes et femes qu'ilz

1. Le Canarien, livre de la conquête et conversion des Canaries, édition Gravier, p. 169. 
amenerent avec eux et plus de trois mille chamyaux; nais iiz ne les purent recuellir au navire, et en tuerent et jarerent. Et puis s'en retournerent à la grant Canare. "Le port de Bugeder ou Bojador ${ }^{1}$ est au sud du cap du même nom, que les Portugais eurent tant de peine à doubler et qui est resté célèbre dans les annales de la géographie. C'est à leur compatriote Gil Eannes que les Portugais attribuent l'honneur de celte découverle, qui eut lieu en 1434. On voit pourtant que, vingt-neuf ans auparavant, notre compatriote le Normand Bèthencourt avait pris possesion de cette terre, et par un acte de sauvagerie qui ne rappelle que trop les pillages de ses ancêtres les Northmans. Peut-être même celte expédition au sud du cap Bojador n'était-elle pas la première, car Béthencourt possédait une carte ${ }^{2}$ sur laquelle le fleuve de l'Or était marqué à cent cinquante lieues françaises au sud du cap Bugeder; et en outre ce cap et ce port sont indiqués sur le Portulan Medicéen de 135๊1, sur la carte vénitienne des Pizzigani de 1367, et sur l'allas catalan de $1377^{\circ}$, ce qui suppose des expédilions antérieures même à celle de Béthencourt.

Dès lors les Normands, surtout les Dieppois, paraissent avoir fréquenté ces parages. On croit même qu'ils se seraient établis à Rio-Fresco, c'est-à-dire à Rufisque. Il nous faudra pourtan' reconnaître qu'il est impossible de déterminer la date exacte de la fondation du premier poste français du Sénégal. Ce qu'on peut affirmer, c'est que cette fondation est antérieure au seizième siècle. Très probablement, ce sont des Normands de Rouen qui, chassés des côtes de Guinée par la jalousie portugaise et espagnole, et victimes de la coupable indifférence de nos souverains, se formèrent en compagnie, vers 1582 , et conccntrèrent leur activilé et leurs efforts sur un élablissement qu'ils fondèrent à l'embouchure du fleuve Sénéga ou Sénégal, d'abord dans une petite île appelée Bocos, puis dans une autre

1. D'Avezac, Note sur la véritable situation du mouillage marqué au sud du cap Bugeder dans toutes les cartes nautiques; 1846.

2. Le Canarien, édition Gravier, p. 100-101: "Et dit ainsi le frere mendeant en son livre que l'on ne compte du cap de Bugeder jusques au fleuve de l'or Ique 6 et cinquante lieus françoises; et ainsi l'a monstré la carte, ce n'est singlure que pour trois jours pour nayes et pour bargez; car galées, qui vont à terre, prennent plus lonc chemin; et quant pour y aler d'icy nous n'en tenous pas grand compte." 
île, plus grande, à laquelle ils donnèrent le nom de Saint-Louis. Bocos fut bientôt abandonnée, car le terrain était bas. marécageux, malsain et sujet aux inondations. En 178ว on voyait encore ${ }^{1}$ les vesliges de quelques constructions à la pointe nord de l'île. Saint-Louis, au contraire, ne cessa de grandir. L'humble comptoir des Normands était destiné à devenir la capitale de l'Afrique occidentale.

Nos marchands portèrent sur les rives du Sénégal leur expérience des affaires et leur caractère liant et sympathique. Ils ne songeaient ni à conquérir ni à annexer, mais s'occupaient exclusivement du commerce, surtout de la traite des nègres, qui leur étaient amenés aux ports d'embarquement par les courtiers de l'intérieur. Au trafic de la chair humaine s'ajoutait par surcroît celui des gommes, de la poudre d'or, de l'ivoire, elc. Afin de réaliser des bénéfices plus considérables, nos négociants se hasardèrent bientôt à remonter le fleure, et construisirent sur ses rives quelques comptoirs permanents, des escales ou échelles, ainsi qu ïls les nommaient. Le gouvernement les laissait s'administrer à leur guise. On a conservé le nom de Thomas Lombart, qui fut, en 1626, nommé directeur des établissements du Sénégal par les marchands associés. On possède également deux relations de royages, les premières descriplions de la région sénégalaise, qui furent composées par Jannequin Rochefort ${ }^{2}$ et par les capucins rouennais Alexis et Bernardin de Renouard; mais elles ne présentent qu'un intérèt médiocre.

En 1664, les marchands associés cédèrent, morennant la somme de cent cinquante mille livres tournois, leurs établissements de la côte d'Afrique à la Compagnie des Indes Occidentales, créée par un édit du mois de mai de la mème année. La nouvelle compagnie, ayant beaucoup trop étendu ses opérations, fléchit en quelque sorte sous leur poids, et, par arrèt du conseil en date du 9 arril 16\%2, vendit ses droits à une compagnie spéciale, dite du Sénégal. Dès lors commence une série de cessions et de rétrocessions à diverses compagnies,

1. Dcraxd, Voyage au Sénégal, t. Ier, p. 203.

2. Cusuds Jaxrepers, sieur de Rochefort-Chaalonnois, Voyage de Lybie au royaume de Senega, le long du Niger. 
dont aucune ne réussit, ni la Compagnie du Sénégal, côtes de Guinée et d'Afrique, formée en 1681, ni celle de Guinée, formée en 1685, ni la troisième et la quatrième compagnic du Sénégal, qui durèrent de 1694 à 1709 , et de 1709 à 1718 , ni même la Grande Compagnie des Indes, qui administra les établissements africains pendant près d'un demi-siècle, jusqu'à la conquête anglaise de $1758^{1}$. L'histoire du Sénégal pendant toute cette période n'est qu'une lamentable énumération de fautes et d'imprudences, de faillites et de banqueroutes. On n'a pour s'en convaincre qu'à parcourir les très rares ouvrages alors composés sur le Sénégal, par exemple ceux de Lemaire, Voyage aux Canaries, cap Verd, Sénégal et Gambie, en 1693; de des Marchais", Voyage en Guinée, isles voisines et à Cayenne, en 1730; et surtout du père Labat ${ }^{3}$, Nouvelle relation de l'A frique occidentale, en 1728. Seule la Compagnie des Indes fit exception. Elle fonda ou releva plusieurs forts ou comptoirs et tira de - grands profits de tous ses établissements. Il est vrai que ses affaires furent dirigées avec une grande habileté par quelques-uns de ses agenls, surtout par l'un d'entre eux, André Brue, dont l'intégrité, les lumières et l'activité méritent d'ètre mis en lumière ${ }^{4}$. Si nous étions plus attentifs aux découverles géographiques de nos compatriotes, André Brue occuperait une place éminente dans notre histoire coloniale, car il a donné à nos possessions sénégaliennes des limites qui viennent à peine d'être dépassées, et il a dirigé des explora-

1. Article 10 du traité de Paris (10 février 1763): "Sa Majesté britannique restituera à la France l'île de Gorée dans l'état où elle s'est trouvée quand elle a été conquise, et Sa Majesté très chrétienne cède en toute propriété et garantit au roi de Grande-Bretagne la rivière de Sénégal, avec les forts et comptoirs de Saint-Louis, de Podor et de Galam, et avec tous les droits et dépendances de ladite riviere de Sénégal. "

2. Le père Labat est le rédacteur du Voyage du chevalier Renaud des Marchais en Guinée, isles voisines et à Cayenne, fait en 1725, 1726 et 1727, contenant une description très exacte et tr'ès étendue de ce pays et du commerce qui s'y fait; 4 vol. in-12, Paris, 1730.

3. Nouvelle relation de l'A frique occidentale, contenant une description exacte du Sénégal et des pays situés entre le cap Blanc et Serre Lione jusqu’à plus de trois cents lieues en avant dans les terres; l'histoire naturelle de ces pays, les différentes nations qui y sont répandues, leurs religions et leurs mœurs, avec l'élat ancien el présent des compagnies qui y font le commerce; 5 vol. in-12, Paris, 1728.

4. Berlioux, André Brue. 
tions vers des contrées qu'on n'a pas encore toutes revues depuis l'époque où il vivait. De 1694 à 1724, il administra le Sénégal à divers titres, et pendant cetle longue carrière, malgré la mauvaise volonté ou les absurdes instructions des diverses compagnies dont il fut l'agent, il ne cessa de se conduire d'après un plan bien arrêté, et il aurait certainement réussi si on lui avait permis d'exécuter ce plan. En outre, il tint toujours haut et ferme le drapeau de la France. Il ne fut pas seulement administrateur émérite, mais plus encore grand citoyen. A lui seul remontent les premiers projets de colonisation sérieuse du Sénégal, projets dont les hésitations et les faiblesses du gouvernement ou le malheur des temps firent ajourner pendant plus d'un siècle la réalisation. Qu'on l'étudie soit comme voyageur el géographe, soit comme organisateur d'une colonie qui nous appartient toujours, son rôle a été des plus brillants. Comme géographe, c'est lui qui le premier fit connaître le Galam, le Bambouck, une partie du Khasso el du Fouta; lui qui appela l'attention sur les Sarakolès, dont personne encore n'avait parlé, et sur les Mandingues, dont on connaissait à peine le nom; lui qui donna des renseignements précis sur la route de l'Atlantique à Tombouctou. Au point de vue des intérêts français, il peut être regardé comme le véritable organisateur de notre colonie. Elle se composait à son arrivée des deux comptoirs de Saint-Louis et de Gorée. Brue l'augmenta considérablement. C'est lui qui le premier indiqua nettement le caractère de la vallée du Sénégal, qui touche à la fois au Sahara et au Soudan, et qui est à vrai dire le grand chemin de transit des marchandises européennes vers l'Afrique centrale. Il en fit la première exploration régulière jusqu'à la chute du Félou. Il a étudié avec autant d'intelligence que d'exactitude les races qui habitent. celte contrée et les intérêts qui les divisent. Ses observations ont conservé même de nos jours toute leur valeur. Il a conclu des trailés avec ces diverses tribus, el, pour s'assurer le monopole du commerce, il a construit deux forts dans le haut pays, à Saint-Joseph et à Saint-Pierre. Il songeait même à s'ouvrir la route du Soudan, et disputait aux Anglais la Gambic et aux Porlugais la Guinée. Enfin, comme l'a si bien. 
dit son plus récent historien, notre savant collègue MI. Berlioux, "il a expliqué comment les Français pouvaient fonder au Sénégal une colonie prospère et y prendre un grand rôle, en devenant les arbitres des indigènes, en utilisant les richesses de ce pays, en ouvrant des communications avec la vallée du Niger, et en se faisant les intermédiaires d'un vaste commerce ". Il est seulement bien triste de penser que, malgré son génie, Brue ne fut qu'un marchand d'esclaves. Il eût mérité de vivre à une époque où les principes de justice et de civilisation auraient été plus en honneur.

A côlé de Brue il nous faudra mentionner les noms du moine Apollinaire, qui visita le pays de l'or dans le Bambouck, et d'un traitant du Sénégal, Compagnon, qui fut chargé par lui de parcourir les pays de Galam et de Bambouck, afin de rechercher les gisements aurifères d'où les nègres tiraient la poudre d'or qu'ils apportaient à nos comptoirs. Compagnon explora avec soin toute la région aurifère, et partout il constata la présence du précieux métal. A l'entendre, le sol tout entier du Bambouck est un immense placer. La Falémé, ses affluents et tous les ruisseaux rouleraient des pailleltes d'or; mais les nègres exploitent au hasard ces richesses, creusant des trous à leur fantaisie, les abandonnant quand les parois menacent de s'ébouler. Il y a sans doute de l'exagération dans ces récits; mais depuis Compagnon ${ }^{1}$ la région a été peu étudiée, et il se pourrait que le Bambouck fùt une Californie encore inexploitée.

Le naturaliste Adanson ${ }^{2}$, qui séjourna cinq ans au Sénégal, de 1749 à 1754 , en étudia la flore et la faune, et rapporta d'importantes collections, qui lui permirent de composer une Ilistoire naturelle du Sénégal que l'on peut encore aujourd'hui consulter utilement.

Ces trois noms, André Brue, Compagnon et Adanson, sont à peu près les seuls qui méritent d'échapper à l'oubli dans la longue période qui s'étend de 1664 à 1758.

1. La carte de Compaguon, qui se retrouve dans l'ouvrage de Labat, renferme des détails qui n'ont pas eucore été contrôlés par les explorateurs de uotre époque.

2. Ananson, IIisloire naturelle du Sénégal; Paris, 1757, in-40, avec une carte et dix-ncuf planches de coquillages. 
Lorsque éclata la guerre d'indépendance des Étals-Unis d'Amérique, le lieutenant Eyriez ayant proposé un plan de campagne pour rentrer en possession du Sénégal, le marquis de Vaudreuil et le duc de Lauzun furent chargés de l'exécuter. Saint-Louis fut en effet repris le 30 janvier 1779 , et les Anglais perdirent en outre tous leurs établissements de Gambie et de Sierra-Leone. La paix de Versailles, en 1783, confirma en partie ces acquisitions. Par l'article 9 du trailé du 3 séptembre, le roi d'Angleterre consentait à restituer à la France Saint-Louis, Podor, Galam, Arguin, Portendick et Gorée. C'était la revanche de nos malheurs passés. Restait à assurer par de bonnes mesures l'avenir de la colonie restituéc.

Au lieu de profiter des dures leçons du passé, on ne songea qu'à reprendre les errements anciens. Deux compagnies nouvelles furent créées : celle de la Guyane, à laquelle fut concédé le privilège exclusif de la traite de la gomme, en indemnité des dommages éprouvés, et, à partir de 1785, une autre Compagnie du Sénégal, qui fut dissoute le 23 janvier 1791 par un décret de l'Assemblée constituante. Ni l'une ni l'autre de ces compagnies n'accomplit rien d'important. La colonie continua à végéter. Quelques noms méritent néanmoins d'être tirés de l'oubli, entre autres celui du chevalier de Boufflers, nommé gouverneur, qui essaya de rendre une vie factice à ce débris de notre empire colonial, mais se heurta contre un mauvais vouloir obstiné et n'eut pas la constance nécessaire pour triompher des difficultés accumulées. "Je veux toujours et je ne peux pas, écrivait-il à son amie la comtesse de Sabran ${ }^{1}$. Les obstacles se rassemblent contre moi et sur la terre et sur la mer. Cette maudite barre devient tous les jours pire. Je n'ai aucun moyen de communiquer avec les vaisseaux qui sont au mouilage. On tente vainement le passage des deux côtés. La moitié des effets qu'on m'avait donnés pour la colonie ne m'est point parvenue, et ne me parviendra peut-être point. Je manque d'outils, d'ouvriers, de vivres. Je trouve dans mon intérieur des résistances qui me chagrinent. Tout cela m'attriste, mais ne m'abat point. »

1. Correspondance de la comtesse de Sabran et du chevalier de Boufters, p. 429 . 
"Je fais réparer, écrivait-il encore au maréchal de Beauveau, les lits et les fournitures des casernes, dont le délabrement m'a fait venir les larmes aux yeux à mon arrivée. Je fais remanier toutes les cloisons, tous les murs, toutes les toitures de l'hôpital, pour le mettre en état de recevoir la foule des malades qui doit y entrer dans la mauvaise saison. Je suis en même temps obligé de faire quelques réparations urgentes à ce qu'on appelle mon gouvernement : c'est la plus pauvre, la plus sale et la plus dégradée de toutes les masures. "

Tel était le Sénégal en 1786; tel devait-il rester de longues années encore. Quelques progrès cependant furent réalisés. Quatre voyages d'exploration furent entrepris : le premier par le négrier Lamiral, conduit par les besoins de son commerce jusque dans le pays de Galam, et qui a donné sur les Maures de la rive droite du Sénégal de très curieux détails; le second par le commandant de la corvette la Bayonnaise, la Jaille ${ }^{1}$, qui, de 1784 à 1785 , reconnut les côtes du cap Blanc à SierraLeone; le troisième, en 1786, par Rubault, agent de là Compagnie du Sénégal ${ }^{2}$, qui traversa la partie septentrionale du Cayor, le Djolof, le Niani, le Bondou, franchit la Falémé près de Kagnousa et atteignit le fort Saint-Georges, d'où il revint à Saint-Louis par le fleuve; le quatrième par le capitaine du génie Golberry³ ${ }^{3}$ qui traversa le Cayor de SaintLouis à Dakar, visita les escales du désert, le comptoir d'Albreda, et alla jusqu'à la colonie anglaise de Sierra-Leone. Ce dernier insistait sur la nécessité de s'élablir fortement dans la contrée, dont il énumérait toutes les ressources. Il déplorait l'incurie des administrateurs, l'indifférence du gouvernement, le déplorable état des fortifications; mais on ne l'écouta seulemerit pas. Il faudra de nouveaux désastres pour démontrer le bien fondé de ses réclamations.

1. La Barthe, Voyages au Sénégal pendant les années 1784-85, d'après les mémoires de la Jaille, ancien officier de la marine, contenant des recherches sur la géographie, la navigation et le commerce de la côte occidentale d'Afrique; $1 \mathrm{~S} 02$.

2. Ce voyage a été raconté par Durand, agent supérieur de la Compagnie, qui visita lui-même nos comptoirs, et décrivit la côte depuis le cap Blanc jusqu'à Sierra-Leone. Son ouvrage est accompagué d'un atlas de cartes très soignées. Il est intitulé : Voyage au Sénégal, an X (1802).

3. Golberry, Fragments d'un voyage en Afrique fait en 1784; 1502. 
Pendant toute la période révolutionnaire, le Sénégal fut à peu près oublié. La métropole ne daigna même pas songer au remplacement du gouverneur. Par une exception peutêtre unique dans notre histoire coloniale, le major d'infanterie Blanchot, nommé gouverneur en 1788 par le roi Louis XVl, conservait son commandement sous le consulat de Bonaparte. Les Anglais eux-mêmes - et pourtant ils étaient les maîtres incontestés de l'Océan - ne songèrent à s'emparer de Gorée qu'en 1800, et attaquèrent Saint-Louis avec tant de mollesse que toutes leurs attaques furent vigoureusement repoussées.

La paix d'Amiens avait rendu Gorée à la France. Malgré les stipulations formelles du traité, les Anglais ne consentirent pas à rendre ce poste, dont l'importance stratégique ne leur avait pas échappé. On se décida à le reprendre de vive force. Victor Hugues, le glorieux corsaire qui avait si vaillamment promené le drapeau tricolore dans la mer des Antilles, venait d'arriver de Cayenne avec quelques goélettes. Un autre bâtiment de corsaires, l'Oncle Thomas, de Rochefort, était alors en rade de Saint-Louis. Le gouverneur Blanchot, estimant que l'occasion était favorable pour tenter un coup de main, joignit à tous ces aventuriers cent cinquante hommes qu'il détacha de la garnison de Saint-Louis, et les envoya tous contre ce rocher, qui passait pour inexpugnable. Pendant que la flottille exécutait un simulacre d'atlaque dans la rade de Dakar, quelques soldats et corsaires débarquaient à l'improviste au pied de la falaise où est bâlie la citadelle, escaladaient les remparts, et, après un brillant combat, forçaient la garnison anglaise à capituler. Ce fait d'armes eut un grand retentissement. Il rétablissait la réputation militaire de la France dans l'Afrique occidentale; mais l'empereur Napoléon $I^{\text {er }}$ ne sut pas ou ne voulut pas profiter de la supériorité momentanée que nous assurait ce succès. Il n'envoya aucun renfort au Sénégal. Les Anglais, au contraire, revinrent en force, et non seulement reprirent Gorée, mais encore, le 14 juillet 1809, débarquèrent à Guet'dnar, du côté où SaintLouis n'était pas défendu, et s'emparèrent sans peine de notre capitale africaine. C'est le seul moment où le pavillon 
français n'est plus arboré sur un point quelconque du continent africain. Jamais notre situation coloniale n'a été plus compromise.

\section{V \\ HISTOIRE DU SÉNÉGAL DE 1815 A 1854}

Le trailé de Paris du 30 mai 1815 restituait sans réserve à la France tous les établissements qu'elle possédait à la côte occidentale d'Afrique au ${ }^{\text {or }}$ janvier 1792; mais la reprise de possession effective du Sénégal et de ses dépendances ne put être opérée qu'en janvier 1817. La Méduse, cette frégate de sinistre mémoire, portait les fonctionnaires et les soldats chargés de la recevoir des mains des Anglais, quand elle périt dans un naufrage tristement fameux ${ }^{1}$, symbole néfastc de l'avenir réservé, pour de longues années encore, à notre élablissement sur la terre sénégalaise.

Un ancien officier de marine, émigré depuis vingl-cinq ans, Duroys de Chaumareys, avait été chargé de conduire au Sénégal quatre bâtiments, dont la frégate la Méduse. Cet officier, incapable et lâche, commit une première faule en se dirigeant seul, avec son navire, vers le but de l'expédition. Il en commit une seconde en conduisant, par sa coupable impéritie, la frégate sur le banc d'Arguin, où elle échoua et fut démolie par la mer. Il fit alors construire avec les débris du navire un radeau, sur lequel il entassa cent quarante-cinq marins et passagers, mais sans leur laisser ni vivres, ni instructions, ni direction, et, au lieu de monter sur ce débris, au lieu de le convoyer et, au besoin, de le remorquer avec ses canots, il s'enfuit honteusement au Sénégal. Les infortunés abandonnés, sur ces planches mal assemblées, à la violence de la tempête et aux angoisses de la famine, moururent les uns après les autres, et de tous les genres de mort. Les uns tombèrent à l'eau et furent dévorés par les requins, les autres

1. Zurcher et Margollé, les Naufrages célébres (Bibliothèque des merveilles), p. $93-113$. 
s'entre-tuèrent; ceux-ci éprouvèrent les tortures de la famine, ceux-là essayèrent de la conjurer en recourant à l'abominable extrémité du cannibalisme. "Trois jours se passèrent encore dans des angoisses inexprimables, lisons-nous dans la relation de l'un des rares survivants, l'ingénieur Corréard ${ }^{1}$; nous méprisions tellement la vie que plusieurs d'entre nous ne craignirent pas de se baigner à la vue des requins qui entouraient notre radeau. Le 17 (juillet) au matin, le soleil parut dégagé de tout nuage. Après avoir adressé nos prières à l'Éternel, nous partageâmes une partie de notre vin; chacun savourait avec délices sa faible portion, lorsqu'un capitaine d'infanterie, jetant ses regards sur l'horizon, aperçut un navire et nous l'annonça par un cri de joie. Nous reconnùmes que c'était un brick, mais il était à une grande distance. La vue de ce bâtiment répandit parmi nous une allégresse difficile à dépeindre; chacun de nous croyait son salut certain, et nous redimes à Dieu mille actions de grâces. Cependant les craintes venaient se mêler à nos espérances. Nous redressâmes des cercles de barriques, aux extrémités desquels nous attachâmes des mouchoirs de différentes couleurs. Un homme, avec nos secours, monta au haut du mât et agita ces petits pavillons. Pendant plus d'une demi-heure nous flottâmes entre l'espoir et la crainte : les uns croyaient voir grossir le navire, et les autres assuraient que sa bordée le portait au large de nous. Ces derniers étaient les seuls dont les yeux n'étaient pas fascinés par l'espérance, car le brick disparut. "

Après cette scène dramatique, qu'a immortalisée le pinceau de Géricault, un affreux désespoir s'empara des naufragés. Ils s'étendirent sous la tente sans seulement relever la tête, car ils n'attendaient plus que la mort. Soudain un cri retentit. C'est un navire signalé, et cette fois il court vers le radeau. Le brick l'Argus les avait en effet aperçus, et s'empressa de les recueillir et de leur prodiguer les soins les plus touchants. Ils n'étaient plus que quinze, dont dix à peine pouvaient se mouvoir. "Nos membres étaient dépourvus d'épiderme; une profonde altération était peinte dans tous nos traits; nos

1. Corréard, ingénieur-géographe, et H. Savianr, chirurgien de marine, Nalifrage de la frégate la Méduse. 
yeux caves et presque farouches, nos longues barbes, nons donnaient encore un air plus hideux. Nous n'étions plus que des ombres de nous-mêmes. "Quant au capitaine et autres passagers embarqués dans les chaloupes, la plupart d'entre eux réussirent à aborder au Sénégal.

Cette catastrophe jeta un tel discrédit sur le Sénégal, que les fonctionnaires semblèrent se donner le mot pour fuir cette terre maudite. En effet, de 1817 à 1854 trente-deux gouverneurs ${ }^{1}$ généraux ou intérimaires se succédèrent dans la colonie, sans y apporter de changements marquants. En dépit de ses riches productions et de sa réelle fécondité, le Sénégal semblait condamné à une irrémédiable malechance. Aucun colon sérieux ne venait s'y installer à demeure. Les rares Européens qu'on y rencontrait, entassés sur un îlot malsain, sans verdure, sans arbre et presque sans eau potable, n'y venaient que pour s'enrichir et retourner au plus vite vers des climals meilleurs. Quant aux fonctionnaires, ils se croyaient en disgrâce quand on les envoyait au Sénégal, et n'aspiraient qu'au moment de le quilter. Ainsi s'expliquent les fréquents changements de nos gouverneurs. Ce poste, pourtant si honorable, était d'ordinaire confié à des officiers' en retraite, à des commissaires de marine, à de simples commandants. Il est vrai que nos administrateurs ne trouvaient: dans leur séjour rien d'attrayant. A l'exception de SaintLouis, de Gorée et de quelques comptoirs fortifiés, nous n'étions nulle part les maîtres. Aucun terrain ne nous appartenait en droit et d'une manière définitive. Nous n'étions en quelque sorte que tolérés par les indigènes. Même à SaintLouis, nous étions censés sur le territoire du roitelet de So". Il nous fallait payer de véritables tributs aux chétifs souve-

1. Schmaltz (1817-20), - de Fleuriot (2 janvier 1818-10 juillet 1819), - Lecoupé (1820-22), - baron Roger (1822-29), - baron Hugon (1er septembre 18241 er novembre 1825), - Jobelin (1828-27), - Brou (1829-31), - Renault de SaintGermain (1831-34), - Cadéol (1833), - Quernel (1833), - Pujol (1834-36), Malavois (1836), - Guillet (1836), - Soret (1837-39), - Charmasson (1839-41), - Montagnies de la Roque (1841-43), - Pageot des Noutières (1842), - BoueitWillaumez (1843-45), - Laborel (1844), - Thomas (1844), - Olivier (1845-46), Hubé (1846), - Bourdon de Gramont (1846-47), - Caille (1847), - Bertiu du Château (1847), - Baudin (1849-50), - Aumont (1850), - Protet (1850-54), Aumont (1853), - Véraud (1854), - Faidherbe (16 décembre 1854 
rains du Oualo, du Cayor, du Foula, du Bondou. Comme nous n'avions avec les indigènes que des relations de commerce, ils nous traitaient en marchands. Des deux races principales de la contrée, les uns, les Maures, nous méprisaient et nous exploitaient, quand ils ne nous brutalisaient pas; les autres, les Nègres, nous croyaient anthropophages et nous détestaient. Les uns et les autres ne perdaient aucune occasion de nous témoigner leur dédain ou leur haine. Ainsi le roi de Cayor prétendait à la propriété de tous les navires naufragés à l'entrée du fleuve, s'ils n'avaient pas été renfloués avant la seconde marée, et nos matelols étaient souvent obligés de lui disputer à coups de fusil les épaves ${ }^{1}$. Sur le fleuve, ct sous le moindre prétexte, d'inoffensifs traitants étaient pillés et assassinés. Nos officiers, nos soldats, ne pouvaient sans danger sortir des forts, où ils se consumaient dans une impuissante oisiveté. De temps à autre, poussé à bout par des outrages quotidiens, un de nos gouverneurs allait faire sur le fleuve une reconnaissance militaire. Quelques villages étaient brûlés, quelques récoltes enlevées; mais les vrais coupables avaient fui, et à peine nos vaisseaux étaientils à Saint-Louis que les maraudeurs reparaissaient, et que tout élait à recommencer.

Le plus singulier, c'est que le gouvernement français, d'ordinaire si chatouilleux sur ces questions d'étiquette, ne pro- tesia jamais contre ces humiliations presque quotidiennes. Il se résignait au rôle toujours piteux de tributaire. Sous forme de cadeaux, déguisés sous le nom de coutumes ${ }^{2}$, il payait des

1. Traité conclu en octobre $182 \mathrm{~s}$ et en décembre 1826 avec les chefs de la presqu'ile du cap Vert et avec les Nègres de Gandiole pour racheter ce prétendu droit d'épave.

2. Voir, dans l'ouvrage, cité plus haut, de Durand, les traités conclus avec les Maures sur la rive droite du fleuve :

LES COUTUMES AU SÉNÉGAL

Traité conclu, sous les auspices du comte de Repentigny, gouverneur du Sénégal, entre Durand, directeur général de la Compagnie de la gomme, et les Maures d'Armankour. - 2 mai 1785.

... Article 7. - L'usage ayant introduit l'habitude de payer aux marabouts d'Armankour une coutume quelconque pour traiter la gomme dans leur pays, et cette coutume ayant varié suivant les circonstances, elle vient d'être fixée d'une manière positive et permanente par l'article suivant:

Article 8. - Lorsque les marabouts d'Armankour viendront dans l'île Saint- 
sommes parfois considérables à ces misérables souverains. Ce n'étaient pas seulement les rois sénégalais, mais encore des personnages secondaires, et jusqu'à des serviteurs et même des esclaves, qui vivaient ainsi à nos dépens. Les coutumes n'étaient pas de notre part de simples complaisances, elles étaient bel et bien consenties à perpétuité, avec les formes les plus solennelles, et consacrées par des lois spéciales. Ces grotesques tyranneaux ${ }^{1}$ africains qui exploitaient ainsi notre faiblesse, sans avoir pour eux le prestige de la force, n'avaient-ils pas poussé l'outrecuidance jusqu'à ne pas se contenter des coutumes d'usage! De temps à autre ils s'arrogeaient le droit de permettre ou de défendre aux négociants français d'entrer en relations commerciales avec leurs sujets. Nous avions beau redoubler à leur égard de complaisance et de douceur, ils se permetlaient contre nous. des vols et des violences de toute nalure. Les Maures surlout ne savaient plus quelle humiliation nous infliger. Non seulement les Europ éens n'avaient plus le droit de remonter le Sénégal, ma:s les habitants de Saint-Louis, qui seuls jouissaient de ce privilège, ne pouvaient s'arrêter devant le moindre village sans payer des coutumes plus ou moins exorbitantes. Avant même de savoir si on ferait ou si on ne ferait pas des affaires, il

Louis pour visiter le directeur général de la Compagnie, ce qui ne doit être qu'une fois l'année, le directeur leur fera délivrer chaque jour pour leurs vivres douze meules de mil, six bouteilles de mélasse, deux bouteilles de vin, un mouton ou l'équivalent en bœuf, deux chandelles, du bois à brûler. Lors. qu'ils partiront de l'île Saint-Louis pour leur pays, le directeur leur fera donner : trente pièces de guinée, trente bassins de cuivre ou l'équivalent, trente paires de ciseaux, trente miroirs, trente tabatières pleines de girofle, trente jambettes, trente peignes, trente cadenas, trente mains de papier, dix barres de verroterie.

Lorsque le bâtiment sera rendu au désert, le premier kantar de gomme mesuré, on tirera un coup de canon pour saluer et annoncer la traite, et au même instant on payera aux marabouts d'Armankour : vingt pièces de guinée, cinq fusils à deux coups, vingt fusils ả un coup, quinze aunes de drap écarlate, dix pièces de platille, vingt barres de fer de huit pieds, cinq ancres de mélasse, dix barres de verroterie. Pendant la traite de la gomme, on fournira aux marabouts d'Armankour pour leurs vivres au désert, par chaque jour que durera la traite, quarante meules de mil, deux moutons, six bouteilles de mélasse. On leur fera présent, en outre, d'une pièce de guinée pour chaque huitième kantar qu'on aura mesuré et conduit à bord.

A la fin de la traite, on leur payera trente pièces de guinée, cinq turbans de mousseline ou dix aunes. Finalement, pour les dcrniers adieux, on tirera un coup de canon et on donnera vingt pièces de guinée.

1. Voir, daus la Correspondance de Boufflers, la lettre du 17 avril 1787 a 
fallait s'exécuter et payer la coutume, ou sinon on saisissait à bord des navires portant notre pavillon les marchandises qui ne provenaient pas directement des escales autorisées ${ }^{1}$, et qui, par conséquent, n'avaient pas payé la contribution exigée. Le roi des Maures Trarzas ${ }^{2}$, le plus puissant des monarques sénégalais, avait même dressé le tarif de ses prétendus droils aux escales de son territoire : deux pièces de guinée, c'est-à-dire de cotonnade bleue, par mille kilogrammes de marchandises achetées, et autant pour la même quantité de marchandises vendues et achelées à Saint-Louis; en outre, deux pièces de guinée pour son repas, deux autres pour sa bagatelle, c'est-à-dire pour ses plaisirs, une pièce et demie pour la bagatelle de la reine, une demi-pièce pour la bagatelle du ministre. Ce n'est pas tout : l'acheteur européen devait chaque soir envoyer au ministre un plat de riz ou payer une amende de deux francs cinquante. En cas de refus, on fermait le marché, et les relations commerciales étaient brusquement interrompues.

A l'exemple du roi des Trarzas, tous les tyranneaux ${ }^{3}$ sénégalais exagéraient leurs prétentions, et le gouvernement français, débonnaire, consentait à signer avec tel d'entre eux, par exemple avec le brack du Oualo", un traité parfaitement

Ime de Sabran : "Je ne t'ai point encore fait la peinture d'un roi maure, et, sûrement, sans cela tu ne pourrais pas t'en faire une idée. Celui avec qui je viens de passer deux jours est un homme fort puissant, mais fort doux, et en même temps fort dévot. Il n'aime que les femmes et les prêtres, et passe sa vie le plus qu'il peut à Podor, pour être loin de son camp, loin de ses ennemis, sous la protection de notre canon, à portée de piquer l'assiette de nos pauvres officiers et de faire demande sur demande au gouverneur et aux marchands... Il a absolument la dégaine d'un roi fainéant, et, qui plus est, d'un roi mendiant. En voilà assez sur le compte d'Ahmet-llochtar. Je ne veux pas qu'il t'ennuie autant qu'il m'a ennuyé. "

1. On n'en comptait que trois : Darmankour, le Désert, le Coq.

2. Voir le traité conclu le 7 juin 1821 avec le roi Amar-Ouldon-Moctar (articles $13,14,15)$, traité confirmé par deux nouvelles conventions en date du 15 avril 1829 et du 30 août 1835 .

3. Voir le traité conclu le 25 juin 1821 avec Ha metdou, chef des Maures Braknas.

4. Traité du 8 mai 1819, confirmé par la convention du 4 septembre 1835. Les articles 12 et 13 étaient ainsi conçus : "Les redevances ou coutumes consenties par le présent traité en faveur du brack et des principaux chefs du pays de Oualo, ayant un objet particulier bien distinct, et dont les parties contractantes reconnaissent azoir pleine et entière connaissance, ne pourront, dans aucun cas ni pour aucun motif, être augmentées ni diminuées à l'avenir. Elles seront payées par l'administration du Séuégal le 1er janvier 1820, et seront exigibles ensuite tous les ans à pareille époque." 
en règle et dùment collationné, dans lequel figuraient ces clauses étranges: "Le gouvernement payera au brack de Oualo dix bouleilles d'eau-de-vie, etc., à son domestique deux bouteilles d'eau-de-vie et une barre de fer, à la princesse Guimbotte une petite malle, une pièce de mousseline, quatre bouteilles d'eau-de-vie, dix têtes de tabac, et cinq cents grammes de clous de girofle, plus, pour sa ration de vivres, une dame-jeanne d'eau-de-vie. " On ne sait vraiment ce qu'il faut admirer le plus, ou l'outrecuidance de ces fantoches royaux, ou l'inexplicable longanimité du gouvernement français ${ }^{1}$.

Malgré ces déboires, malgré cette attitude humiliante, quelques progrès s'accomplirent pourtant dans la période qui s'étend de 1815 à $185 \% 4$. Le Sénégal ne fut plus exclusivement un marché d'esclaves. Le bois d'ébène, ainsi que les traitants appelaient leurs esclaves, avait été jusqu'alors à peu près l'unique production locale, et nos forts n'élaient que des comptoirs destinés à protéger les trafiquants de chair lumaine; mais, après les décrets de la Constituante, après l'abolition solennelle, et proclamée par les traités, de la vente des nègres, les négociants durent renoncer à ce honteux commerce. Quelques-uns d'entre eux le continuèrent, il est vrai, mais en cachette : car les profits en étaient considérables, - il suffisait de sauver une cargaison sur deux pour gagner cént quarante pour cent - si les risques étaient grands. Lorsque l'Angleterre et la France se décidèrent à pourchasser résolument les négriers, les croisières furent conduites avec tant d'habileté et de vigueur, que peu à peu disparurent ces honteux vestiges d'un passé regrettable. Le Sénégal cessa d'alimenter d'esclaves les marchés américains; mais les négociants sénégalais furent ruinés, et l'avenir de la compagnie sembla compromis à tout jamais.

Ce fut alors que le gouvernement songea à faire du Séné-

1. En 1838, la dépense occasionnée par les coutumes, soit en argent, soit en marchandises, s'élevait à la somme de 41,000 francs, ainsi répartie : SaintLouis, 1,031 fr. 4ว̃ ; - banlieue de Saint-Louis, 316 fr. 77; - Oualø, 9, 470 fr. 57 ; - Cayor, 1,558 fr. 98; - Trarzas, 10,54วั fr. 81; - Darmankour, 396 fr. 10 ; Braknas, 2,835 fr. 12; - Foula, 3,266 fr. 76; - Galam, 1,517 fr. 18; - Bondou, c0s fr. 18 ; - Tuabo, 814 fr. 06; - Douaichs, 1,257 fr. 59 ; - Barr en Gambie, $6 ! 3$ fr. 69 ; - Dakar, $6 ว 3$ fr. 20 ; - Casamance, 156 francs; - Vivres délivrés aux cheis venant recevoir.leurs coutumes, $3,6 \nsucceq 6$ fr. 40 . 
gal un vaste champ d'expériences agricoles. Il aurait voulu y acclimater en même temps le coton, l'indigo, le café et toutes les plantes tropicales. Des terrains furent achetés sur la rive gauche du Sénégal, et le fort de Dagana fut construit pour protéger les nouveaux colons. A Dagana, à Richard-Toll, à Faf et à Lampsar, une quarantaine de plantations modèles

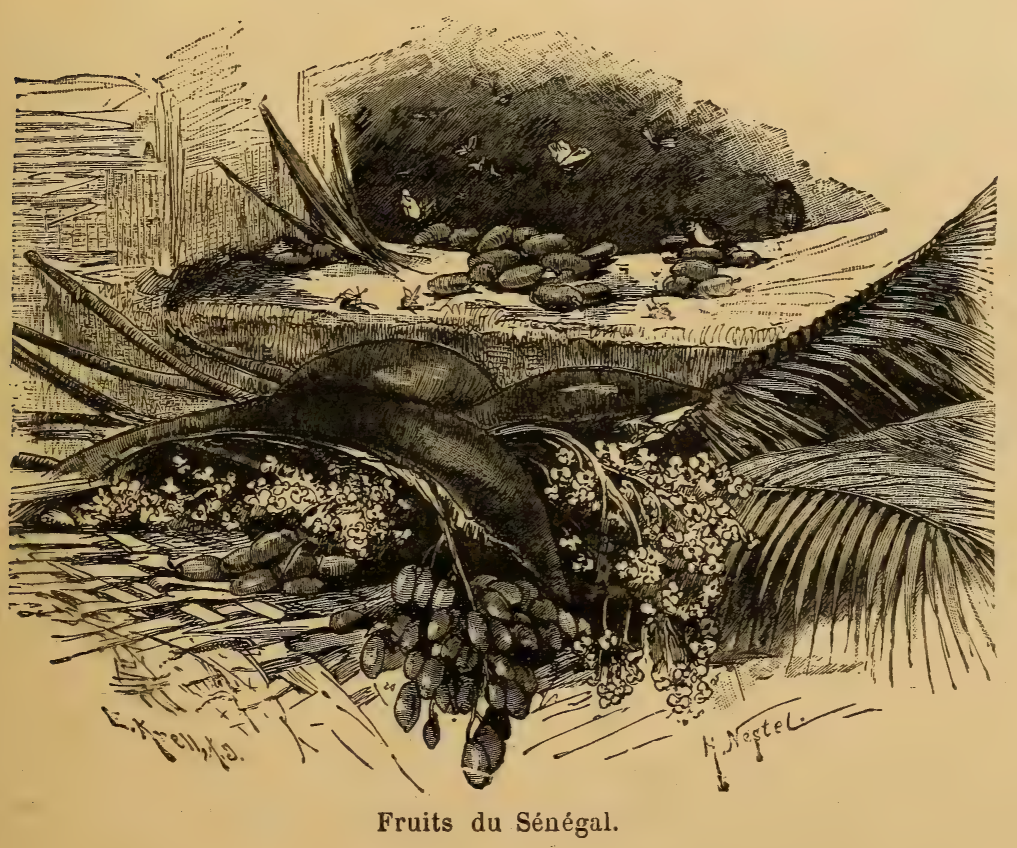

furent créées, et on espéra que les nouveaux possesseurs du sol, encouragés par de fortes primes, réussiraient à convertir en champs fertiles les mornes solitudes qui entouraient SaintLouis. Aucun de ces essais ne réussit, et plusieurs millions furent gaspillés bien inutilement. On eut toul d'abord à lutter contre les indigènes, Maures ou Nègres, qui envahirent les plantations et les ravagèrent à diverses reprises. Il fallut ensuite lulter contre le découragement des colons, décimés par la maladie, et traités avec dédain par certains fonctionnaires. Il fut enfin nécessaire de réprimer la fraude, car le gouvernement fut parfois servi d'une façon singulière par ses 
agents. "Lorsque la visite de l'inspecteur était annoncée, lisons-nous dans la relation de Raffenel, témoin oculaire, des chefs de culture faisaient ficher en terre, pendant la nuit, des branches de cotonnier et d'indigofère, et, à la faveur de celle grossière supercherie, le nombre des plants, s'accroissant facilement dans une proporlion indéfinie, non seulement donnait droit à des primes d'un prix élevé, mais encore entraînait à faire sur la prospérité des cultures des rapports inexacts, qui entretenaient une erreur déplorable. La fraude ne s'arrêtait pas là : elle spéculait aussi sur les travailleurs pour percevoir des subventions indues: On trompait les inspecteurs sur le nombre des ouvriers, en faisant répondre à l'appel des hommes qui n'étaient pas occupés à la culture. "

La culture du coton fut la première abandonnée. Aussi bien, on n'avait exporté du Sénégal, de 1822 à 1825 , que quaranteneuf mille six cents kilogrammes de coton égrené. L'indigo ne réussit pas mieux. On reconnut, après quelques années d'expérience, que le prix de revient des indigos sénégalais serait toujours trop élevé pour leur permettre de lutter sur les marchés d'Europe contre leurs similaires de l'Hindoustan. Nême insuccès pour le café, la canne à sucre, le giroflier, le séné, le rocouyer, la salsepareille, le cannellier, ainsi que pour l'éducation de la cochenille et celle des vers à soie. Seul le jardin pépinière de Richard-Toll offrit quelques exemples de réussite, mais dans un terrain de choix et dans des conditions trop dispendieuses pour une exploitation industrielle.

On comprit l'inutilité de ces tentatives agricoles. Dès 1830 étaient supprimées les dernières allocations qui figuraient au budget local pour encouragement à la colonisation. La conséquence de cet avortement fut de jeter un profond diserédit sur les richesses, pourtant bien réelles, du sol. L'erreur se répandit que le Sénégal était impropre à l'agriculture. On ne le considéra plus que comme un marché à exploiter.

Malgré ces préjugés économiques, notre situation s'améliorait pourtant. Les Maures campés sur la rive droite du fleuve étaient sévèrement rappelés au respect des traités. Les tribus nègres étaient punies de leurs velléités de révolte, et nous n'hésitions plus, quand les insolences de leurs tyran- 
neaux avaient épuisé la palience de nos gouverneurs, à sortir de notre impassibilité voulue, et à frapper quelque coup retentissant. Il est vrai que ces expéditions n'élaient le plus souvent que des coups de main et des razzias; mais elles inspiraient pour quelque temps une salutaire terreur, et nos négociants pouvaient du moins se risquer sur le fleuve. Nous achetions quelques comploirs dans la vallée de la Casamance. Sur Ie

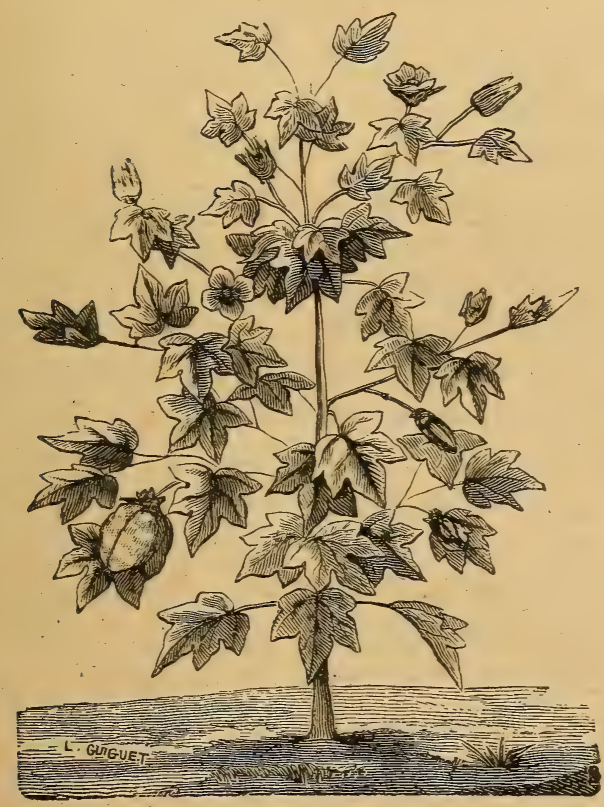

Cotonnier.

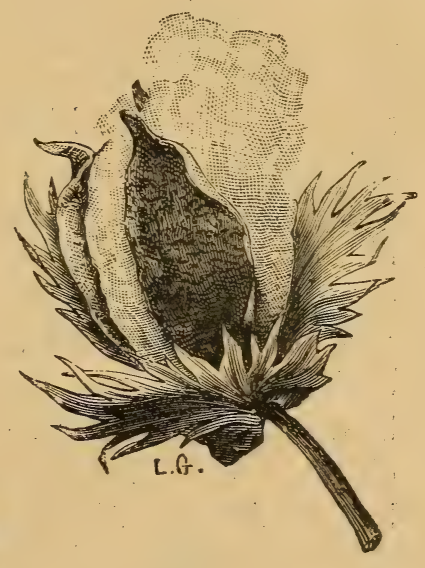

Coton.

haut fleuve, Bakel était fondé en 1820 , et une compagnie privilégiée pour le commerce de la région élait créée sous le nom de Compagnie du Galam. Enfin divers explorateurs étendaient le champ de nos connaissances, et, par leurs patientes recherches, préparaient notre future grandeur, et jetaient sans s'en douter les bases de notre empire colonial dans l'Afrique occidentale. Quelques-uns de ces explorateurs méritent l'honneur d'une mention spéciale.

Le premier d'entre eux se nommait Gaspard Mollien². Il

1. Moluten, Voyage clans l'intérieur de l'Afrique, fait aux sources du Sénégal et de la Gambie en 1818;1820. 
était fils d'un des meilleurs ministres de l'empereur Napoléon. Il venait au Sénégal en qualité de commis de marine.Par un hasard providentiel, il avait survécu à la dramatique catastrophe de la Méduse. Tout autre se fût arrêté; lui ne fut que plus ardent à poursuivre le projet qu'il avait formé en touchant la terre africaine, celui de pénétrer dans des régions inconnues et d'augmenter le domaine colonial de la France. Il aurait voulu découvrir les sources du Sénégal, de la Gambie et du Niger, puis descendre ce grand fleuve jusqu'à son embouchure; mais il fut obligé de renoncer à cette entreprise, trop au-dessus des forces d'un homme, et de se borner à l'exploration du Fouta-Djallon, c'est-à-dire du pâté montagneux qui sépare le Sénégal et ses affluents du Niger et des Rivières du Sud. Il désirait s'assurer par lui-même s'il existait entre ces fleuves, comme on l'affirmait, des canaux de communication, et, dans tous les cas, les relier fortement les uns aux autres, par des ilinéraires bien tracés. Seul et sans autre guide que son courage, sans autres ressources que sa petite fortune, mais soutenu par l'ardeur de ses vingt ans, il se lança résolument en pays inconnu. Mollien constata qu'à l'époque des grandes pluies une sorte de marécage situé sur les limites du Fouta et du Bondou, et nommé Nerico, établissait une véritable communication entre la Gambie et le Sénégal. Malheureusement, le peu de profondeur de ce cours d'eau et les obstacles dont il est encombré le rendaient, même pendant les grandes eaux, impraticable à la navigation.

Ce fut Mollien qui donna la première description du FoutaDjallon et du pays des Yolofs. Il en décrivit les sites pittoresques, les habitants à la fois guerriers et pasteurs. Épuisé par la fièvre, et à bout de forces, il dut s'arrêter en chemin, dans le petit village de Bandéia. Son hôte, qui convoitait son mince bagage et trouvait que sa mort était trop lente, essaya de l'empoisonner. Mollien échappa par miracle à ce danger, et, quoique bien faible, s'enfuit jusqu'au Rio Geba, où les Portugais l'accueillirent avec empressement. Une goélette française le ramena bientôt à Gorée, et de là à Saint-Louis, où il rentra le 19 janvier 1819, après une absence d'une année. Ce fut l'initiateur et le précurseur de tous ceux qui suivirent ses 
traces, car il détermina la situation exacte des principaux cours d'eau de la Sénégambie, et commença les corrections sérieuses qui devaient bientôt renouveler la carte de l'Afrique occidentale.

L'enseigne de vaisseau de Beaufort ${ }^{1}$, après Mollien, parcourut, en 1814 et 1825 , le Bambouck, les bords de la Gambie, le Khasso et le Kaarta. Il fut surpris par la mort à Bakel, le 3 septembre 1825, avant d'avoir pu rédiger le récit de ses voyages; mais il avait écrit de nombreuses lettres et déterminé plusieurs longitudes et latitudes, qui servirent à rectifier les explorations précédentes.

Nous ne citerons que pour mémoire René Caillié, car ce n’est pas au Sénégal, mais au Soudan, que notre héroïque compatriole fit ses découvertes les plus intéressantes. Sa grande exploration eut lieu de 1827 à 1828.

Ce fut seulement en 1843 que le gouverneur Bouët-IVillaumez, résolu à tirer le Sénégal de la torpeur où il languissait, organisa une véritable mission d'exploration " pour étudier les moyens de multiplier nós relations commerciales, examiner avec soin les mines du Bambouck et les procédés d'exploitation des indigènes, enfin déterminer la position astronomique de divers lieux et établir la carte de la Falémé ". Le directeur de la mission était Huard-Bessinières, pharmacien de la marine, auquel on adjoignit Jamin, enseigne de vaisseau, Raffenel, commissaire de la marine, Ferry, chirurgien, et Pottin-Paterson, habitant du Sénégal. Le chef de la mission mourut avant d'avoir pu mettre ses notes au net. Raffenel fut alors chargé de les rédiger; mais comme elles étaient écrites au crayon et à demi effacées, il fut obligé de les reconstituer avec son propre journal, itinéraire d'un touriste plutôt que d'un savant. De là peu de données scientifiques, mais beaucoup de détails intéressants ${ }^{2}$.

1. Ancelle, les Explorations au Sénégal et dans les contrées voisines depuis l'antiquité jusqu'à nos jours, p. 70.

2. A. Raffenel, Voyage dans l'Afrique occidentale, comprenant l'exploration du Sénégal depuis Saint-Louis jusqu’à la Falémé au delà de Bakel; de la Falémé depuis son embouchure jusqu'à Sansandig; des mines d'or de Kenieba dans le Bambouck; des pays de Galam, Bondou et Woollı; et de la Gambie depuis Barocomida jusqu'à l'Océan, Paris, 1846 , in-8 ${ }^{\circ}$, et atlas in-4º. 
Le 16 août 1843 , les voyageurs quiltaient Saint-Louis sur deux petits bâtiments et remontaient le Sénégal jusqu’à Bakel. Après avoir payé tribut aux intempéries du climat, la petite caravane, remontant toujours le Sénégal, parvint à Kounguel, capitale du bas Galam, où elle reçut un accueil empressé du souverain indigène, Kounko. Remontant alors la Falémé, nos compatriotes atteignirent Kidira Fioulabou, où régnait la reine Sadiaba. Cette négresse était devenue presque Française par son mariage avec un colon du Sénégal, Duranton, qui, poussé par ses goûts aventureux, avait renoncé à ses fonctions d'employé du gouvernement et s'était lancé dans l'intérieur du pays pour y chercher fortune. Il avait rencontré l'amour sous les traits de la fille du roi de Khasso, la belle Sadiaba, qui lui avait accordé sa main. Duranton resta toujours fidèle à sa patrie. Dénoncé par les agents de la Compagnie privilégiée du Galam comme un vulgaire ambitieux et ramené à Saint-Louis comme un malfaiteur, Duranton n'eut pas de peine à disssiper les calomnies. La passion d'aventures qui lui avait valu un trône lui coûta la vie. Il mourut en effet, après quelques mois d'une union fort heureuse, dans une course qu'il avait entreprise aux environs de sa principaulé. La veuve de Duranton avait pris de son mari le caractère facile et gai. Elle mit tout en œuvre pour se rendre agréable et utile à ses hôtes, et ceux-ci rapportèrent de leur séjour à Kidira Fioulabou le moilleur souvenir.

L'expédition séjourna ensuite quelque temps à Sénoudébou, où elle se mit en relations avec l'almamy du Bondou, et parvint à conclure avec lui un traité de commerce qui concédait à la France un territoire à Sénoudébou, moyennant quatre mille francs de capital et sept cents francs de rente. Les pourparlers nécessités par celte négociation furent assez longs, et l'expédition profita de cette halte forcée pour explorer le cours de la Falémé. Malheureusement, l'expédition se trouva interrompue par la maladie de Raffenel, et ses compagnons, faligués eux-mêmes, renoncèrent à pousser plus avant et rentrè rent à Bakel.

Cette expédition rendit de grands services à la géographie et à l'administralion coloniale. Ses membres avaient exploré 
avec soin la Falémé, rivière encore peu connue, ils avaient reconnu les passes et les îlots, enfin ils avaient établi que la Falémé et la Gambie étaient en communication par deux cours d'eau, le Badiara et le Walgha, qui les réunissent à l'époque des inondations. Raffenel pensait même que le Sénégal et la Gambie sont en communication par le Mermeriko, le Neriko de Mollien. Ces canaux transversaux ne lui paraissaient d'ailleurs que d'un intérêt secondaire, attendu qu'aucun d'eux ne se prête à la navigation même des barques les plus légères. Dans la Falémé elle-même, la hauteur de l'eau est très variable, et les pluies occasionnent des crues presque subites. Aussi la navigation sur ce fleuve est-elle peu facile. Une autre cause de difficulté provenait encore des attaques incessantes des musulmans. Pour ces fanatiques, tuer ou voler un chrétien, un nazareh, c'est à la fois un profit et une œuvre pie.

L'expédition de 1843 donna encore quelques renseignements précieux sur les productions du sol. Dans une de leurs excursions à Sansandig, les explorateurs visitèrent les mines d'or de Kenieba, dont on vantait au loin les produits; mais ils constatèrent qu'elles étaient peu riches et ne valaient pas les frais d'exploitation. Quelques années plus tard, en 1852, Rey, commandant de Bakel, visitait à son tour les gisements aurifères de Kenieba. Il concluait au contraire à la possibilité d'une exploitation largement rémunératrice, mais les frais de première installation devaient être considérables. Ne vaudraitil pas mieux renoncer à chercher au Sénégal un nouvel Eldorado, et se contenter des richesses certaines que promettent ses produits agricoles et son commerce?

Deux ans plus tard, en 1846, Raffenel obtenait du gouvernement une nouvelle mission. Il voulait cette fois traverser l'Afrique de l'occident à l'orient, en passant par le Soudan, le Bornou, le Darfour et les sources du Nil; mais il ne put s'avancer au delà du Kaarta. Fait prisonnier par les gens de Mahmoudy Kandia, il fut emmené par eux au village de Foutobi, et y subit une captivité de huit mois. Au moins profitat-il de son séjour forcé pour étudier avec soin les mœurs et l'bistoire des Bambaras. A son retour, il composa une relation 
fort intéressante ${ }^{1}$, à laquelle il joignit l'histoire du Sénégal et exposa ses projets pour l'avenir de cetle colonie. L'originalité de celte relation consiste même dans les grandes vues qu'il développa avec hardiesse, el dont l'exéculion est aujourd'hui commencée. Raffenel aurait voulu que la politique avilissante des concessions et des coulumes fût remplacée par une fermeté inflexible, mais loyale. Suppression des esclaves, protection des Nègres contre les Maures, création d'écoles françaises, exlension du christianisme par des missionnaires noirs, et surtout pénétration de la France au Soudan, tels étaient les principaux objets de son programme. «Des steamers français naviguant sur le lac Tchad, s'écriait-il avec une singulière prescience de l'avenir, il y a de quoi tenter l'ambilion d'un grand peuple, et lui faire dépenser des millions... Dans dix ans nous pourrons déployer au milieu de l'Afrique le pavillon de la France et montrer aux yeux ravis des Nègres un bateau à vapeur, pour eux merveille et mystère, cause de ter.. reur et d'admiration. Dans vingt ans nous pourrons avoir des relations permanentes entre l'Algérie et l'Afrique centrale, et exercer sur cette immense contrée un protectorat salutaire pour la civilisation de ses habitants et profitable à nos intérêls commerciaux. Et tout cela est simple, facile, réalisable avec trois choses: de la volonté, de la persévérance et trois millions par an. ")

Certes, toutes les parties de ce vaste programme ne sont pas encore réalisées; mais au moins Raffenel ${ }^{2}$ ne prêcha-t-il pas dans le désert. On discuta ses projets, et par conséquent on s'y intéressa. S'il souleva des critiques, il rencontra des défenseurs. L'un d'entre eux, et ce n'est pas le moins éminent, porté par les circonstances aux importantes fonclions de gouverneur du Sénégal, essaya de faire passer dans la réalité ce qui n'était pas encore sorti du dómaine de l'utopie.

1. A. Raffevel, Nouveau Voyage dans le pays des nègres, suivi d'études sur la colonie du Sénégal, et de documents his.oriques, géographiques et scientifiques; Paris, 1856, 2 vol. in -80.

2. Richardson, dans sa grande exploration de l'Afrique centrale, aurait désiré Raffenel pour compagnon de voyage; mais notre compatriote ne put répondre à son appel, et ce fut le docteur Barth qui lui ravit l'honneur de ce voyage de découvertes. Il mourut en 183 i, gouverneur de Sainte-Marie de Madagascar. 
A cette grande cuvre de rénovation il consacra une vie d. labeurs intenses et de propagande ininterrompue. Sans loute il éprouva des déceptions; mais ce n'est pas du jour au lendemain qu'on fonde un empire colonial; et si, comme tout le fait espérer, l'Afrique occidentale devient quelque jour partie intégrante de la patrie française, nous le devrons aux efforts persévérants du général Faidherbe; mais nous aurions mauvaise grâce à ne pas rendre justice à celui qui le devança dans cette voie féconde, à Anne Raffenel.

En résumé, malgré ces découvertes et ces progrès, la siluation du Sénégal n'était pas plus brillante en $185 \%$ qu'aux premiers jours de notre établissement. Vexations, outrages, menaces d'expulsion, razzias dangereuses, tel avait été jusqu'alors le rôle piteux joué par la France au Sénégal. Ce rôle ne convenait ni à notre dignité ni à nos intérêts. Déjà quelques négociants avaient, en 1831, fait entendre leurs doléances, et demandé la suppression des escales et leur remplacement par des établissements de commerce permanents et fortifiés, l'un à Dagana, l'autre à Podor. Le gouvernement accucillit leur demande, et chargea le capitaine de vaisseau Protet d'exécuter ce programme.

La province dans laquelle allaient s'engager les Français se nomme le Dimar. Elle est peuplée par des Nègres remuants et énergiques, les Toucouleurs. Ces Nègres s'étaient nettement, et dès le premier jour, déclarés contre la France. Non seulement ils s'étaient associés aux razzias des Maures dans le Oualo, mais, à diverses reprises, ils nous avaient fait la guerre pour leur propre compte. Soutenus par leurs belliqueux voisins, les Peuls du Toro, ils avaient envahi le Oualo et insulté la banlieue de Saint-Louis. En 1830, sous la conduite d'un prétondu prophète, Mohammed-Omar, ils s'étaient même avancés assez près de notre capitale. Sans doute ils avaient été arrêtés, baltus même à Dagana, et leur chef, fait prisonnier, avait été pendu à un tamarinier, en face de Richard-Toll; mais la leçon avait été vite oubliée. En 1842 ils envahissaient de nouveau lc Oualo, et le commandant Bouët-Vuillaumez était obligé de les poursuivre jusque dans leurs forêts. Ce fut même dans cette campagne et à leur occasion que fut pour la première 
fois organisé le corps auxiliaire des spahis indigènes, qui depuis ont rendu tant de services.

En 1854, afin de mater ces remuantes tribus, et de nous assurer la libre navigation du Sénégal jusqu'à l'extrémité orientale de l'île à Morfil, c'est-à-dire une voie fluviale, toujours en état, de deux cent cinquante kilomètres de longueur, le capitaine de vaisseau Protet reçut l'ordre de bâtir un fort à Podor. Il s'embarqua donc (18 mars) avec environ quinze cents hommes, mais, à partir de Dagana, fut obligé de faire le coup de fusil contre les riverains du Dimar, qui, malgré leurs promesses, venaient une fois encore de se déclarer contre nous. Arrivé à Podor, Protet en débusqua, non sans peine, les Peuls du Toro, et tout aussitôt commencèrent les travaux de construction d'un fort, sous la direction d'un jeune capitaine du génie, Faidherbe, qui était depuis deux ans dans la colonie, avait pris part, avec le commandant Baudin, à l'expédition du grand Bassam, au combat d'Éboué, et avait construit le fort de Dabou. Les travaux furent si bien conduits, et avec une telle activité, que la citadelle française était debout en quarante jours, et que la colonne expédilionnaire pouvait reprendre le chemin de Saint-Louis.

Les gens du Dimar nous avaient ménagé une surprise. Cinq mille d'entre eux s'étaient réunis en avant de leur capitale, de leur ville sainte, Dialmath, espérant nous surprendre dans les immenses forêts qui la couvrent. Le capitaine Protet n'leésita pas à marcher contre eux. Deux routes conduisaient à Dialmath : la première par Risgo, courte, mais peu connue; la seconde par Fanaye, plus longue, mais pratiquée. On se décida pour la seconde. Le 8 mai, la colonne expéditionnaire était réunie à Fanaye. Elle comptait environ huit cents hommes, pleins d'ardeur et d'entrain, car bon nombre d'entre eux, surtout parmi les officiers, avaient absorbé de fortes doses de quinine pour prendre part à ces périls. Les guides la conduisirent mal, ou plutôt l'égarèrent à travers des fourrés, et loin du marigot de N'dor, qui aurait donné de l'eau potable. "Ici a commencé pour nous une assez rude épreuve, lisons-nous dans le rapport officiel ${ }^{1}$. A partir de dix heures, chaque halte

1. Rapport du copitaine de vaisseau Protet au ministre de la marine; SaintLouis, 28 mai 1854 . 
que j'autorisais pour faire reprendre haleine me faisait entrcr des hommes à l'ambulance. Des officiers, et des plus énergiques, en parfaite santé le matin, tombaient subitement et n'avaient même plus assez de force pour monter les chevaux de l'état-major que je mettais à leur disposition. Un militaire, ce que je ne croyais pas possible, est mort en route de fatigue, et tous mes cacolets étaient occupés, alors que je ne savais pas encore à quelle distance nous étions de Dialmath. Heureusement que la vue de cette ville vint rendre à chacun toute son énergie, et l'enthousiasme fut si grand, que l'on vit des malades descendre presque immédiatement de leurs cacolets pour reprendre leurs armes. "

Dialmath était entourée d'une muraille en bois recouverte d'une épaisse couche de terre glaise. Les obus opéraient bien une trouée dans ce rempart, mais les madriers restaient debout. Il était, en outre, impossible d'allumer des incendies, car l'ennemi avait pris la précaution d'enlever tous les tas de paille. Enfin, nous n'avions que quatre canons, et seulement cinquante coups par pièce. Déjà cent vingt coups avaient été tirés sans résultat,. et nos soldats commençaient à souffrir de la soif. Protet voulut en finir, et ordonna l'assaut. Arrivées à cent mètres, les troupes régulières hésitent, puis s'arrêtent. Une vingtaine de soldats d'infanterie, et le détachement des sapeurs du génie, dont il ne restait plus que cinq hommes debout sur dix, continuent seuls à courir, et atteignent enfin la muraille, qu'ils escaladent. Le capitaine Faidherbe était à leur tête. Les autres troupes, entraînées par leurs officiers, suivent le mouvement, et bientôt Dialmath est à nous. Celte victoire nous coûtait cher : cent soixante-quinze hommes avaient élé tués ou blessés. Il est vrai que les défenseurs de la ville nègre perdaient près de quinze cents d'entre eux. On brûla en hâte tous les cadavres, et on retourna à Saint-Louis. Les Français n'avaient plus que quatre cents hommes en état de combattre.

L'effet moral de ce beau succès fut extraordinaire sur les populations riveraines. Elles comprirent que le temps des humiliations était passé pour la France, et qu'elles n'avaient qu'à s'incliner devant la puissance nouvelle qui se manifes- 
tait par de tels coups d'éclat. En effet, quelques jours après la bataille de Dialmath, un simple décret supprimait les contumes dans lout le Dimar, et aucune protestation ne s'élevait.

Ce n'était pas encore assez. Les négociants de Saint-Louis adressèrent au gouvernement une nouvelle pétition, à l'effet d'obtenir un gouverneur séjournant dans la colonie un temps assez long pour acquérir une expérience sans laquelle rien de sérieux ne pouvait être fondé. Ilș appelaient en même temps l'attention du ministre sur le capitaine du génie Faidherbe, que les récentes expéditions avaient mis en relief et qui semblait disposé à se consacrer au Sénégal. Le ministre de la guerre, maréchal Vaillant, le nomma aussitôt chef de bataillon, et le ministre de la marine, Ducos, le désigna comme gouverneur du Sénégal (16 décembre 1854).

Voici le programme que le nouveau gouverneur était chargé d'exécuter : "Nous devons dicter nos volontés aux chefs maures pour le commerce des gommes. Il faut supprimer les escales, employer la force si l'on ne peut rien obtenir par la persuasion. Il faut supprimer tout tribut payé par nous aux États du fleuve, sauf à donner, quand il nous plaira, quelques preuves de notre munificence aux chefs dont nous serons contents. Nous devons être les suzerains du fleuve. Il faut émanciper complètement le Oualo en l'arrachant aux Trarzas, et protéger en général les populations de la rive gauche contre les Maures. Enfin, il faut entreprendre l'exécution de ce programme avec conviction et résolution."

Faidherbe allait être l'homme de la situation. Il arrivait au Sénégal avec la résolution de rendre à la colonie sa dignité devant les populations indigènes, avec les talents nécessaires pour mener à bonne fin cetle tâche difficile, avec la persévérance qui prépare le succès et l'hcureuse chance qui le facilite. De son arrivée à Saint-Louis date une ère nouvelle dans l'histoire de la colonie. Le Sénégal n'est plus un marché d'esclaves ou un comptoir de gommes. C'est une terre française, dont les progrès seront incessants, un foyer d'influence d'où rayonneront au loin, jusque dans les profondeurs de l'Afrique centrale, les idées et la civilisation françaises. 
CONQUETE DU OUALO. - REFOULEMENT DES MAURES. EXPEDITIONS DU SINE ET DU SALOUM. - GUERRES DU CAYOR.

Depuis la nomination de Faidherbe comme gouverneur du Sénégal, tout change dans notre colonie.

Le premier soin du nouveau gouverneur fut d'assurer la sécurité immédiate de la colonie. Les indigènes, en effet, Maures ou Nègres, nous considéraient comme des intrus, el n'attendaient qu'une occasion favorable pour jeter à la mer ces chiens de chrétiens, ces keffirs, qu'ils détestaient de toule l'ardeur de leurs convictions religieuses ou de leurs haines nationales. Ce n'étaient pas seulement nos postes du haut fleuve qui étaient journellement insultés et menacés par eux; dans la banlicue immédiate de Saint-Louis, nous n'étions même pas les maîtres incontestés du territoire occupé par nos troupes; à Gorée, à Rufisque, nos négociants étaient maltraités et pillés; ceux de nos navires qui élaient jetés à la côte élaient aussitôt la proie de pilleurs d'épaves, qui, à main armée, disputaient aux malhcureux naufragés les débris de leur fortune. Il n'y avait plus, en un mot, pour la France ni sécurité ni même dignité, et le drapeau national recevait chaque jour des outrages, qui méritaient une prompte répression. Le grand mérite de Faidherbe fut de comprendre la nécessité de cette répression, et d'y consacrer toutes ses ressources, toute son ardeur et tous ses talents. C'est lui qui résolument substitua, en passant de la défensive à l'offensive, une politique ferme et patriotique aux déplorables compromissions de ses prédécesseurs, et réussit en peu de temps à rendre à la France la place et l'influence qui lui étaient dues dans tout le bassin du Sénégal.

Les gens du Oualo furent les premiers rappelés au sentiment de leurs devoirs. On nomme Oualo la province au milieu 
de laquelle est située Saint-Louis. Bien que gouverné par une dynastie prétendue nationale, le Oualo n'était plus qu'une dépendance des Maures campés sur la rive droile du fleuve. Les Maures, en, effet, passaient le fleuve sous le moindre prétexte et venaient razzier les troupeaux et ravager les cultures. La tribu des Azouna s'était tellement habituée à inspirer l'effroi, qu'elle ne supposait même pas qu'on osât lui résister. Le reine du Oualo, très humble servante du principal chef des Maures, tremblait devant lui, mais avait assez de courage pour écrire à Faidherbe, dans les premiers jours de 185 , en lui intimant l'ordre d'évacuer les îles de Roup, de Diombor et de Thiouq, qui entourent Saint-Louis à une portée de canon. Il n'était que temps de punir celte insolence et de montrer aux indigènes que nous savions au besoin faire parler la poudre.

Faidherbe commença par surprendre les Maures Azouna et Tendra, qui, comptant sur l'impunité, ne prenaient même plus la précaution de surveiller leur camp. Il leur enleva un butin considérable ( 15 février $185 \%$ ). Il espérait que cette exécution suffirait pour prouver aux indigènes que nous ne voulions que les délivrer de leurs oppresseurs; mass la reine N'dèlé-Yalla, un instant étonnée, prit la fatale résolution de s'associer à ses pires ennemis, et ouvrit les hostilités en tendant une embuscade à une petite colonne française commandée par le capitaine Bilhau (20 février 1855). Faidherbe entra aussitôt en campagne. Près de quatre cenls volontaires de Saint-Louis s'étaient joints à la colonne expéditionnaire. Le 25 février, les Français rencontraient à Dioubouldou l'armée réunie des Maures et du Oualo. La bataille s'engagea aussitôt. Une charge brillante de nos spahis la décida en notre faveur. L'ennemi s'enfuit dans toutes les directions. Plusieur's d'entre eux étaient partis avec des cordes pour attacher les nombreux captifs qu'ils devaient faire. Ils revinrent, après la défaite, saisis d'effroi. "Ce ne sont pas des hommes que nous venons de combaltre, disaient-ils, mais des démons. "

La victoire de Dioubouldou eut un grand retentissement. Tous les villages nous ouvrirent leurs portes, et la reine s'enfuit à la hâte dans le Cayor. Quelques-uns des chefs les 
plus déterminés essayèrent pourtant un simulacre de résistance. Ils se réunirent à Diagan, village de l'intérieur, près de Mérinaghen, et jurèrent par le nez de leurs mères, serment le plus redoutable, de se faire tuer plutôt que d'abandonner ce dernier refuge. Il était nécessaire de les altaquer. Lne

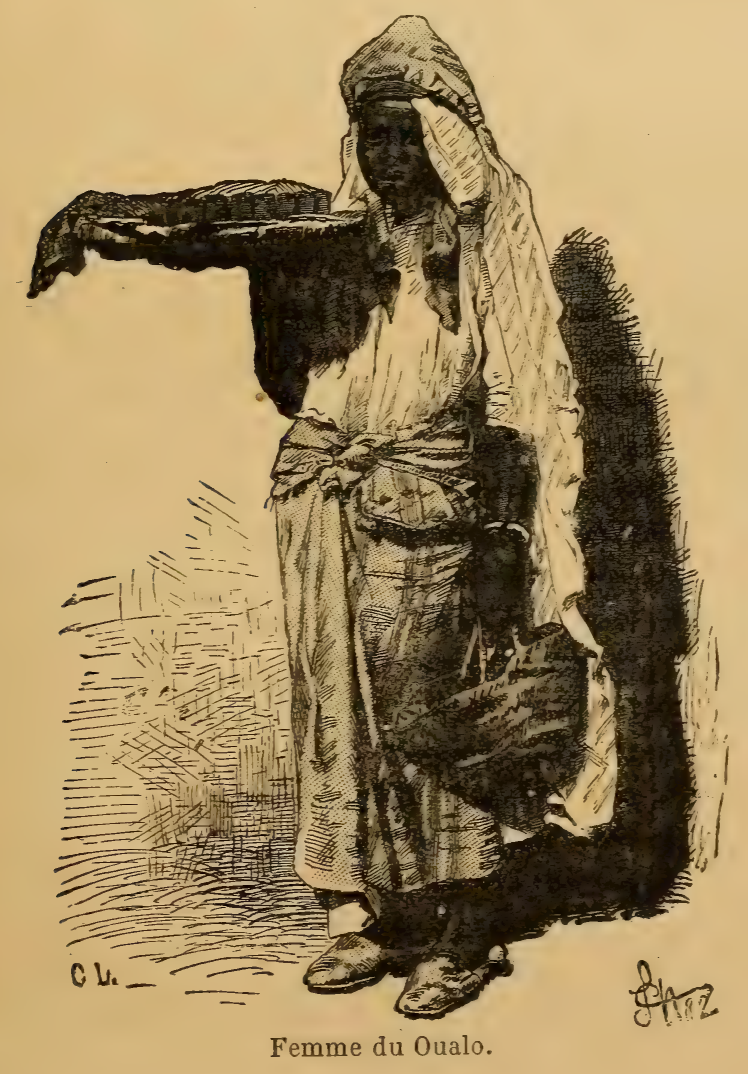

colonne fut donc envoyée à Diagan. Elle y arrivait le 18 mars $18 ว ั 3$; mais les ennemis, malgré leur serment, étaient déjà en fuite.

Le Oualo se trouvait donc conquis de fait, et les guerriers de ce pays, naguère si pleins de dédain pour les blancs, ne nous avaient opposé qu'une bien faible résistance. Aussi bien une réaction se préparait dans les esprits. A l'exception 
des diamgallo, ou captifs de la couronne, véritables bandits, habitués au pillage et à l'ivrognerie, et seuls intéressés à léfendre, avec les Maures, le gouvernement de la reine, les indigènes, diambourd, ou hoinmes libres, et badolo, ou simples particuliers, pillés indistinctement par les Maures et par les diamgallo, étaient découragés et n'aspiraient qu'à la paix. Faidherbe aurait voulu reconstituer cette malheureuse contrée, en lui donnant une administration régulière; mais les indigènes auxquels il proposa de les nommer chefs de pays déclinèrent ses offres. Perpétuer l'anarchie, abandonner le Oualo aux razzias des Maures, déconsidérer à tout jamais la France, tel aurait été l'unique résultat de ces succès répétés si Faidherbe avait repris le chemin de Saint-Louis sans régler la question du Oualo. L'annexion pure et simple s'imposait comme une nécessité. La grande masse des indigènes la réclamaient, ct c'élait en effet l'unique moyen de rétablir l'ordre et de ramener la paix dans ce malheureux pays, dévasté par des luttes séculaires. Ce fut en décembre 1855 que Faidherbe proclama l'annexion. Un décret du $1^{\text {er }}$ janvier 1856 organisa la nouvelle possession. Elle fut administrée directement par un commandant et par cinq chefs de cercle (Khouma, Ngniangué, N'der, Foss, Ross) français, sous les ordres desquels les chefs de village, tous indigènes, continuèrent à se gouverner d'après les coutumes locales. Les gens du Oualo acceplèrent volontiers notre domination. En deux ans la population doubla. Ils sont aujourd'hui très altachés à leur nouvelle patrie, et c'est surtout parmi eux que se recrutent nos tirailleurs et nos spahis sénégalais.

Nos ennemis les plus délerminés el les plus dangereux étaient les Maures, et surtout les Maures Trarzas. Tant que nous ne les aurions pas réduits au respect des traités, tant que nous ne les aurions pas refoulés sur la rive droite du Sénégal, il n'y aurait pas de sécurité pour notre colonie, et aucun des grands projets du gouvernement ne pourrait être exéculé. Ces Maures nous détestaient à la fois comme chrétiens et comme usurpateurs. Ce n'étaient pas de méprisables adversaires. Armés de fusils à pierre, en général à deux coups, qu'ils achètent à nos comptoirs, vêtus d'une culotle 
courte et d'une gandoura qu'ils relèvent au-dessus de l'épaule afin d'aveir les bras libres, tête nue, longs cheveux bouclés flottant au vent, ils ont l'air redoutable. Comme ils n'attaquent que pour enlever du butin ou des captifs, et que leur point d'honneur consiste à ne pas revenir les mains vides, s'il n'y a rien à gagner ils refusent le combat. On a prétendu qu'ils étaient lâches: ils le sont d'après nos idées, car ils ne s'exposent pas volontiers à la mort; mais, ainsi que l'écrivait un des hommes qui les a le mieux connus et qui les a souvent combattus, Faidherbe ${ }^{1}$ : " Ne faut-il pas à une bande de ces brigands un grand courage pour traverser le fleuve à la nage, par une nuit noire, malgré les croisières et les crocodiles, pour s'engager dans un pays où ils sont détestés, pour passer entre des villages populeux, se cacher pendant des jours et des nuits en pays ennemi, attaquer hardiment un village qui a quelquefois beaucoup plus de fusils qu'eux, faire des prises considérables et les ramener, malgré la poursuite des populations, à travers les forêts, les marigots, les bras du fleuve, où ils peuvent à chaque pas tomber dans des embuscades?"

A maintes reprises les Maures avaient déjà essayé de surprendre Saint-Louis. Dès 1825 ils avaient envahi le Oualo et occupé les environs immédiats de notre capitale sénégalaise. En 1830, 1837 et 1843, ils renouvelèrent leurs tentatives. Ils ne réussirent sans doule pas à enlever les postes où flotlait notre drapeau, mais ils plièrent sous leur joug les populations noires qui avaient recouru à notre protection, et commencèrent à les massacrer systématiquement, sous prélexte qu'elles n'avaient pas encore abandonné le culte de leurs faux dieux. Bientôt toute la vallée du haut Sénégal fut le théâtre de scènes odieuses. Les ambitieux et les bandits de race maure se partagèrent la contrée et la découpèrent en véritables fiefs. La France, par insouciance ou par ignorance, tolérait depuis trop longtemps ces désordres, et les Maures exploitaient notre faiblesse ou notre indifiérence pour arracher à notre domination les tribus nègres qui n'auraient pas mieux demandé qu'à vivre en bons rapports avec nous. 
Le danger devint sérieux en 18כ̌4. Le chef des Trarzas, Mohammed-el-Habib, qui depuis vingt-cinq ans était devenu le véritable et seul maître des deux rives du Sénégal, et qui d'ailleurs s'était habitué à traiter nos gouverneurs avec une insolence singulière, ne voulut pas laisser passer sans protestation la conquête du Oualo: "J'ai reçu tes conditions, écrivait-il à Faidherbe, voici les miennes : augmentation des coutumes des Trarzas, des Braknas et du Oualo; destruction. immédiate de tous les forts bâtis dáns le pays par les Français ; défense à tout bâtiment de guerre d'entrer dans le fleuve; établissement de coutumes nouvelles pour prendre de l'eau et du bois à Guètdnar et à Bop-N'kior; enfin, préalablement à tout pourparler, le gouverneur Faidherbe sera renvoyé ignominieusement en France. "La question était donc nettement posée : il s'agissait de savoir qui l'emporterait au Sénégal des Français ou des Maures. Profitant du départ de Faidherbe, qui était allé visiter notre établissement de Richard-Toll, Mohammed-cl-Habib, en avril $185 \%$, se jeta soudainement sur ses derrières, avec ses rapides cavaliers, annonçant qu'il les conduisait à Saint-Louis, et que sous peu de jours il ferait sa prière, le salam, dans la cathédrale convertie en mosquée. Déjà, en effet, les Nègres élaient hésitants. De nombreux volontaires avaient grossi les rangs des envahisseurs. Ils arrivèrent jusqu'au marigot de Leybar et se trouvèrent tout à coup arrêtés par une tour hexagonale en grosse maçonnerie, récemment construite pour défendre cet important passage. Un obusier de campagne, tirant par les fenêtres en guise d'embrasures, avait été installé à l'élage, et le rezde-chaussée était percé de huit créneaux. Le sergent d'infanterie de marine Brunier s'était jelé dans celte tour. Il n'avait sous ses ordres que onze hommes de son corps et deux canonniers, mais tous résolus à vendre chèrement leur vic. Le 21 avril 1855 s'engagea un de ces combats extraordinaires dont est remplie notre histoire coloniale, et que nous avons le tort de ne pas suffisamment connaître. De sept heures du matin à midi, Brunier et ses braves compagnons soutinrent le choc de toute l'armée maure. Les cavaliers venaient boucher les fenêtres du rez-de-chaussée, d'autres cherchaient 
à démolir la maçonnerie avec leurs poignards. Sans se laisser déconcerter par les cris furieux des ennemis, dont les pertes augmentaient la rage, sans s'inquiéter de la fumée et des étincelles qui remplissaient la tour, ils tinrent jusqu'au bout

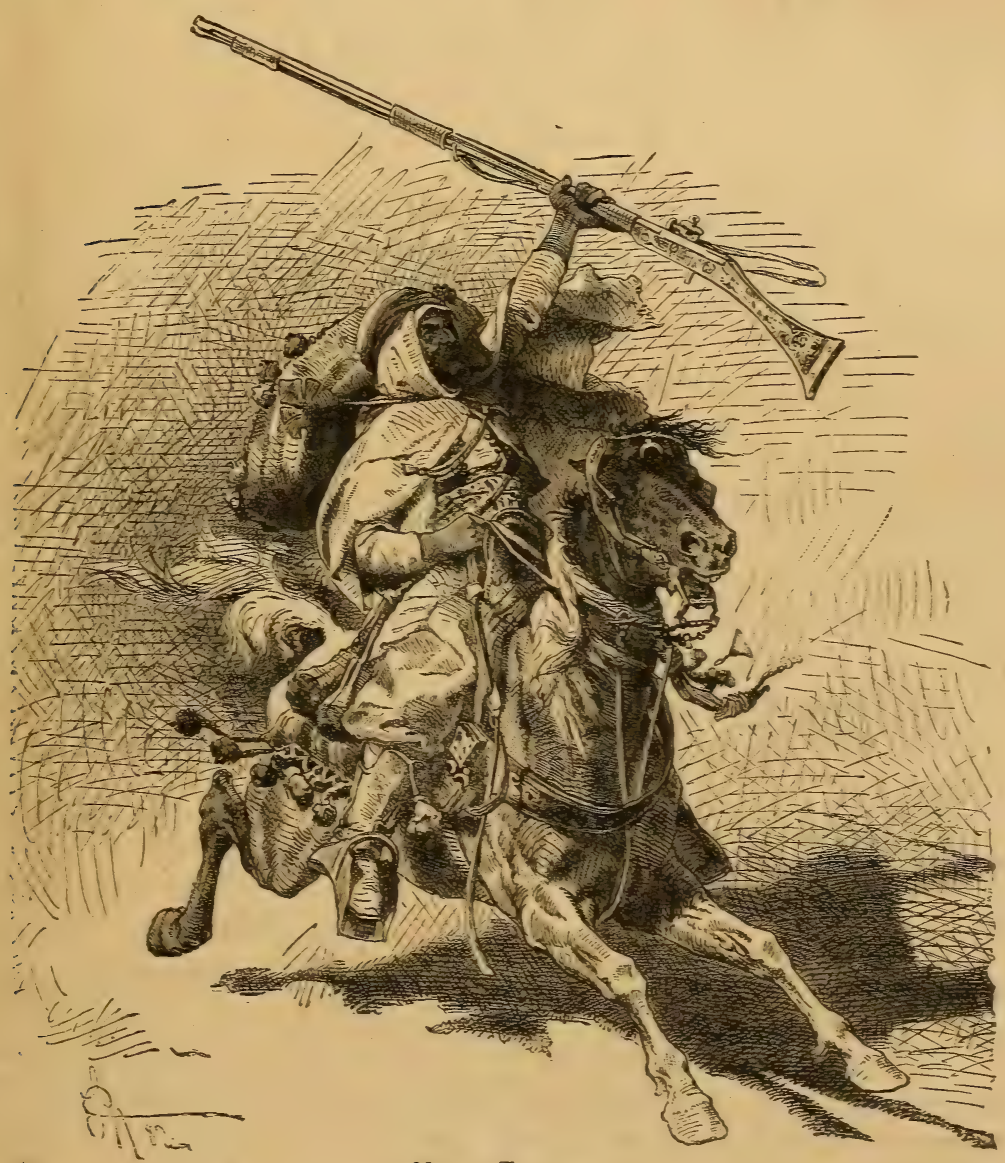

Maure Trarza.

et forcèrent Mohammed-el-Habib à battre en retraite, sous prétexte d'aller chercher des renforts. Il laissait en effet dans le Oualo son fils favori, le prince Ely, avec mission de continuer la lutte ; mais Faidherbe était accouru et avait déjà commencé une poursuite acharnée, qui se termina à l'avantage de la France. Les Maures furent obligés d'abandonner la 
province et de se retirer sur la rive droite du Sénégal (mai à décembre 185̋).

Faidherbe n'hésita pas à les suivre au delà du fleuve. Ayant reçu quelques renforls de France, il partit de Podor à la tête d'environ mille soldats européens et deux fois autant de volontaires nègres, très fiers de servir à nos côlés et heureux à la pensée de solder un long arriéré de vengeances. Nos moyens de transport faisaient défaut. Nous n'avions que six chameaux et quarante chevaux ou mulets. On devait chercher à atteindre le lac Cayar, autour duquel se rencontrent les Trarzas quand ils ne peuvent s'approcher du fleuve. Le 17 févricr au matin, on se mil en marche. Les sentiers avaient élé défoncés par des troupes d'hippopolames, au moment où le sol était détrempé par la pluie, et la colonie n'avançait qu'avec peine. On se crut un instant égaré dans le désert, car les guides ne reconnaissaient plus leur chemin; et comme nos hommes avaient soif et que quelques-uns d'entre eux ne pouvaient déjà plus avancer, la situation devenait critique. Par bonheur, nos cavaliers trouvèrent un marigot d'eau douce, qui les conduisit bientôt au lac Cayar (19 février). Les Maures n'avaient nulle part essayé de résister. L'expédition du lac Cayar n’avait donc été qu'une promenade militaire, mais dont l'effet moral fut considérable. Nos ennemis se découragèrent en royant qu'ils ne se trouvaient plus à l'abri dans leurs retraites jadis inexpugnables, et les Nègres, qui se sentaient protégés, s'habiluèrent à la pensée de revendiquer leurs anciens domaines et de se soustraire à une tyrannie et à des outrages quotidiens.

Les Nègres se crurent même trop vite assez forts pour entrer en campagne sans le concours de la France contre leurs oppresseurs séculaires. Un de nos alliés du Oualo, FaraPenda, voulut aller attaquer une tribu de Trarzas, les Mradins," au nord du lac Cayar. Mohammed-el-Habib le laissa s'aventurer au delà du Sénégal, le battit sans peine, repassa le fleuve à sa poursuite et se vengea de son humiliation de Leybar en mettant le Oualo à feu et à sang. Les prisonniers furent impitoyablement massacrés. Les Maures s'amusèrent à en couper quelques-uns par morceaux dans leurs festins (avril 185̆7). 
Faidherbe ne voulut pàs rester sous le coup de cet échec indirect. Il courut au secours des alliés de la France, franchit à son tour le Sénégal et, le 13 mai 185̆7, grâce à l'impétuosité de nos soldats, remporta une victoire décisive près du marigot de Télkélé. Pour mieux marquer sa supériorité, il fit opérer à petites journées la reconnaissance du lac Cayar, qui passait pour inaccessible à tout autre peuple qu'aux Maures. Ceux-ci n'essayèrent même pas de troubler l'opération. Elle fut conduite avec tant de prudence que le chef du génie, Fulcrand, put lever la carte de la région et que l'armée rentra à SaintLouis sans être inquiétée. A vrai dire, elle n'avait souffert que de la chaleur. Le jour de la bataille de Tékélé, le thermomètre s'était maintenu, jusqu'à six heures du soir, à cinquante-sept degrés centigrades.

Mohammed-el-Habib, baltu, mais non découragé, opérait au même moment une diversion très hardie. Il traversait le fleuve à Mékinack, razziait le village de Gandou, et semait l'épouvante dans tout le Oualo; mais il fut arrêlé, comme il l'avait été naguère à Leybar, devant le blockhaus à demi ruiné de N'der. Il n'était défendu que par le caporal blanc Valette, un soldat blanc et sept soldats nègres. Ces braves essayèrent à deux reprises de se servir de leur espingole; mais deux fois tous les madriers d'une des faces du blockhaus leur tombèrent sur le dos. Ils le reconstruisirent sous le feu de l'ennemi, et finirent par le mettre en fuite, après avoir tué les plus audacieux des assaillants (25 mai 1857). Les Français les poursuivirent à outrance, finirent par les atteindre à Langobé, près de Dialmath, et les exterminèrent (31 mai).

Le roi des Trarzas, découragé celte fois, comprenant que la fureur de ses sujets se briserait toujours contre la discipline française, se décida à s'avouer vaincu. Des négociations furent entamées. Elles aboutirent promptement à un traité par lequcl il s'interdisait à lui et aux siens de passer en armes sur la rive gauche du Sénégal, renonçait aux coutumes, remplacées par un droit fixe perçu par des agents français, et donnait toute liberté au commerce de la gomme ${ }^{1}$ (20 mai 1858).

1. Ce traité est inséré daus les Annales sénćgalaises, p. 398. 
Ce traité fut loyalement exécuté par le chef des Trarzas. Ses sujels, dont les intérêts se trouvaient lésés, surtout par la suppression des coulumes, ne lui pardonnèrent pas ce qu'ils appelaient sa trahison. Un complot se forma. Le 15 septembre 1860 notre ancien adversaire était assassiné. Son fils le prince Sidi se trouvait alors dans le Oualo. Aussitôt prévenu, il accourait, surprenait el immolait neuf des assassins, ct prenait le commandement. Il le garda jusqu'en 1871, époque à laquelle il fut assassiné à son tour : il n'avait pas un instant cessé d'exécuter la convention de 18ว8. Son successeur fut un autre fils de Mohammed-el-Habib, le prince Ely. Bien que Nègre par sa mère, la princesse Guimbotte du Oualo, et par conséquent méprisé par les Maures, très fiers de la pureté de leur race, Ely était néanmoins reconnu comme chef légitime par la majorłté des Trarzas. Il s'empressait de faire parvenir à Faidherbe l'assurance de ses sentiments d'amilié pour la France, et, en effet, il est toujours resté fidèle aux clauses du traité de $1858^{1}$. Il a constamment reçu avec honneur nos envoyés, il a protégé nos négociants, il a tenu, en un mot, à prouver qu'il était devenu notre allié sincère et dévoué. En 1879, notre héroïque explorateur Soleillet était admirablement accueilli par lui, lors de son voyage à l'Adrar. Ely le chargeait de tous ses compliments pour notre gouverneur, et il se considérait, disait-il, comme l'enfant de la France. "Tu rois que je suis un véritable chef français, lui disait-il encore au moment des adieux. Je ferai ce que voudront les Français, et je pense que vous ne m'abandonneriez pas si j'avais besoin de vous. - Je ne suis qu'un simple taleb, répondit Soleillet, je ne m'occupe pas de politique; mais je dirai partout combien ton accueil a été cordial. ")

Les Maures Braknas étaient, de même que les Trarzas, tout disposés à continuer, aux dépens de nos alliés et de nos nalionaux de la rive gauche du Séné gal, leur fructueuses razzias. La politique ferme et prudente du gouverneur préserva la colonie de ce nouveau danger. Profitant habilement de la rivalité de deux princes qui se partageaient le pouvoir, Moham-

1. Cf. traité du 24 août 1877 conclu avec Ely, confirmant le traité précédent, et acte addilionnel du 2 avril 1879. 
med-el-Sidi et Sidi-Eli, Faidherbe leur vendit sa neutralité en leur faisant signer à tous deux un traité analogue à celui que venait de signer Mohammed-el-Habib ${ }^{1}$ (10 juin 1858). Six mois plus tard, lorsque Sidi-Eli eut tué son rival, Faidherbe le somma d'exécuter le traité. Ce dernier ne fit aucune résistance, et c'est ainsi que non seulement la sécurilé fut assurée sur la rive droite du fleuve, mais que le Oualo fut délivré, et

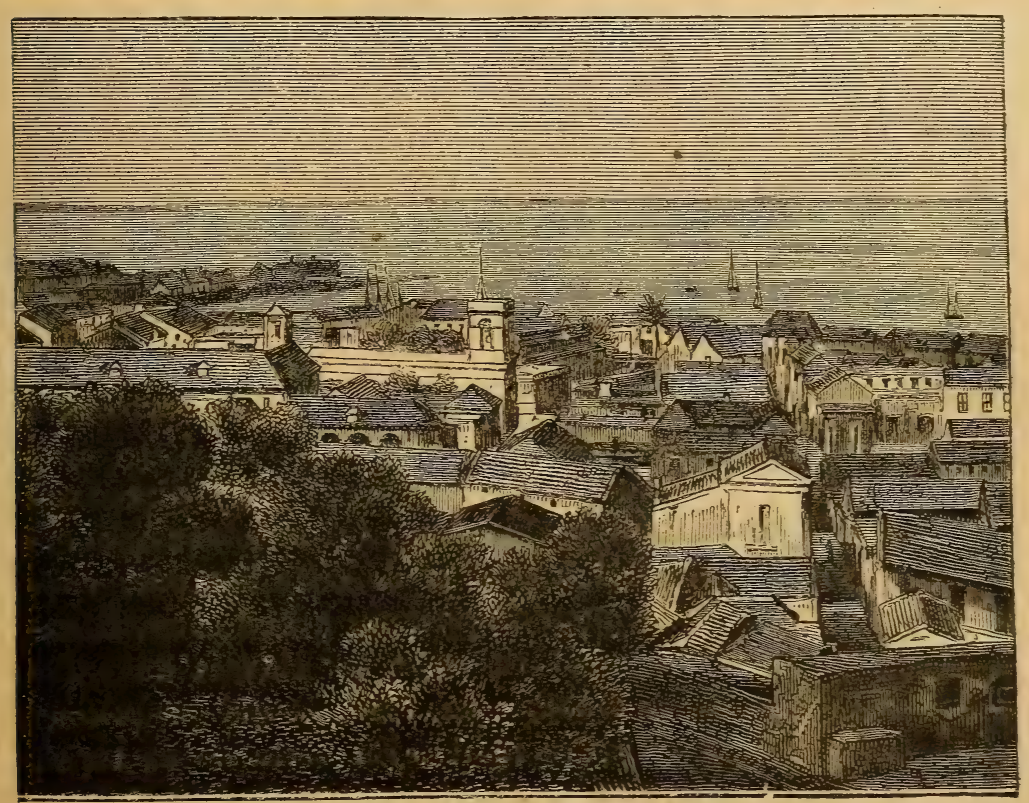

Gorée.

que la France, désormais rassurée contre les incursions des Maures, put tourner son activité d'un autre côté.

Le refoulement des Maures sur la rive droite du Sénégal et l'annexion du Oualo avaient complètement dégagé notre capitale Saint-Louis, mais Gorée, notre autre possession, restait toujours exposée aux altaques de ses voisins, les petils rois de Baol, du Sine, du Saloum. Refaire à Gorée ce qui avait si bien réussi à Saint-Louis, c'est-à-dire renoncer à la défensive, et non seulement soumettre ou réduire les voisins,

1. Le traité est inséré dans les Annales sénégalaises, p. 403. - Cf. acte additionnel du 5 juin $15 \pi 9$ (id., p. 404 ). 
mais encore augmenter le territoire direct de la France, telle était la politique qui s'imposait. Faidherbe l'adopta résolument. Il eut le mérite, trop rare pour ne pas être signalé, de persévérer, et la chance de réussir.

Notre situation aux alentours immédiats de Gorée était piteuse. Les roitelets du voisinage ne se contentaient pas d'humilier et de piller nos négociants, ils insultaient le drapeau de la France. N'avaient-ils pas eu l'audace de nous défendre d'élever des constructions en pierres! C'était assez dire que notre occupation n'avait qu'un caractère provisoire, et que nous n'étions que tolérés. Le fitor ou percepteur du roi de Sine se signalait par son audace. Il s'était introduit par force dans l'humble demeure de nos missionnaires à Joal, et l'avait mise au pillage. A Rufisque, presque sous le canon de Gorée, un négociant français, M. Albert, et son serviteur Tamba avaient été assassinés, le 7 déccmbre 1858, et, malgré nos réclamations, ce crime, dont on connaissait pourtant les auteurs, était resté impuni ${ }^{1}$.

Faidherbe venait d'obtenir que Gorée, qui jusqu'alors avait formé un gouvernement indépendant, fùt mise sous ses ordres. Il chercha aussitôt à profiter de celte heureuse concentration de pouvoirs pour frapper un grand coup. Il annonça donc qu'il entendait exécuter les clauses du traité signé par le capitaine Ducasse en 1679 , et qui jusqu'alors était resté à l'élat de lettre morte. En vertu de ce trailé, la côte depuis Dakar jusqu'à l'embouchure du Saloum, sur une profondeur de six licues, devait áppartenir à la France. Comme en Afrique, et avec les souverains nègres, de pareilles revendications ne sont sérieuses que soutenues par les armes, Faidherbe se disposa en même temps à appuyer par une vigoureuse démonstration les droits oubliés, mais persistants, de la France. Le 3 mai 1859 il quittait SaintLouis, ralliait en passant les volontaires de Gorée et débarquait à Dakar, dont il prononçait l'annexion (7 mai).

Rufisque et Joal étaient également annexés, et le 14 mai une messe solennelle était célébrée dans la chapelle calho-

1. X., Expédition du Sine et du Saloum en 1850 (Tour du monde, 1861). MAGe, les Royaumes de Sine et de Saloum (Revue maritime et coloniale, 1863.) 
lique, naguère insultée. Partout les indigènes se pressaient autour de nos soldats, et pas une protestation ne s'élevait contre cette prise de possession.

Le 14 mai, au moment où l'on célébrait à Joal la messe d'action de grâces, nos patrouilles tombaient, tout à fait par hasard, sur des cavaliers indigènes qui escortaient le successeur du roi de Sine, jeune prince qui venait de commettre un meurtre, et, suivant la coutume, se rendait à la mer pour s'y baigner en expiation. Un combat s'engagea, et nos soldats donnèrent rendez-vous à leurs ennemis dans la capitale du Sine, à Fatiko. Faidherbe se crut lié par la parole de ses officiers, et l'armée se mit en marche contre Fatiko. L'entreprise élait difficile. Nous n'avions que deux cent soixante-quinze Français et trois cent vingt-cinq volontaires. Comme artillerie, nous n'emportions qu'un obusier mál monté, dont l'affùt devait se briser à la troisième décharge. De plus, nous nous engagions par une chaleur torride, dans un pays à peu près inconnu, contre des ennemis dont nous ignorions jusqu'au nombre, et qui défendaient leur patrie. C'était une grosse partie que jouait Faidherbe, mais il était résolu à tout risquer.

Surpris dans la forêt de Fatiko par les cavaliers ennemis, les Français furent d'abord repoussés. Déjà les volontaires nègres avaient pris la fuite, et le roi du Sine se croyait assuré de la victoire. Mais Faidherbe avait gardé autour de lui, comme réserve suprême, trente-cinq soldats de l'infanterie de marine. Lancés à propos, ces braves eurent en un instant rélabli le combat. Les cavaliers du Sine, malgré leur bravoure et leur altaque trois fois renouvelée, durent fuir à leur tour. Ils n'avaient réussi à blesser que cinq de nos hommes, et pourtant la fusillade avait duré plus d'une heure, à petite portée; mais ces cavaliers tiraient au hasard des fusils de six pieds de long, qu'il chargeaient de douze à quinze chevrotines, selon le degré de fureur qu'ils éprouvaient, tandis que tous les coups de nos soldats portaient dans la masse de leurs adversaires.

La victoire de Fatiko nous ouvrait le chemin de la capitale. Faidherbe, afin de frapper l'imagination des indigènes, 
ordonna de la détruire. Les huttes de paille qui la composaient en grande partie devinrent la proie des flammes, et c'est à la lueur de cet incendie que la colonne expéditionnaire reprit la direction de Dakar.

Quelques jours plus tard le roi de Saloum, Samba-Laobé, était également baltu, et le forl de Kaolack construit sur son territoire, afin de prévenir un retour offensif de sa part.

Aussi bien, ces princes, effrayés par la rapidité de nos succès, ne cherchaient qu'à détourner notre colère. Les rois du Sine, Boukarkilas, et de Saloum, et bientôt celui de Baol, Tié-Yacim, s'empressèrent d'accepter nos conditions de paix ${ }^{1}$. Non seulement ils nous cédaient tout le territoire compris entre le cap Vert et la pointe Songomar, c'est-à-dire consentaient à l'exécution du traité Ducasse, mais encore ils acceptaient notre protectorat et promettaient de renoncer à toute vexation contre nos compatriotes, nos sujets et nos alliés. C'était un grand succès, rapidement obtenu, et qui consolidait notre prise de possession d'un territoire important autour de Gorée.

Il est vrai que, dès 1861 , deux de ces souverains, les rois de Saloum et du Sine, reprenaient une attitude hostile; mais le chef de bataillon Pinet-Laprade marchait immédiatement contre le premier de ces souverains, remontait le Saloum, s'emparait de sa capitale Kahoné ${ }^{2}$ et lui imposait, avec une forle rançon, la stricle exécution du traité de 1899. Se retournạnt aussitôt contre le roi du Sine, il entrait dans sa nouvelle capitale Diakao, et lui imposait les mêmes conditions. Ces souverains indigènes se trouvaient dès lors matés, et la France n'avait plus à redouter de leur part aucune tentative de rébellion.

Saint-Louis et Gorée n'avaient plus rien à craindre. Autour de ces deux capitales, directement protégées par des territoires annexés à la métropole et administrés par nos fonctionnaires et nos officiers, l'influence française pouvait en quelque sorte rayonner et s'étendre au loin. C'était un premier et un incon-

1. Ces traités ont été insérés dans les Annales sénégalaises, p. 406.

2. Traité du 8 mars 1861. - Il a été confirmé expressément par un nouveau traité, le 13 septembre 1877. 
testable succès. Faidherbe trouva avec raison qu'après avoir assuré l'indépendance el augmenté l'importance des deux capitales sénégalaises, il fallait autant que possible les rapprocher, soit en créant entre les deux villes une chaîne non interrompue de postes français, soit en annexant, ou tout au moins en réduisant à l'obéissance le pays intermédiaire. Or les cent cinquante kilomètres qui séparent Saint-Louis de Gorée sont compris dans la province indigène de Cayor, dont le souverain ou damel était notre ennemi déclaré. Forcer le damel à accepter nos conditions, ou conquérir le Cayor, tel était le programme à exécuter.

C'est un pays fort étrange que le Cayor. On dirait une prinpauté féodale de l'Europe au moyen âge. Gouverné par un souverain absolu, mais dont l'avènement ${ }^{1} \mathrm{au}$ trône est souvent marqué par de sanglantes révolutions; opprimé par une aristocratie remuante, les tiédos ${ }^{2}$, ennemis de tout travail autre que la guerre; habité par des populations féroces et fanatisées, le Cayor, par sa position géographique entre nos deux métropoles sénégalaises, pouvait devenir un voisin dangereux. C'était en outre un pays inconnu. Il n'est arrosé que par des lacs et des marais, et couvert de forêts que l'exubérante végétation des tropiques rend à peu près impénétrables. Aussi, à travers ces fourrés épais où manquaient l'eau et les vivres, dans ce labyrinthe inextricable où il était si facile de tendre des embuscades, la lutte, si on l'engageait, pouvait se prolonger indéfiniment. Faidherbe ne reculait pas devant celte extrémité, mais il aurait préféré les voies pacifiques. Il aurail voulu jeter à travers le Cayor une voie télégraphique, défendue par des postes fortifiés. C'était à son avis le meilleur moyen d'assurer les communications entre Saint-Louis et Gorée, et en même temps de protéger les rares Français qui s'aventuraient dans cette province inhospitalière.

1. Général Faidherbé, Notice historique sur le Cayor (Société de géographie de Paris); 1883.

2. Le souverain ou damel est toujours choisi dans une famille ayant la prérogative royale, et les électeurs, qui ne peurent briguer pour eux-mêmes le pouvoir, ne sont qu'au nombre de quatre. Quand il est nommé, le damel reçoit, comme symbole de ses pouvoirs, un vase dans lequel se trouvent des graines de toutes les plantes cayoriennes, et il ne peut prendre possession du trône qu'après une retraite de huit jours dans un bois sacré. 
Il s'adressa donc au damel régnant, un jeune homme de vingtcinq ans nommé Biraïma, et lui demanda l'aulorisation de construire la ligne télégraphique à travers son territoire (1859).

La réputation de Faidherbe était déjà fortement établie dans le Cayor. En 1858, ayant eu à se plaindre des habitants du N'diambour, province du Cayor voisine de Saint-Louis, il n'avait pas hésité à les attaquer. Une marche rapide l'avait conduit aux puits de Ngirick, où il avait remporté un premier succès. Une vraie bataille s'était engagée en avant de Niomré, la capitale de la province, et, malgré la résistance désespérée des indigènes, nous avions remporté une victoire complète. Le roi de Cayor avait aussitôt écrit à Faidherbe pour le féliciter. Ce n'était pas tant notre victoire qui l'avait épouvanté que la rapidité avec laquelle avaient été conduites les opérations. Faidherbe avait en effet imaginé, pour la circonstance, d'organiser un convoi de chameaux pour le transport des bagages, et ces animaux avaient rendu de grands services. Aussi Biraïma, tremblant déjà pour sa propre sécurité, avait-il pris les devants et accablé de protestations le Français vainqueur. Il s'empressa de satisfaire toutes ses demandes et lui accorda aussitôt l'autorisation sollicitée pour l'établissement de la ligne télégraphique.

Les tiédos de Biraïma avaient éprouvé les mêmes craintes que leur damel; mais, couvrant leur pusillanimité sous le spécieux prétexte du patriotisme, ils feignirent d'éprouver une vive irritation de la prétendue trahison de leur maître, et l'assassinèrent.

Macodou, le nouveau damel, retira aussitôt l'autorisation accordée par son prédécesseur. Ce refus équivalait à une déclaration de guerre. Faidherbe marcha immédiatement contre lui, le battít en diverses rencontres (janvier 1861), et lui imposa un traité onéreux ${ }^{1}$, en vertu duquel, moyennant trois chevaux et dix mille francs, le damel cédait à la France tout le littoral sur une profondeur de dix kilomètres, et renonçait à ses prétentions sur la province de Diander. A peine nos troupes étaient-elles rentrées à Saint-Louis que Macodou 
dénonçait le traité et reprenait la campagne. Le gouverneur, très irrité d'avoir été joué par ce tyranneau africain, envahit de nouveau le Cayor et, le 11 mars 1861, remporta la grande victoire de Diati, à la suite de laquelle Macodou se voyait forcé non seulement de ratifier à nouveau la première convention, mais de consentir à la création sur son territoire des postes fortifiés de Lompoul, Mboro, Mbidgen, Gandiole, Potou, Pont et Thiès.

Le Cayor était donc entamé par la France, et tout semblait annoncer notre prochaine domination, car cette malheureuse province se trouvait en pleine décomposition. Damels se disputant le pouvoir, tiédos acharnés dans leurs querelles intestines, populations horriblement foulées et n'attendant pour se déclarer que l'apparition du drapeau tricolore, nous n'avions pour ainsi dire qu'à laisser faire et qu'à fermer la main au moment favorable. Notre tort fut peut-être de prendre trop au sérieux les prétentions des damels opposés, et de ne pas déclarer assez netlement nos intentions futures. Il semble que nous ayons voulu ménager les susceptibilités nationales en ne procédant que lentement à une annexion qu'il eût été si facile de proclamer dès les premiers moments de notre intervention. Nous eûmes également le tort de nous insinuer dans les querelles intestines des damels, et le tort plus grave encore, une fois que nous eûmes adopté une ligne de conduite, de ne pas y persévérer, et de passer sans raison d'un allié à l'autre. De là de brusques ressauts, de là des contradictions et des reculs inexplicables, de là des fautes qui compliquèrent à plaisir la question du Cayor et retardèrent pour de longues années l'annexion de cette province.

Un certain Madiodio s'était prononcé contre Macodou, et ses partisans l'avaient proclamé damel (mai 1861). Faidherbe se déclara en sa faveur, espérant que le protégé de la France resterait fidèle à ses engagements; mais il avait compté sans un parent du damel dépossédé, Lat-Dior, jeune homme de dix-huit ans, élevé à Saint-Louis à l'École des otages, qui provoqua un soulèvement national, renversa Madiodio, et le força à se retirer à Lampoul, sous la protection directe de nos soldats. 
Le capitaine Jauréguiberry arriva aussitôt dans le Cayor (janvier 1862) ${ }^{1}$ et rétablit Madiodio; mais il commit la faute de ne pas traiter Lat-Dior en ennemi, et se prêta à des pourparlers compromettants. Lat-Dior cut bientôt reconquis unc situation prépondérante, et, pour couper court à de nouvelles révolutions, Faidherbe se vit obligé, en novembre 1862, de rentrer dans le Cayor et d'y proclamer solennellement Madiodio comme damel. Il est vrai qu'il se paya de ses services en arrachant au malencontreux souverain le traité du 4 décembre 1863, par lequel les quatre provinces de Ndiambour, Mbaouar, Andal et Saniakor étaient détachées du Cayor et annexées à la France.

Lat-Dior protesta contre cette cession, et devint du jour au lendemain le héros de la résistance nationale. Les plus aguerris d'entre les tiédos le rejoignirent, et tous ceux des indigènes qui croyaient encore à la possibilité de défendre leur autonomie contre la France se groupèrent autour de lui.

Lat-Dior commença aussitôt contre nos soldats une guerre de surprises et d'embuscades où il n'avait pas toujours le dessous, et qui risquait, en se prolongeant, de devenir dangereuse. Faidherbe résolut d'en finir avec cet insaisissable adversaire. Un de ses plus brillants officiers, le capitaine Lorans, fut chargé de la poursuite; mais il commit la faute de ne pas attendre les renforts annoncés, et entra en campagne seulement avec cent quarante soldats réguliers et les volontaires de Madiodio. Lat-Dior avait réuni des forces supérieures. Il surprit notre petite armée le 30 décembre 1862, à Ngolgol, et bientôt " tout le monde comprit qu'il n'y avait plus qu'à mourir dignement. Le capitaine Lorans et le capitaine de tirailleurs Chevrel, démontés tous les deux, et ce dernier blessé, assistèrent stoïquement, jusqu'à ce qu'ils fussent tués eux-mêmes, à la destruction de leurs hommes, tirailleurs et ouvriers, qui combattirent jusqu'au dernier soupir. Les sept canonniers et l'adjudant Guichard se firent hacher sur leurs pièces. "Vingt-neuf hommes, dont trois officiers, échappèrent seuls à la mort. 
La défaite de Ngolgol eut un retentissement extraordinaire au delà même du Cayor. Du jour au lendemain Lat-Dior se trouva le chef incontesté de toute la région, et tous les mécontenls se groupèrent autour de luı. Il eut bientôt rassemblé une armée considérable, et vint nous provoquer jusque sur notre territoire.

Le colonel Pinet-Laprade fut chargé par Faidherbe de rabattre son orgueil. Les troupes se concentrèrent sous ses ordres, et, le 12 janvier 1864 , une bataille décisive s'engagea à Loro. Lat-Dior n'avait pas oublié les leçons qu'il avait reçues à Saint-Louis. Il avait pris d'assez bonnes dispositions. "Les fantassins étaient à couvert derrière une haie d'euphorbes qui couronnait les bords les plus avancés d'un plateau au centre duquel se tenait Lat-Dior avec une forte réscrve, de telle sorte que le vallon que nous avions à franchir ćtait admirablement battu par la mousqueterie de l'ennemi ; sur les ailes de cette position se tenait une nombreuse cavalerie ${ }^{1}$. " Mais notre artillerie décida la victoire. Près de cinq cents cadavres jonchaient le champ de bataille. La poursuite fut poussée jusqu'à quatre lieues. L'horizon était embrasé par les incendies allumés dans tous les villages. La colonne victorieuse alla rendre les derniers devoirs aux victimes de Ngolgol et rentra à Saint-Louis, laissant le Cayor pacifié et notre protégé Madiodio seul maître du pays.

Mieux aurait valu profiter de l'ascendant que nous donnait la victoire de Loro pour prononcer purement et simplement l'annexion du Cayor. On avait conseillé au gouverneur cet acte de vigueur. Il ne se crut pas assez fort pour l'exécuter, et rendit à notre prolégé Madiodio son trône et son territoire. Aussi bien, il ne tarda pas à reconnaîlre sa faute, car Madiodio, par sa mauvaise administration, provoqua un soulèvement général. Devenu gouverneur, Pinet-Laprade le déposa et, celte fois, prononça l'annexion de Cayor (1866). Cette annexion, nous le verrons plus tard, ne devait pas être définitive. Ce n'en était pas moins un acte de politique ferme et intelligente. Saint-Louis et Gorée se trouvaient maintenant

1. Annales sénégalaises, p. 313. 
réunies non plus par une ligne de postes fortifiés, mais par un territoire directement soumis. Nous n'avions plus en Afrique seulement deux comptoirs isolés, mais plusieurs provinces unies et soudées les unes aux autres, dont les habitants avaient accepté facilement notre domination. L'Afrique occidentale française était fondée. Il ne lui restait plus qu'à grandir, qu'à se développer, et ces beaux résultats, si rapidement obtenus, élaient dus à l'administration habile et à la politique raisonnée de l'éminent gouverneur de SaintLouis.

A cette domination naissante manquait encore le prestige d'une grande victoire, dont la renommée dépasserait les limites du Sénégal et rendrait populaires en France les exploits de nos troupes sénégalaises. Cette victoire, nous allions la remporter contre le fondateur d'un empire africain, auquel ne manquaient ni les talents ni même le génie, et dont les descendants possèdent encore sur les rives du Niger d'importantes possessions. Pour comprendre cette lutte décisive, il est nécessaire de revenir en arrière, et d'appeler l'attention sur des événements presque contemporains, qu'on a peut-être oubliés, mais dont les conséquences durent encore.

\section{VII}

GUERRE GONTRE LE PROPHETE AL-HADJI-OMAR

ET SES SUCGESSEURS

Depuis que Mahomet a déclaré que le plus saint des devoirs était d'exterminer les infidèles, les croyants de l'Islam n'ont pas cessé de lutter contre les chrétiens. Entre les deux religions toute conciliation semble impossible. Depuis le jour où se sont rencontrés et heurtés pour la première fois disciples du Christ et sectateurs du Prophète, et quel que soit l'endroit où ils se sont rencontrés, aux rives du Jourdain ou à colles du Chéliff, dans les plaines du Danube ou sur les sierras espagnoles, une lutte inexpiable s'est engagée entre 
les deux croyances. On n'ignore pas, d'un autre côté, qu'à l'heure actuelle s'opère dans le mahométisme une sorte de renouveau. Il y a, en quelque sorte, recrudescence de vitalité. Il semble que la foi des croyants se ranime et que leur ardeur se réveille. C'est en Afrique surtout, et depuis un demi-siècle environ, que ces progrès du mahométisme sont vraiment extraordinaires. Les Africains se convertissent on masse. De proche en proche, des missionnaires, qu'on croit sortis de

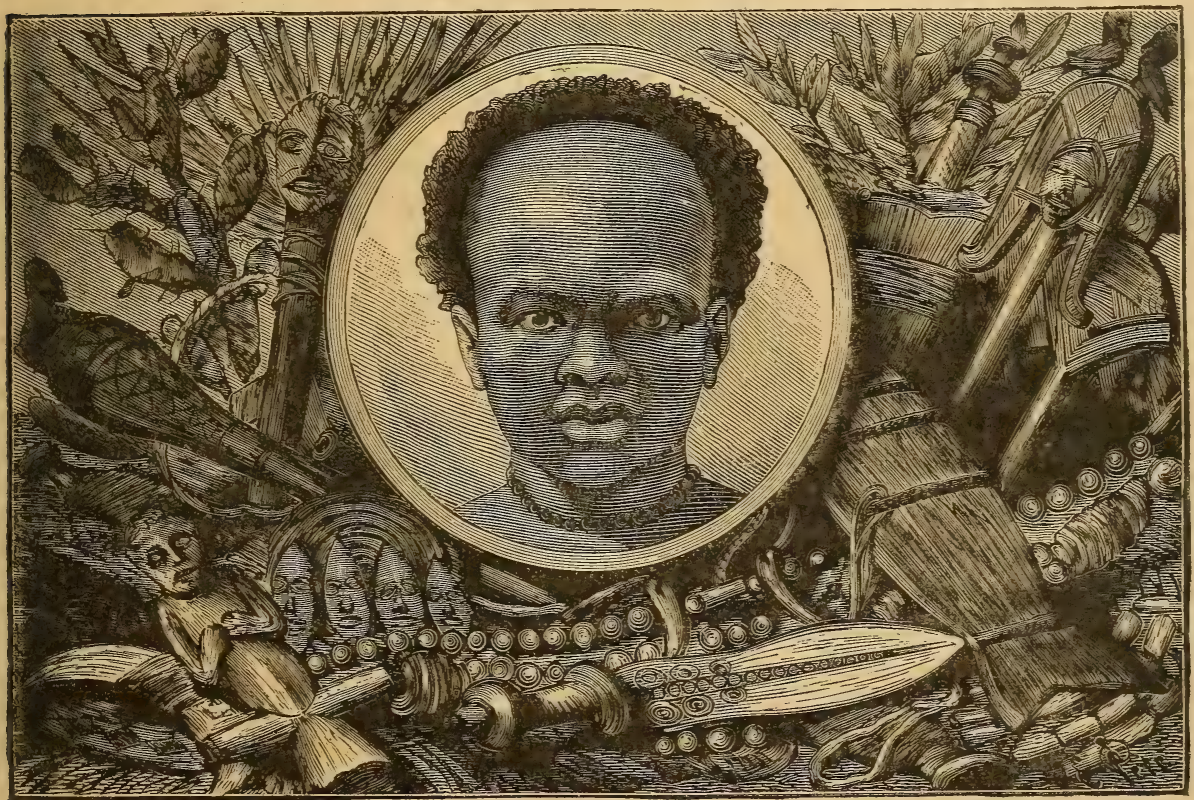

Indigène du haut fleuve.

Bokkara ou de Samarcand, répandent en Afrique la parole nouvelle. Leur éloquence, l'austérité de leur vie, la conformité de leurs préceptes avec les instincts et les nécessités des races africaines, produisent sur ces peuples enfants la plus vive impression. De proche en proche, les missionnaires musulmans font des prosélytes. Ils sont déjà parvenus à l'Atlantique. Les tribus sénégalaises ont été entamées. Elles ont rompu avec leur grossier fétichisme, et embrassé, avec toute l'ardeur qui caractérise les néophytes, la religion nouvelle. Dès ce moment les Français ne furent plus à leurs yeux seu- 
lement des étrangers, mais plus encore des chiens de chrétiens, des lieffirs, qu'il fallait exterminer ou jeter à la mer.

Un Sénégalais, un certain Omar, né vers 1797 à Aloar, près de Podor, dans le Fouta-Toro, résolut d'exploiter ces haines religieuses, et de fonder, à l'aide des fanatiques qu'il recruterait, une vaste principauté dont il se proclamerait le chef. Omar appartenait à la caste torodo, qui seule jouit du privilège de donner des almamys au Fouta; mais c'était moins sur sa naissance qu'il complait que sur une prétendue mission divine dont il se disait investi. De bonne heure il s'était signalé par sa dévotion et son intelligence. On raconte qu'un vieux marabout, ayant interrogé Omar, fut émerveillé de ses réponses et dit aux assistants : "Regardez bien cet enfant: ce sera notre maître à tous. "Bientôt se groupèrent autour de lui un certain nombre de talibés ou élèves, qui ne tardèrent pas à lui attribuer des pouvoirs surnaturels. Ne racontaientils pas gravement qu'Omar n'était soumis à aucune des nécessités de la vie, qu'il était indifférent à la fatigue, qu'il pouvait rester indéfiniment sans manger ni boire? Aussi sa réputation de sainteté était-elle si bien établie, qu'en 1823 il n'eut qu'à se présenter à Saint-Louis pour obtenir des fervents musulmans de la cité française les fonds nécessaires pour exécuter le lointain voyage de la Mecque. Omar partit donc pour les sanctuaires de l'Islam; mais il préparait déjà son retour, car il avait partout fait répandre le bruit que Jésus devait s'incarner de nouveau, et cette fois sous les traits d'un ncir. En effet, une sorte de légende se forma bientôt; et lorsque Omar reparut au Sénégal, quelques années plus tard, ses partisans annonçaient hautement qu'il était le réformateur annoncé et qu'il n'y avait plus qu'à lui obéir.

A son retour de la Mecque, dont il rapportait le titre vénéré d'Al-Hadji, le pèlerin, Omar avait d'abord séjourné dans le Bornou et le Haoussa. Bien vu par les souverains, respecté par le peuple, il avait établi un fructueux commerce d'amulettes et de reliques, et rapidement acquis une grande fortune. Il s'imagina trop vite que le moment était venu de réaliser ses projets ambitieux, et prêcha ouvertement la réforme dans la vallée du Niger, et spécialement à Ségou. 
Or les Bambaras de Ségou, tous fétichistes, n’éprouvaient que de la répulsion pour l'Islam. Omar fut arrêté comme perturbateur et retenu en prison. Il réussit à s'échapper et chercha un refuge dans le Fouta-Djallon. Banboura fut sa première station. C'est là qu'il prêcha le retour aux principes rigoureux de l'Islam, l'abolition des grisgris et la révolte contre l'oppression des familles féodales. Il eut bientôt réuni autour de lui de nouveaux fidèles, qui se rappelèrent très à propos que l'incarnation de Jésus dans un marabout nègre avait été annoncée, et, bien que le prophète ne les y eût pas autorisés, laissèrent entendre qu'Omar n'était autre que Jésus revenu sur la terre pour la glorification de la race nègre. Le prophète ne négligeait pas pour autant ses intérêts temporels. Il faisait un grand et fructueux commerce, amassait de la poudre, des armes, et entassait des approvisionnements dans Banboura, où il construisait une redoutable citadelle.

Ce fut en 1846 qu'il se décida à dévoiler ses projets ambitieux et à tourner vers le nord et vers l'ouest sa dévorante activité. Après s'être assuré du concours de nombreux talibés, et de tous ses compatriotes, les braves et féroces Toucouleurs, il se mit en campagne, prêchant la guerre sainte contre les infidèles. Il commença par s'assurer la possession de la forte place de Dinguiray, ville frontière du FoutaDjallon, d'où il pourrait surveiller à la fois la vallée du Niger et celles de la Gambie et du Sénégal; puis il vint mettre le siège devant Tamba, la capitale du Djallon-Kadougou. Le chef de Tamba était un barbare, qui passait pour invincible. Voyait-il des vautours planer : "Il ne faut pas, disait-il, que les vautours de mon père manquent de nourriture. " Et il faisait aussitôt dépecer par le bourreau un de ses captifs. Ce tyran s'honora par une résistance de six mois. Tamba fut enfin emporté, le butin partagé et les prisonniers massacrés.

Omar, vainqueur, achève alors la conquête du Bouré par la prise de Goufoudé et se tourne contre les Malinkés du Bambouck. Comme il promettait à ses soldats les biens de ce monde, et, s'ils venaient à succomber dans la lutte, les délices du paradis de Mahomet, il eut bientôt réuni tous les fanatiques et tous les bandits de l'Afrique occidentale. La horde 
sanguinaire ravagea impitoyablement le Bambouck, c'est-àdire la riche et fertile région qui s'étend entre le Sénégal et la Falémé. Pas une chaumière ne resla debout. Tout fut rasé ou brûlé, et la population massacrée et réduite en servitude. Ce n'élait pas uniquement par cruaulé que ces terribles agents de destruction accomplissaient leur œuvre : c'était surtout par système. La terreur et le pillage élaient leurs moyens de domination. Ils n'essayaient pas de convertir les vaincus : ils les exterminaient. Omar avait divisé son armée en trois corps. Le premier descendait le Sénégal, le second la Falémé, et le troisième traversait le milieu du pays, entre les deux fleuves, de manière à ce que pas une case, pas un être vivant ne pût échapper. Quelques années plus tard, en 1859 et 1860 , un de nos officiers les plus distingués, le lieutenant Pascal, parcourait le Bambouck ${ }^{1}$ et retrouvait les traces de cette dévastation systématique. "Je passai successivement à Karré-Fattendi, Karé et Alinkel, lisons-nous dans sa relation. Ces trois villages, riches autrefois, sont presque entièrement dépeuplés; à peine y trouvai-je quelques pauvres diables pour me renseigner et me parler de leur pays. L'étonnement que leur causait ma venue les faisait fuir à mon approche ; mais, bientôt rassurés, tous s'offraient pour me montrer l'or sur les bords de la rivière, et, mettant en moi leur confiance, ils n'espéraient, me disaient-ils, qu'en la venue des blancs. Partout on ne rencontre que des ruines, qui contrastent péniblement avec la richesse du sol couvert de cultures, surtout sur la berge de la rivière, où la terre conserve plus longtemps la fraîcheur. Les ravages encore récents d'Al-Hadji avaient distrait les habitants de leurs occupations habituelles, et les avaient contraints à demander à la fécondité de la terre les moyens d'existence que leur donnaient autrefois les dépôts aurifères de la Falémé. " Le lieutenant de vaisscau Mage, qui, plus tard encore, de 1863 à 1866, parcourait le même pays, en déplorait également la ruine : "Pendant trois jours, une espèce de désert. C'était le pays de Bafing; à chaque pas nous marchions sur des ruines qui

1. Pascat, Voyage au Bambouck et retour à Bakel (Tour du monde, 1SS3). 
attestaient à la fois l'ancienne prospérité du peuple et le passage du fanatisme musulman. Quelquefois aussi nos chevaux foulaient une herbe plus grasse, un sol plus noir, et d'horribles débris : des crânes blanchis au soleil, des ossements brisés, dispersés sous la dent des hyènes ou sous le bec des vautours, nous révélaient la cause de cette végétation. Ce n’était pas un cimetière, c'était un lieu de massacre. ")

Omar, après avoir ravagé le Bambouck, se rejela au nord contre le Kaarta, dont il fit un désert. Il traita de même le Nioro et le Khasso, pendant que ses lieutenants cherchaient à soulever contre nous le Fouta et le Bondou, afin d'isoler nos postes et de les réduire successivement. Après ces exploits faciles, qui lui avaient valu une sinistre réputation, Omar se décide enfin à entrer en lutte avec la seule puissance capable de lui résister, avec la France, et brusquement vient mettre le siège devant le petit fort de Médine, sur lequel flotlait depuis quelques mois le pavillon tricolore. Sous les murs de ce fortin allait échouer sa fortune.

Il semble que le prophète ait longtemps hésité à commencer les hostilités contre la France. Il chercha d'abord à nous rassurer sur ses secrets desseins. Dès 1847 il fit proposer son alliance au gouverneur du Sénégal, de Grammont. Plus tard il renouvela sa tentative auprès du gouverneur Protet. Il leur demandait des armes, des munitions, surtout des officiers; mais il ne cherchait ainsi qu'à gagner du temps, et qu'à organiser des forces assez redoutables pour lulter contre nous. En réalité il essayait déjà de soulever contre nous les musulmans du Sénégal et de faire payer à nos tributaires la djézia ou contribution religieuse prescrite par le Coran. Bientôt même, encouragé par ses succès, il ne garda plus de ménagements, et attaqua les négociants français. En 1854 il avait même écrit aux gens de Bakel, qui s'étaient plaints d'avoir été opprimés et pillés par ses talibés, que " qui n’élait pas pour lui élait contre lui "), et c'était pour démontrer le bien fondé de celte fière déclaration qu'il se décida, en 18ว7, à attaquer notre allié le chef de Médine, Sambala, et en même temps la France, qui le protégeait.

Faidherbe n'avait pas atlendu celle allaque direcle pour 
prendre ses précautions contre le prophète. Loin de renoncer, comme le lui conseillaient quelques colons trop timides, à nos postes avancés sur le fleuve, il voulait au contraire les renforcer et même les augmenter, en construisant un nouveau poste au delà de Bakel. En effet, le 7 septembre 18əัo, il quitlait Saint-Louis avec un personnel nombreux de travailleurs et de soldats, achetait, à cent soixante kilomètres de Bakel, à plus de mille kilomètres de la capitale, un terrain à Médine ${ }^{1}$, terrain qui appartenait à notre allié le roi du Khasso, Sambala, mettait tout de suite ses ouvriers en chantier, et en vingt-deux jours le fort était construit, approvisionné, pourvu de quatre canons et d'une petite garnison, sous les ordres d'un homme énergique, le traitant mulâtre Paul Holl.

En élevant ainsi le fort de Médine en plein pays ennemi, Faidherbe affirmait la résolution de la France de ne pas renoncer sans lutter à la prépondérance dans la vallée du Sénégal. Il passait de la défensive à l'offensive et montrait aux Africains que la France était désormais déterminée à les protéger contre tous les envahisseurs. La fondation de Médine était donc un acte politique de grande portée. Les Nègres, terrorisés par les bandes d'Omar, le comprirent si bien qu'ils vinrent en foule demander notre protection. Sambala, l'ancien possesseur de Médine, fit même une démarche bien significative. Avec ceux de ses sujets qui avaient échappé aux massacres du prophète, il bâtit auprès de notre citadelle un village et un tata, grossière fortification en pierres et en terre, et annonça qu'il était disposé à se battre et à mourir à nos côtés.

Le prophète, de son côté, comprenait la nécessité de sanctionner par un acte éclatant la légitimité de sa mission. S'il parvenait à s'emparer de Médine et à battre les chréticns, il pouvait tout attendre de l'avenir. Vaincu, au contraire, la croyance à son apostolat était, sinon détruite, au moins fort ébranlée. C'était donc une partie décisive qui allait se jouer

1. Médine est bâtie à l'endroit où le Sénégal cesse d'être navigable à l'époque des crues. Il est tout près de Caignon, oủ André Brue avait voulu construire un fort, qui lui permettrait de pénétrer dans les hautes vallées du fleure. - Voir Carnère, le Siège de Médine (Revue coloniale, $2^{\circ}$ série, t. XIX). 
sous les murs de Médine. Longlemps il cacha ses projets, car il voulait paraître avoir la main forcée; mais il établit son camp près de Médine, à Koniakari, et dans ses entreliens privés, dans ses prédications du vendredi, ne cessa de surexciter contre la France la haine des talibés, et de leur montrer comme une insulte à leur foi et une menace à leur sécurité notre drapeau flottant sur les murs de Médine. Les plus exaltés des talibés le prièrent de les conduire au combat. Omar refusa, prétendant que l'heure n'était pas encore venue; mais il réunissait ses meilleurs soldats, faisait construire des échelles de bambou et accumulait les munitions et les approvisionnements. Il continuait en même temps ses prédications fanatiques. Bientôt il feignit de ne plus pouvoir résister à l'entraînement général, et permit à ses lieutenants de se lancer contre la ville maudite. Il est vrai que, se défendant toujours de pousser son armée au combat, il ne voulut pas assister au siège, et resta à Sabouciré.

Le 19 avril 1857 , l'avant-garde d'Omar paraissait sous les murs de la place. Dès le lendemain arrivait le gros de l'armée, vingt mille fanatiques déterminés à sacrifier leur vie pour assurer le triomphe de l'Islam. Le prophète avait confié les échelles d'assaut aux plus braves, et ne leur avait épargné ni les encouragements ni les promesses. Ne leur avait-il pas annoncé, à mots couverts, il est vrai, que les canons des keffirs ne partiraient pas! Contrairement à l'habitude africaine, ils s'avançaient silencieusement et par masses profondes. Ils s'étaient partagés en trois colonnes de force inégale : la première, la plus redoutable, devait attaquer le fort; la seconde le village, et la troisième devait faire une diversion sur la face ouest du poste.

Paul Holl n'avait sous ses ordres que sept Européens, vingt-deux soldats noirs, et une trentaine de laptols, mais tous déterminés et résolus. Le commandant joignait même à son patriotisme une passion religieuse qui décuplait son ardeur : catholique romain, il croyait continuer la croisade en luttant contre les musulmans. Il avait, au-dessous du drapeau français, fait broder l'inscription : " Pour Dieu et la France! Jésus! Marie! ” Aussi avait-il fait passer dans le 
cœur de ses hommes la résolution qui l'animait. Lorsque la première colonne des assiégeants se présenta, il la laissa s'avancer et la mitrailla presque à boul portant. Les assaillants, un instant ébranlés, reprirent leur marche en avant, d'un tel élan, que plusieurs d'entre eux parvinrent à se hisser jusqu'à la crête du mur; mais ils furent tous tués. Pendant plusieurs heures, le feu de nos soldats ouvrit de larges trouées dans leurs rangs; mais ils ne reculaient pas, et bravaient la mort le sourire aux lèvres. L'attaque, commencée au point du jour, ne se termina que vers les onze heures, ct encore les assaillants cédèrent-ils à la fatigue plutôt qu'au découragement. Au même moment, la seconde colonne était repoussée par notre allié Sambala, et la troisième ne pouvait exécuter le mouvement prescrit.

C'était un grand succès pour les défenseurs de la place; mais Omar, maintenant que la lutte était engagée, bien que sans son aveu, pouvait dès lors agir par lui-même. Quoique découragé par cet échec, il prit sur lui de cacher sa profonde déception et ranima les courages défaillants: "Vous avez engagé le nom de votre Dieu, leur disait-il Il faut maintenant ne pas le laisser tourner en dérision par les keffirs. Il faut venger ceux qui sont morts pour la foi. " Médine vit donc de nouveau l'ennemi sous ses murs. Seulement le siège fut converti en blocus, et la citadelle fut étroitement investic.

Les assaillants essayèrent d'abord de prendre Médine par la soif. Ils réussirent à s'emparer d'un îlot sablonneux qui dominait le fleuve. Or la place tirait toute son eau du fleuve. Paul Holl fit armer l'embarcation du poste. On la blinda avec des peaux de bœuf que les balles ennemies ne pouvaient traverser, et le sergent Desplat, avec une quinzaine de laptots, finit, après un combat acharné, par reprendre ce poste. Pendant plusieurs jours l'îlot devait être entouré par de nombreux caïmans, attirés par l'odeur des cadavres.

Omar, rendu furieux par ce nouvel échec, ordonna un second assaut. Il s'agissait cette fois d'une attaque de nuit. Les musulmans semblaient peu disposés. Plusieurs d'entre eux ne voulaient.pas se charger des outils destinés à détruire les murs du tala et du fort. Aussitôt Omar se précipite en 
avant, portant sur ses épaules les outils dont ne voulaient pas ses soldats, et poussant son cri de guerre: "Dieu est Dieu, et Mahomet est son prophète! "Ses guerriers, honteus, le suivirent; mais les assiégés étaient sur leurs gardes, et, après un combat très vif, réussirent à se maintenir sur leurs posilions. Il est vrai que c'était leur dernier effort, et qu'ils n'auraient pu soutenir un troisième assaut. Par bonheur pour eux, Omar ignorait leur épuisement, car il n'aurait pas hésité à lancer de nouveau ses compagnons contre la citadelle française, et il se contenta de prescrire un blocus rigou-

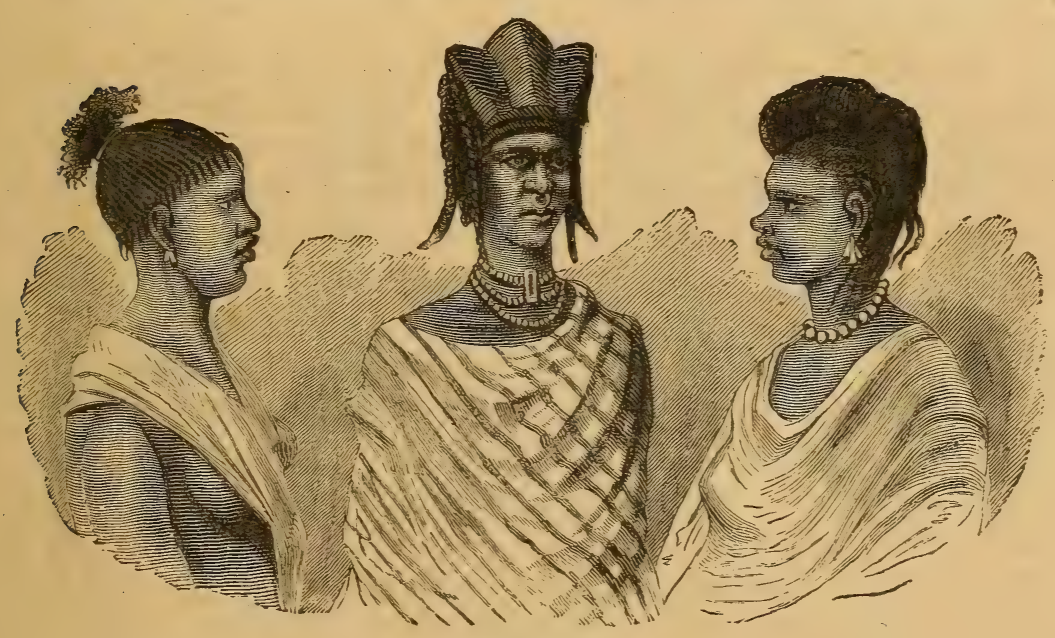

Bambaras.

reux, espérant que la famine ou le manque de munitions aurait bientôt raison des défenseurs de Médine. Celte tactique élait la meilleure. Notre commandant, Paul Holl, qui en connaissait les dangers, avait expédié des courriers à tous les postes; il avait également écrit pour demander des approvisionnements, mais aucun secours ne lui était annoncé. Les assiégeants resserraient leurs lignes d'investissement et coupaient toute communication avec le dehors. Dès la fin de mai, les vivres élaient rares. Iloll mit en commun loutes les subsistances et réduisit tout lo monde à la ration. Les arachides constituaient la principale ressource; mais comme le bois manquait, au lieu de les brûler, il fallait se résig̨ner à 
les manger pilées et mouillées. Depuis longtemps le vin et l'eau-de-vie avaient disparu, la farine et le biscuit élaient avariés. Chaque jour les assiégeants se rapprochaient des murs et s'efforçaient, par leurs menaces, de décourager les intrépides défenseurs du fort. Ils cherchaient aussi à semer la division et la défiance, car ils promettaient la vie sauve à tous, à l'exception des Européens et de Sambala. Ce n'étaient pas de vaines menaces. On connaissait, pour l'avoir éprouvée, la férocité des soldats d'Omar, et, pour peu que les renforts espérés tardassent davantage, Médine succomberait fatalement.

La poudre manqua bientôt. On s'en procura de fort mauvaise en vidant un cerlain nombre d'obus. Les soldats étaient pour la plupart réduits à un scul coup. Les volontaires et Sambala lui-même venaient fréquemment demander des munitions au commandant, qui se contentait de leur répondre: "J'ai là, dans ce magasin, beaucoup de poudre; mais n'avons-nous pas tué assez d'ennemis? L'air en est empesté. Attendez le jour du combat, et n’ayez peur. La délivrance approche! " Cependant, à part lui, Paul Holl savait que le fort, dépourvu de vivres et de munitions, ne tiendrait plus longtemps. Déjà ses hommes ne pouvaient plus supporter les gardes et les veilles, et près de six mille $\mathbf{A}$ fricains entassés dans le tata mouraient de faim et de misère. Déterminé à ne pas capituler, Holl fit part de sa résolution au sergent Desplat, et tous deux convinrent de mettre le feu aux dernières munitions quand ils verraient l'ennemi pénétrer dans la place.

Le 18 juillet il n'y avait plus à Médine. de vivres que pour quelques heures, - et quels vivres! - lorsque de sourdes détonations retentirent au loin. La petite garnison courut aux murs, tout enfiévrée d'espoir. Bientôt on croit voir des costumes européens. Plus de doute, ce sont les libérateurs! Faidherbe, en effet, à la première nouvelle de l'investissement, avait ordonné au vapeur le Guet-Dnar de porter à Médine des renforls et des munitions; mais les eaux du fleuve étaient basses, et le navire ne pouvait avancer. Faidherbe réunit alors deux à trois cents hounmes, quitte Saint- 
Louis sur le Basilic, rallie en passant le Guet-Dnar, et court à Médine. Par bonheur, les eaux avaient monté, et les paquebots passèrent.

C'était un acte singulièrement hardi que de se heurter ainsi avec une poignée de soldats contre toute une armée, que les calculs les plus modérés portaient au moins à vingtcinq mille hommes. En aval de Médine, face à face, sur les deux rives dufleuve, se dressent deux gigantesques rochers, les Kippes, qui semblent comme une écluse dans l'ouverture béante de laquelle le fleuve se précipite avec rapidité. Omar avait fait occuper ces roches par un corps nombreux, dont les feux plongeants arrêtaient tout navire en marche. Tenter de forcer ces deux redoutes naturelles était bien dangereux. Faidherbe imagina de débarquer tout son monde sur la rive droite et d'attaquer le Kippe de cette rive. Les ennemis ne s'attendaient pas à cette attaque audacieuse et s'enfuirent en désordre. Aussitôt un obusier est installé, dont les coups, bien dirigés, frappent le Kippe de la rive gauche et en délogent l'ennemi. Au même moment, le Basilic forçait le passage, et, à la vue de nos soldats, Holl et Sambala ordonnaient une sortie générale. "De la poudre! de la poudre! réclame le chef nègre. - Il y a longtemps que je n'en ai plus, réplique le commandant de Médine. - Et ce magasin qui en était plein? - Qu'aurais-tu fait si je t'avais avoué ma pénurie? - Les blancs sont habiles; tu as bien fait. Je le remercie. "Quelques instants après, les assiégeants, pris entre les baïonnettes des assiégés et les balles de l'armée libératrice, se débandaient, et Faidherbe, pénétrant dans lé fort, s'assurait par lui-même de ce qu'il avait fallu d'énergie aux défenséurs de la place pour résister, du 19 avril au 18 juillet, à un ennemi si déterminé. "Les environs du poste offraient l'aspect d'un charnier. Aucun ossement n'avait été enlevé depuis le commencement du siège. A l'intéricur du village, le tableau élait encore plus désolant. Toute une foule affamée, en guenilles; des enfants, des vieillards surtout, pouvant à peine se traîner, entassés, grouillant au milicu des immondices, et n'ayant même pas la force de remercier ceux qui venaient les délivrer. Certes, le secours 
Ćlait arrivé bien juste à temps ${ }^{1}$ ! "Le preslige du prophète n'en était pas moins à tout jamais détruit. Celui de la France, au contraire, ne devait cesser de grandir.

Faidherbe, en effet, poursuivait le cours de ses succès. Cinq jours après la délivrance de Médine, il livrait bataille à toute l'armée d'Omar et lui enlevait un immense convoi. Le prophète ne voulut plus tenter la fortune contre le chef aux quatre yeux, Lamdo diom guitte naii, ainsi qu'il avait surnommé Faidherbe, à cause des lunettes que portait le gouverneur, et s'enfonça dans le Natiaga, sous prétexte d'aller chercher des vivres. Il revenait dans le Fouta l'année suivante, quand il apprit le retour à Saint-Louis de son redoutable adversaire; mais il n'osa pas s'altaquer à nos postes, bien organisés et solidement défendus. En avril 1859, les forts de Matam et de Bake] le saluèrent même de quelques obus; mais il ne répondit pas à ces provocations. Ún jour pourtant, en mai 1859 , il trouva au confluent de la Falémé un brick français, le Pilote. Croyant que c'était une proie facile, il ordonne de tirer sur le câble qui l'altache au rivage. Le navire approche; mais soudain le canon tonne, et la mitraille éclaircit les rangs ennemis. Omar jura de ne plus s'allaquer aux keffirs français. Il s'enfonça en effet dans l'est, et passa de la vallée du Sénégal dans celle du Niger.

De grandes destinées lui étaient réservées sur ce nouveau théâtre d'opérations. Le roi de Ségou, Ali, s'imagina, bien à tort, qu'il lui suffirait pour repousser Omar d'envoyer contre lui quelques-uns de ses lieutenants. Ils furent tous battus. Omar, changeant de tactique, et résolu à fonder dans cette riche vallée le grand empire africain qu'il voulait pour lui et pour les siens, se porta aussitôt contre le souverain, dont il s'élait promis la chute. Afin d'être plus libre dans ses mouvements, il avait abandonné comme bouches inutiles les femmes et les enfants qui suivaient l'arméc. Plusieurs milliers de ces malheureux moururent de faim dans ce pays ruiné par la guerre. Le licutenant Mage, en 1860, recucillait à Makhana plusieurs centaines de ces infortunées victimes. Suivi par un

1. Pietri, les Françals au Niger, p. 94. 
Iroupeau de femmes, qu'on chassait tous les soirs comme des chicns affamés, le prophète précipite sa marche, s'empare de la place forte d'Oïtala, entre à Sansandig, dont les portes lui sont ouvertes par des traîtres, repousse une armée que le roi du Macina enroie au secours d'Ali, et fait son entrée à Sćgou. Il y trouve des armes anciennes, des meubles, et beaucoup de pendules qui sans doute avaient été apportées par les négociants du Sénégal ou de Sierra-Lcone. On détruisit impitoyablement, comme sacrilèges, tous ces produits de l'industrie curopéenne, et le conquérant s'installa dans sa nouvelle capitale. Ahmadi-Ahmadou, le roi du Macina, très inquiet du voisinage, ne tarda pas à déclarer la guerre au nouveau sourerain. Omar s'était préparé à cette lutte suprème. A vant d'entrer cn campagne, il envoie à Dinguiray toute sa famille, installe à Ségou son fils Ahmadou, auquel il laisse, avec les insignes du pouroir, deux de ses quatre canons, puis marche contre son redoutable ennemi. Deux grandes batailles furent livrées.

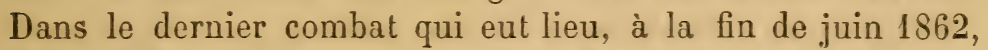
Ahmadi-Ahmadou, voyant que ses efforts ne pourraient rallier l'armée, s'élança en avant, et, s'ouvrant un passage au milieu des talibés, planta trois lances dans la poitrine de trois chefs, cn s'écriant: "Pour mon grand-père, pour mon père, pour moi ! " C'élaient en effet les lances de sa famille dont il s'était armé pour ce combat suprême. Tant d'héroïsme fut inutile. Il fut obligé de s'enfuir, et quand il fut repris, quelques jours après la bataille, Omar ordonna de l'étrangler.

Maître du Ségou, du Macina, du Bambouck, Omar possédait alors un empire qui s'étendait de Médine et du FoutaDjallon à Tombouctou. Cette ville tomba même entre ses mains en 1863. Tous ses rêves n'étaient-ils pas réalisés? N'était-il pas le'maître incontesté d'un immense territoire, où sa volonté avait force de loi? Pourtant cette grandeur était éphémère, et les populations soumises n'avaient accepté qu'arec répugnance la domination élrangère. En 1863 éclata dans le Macina une formidable révolte. Omar fut cerné dans la ville d'Hamdallahi. Longtemps il résista, mais finit par être tué dans une sortie. Le mystère de sa mort n'a jamais été éclairci. Lorsque le lieutenant Mage fut enroyé en mission 
à Ségou, en février 1864, on était depuis neuf mois sans nouvelles du prophète. Son fils Ahmadou affectait une confiance qu'il ne ressentait pas et annonçait son prochain retour. Les croyants et les fidèles racontaient déjà qu'Omar n'avait disparu que pour s'incarner de nouveau, plus glorieux et plus puissant que jamais. Renouvelant, sans qu'il s'en doutât, la légende de Barberousse, voici comment un de ses lieutenants les plus dévoués, Samba N'diaye ${ }^{1}$, racontait à Solcillet, en 1879 , les derniers moments du prophète : "Se voyant sur le point d'être pris, il appelle un enfant et lui remet sa satalla; puis, prenant son sabre, il se dirige vers un endroil où la montagne est taillée perpendiculairement comme un mur. "Ce qui arrive devait arriver, dit-il. Je reviendrai. Il descend des marches d'escalier qui se forment sous ses pas et disparaissent derrière l'enfant qui le suit. Il arrive ainsi au fond du précipice. Là se trouve, dans la direclion de la Mecque, une muraille très haute et très large, sans la moindre fissure, loule d'une pièce, unie comme un marbre de commode. Placé devant cette muraille, Omar prend la satalla des mains de l'enfant et lui dit : "Je vais prier. "Il ôte ensuite ses chaussures, s'évanouit, s'anéantit devant la muraille. Est-il encore dans le rocher? est-il retourné à la Mecque? Ce qui est certain, c'est qu'un jour il reviendra, et que l'on verra des choses écrites depuis longtemps et que peu comprennent. "

Omar n'était plus, mais l'empire qu'il avait fondé restait debout, et les soldats qu'il avait si souvent conduits à la balaille entendaient bien ne pas renoncer à leur lucrative profession. Aussi, pour de longues années encore, les malheureuses contrées ravagées par le prophète allaient-elles servir de champ de bataille à tous les ambitieux qui se partageaient ses dépouilles. Même dans. les contrées directement soumises à la France ou qui acceptaient son protectorat, de nombreuses bandes tinrent longtemps la campagne. Il fallut deux ans ${ }^{2}$ de courses et de promenades militaires pour en purger le lihasso, le Kaarta et le Bondou. Sambala, notre allié de Mé-

1. Gravier, Voyage de Soleillet à Ségou, p. 339 .

2. Ces guerres incessantes ont été racontées par le général Faidherbe dans lc beau livre qu'il écrivit sur le Sénégal en 1889, p. 200-230. 
dine, et Boubaliar-Saada, almamy du Bondou, nous rendirent en cette circonstance de réels services. Non seulement ils combattirent à nos côtés, mais, pour faciliter l'œuvre de pacification entreprise par la France, ils nous cédèrent le district aurifère de Kenieba, Sénoudébou, et tout le territoire entre Bakel et la Falémé. Ils consentirent mème à la construction de nouveaux forts à Matam dans le Fouta et à Saldé. Enfin ils nous aidèrent à chasser les derniers partisans d'Omar, qui s'étaient réunis à Guemou, non loin de Bakel, et avaient organisé dans celte citadelle un centre de résistance.

Un neveu du prophète, un certain Siré-Adama, avait réuni autour de lui près de six cents Toucouleurs, soldals d'élite, vétérans des campagnes passées, et, à leur tête, exécutait jusque dans le Bondou d'incessantes razzias. Protégé par une longue impunité, non seulement il avait intercepté les relations de Bakel avec les provinces de l'intérieur, mais encore. maltraitait et ruinait les traitants du haut Sénégal. Guemou était un danger pour le présent, et pouvait devenir une menace pour l'avenir. La chambre de commerce de Saint-Louis, composée pourtant de négociants pacifiques, fit savoir à Faidherbe que Bakel et le haut fleuve seraient délaissés si Guemou n'élait pas détruit. L'hésitation n'était plus possible. Faidherbe se décida aussilôt à envoyer contre la citadelle toucouleur une colonne expéditionnaire.

Le 18 octobre 18כ̃9, la flottille, commandée par le capitaine de frégate Gaston Desmarais, quiltait Saint-Louis, avec quatre cent cinquante tirailleurs sénégalais, deux cent cinquante soldats d'infanterie de marine, une batterie d'obusiers de campagne, une demi-compagnie de fuséens, vingt-cinq spahis et deux cent cinquante laptots, en tout douze cents hommes, sous la direction du chef de bataillon Faron. Les auxiliaires de Bakel et de Bondou, avec l'almamy Boubakar-Saada, devaient rejoindre en route. Tous les soldats paraissaient pleins d'ardeur. Malgré l'ennui et les lenteurs de la navigation en remontant le Sénégal, ils passaient assez gaiement leurs journées à s'exercer à la cible contre les caïmans, les aigrettes et les aigles pècheurs du fleuve. En cinq jours on arriva à Bakel. A chaque village, les indigènes accouraient 
en foule. Ils se repandaient en protestations, mais bon nom- bre d'entre eux formaient des vœux secrets contre la réussile de l'entreprise. De Bakel les vaisseaux remontèrent encore le Sénégal pendant une quarantaine de kilomètres, jusqu'aux ruines du village de Dioungou-Touré. Le débarquement fut aussitôt exécuté, et la petite armée s'apprêta à franchir vivement les quatorze kilomètres qui la séparaient encore de Guemou.

La marche fut pénible. On avait sonné la diane à deux heures du matin, afin d'éviter les fortes chaleurs. On traversa d'abord une grande plaine, en parlie inondée : aussi nos soldats furent-ils longtemps arrêtés et par l'obscurité et par les fonds vaseux. Ils n'arrivèrent qu'à quatre heures aux premières hauleurs, que couronnait une splendide forêt. Des arbres énormes, d'où pendaient des lianes flexibles, s'élevaient au-dessus d'un véritable tapis de gazon diapré de fleurś. Des herbes gigantesques, propices aux embuscades, car elles élaient plus hautes qu'un homme à cheval, formaient parfois d'épais bouquets. Aucun sentien n’était tracé. Aussi n'avançait-on qu'avec la plus grande prudence, et se ralliait-on aux sonneries répétées des clairons. Enfin on arriva devant Guemou, et le commandant Faron prit aussitôt ses dispositions d'attaque. L'artillerie battrait en brèche, deux colonnes d'assaut attaqueraient de deux côtés à la fois, et les auxiliaires indigènes tourneraient la place, afin d'arrêter la fuite de ses défenseurs.

Guemou présentait un amas confus de maisons au-dessus desquelles s'élevaient deux constructions assez hautes, sans doute la maison de Siré-Adama et la mosquée. Une muraille crénelée, en forme de trapèze, l'entourait comme d'une ceinture. Claque quartier était forlifié, afin de prolonger la défense. En avant de la façade principale s'étendaient de larges mares d'eau. "Le silence le plus profond régnait dans la plaine, lisons-nous dans la relation d'un des assiégeants, le futur amiral Aube ${ }^{1}$, et nul être vivant, nulle figure humaine ne troublait la solitude du paysage. On eût dit une ville endormie ou abandonnée la veille par tous ses habilants. " A la 
première décharge, des vautours à col chauve tourbillonnèrent au-dessus de Guemou, mais personne ne riposta. Déjà les fusées et les obus avaient allumé quelques incendies, et aucun cri n'àvait encore été proféré. Faron donne alors ses ordres pour l'assaut; mais à peine la première colonne s'est-elle élancée que cinq cents fusils partent à la fois et que des faces noires se montrent à tous les créneaux. La seconde colonne est également arrêtée par des feux habilement dirigés ; mais le commandant Faron accourt avec une réserve. Les soldats pénètrent dans les deux brèches. Ils opèrent bientôt leur jonction. Guemou est pris.

- Restait au milieu de la ville le tata de Siré-Adama, grosse lour en terre, casematée, adossée à un énorme baobab. Un puits avait été creusé à l'intérieur. Des vivres et des munitions avaient été accumulés; une muraille en terre percée de meurtrières et une palissade en branches de gonaké, aussi dures que du fer, complétaient la défense. On ne soupçonnait pas l'importance de ce réduit. Au moment où Faron donnait ses derniers ordres, il fut grièvement blessé à la tèle et renversé le cheval. Aussitôt éclatèrent les cris de joie des femmes r'enfermées dans le tata, et les notes graves et prolongées du lam-tam appelèrent à la résistance les derniers défenseurs de Guemou. Il fallut ouvrir la brèche à quinze pas seulement de la palissade et ensevelir sous les ruines du tata les soldats de Siré-Adama, pour triompher de leur obstination. Presque lous, et à leur tête le neveu du prophète, se firent bravement tuer, non sans avoir mis le feu à des amas de poudre qui firent de nombreuses victimes.

Le soir était venu. Vainqueurs et vaincus s'étendirent au hasard dans les ruines du village. Seuls nos auxiliaires, fidèles aux habitudes de la guerre africaine, profitèrent de la victoire pour ramasser du butin et faire des prisonniers. C'était un grand succès, mais il avait été chèrement payé par la mort de soixanté-sept de nos soldats. En oulre, cent quatre-vingls Français ou auxiliaires avaient reçu des blessures. Le lendemain, de grand matin, on rendit les derniers honneurs à ceux qui avaient payé leur dette à la patrie. Chaque soldat avait apporté deux grosses pierres et les jetait en passant sur 
la tombe de ses camarades. C'est ainsi que fut improvisé un lumulus; il existe encore à l'heure actuelle, comme au temps des guerres prélistoriques de nos ancêtres. Aussilôt après cette cérémonic douloureuse, les murs du tala, minés à l'avance, sautaient en l'air, et c'est au bruil de ces sourdes détonations que l'armée reprenait le chemin du fleuve. Lc 2 novembre la colonne expédilionnaire élait de retour à SainlLouis. En moins de deux semaines la campagne avait élé décidée, exéculée et terminée.

Ces foudroyants succès eurent un retentissement extraordinaire. Ils nous valurent la prépondérance dans toute l'Afrique occidentale. Faidherbe put dès lors aborder la seconde partie de son programme, le développement des ressources de la colonie, et sa réorganisation administrative.

\section{VIII}

RÉFORMES ADMIXISTATIVES DU GÉNÉRAL FAIDHERBE

Comprenant que la France ne prèterait au Sénégal qu’une altention pour ainsi dire intermiltente, et qu'il était nécessaire que la colonie pût se suffire à elle-même, le gouverneur arait tout d'abord résolu de créer un corps de troupes indigènes, qui combattraient à côté de nos soldats réguliers et comble. raient les vides trop fréquents ouverts dans les rangs de l'armée, soit par la maladie ou le feu de l'ennemi, soit par la faiblesse du recrutement. C'étaient d'abord des volontaires, auxquels le butin servait de solde, qui s'étaient associés à no: hommes et les avaient suivis dans leurs campagnes; mais leur concours n'élait que temporaire, et, en cas de revers, ces prétendus auxiliaires seraient vite devenus des ennemis. Faidherbe préféra organiser un corps de troupes recevant une solde fixe, enrégimentés el soumis à la discipline française. Les tirailleurs sénégalais, ainsi qu'on les nomma, se recrutèrent facilement et devinrent vile d'excellents soldats. Les noirs, en effet, sont braves. Ils s'attachent à leurs chefs, si 


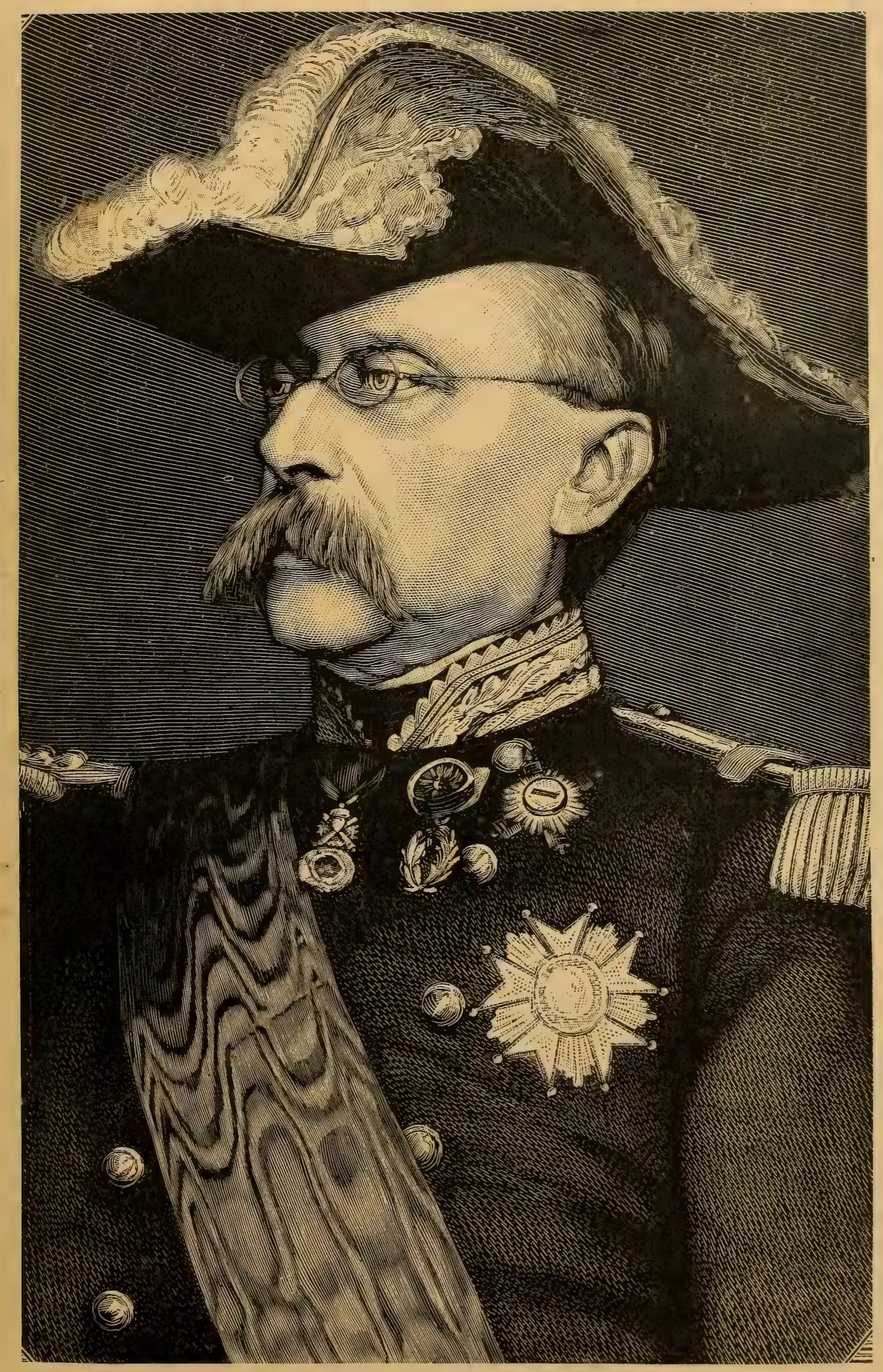

Le général Faidherbe. 

on les traite avec douceur. Ces nouveaux soldats, fiers de leur uniforme et de leurs armes perfeclionnées, heureux d'être traités par les nôtres comme des égaux, très salisfaits des avantages matériels qu'on leur assurait, nous ont rendu dans toules les campagnes du Sénégal et du Soudan d'inappréciables services. Leur création remonte à l'année. 1857. Bon nombre d'entre eux se sont signalés par des actes d'héroïsmo ou de dévouement, et le ruban rouge qui orne leur poitrine a été bien mérilé.

Un des prédécesseurs de Faidherbe, Bouët-Vuillaumez, avait déjà créé le corps des spahis indigènes. Faidherbe le conserva et même en augmenta les cadres. Les spahis, dans sa pensée, devaient servir non seulement de cavaliers pendant la guerre, mais aussi de gendarmes en temps de paix. En effet, le manteau rouge de ces hommes d'élite est aujourd'hui respecté dans toute l'Afrique occidentale à l'égal du tricorne et du baudrier jaune de nos gendarmes. Ce sont d'utiles serviteurs, belliqueux et dévoués.

Les laptots ou marins du fleuve, bien qu'ils n'aient pas été enrégimentés, ont souvent combaltu à côté des tirailleurs et des spahis, et peuvent être considérés comme des soldats de la France. Les laptots aiment les eaux tranquilles; ce sont des rameurs infatigables, mais ils ne s'aventurent pas volontiers sur la mer. S'agit-il au contraire de remonter le fleuve, ils marcheront à la cordelle le long de ses berges ou rameront pendant des journées entières; on les emploie également comme porteurs de bagages ou convoyeurs, et, en cas de besoin, ils font volontiers le coup de fusil.

Une autre création de Faidherbe, délaissée bien à tort, car clle a donné d'excellents résultats, fut l'École des otages installée à Saint-Louis. Le gouverneur avait demandé leurs fils aux principaux chefs africains, promettant de les instruire et espérant qu'ils deviendraient les partisans et les propagateurs de la civilisation française. Sans doute, quelques-uns de ces élèves se sont montrés rebelles à tout enseignement, et se sont considérés comme de vrais otages, c'est-à-dire comme des victimes à l'avance désignées aux vengeances françaises; d'autres ont abusé de nos leçons, comme ce Lat-Dior qui 
pendant si longtemps lulta contre nous dans le Cayor; mais la plupart d'entre eux se sont montrés reconnaissants, Ely, par exemple, le roi des Maures Trarzas, qui s'est toujours déclaré l'enfant de la France. On a depuis renoncé, sous prétexte dinsuffisance de crédits, à celte École des otages. Nous ne pouvons que regreller la disparition de cet excellent instrument d'influence et de domination.

Aussi bien, le gouverneur du Sénégal élait tellement persuadé de la nécessité d'étendre à tout prix l'instruction, que, bien avant qu'on eût décrélé en France linstruction gratuite et obligatoire, il en avait doté le Sénégal. Il est vrai que cette universalité de l'instruction devait n'exister qu'à l'étal de lettre morte, car les instituteurs, si les élèves ne manquaient pas, faisaient absolument défaut. Mais le principe était posé. Et n'était-ce pas déjà un progrès singulier dans ce pays encore barbare et qui s'ouvrait à peine à la civilisation française?

C'est encore le général Faidherbe qui fonda à Saint-Louis (1857) une imprimerie et un journal, Moniteur du Sénégal; lui qui commença en 18 š la série de ces Annuaires du Sénégal où l'on trouve de si précieux renseignements sur la colonie; lui enfin qui consacra ses rares moments de loisir à réunir les éléments d'ouvrages qui ont renouvelé l'histoire, la linguistique et l'économie politique de l'Afrique occidentale. La première de ces notices parut en février 1854, dans le Bulletin de la Société de géographie de Paris. Elle est intitulée les Berbers et les Arabes des bords du Sénégal. En 1856, Faidherbe reprit le même sujet avec plus d'étendue, et s'occupa non seulement de tous les peuples de race blanche, Arabes et Berbères, répandus dans les oasis jusqu'au Sénégal, mais encore des nègres qui depuis le Sénégal occupent le reste de l'Afrique tropicale. Son livre Considérations sur les populations de l'A frique septentrionale peut être disculé sur certains points, mais il est en quelque sorte resté classique et fait autorité dans la matière. Il y a encore beaucoup à glaner dans une Notice sur la colonie du Sénégal, qui fut publiée dans l'Annuaire du Sénégal de 1858; dans le mémoire intitulé : Renseignements géographiques sur la partie du Sénégal comprise entre l'Oued-Noun et le Sénégal (Annales des voyages, 185̋9), 
qui forme comme le complément du Mémoire de 1854 sur les Berbers et Arabes. Cilons encore un Mémoire sur les populations noires des bassins du Sénégal et du haut Niger (Société de géographie de Paris, 1856), une Notice historique sur le Cayor (id., 1883), et surlout toute une série d'études philologiques ${ }^{1}$ et de vocabulaires des tribus sénégalaises, contribulion de la plus haute importance à la grammaire générale.

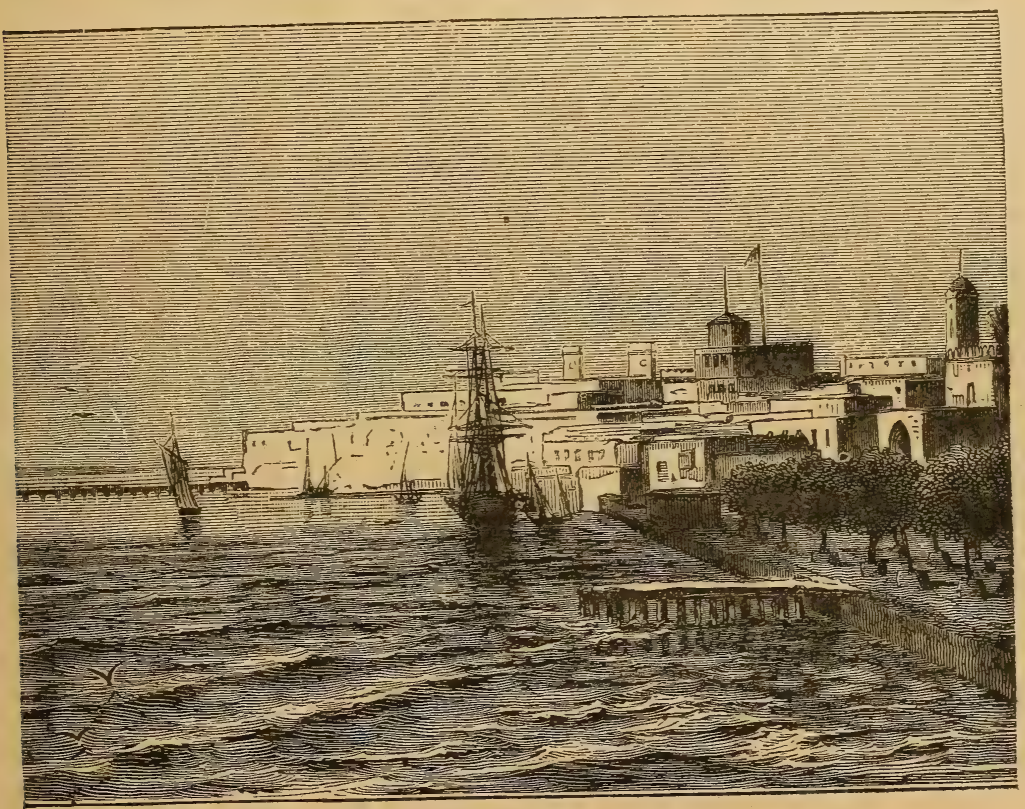

Saint-Louis.

Ces travaux de l'éminent gouverneur ne sont pas des études purement spéculatives : ce qui leur donne, au contraire, un caractère tout spécial, c'est qu'ils ont un côté pratique qui ne peut qu'être utile à nos négociants, à nos soldals et à nos administrateurs. C'est ainsi qu'en améliorant le présent, Faidherbe ne négligeait pas le passé et se préoccupait de l'avenir.

La meilleure preuve que ces recherches ne délournaient nullement le gouverneur de travaux plus pratiques, et que le

1. Vocabulaire français-woloff; 1854. - Étude sur la langue kéguem ou sérèresine; 1865. - Essai sur la langue poul; grammaire et vocabulaire; 1875. - Le Zénaga des tribus sénégalaises, contribution à l'étude de la langue berbère; 1877. 
théoricien ne passait pas avant l'administrateur, c'est que Faidherbe ne négligea pas pour autant les intérêts matériels. C'est ainsi qu'il s'appliqua à transformer Saint-Louis, et qu'il essaya de construire une ville à la place d'une agglomération de huttes en paille. Des quais furent partout bâtis qui prévinrent les inondations et facilitèrent les transactions commerciales. Deux ponts furent jetés sur le fleuve : celui de Saint-Louis à Guetdnar, sur la pointe de Barbarie, et le pont Faidherbe, sur le grand bras du fleuve, dans la direction du Cayor. Ces utiles constructions non seulement reliaient Saint-Louis à la terre ferme, mais encore permettaient à nos soldats de déboucher rapidement dans les provinces voisines. Des travaux furent également commencés pour donner à la ville l'eau potable qui lui manquait. Un essai de puits artésien ne réussit pas. Il fallut construire un barrage au marigot de Lampsar, à seize kilomètres en amont, et commencer un canal; qui n'est pas encore achevé. Des routes et des lignes télégraphiques relièrent la capitale aux postes les plus voisins. Le magnifique port de Dakar fut aménagé (1863) et dolé de trois phares. De toutes parts une vie nouvelle circula, et, sous la féconde impulsion du gouvernement, la colonie prit un essor inatlendu.

Malgré les essais infructueux à la suite desquels s'était répandu le préjugé que le Sénégal ne pourrait devenir colonie agricole, Faidherbe s'efforça de développer des cultures nouvelles. Celle du coton et celle de l'indigo ne réussirent que médiocrement, mais celle des arachides prit un développement considérable, et à l'heure actuelle le Sénégal est un des centres les plus importants de la production oléagineuse. Le gouverneur se préoccupa également de la question industrielle, et par son ordre les gisements aurifères du Bambouck furent recherchés avec soin. A cette œuvre multiple, et sans se soucier de sa santé, Faidherbe consacrait tout son temps. Le Sénégal renaissait sous cette direction vigoureuse. Peu à peu se créait une France nouvelle dans l'Afrique occidentale.

A partir de $18 \% 9$, tout étant relativement tranquille, le gouverncur résolut de reprendre l'œuvre ébauchée par André 
Brue et envoya dans toutes les directions quelques-uns des plus dévoués et des plus vaillants de ses collaborateurs pour explorer les régions encore inconnues, et compléter les notions cncore peu étendues que nous possédions sur cette parlic de l'Afrique. Nous citerons parmi ces ouvriers de la première heure le capilaine d'état-major Vincent ${ }^{1}$, envoyé dans l'Adrar, c'est-à-dire dans la grande oasis de l'extrémité occidentale du Sahara, entre le Sénégal et le Maroc. Vincent ne reçut pas un accueil très empressé. Le chef du pays, Ould-Aïda, ne l'admit à son audience qu'après plusieurs jours d'attente, et lui prodigua tout d'abord les humiliations et même les insultes. Notre envoyé courut de grands dangers, car on essaya à diverses reprises d'empoisonner sa nourriture avec des têtes de vipère. Les renseignements qu'il rapporla sont nombreux et importants. On sait grâce à lui que les indigènes de l'Adrar, bien qu'ils se vantent d'être Maures, appartiennent plutôt à la race berbère et se rapprochent des Touaregs. On retrouve chez eux les trois classes des. Touaregs : les hâsoun ou guerriers, qui n'ont d'intelligence que pour le mal et se signalent par une rapacilé inouie; les tolbas ou marabouts, assez peu considérés, et les azaunougs ou serfs. Ces derniers sont encore appelés lahmés, ou morceaux de viande à manger : ils constituent, en effet, vis-à-vis des deux premières classes, un véritable troupeau taillable et corvéable ả merci.

Presque au même moment, Faidherbe envoyait deux autres officiers, Mage el Bourrel ${ }^{3}$, chez les Maures Douaichs et Braknas. Le premier s'avançait jusqu'à l'oasis de Tagant, très avant dans l'intérieur du pays, et renouvelait en partic la carte de cette région africaine. Enfin un indigène, Bou-clMoghdad ${ }^{4}$, était dirigé de Saint-Louis à Mogador, et exéculait son difficile voyage. En envoyant ainsi ces intelligents auxiliaires au nord de notre colonie, ce n'était pas tant l'alliance

1. Vincent, Voyage dans l'Adrar (Revue maritime et coloniale, 1\$60, t. III, p. 445-49'; - Tour du monde, 1861, p. 49).

2. Mage, Voyage au Tagant (Afrique centrale), décembre 1859, janvier 1860 (Revue algérienne et coloniale, $t$. III, 1860).

3. Bournel, Voyage dans le pays des Maures Braknas, rive droile du Sénégaı, juin-octobre 1860 (Revue maritime et coloniale, septembre 1861).

4. Bou-EL-Moghdad, Voyage entre le Sénégal et le Maroc (Nouvelles Annales des voyages, 1861; Revue maritime et coloniale, 1861). 
ou le prolectorat de la France que Faidherbe voulait imposer à ces barbares: il cherchait plus encore à consolider de bons rapports réciproques, et surtout à reconnaître le pays, dans l:quel pourraient un jour ou l'autre aller nos soldals et nos négociants.

Tel fut également le but des missions confiées au capilaine du génie Fulcrand ${ }^{1}$, qui, en octobre 1860, étudia les parages du cap Blanc et de la baje d'Arguin; au capitaine de frégate Vallon $^{2}$, qui explora les fleuves au sud de la Gambie; au capitaine Azan ${ }^{3}$, qui éludia avec le plus grand soin le Oualo, et au lieutenant de vaisseau Mage", qui, à peine de retour de Tagant, visita les rivières de Sine et de Saloum.

Dans les vasles projets d'avenir formés par Faidherbe, ce n'étaient pas seulement les pays directement soumis à l'influence française qui devaient être ainsi étudiés. Le gouverneur s'élançait dans son imagination bien au delà des limites actuelles de la colonie. Toute la vallée du haut Sénégal, encore fermée à notre commerce et à nos armes; le FoutaDjallon, ce mystérieux pâté de montagnes, cette Suisse africaine, d'où s'écoulent dans toutes les directions des rivières considérables, et surtout le Niger, celle magnifique voie de pénétration vers l'Afrique centrale, tels étaient les pays quil'attiraient, telles étaient les régions où il aurait voulu que flottât le pavillon national. De là de nouvelles missions, plus importantes que les précédentes, car elles ont préparé l'avenir.

Le lieutenant d'infanterie de marine $\mathbf{P a s c a l}{ }^{5}$, envoyé dans le Bambouck, partit de Bakel, remonta la Falémé jusqu'à lioloba, et se rendit à Médine, après avoir visilé la cataracte de Gouina. La région qu'il visita présentait toutes les apparences de la richesse et de la fécondité : forêts luxuriantes, vallées gracieuses, prairies à perte de vue; mais l'invasion d'Al-Hadji-Omar avait couvert le pays de ruines. Il n'y avait

1. Fclcraxd, Exploration de la baie d'Arguin (Revue maritime et coloniale, mai 1S61).

2. A. Vallos, la Cóte occidentale d'Afrique (Revue maritime et coloniale, norembre et décembre 1863).

3. Azav, Nolice sur le Oualo (Revue maritime et coloniale, 1864).

4. E. MAGE, les Rivieres de Sina et de Saloum (Revue maritime et coloniale, arril 1863).

5. Pascal, Voyage au Bambouck (Tour du monde, 1861). 
pas un scul village qui ne portât les traces des dévastations systématiques ordonněes par le prophèle. Aussi les habitanls altendaient-ils avec impatience la venue des Français, el ne cachaient pas leurs espérances à l'envoyé du gouverneur.

Le lieutenant Lambert ${ }^{1}$, chargé de nouer des relations d'amilié avec un des plus puissants souverains africains, l'almamy de Fouta-Djallon, fut également heureux dans s ? mission. Nous aurons à la raconter plus tard.

Dans la direction du Niger, ce fut un traitant indigène, de M. Lédine, dont Faidherbe avait deviné les rares aplitudes et au courage duquel il aimait à rendre justice, un cerlain Alioun-Sal, qui fraya la voie; mais il fut obligé de s'arrèter à quarante kilomètres au nord de Tombouctou, à Araouan, ct tomba, premier martyr nègre de la géographie. Faidherbe ne se laissa pas décourager par ce premier insuccès, car il était intimement convaincu de la nécessité de relier le Sénégal au Niger, et confia à un de ses auxiliaires les plus éprouvés, au lieutenant de vaisseau Mage ${ }^{2}$, auquel fut adjoint le docteur Quintin, la délicate mission de pénétrer jusqu’à Ségou, sur le Niger, près du sultan A hmadou, le fils de notre ancien ennemi Omar, el de signer avec lui un trailé. Cette mission réussit au gré de ses désirs : nous aurons occasion de revenir sur celte importante question.

A l'écho de ces lointains succès, l'opinion publique se mndifiail peu peu dans la métropole. On commença à se rendre compte en haut lieu de l'importance des résultats acquis, et on ne marchanda plus au gouverneur les renforts et les subsides qu’il réclamait. La presse ne dédaigna plus les informations du Sénégal. De jour en jour se formait un courant favorable. Le gouverneur n'avait plus qu'à profiter de ces dispositions nouvelles, et le Sénégal allait prendre son essor; mais dix ans de séjour à peu près sans interruption dans la colonie, des campagnes, des voyages, des études sans cesse renouvelées, avaient usé la santé de Faidherbe. Il avait

1. Lanbert, Voyage dans le Fouta-Djallon (Tour du monde, 186I).

2. MAGE, Relation d'un voyage d'exp'oration au Soudan (Revue maritime et colnniale, 1866-67; - Société de géographie de Paris, 1868; - Toul du monde, 15(S)). 
gagné le droit de demander son rappel. Grâce à lui nous élions, non plus tolérés, mais solidement assis, et sur un terrain qui nous appartenait. Les entraves commerciales avaient disparu; les souverains indigènes acceptaient notre prépondérance; en un mot, la base d'opérations était créée, et nous pouvions marcher à la conquête du Soudan. Lorsque Faidherbe dut se résigner à rentrer en France (12 juillet 186ə), il put se vanter d'avoir plus fait pour le Sénégal que tous ses prédécesseurs réunis.

La tâche des successcurs de Faidherbe élait facile ${ }^{1}$. Ils n'avaient qu'à se conformer à sa politique à la fois ferme et prudente. Ils n'avaient surtout qu'à aimer le Sénégal. Peutĉtre n'ont-ils pas tous aussi bien réussi. Peut-être même des fautes ont-elles été commises. Aussi bien, les circonstances furent plus difficiles. Au moment où la métropole se débattait contre l'invasion étrángère, la colonie ne pouvait que se suflire à elle-même. L'impulsion donnée avait élé pourtant si vigoureuse, que les progrès continuèrent.

Les Maures furent définilivement cantonnés sur la rive droite du Sénégal, et les Maures Trarzas furent punis de lcurs velléités de révolte en se voyant privés de toutes leurs escales de commerce, à l'exception de Dagana (1880). Celle fermeté leur en imposa tellement, que lorsqu'un des chefs du Oualo, qui pourtant avait été élevé à l'européenne, au lycée d'Alger, et nommé officier dans les tirailleurs sénégalais, un certain Sidia, essaya de soulever contre nous celte province, le roi des Maures Trarzas, Ely, refusa non seulement de s'allier avec lui, mais même de le recevoir dans ses États.

1. Les gouverneurs du Sénégal après Faidherbe ont été : Pinet-Laprade (1 er mai 1863 -17 août 1869), Vallière (22 septembre 1869-20 avril 1876), Brière de l'Isle (20 avril 1876-4 mars 1880), Delanneau (4 mars 1880-26 août 1881), colonel Canard-Vallon (26 août 1882-26 octobre 1882), Servatius (26 octobre 188225 juillet 1883), Seignac-Lesseps, Genouille (24 juillet 1883), etc. 
Les tribus nègres résistèrent davanlage, mais finirent par se résigner. C'est dans le Cayor et dans le Fouta que lultèrent avec le plus d'énergie les derniers défenseurs de l'indépendance nationale.

On sait que le damel dépossédé du Cayor, notre implacable adversaire Lat-Dior, malgré les échecs sanglants et répétés qu'il avait éprouvés, tenait toujours la campagne. Ambiticux et fanatique, mais convaincu de la légitimilé de sa mission, Lat-Dior, comme autrefois Abd-el-Kader en Algérie, était toujours vaincu, mais retrouvait toujours des partisans ét des soldals. De 1864 à 1869 l'histoire du Cayor est celle des prises d'armes de notre adversaire, et des répressions impitoyables de la France. L'insurrection de 1870 fut particulièrement terrible; mais nos soldats venaient d'être armés du fameux chassepot, et les armes à tir rapide "firent merveille ", mieux qu'à Mentana, contre les bandes indisciplinées de Lat-Dior. Ce dernier, malgré ces défaites successives, allait pourtant recevoir le prix de sa persévérance, et c'était la France qui, par un singulier retour, allait être l'unique auteur de ce changement inattendu.

Le gouverneur Pinet-Laprade, un des plus énergiques successeurs de Faidherbe, venail de mourir du choléra (17 août 1869). Il eut pour successeur le colonel d'infanteric de marine Vallière, qui, bien mal inspiré, adopta la plus funeste des politiques. Renonçant, en effet, à traiter en ennemi Lat-Dior, non seulement il fit la paix avec lui et le reconnut seul et unique damel, mais encore il lui restitua la majeure partie des provinces annexées par Faidherbe et par PinctLaprade. C'était un recul de dix années, et qui n’était juslifié par rien. La stupeur de nos désastres dans la guerre d'Allemagne peut seule expliquer, de la part d'un officier aussi brave et aussi intelligent que le colonel Vallière, celte grosse erreur, qui devait coûter à la colonie plusieurs années de troubles et de désorganisation.

Lat-Dior profita de notre incroyable condescendance. Non sculement les tiédos qui l'avaient soutenu eurent toute licence de piller et de pressurer les malheureux indigènes qui avaient cu le malheur de se croire à l'abri de toute vexation sous lc 
drapeau de la France, mais encore le nouveau damel, nous jugeant d'après ses propres passions, affecta de nous dédaigner et de ne plus tenir compte de nos observations. Il ordonna le pillage d'un royaume allié, le Baol. Il envoya jusqu'à Rufisque pour réclamer les anciennes coutumes. Én août 1872, apprenant que des élections allaient avoir lieu à Saint-Louis, - il s'agissait de nommer des conseillers municipaux, - ne s'imagina-t-il pas, dans son ignorance de despote africain, qu'il n'y avait plus de gouverneur à Saint-Louis, et que, par conséquent, l'occasion élait excellente pour conquérir le Oualo, le Dimar et toules les possessions françaises? Aussilôt il marcha contre notre capitale, mais reconnut bien vite son erreur et envoya de plates excuses.

Nous aurions dû profiter de celte fausse manœuvre pour déposséder Lat-Dior, et reprendre hardiment la grande politique inaugurée par Faidherbe. On crut plus habile de simuler la confiance. On poussa même l'oubli des injures jusqu'à venir à son aide contre l'almamy du Fouta, Ahmadou-Sékou, qui venait de proclamer la guerre sainte contre les blanes et contre leurs amis, et avait inauguré la campagne en dépossédant Lat-Dior. Le gouverneur, excilé par un général inspecteur alors en tournée au Sénégal, le général Pélissier, ne crut pas pouvoir se dispenser d'agir, et organisa une colonne cxpéditionnaire. Le commandement en fut confié au colonel Bègin. Il partit de Saint-Louis le 4 février 1875, avec cinq cents hommes d'infanterie, deux canons et quelques cavaliers, rallia en passant les partisans de Lat-Dior, et, le 11 février, livra aux ennemis la grande balaille de Coki ou Bomdon. Les gens d'Ahmadou-Sékou essuyèrent bravement le feu des chassepots, et ne nous cédèrent le champ de bataille qu'après l'avoir jonché des cadavres de cinq cents des leurs. Nous avions, de notre côté, perdu près de cent soldats. Jamais combat en rase campagne n'avait encore élé plus vịvement discuté au Sénégal.

Nous n'avions, après celle vicloire, qu'à reprendre le Cayor. On commit la faute de tout rendre à Lat-Dior : en sorte qu'aux yeux des Africains, nous ne nous élions baltus que pour rétablir un souverain délesté. Nous n'eûmes même pas la salis- 
faction d'inspirer à notre protégé des sentiments de reconnaissance. En 1879, lorsque la France s'occupa de construire un chemin de fer de Dakar à Saint-Louis, Lat-Dior, qui avait d'abord consenti et donné toules les autorisations nécessaires, revint brusquement sur sa déterminalion. "Le territoire de la banlieue de Saint-Louis est à moi, écrivait-il insolemment au nouveau gouverneur, Servatius. Je ne souffrirai pas que le chemin de fer y passe. Si je vous laisse celte banlieue, c'est à cause des bonnes relations que nous arons toujours eues. Je ne veux pas de chemin de fer. Ne le construis pas, et nous vivrons en paix. "Lat-Dior s'imaginait que la construction lu chemin de fer amènerait l'émancipation des esclaves, en quoi il ne se trompait pas; mais il ne voulait à aucun prix consentir à celte diminulion de puissance. Malgré la frayeur qu'inspiraient à cet ivrogne les wagons, qu'il se représentait comme des frégales montées sur des roues et traînant de formidables canons, il déclara " qu'il serait aussi difficile de faire passcr une voie ferrée dans le Cayor qu'un chameau par le trou d'une aiguille ") et bouleversa tous les chantiers. A cette insolente provocation il n'y avait à répondre que par la guerre. Une colonne expédilionnaire fut envoyée dans le Cayor sous les ordres du colonel Wendling. Lat-Dior n'essaya même pas de résister et s'enfuit dans le Djolof.

Cette fois encore les leçons de l'expérience furent inutiles. Au lieu de prononcer l'annexion définitive du Cayor, le gouverneur Servatius préféra installer un nouveau damel, AmadiNgoué-Fal, qui fut aussitôt renversé par un neveu de LatDior, Samba-Laobé, et chassé jusqu'à Gandiole, tout près de Suint-Louis. Cette fois l'injure fut vivement ressentie. En trois jours une colonne expéditionnaire était organisée, sous le commandement du chef de bataillon d'infanterie de marine Dodds, et alors commença, sans trêve ni merci, une vérilable chasse à l'homme. Montés sur de rapides dromadaires, nos soldats ne laissèrent aucun relâche à Samba-Laobé. Ils finirent par l'atteindre, et le forcèrent à se rendre sans condilions (2 mai 1883).

Samba-Laobé est depuis devenu notre ami. Lorsque son oncle Lat-Dior reparut dans le Cayor, il marcha contre lui 
sans l'aide de nos soldats et le refoula dans le désert. Il a, de plus, consenti à l'exécution des travaux du chemin de fer entre Dakar el Saint-Louis. Il a même fourni des ouvriers, ct aidé, par tous les moyens possibles, à l'achèvement de la ligne. Cette voie, à la fois stratégique et commerciale, est aujourd'hui achevée. Elle met, à vrai dire, le Cayor entre nos mains, et rend difficile toute insurreclion des indigènes; mais Samba-Laubé ne resta pas longtemps notre allié. Dès l'année 1886 il rançonnait les colons français établis sur son territoire et élevait des prélentions inadmissibles sur la propriété de la voie ferrée. On essaya d'abord de la conciliation. Toutes les tentalives échouèrent. Le 6 octobre 1886, un peloton de nos spahis, commandé par le capitaine Spitzer, rencontra à Tiwawane le damel et son escorte. Les deux troupes engagèrent aussitôt le combat. Samba-Laobé dut bientôt chercher son salut dans la fuite; mais, poursuivi à outrance par le lieutenant Chauvet, il fut transpercé et mourut en brave.

Le gouverneur du Sénégal, décidé à mettre un terme à ces agitations, qui pouvaient devenir dangereuses, et soutenu d'ailleurs par la majorité des indigènes, qui préféraient à une indépendance nominale le calme et la sécurité sous la domination française, prononça aussitôt la division du Cayor en six provinces, gouvernées chacune par un chef à notre dévotion. Lat-Dior protesta et rentra en campagne. Le capitaine Vallon fut envoyé à sa poursuite, et l'atteignit au puits de Delikelé (26 octobre 1886), Lat-Dior vendit chèrement sa vie, mais il fut tué avec ses fils et les plus courageux de ses partisans. Dès lors la paix n'a plus été troublée au Cayor. Sans doute l'annexion n'a pas encore été prononcée; mais le système des damels a fini son temps, et les six chefs, nommés par nous et protégés par nous, ont tout intérêt à nous rester fidèles. Le protectorat, de la sorte, prépare et annonce une prochaine annexion.

Pinet-Laprade avait élé mieux inspiré, en 186马, lors de l'affaire restée célèbre dans l'histoire du Sénégal sous le nom d'expédition du Rip ${ }^{1}$. Un des damels dépossédés du Cayor, 
Macodou, s'était associé à un faux prophète, Maba, et lous deux, unissant leurs ressentiments et leurs convoilises, avaient chassé un de nos alliés, le roi du Rip, qui s'enfuit dans un de nos postes, Kaolack, sur le Saloum. Ils vinrent aussitôt l'y assiéger. Kaolack n'était défendu que par un sergent français, Burg, et douze soldats. Ces braves repoussèrent l'assaut, qui dura tout un jour et une partie de la nuit (3 octobre 1862). Maba, blessé, fut obligé de se retirer, après avoir perdu trois

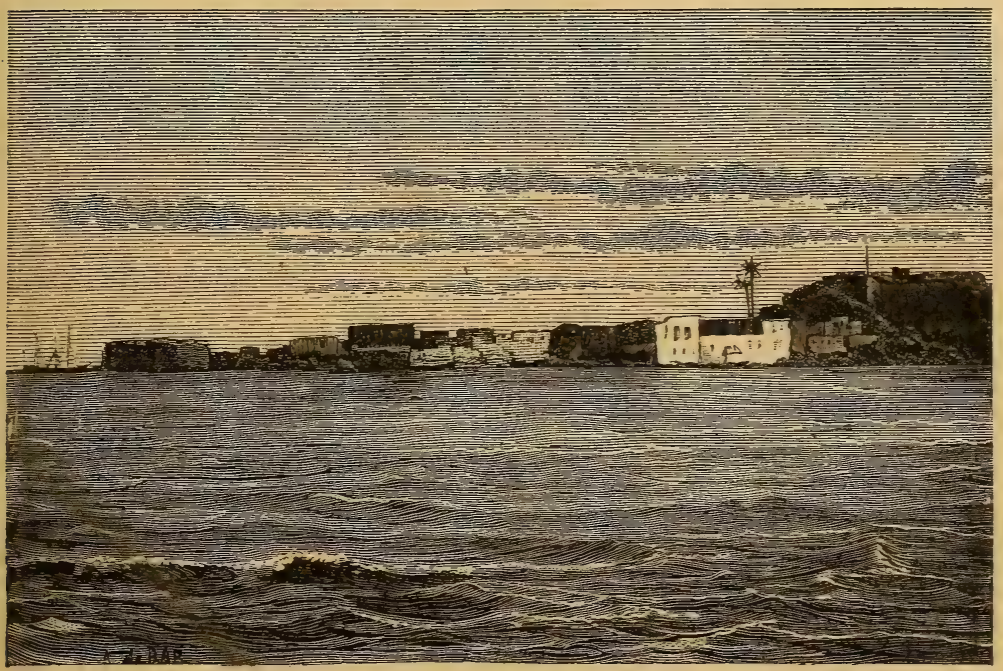

Dakar.

cents de ses partisans. Rendu furieux par ce honteux échec, il se débarrassa, sans doute en le faisant empoisonner, de son associé Macodou, et, resté seul maître du Saloum et du Rip, envahit le Djolof (juin 1865) el se prépara à conquérir lc Baol et le Cayor. Il avait déjà entamé des négociations avec les Toucouleurs du Fouta et même avec les Maures du désert. Il devenait le chef d'une vaste confédération formée par tous nos ennemis, et annonçait hautement son intention d'exterminer tous les blancs. Le danger devenait grave, car le Cayor était encore insoumis, et nos nouveaux ennemis pouvaient donner la main aux Toucouleurs d'Al-Hadji-Omar et de son 
fils Ahmadou. Il n'était que temps de rompre par un coup d'éclat cette coalition naissante.

Pinet-Laprade quitta Dakar en octobre 1865, rallia en passant les contingents du Baol et du Sine, et marcha contre Maba à la tête de huit mille hommes environ. C'était l'armée française la plus considérable qui jusqu'alors eût paru dans le Sénégal. "Dans le pays que traverse pour la première fois une colonne de blancs, lisons-nous dans le récit d'un témoin oculaire $^{1}$, la première impression est une crainte bien naturelle de la part de gens pour lesquels la présence d'une troupe armée est presque toujours le signal d'un pillage; mais l'ordre qui règne dans notre colonne, la discipline de nos soldats, qu'observent les volontaires eux-mêmes, vigoureusement contenus, le respect de la propriété que nous gardons scrupuleusement, et la nouvelle qui se répand de proche en proche que nous marchons pour les protéger et les défendre, change bientôt cetle crainte en un sentiment de reconnaissance et de sympathie, dont nous avons la preuve en voyant accourir sous nos drapeaux, pour marcher avec nous, tous les hommes armés des pays par lesquels nous passons. " Arrivés à Kaolack le 23 novembre, nos soldats marchaient sur la capitale improvisée de Maba, Maka, s'en emparaient (24 novembre), pénétraient dans le Rip, remportaient une victoire décisive dans la forêt de Ngapackh (30 novembre), et poussaient jusqu'à Nioro, à quelques kilomètres de la Gambic, brûlant sur leur chemin une trentaine de beaux villages qui regorgaient des récoltes de l'année. Le 6 décembre ils étaient de retour à Kaolack.

Cette courte et brillante campagne rendit à la France sa grande situation dans l'Afrique occidentale. Elle nous assurait un territoire considérable, et faisait de nos gouverneurs les arbitres incontestés et redoutés des différents États indigènes. La fermeté et la décision ne sont-clles pas toujours la meilleure des politiques?

Les tribus riveraines du Sénégal furent traitées de même²;

1. Annales sénégalaises, p. 334.

2. X., Opérations militaires dans la colonie du Sénégal et dépendances pendant les années 1862, 1863, 1864 (Annales maritimes et coloniales, août 1864). 
ce fut à leur avantage et au nôtre : non pas les tribus du bas fleuve, qui entretinrent toujours avec nous de bonnes relations, mais celles du moyen Sénégal, plus remuantes, plus belliqueuses, et qui avaient besoin d'être plus surveillées. Les chefs du Fouta n'avaient pas été corrigés par les défailes que leur avait infligées, à Loumbel et dans la forêt de Touldégal, Jauréguiberry, gouverneur intérimaire du Sénégal. Ils avaient sans doute signé la paix, le 20 mars 1863, à Moctar Salam, et consenti à l'annexion du Toro; mais ils n'avaient pas oublié leur humiliation et n'attendaient qu'une occasion pour rentrer en campagne. Les haines françaises se groupèrent autour d'un cerlain Abdoul-Boubakar, el dans la tribu des féroces et orgueilleux Bosséyabés. Enhardis par une impunité rélative, les Bosséyabés, sous prétexte de guerre sainte, ravageaient tout le Sénégal. Ils insultaient nos négociants et nos explorateurs. A Saldé, ils prélevaient d'énormes droits de passage, jusqu'à quinze cents francs par navire de commerce. En juin 1864, huit de nos chalands avaient échoué en face de Daoudel, à six lieues au-dessus de Saldé. Ils furent altaqués par Ould-Eyba, le chef des Bosséyabés. Après un combat de plusieurs heures, quatre des patrons eurent la soltise de se rendre, car il était bien imprudent de se mettre à la merci de vrais brigands; les autres, mieux inspirés, réussirent à s'enfuir. Il était impossible de tolérer plus longtemps, en pleine paix, de pareils brigandages. Une expédition fut résolue.

Le 15 juillet 1864, le capitaine de frégate Aube et le colonel Despallières quittaient Saint-Louis, à la tête de huit cent six hommes. Le 18, un premier engagement avait lien à Daouadel, et le village était brûlé. Le 19, le colonel Despallières cernait l'immense village de Kaidi, sur la rive droite, ct brûlait deux cents tentes de Maures et près de deux mille cases de Toucouleurs, avec tout ce qu'elles contenaient. Le lendemain 20, c'était le tour des villages bosséyabés, dont l'incendie annonçait aux riverains que la France étail désormais résolue à venger ses injures. Les Bosséyabés, terrifiés, implorèrent leur pardon, et nos soldats rentrèrent à SainlLouis (24 juillet). Celte fois encore nous étions vainqueurs; 
mais notre victoire allait demeurer stérile, car ces barbares ne connaissent que le droit de la force. A peine ont-ils reconstruit leurs huttes qu'ils recommencent leurs déprédations. C'est pour eux une question de vie ou de mort. Le pillage est en quelque sorte leur industrie nationale. Il faut ou les exterminer ou les réduire à l'impuissance par une occupation définilive.

Abdoul-Boubakar, sans doute excité par les Toucouleurs de Ségou et de Kaarla, ne se laissa pas intimider par l'exéculion des Bosséyabés. Rêvant de reconstituer à son profit l'ancien royaume du Fouta, il redoubla d'insolence à notre égard. Il en arriva même bientôt à des insultes directes. Non content de brùler, à diverses reprises, les poteaux de la ligne télégraphique entre Saldé et Bakel, il accabla de vexations nos négociants et annonça qu'il allait bientôt entrer en campagne pour jeter les Français à la mer. La faiblesse du gouverneur Vallière l'encourageait dans ses prétentions. Il se persuada, non sans une apparence de raison, que le gouverneur hésiterait à se prononcer contre lui, et même qu'il renoncerait au Foula, comme il venait de renoncer au Cayor; mais il allait se heurter contre une volonté bien arrêtée, et ses espérances furent bienlôt dissipées.

Brière de l'Isle avait succédé à Vallière en 1876. Convaincu de la nécessité de réagir contre les reculs inexplicables de son prédécesseur, il se détermina à comprimer ces velléités de révolte. Dès 1877, une colonne d'observation était envoyée contre Abdoul-Boubakar; mais le chef toucouleur signait aussitôt à Galoyo (octobre 1871) une trêve par laquelle les différents chefs du Toro reconnaissaient les traités anlérieurs et acceptaient notre suprématie. La trêve était presque aussitôt rompue par Abdoul-Boubakar, qui annonçait qu'il s'opposerait par la force à l'établissement d'une ligne télégraphique de Saldé à Matam. Il fallait châtier cette insolence. En février 1881, le colonel Pons était envoyé contre un des villages toucouleurs les plus compromis, Orefonda. Un grave échec marqua les débuts de l'expédition. Le capitaine Badenhuyer, avec cinquante spahis et trente disciplinaires, avait été envoyé chercher des vivres à bord de la flotlille, restée à 
l'ancre près du village de Mbirboyan. Il fut surpris à N'dourbabian par des forces supérieures, et fut tué, après une résistance héroïque, avec vingt-deux de ses hommes. Le colonel Pons le vengea. Il parcourut le Fouta, brûla trente villages et fit de nombreux prisonniers. Réduit à la dernière extrémité, Abdoul-Boubakar signa un traité par lequel il s'engageait, moyennant un traitement annuel, à protéger nos négocianls et à laisser exécuter la ligne télégraphique. Il est vrai que ce trailé ne devait être qu'une lettre morte, et que notre infatigable adversaire allait se joindre à de nouveaux ennemis de la France, à l'almamy Samory et à Mahmadou Lamine, dont nous aurons à raconter bientôt les dangereuses entreprises; mais l'impression n'en était pas moins produite, et dans tout le Fouta on comprenait la nécessité de respecter les volontés de la France.

Brière de l'Isle fit également respecter notre drapeau par les tribus du haut fleuve. Aux environs de Médine, le chef du Logo, Niamody, avait fait de sa capitale Sabouciré, à seize kilomètres en amont de Médine, un centre de résistance. Il avait même provoqué notre commandant de Médine, en lui écrivant qu'il meltrait à mort tout Français, blanc ou noir, qui pénélrerait dans ses États, et il s'était répandu en épouvantables menaces contre notre fidèle allié, le vieux Sambala. Une colonne expéditionnaire, commandée par un vaillant officier, le lieutenant-colonel d'infanterie de marine Reybaud, fut aussitôt dirigéc contre Sabouciré. Elle comptait cinq cent quatre-vingt-cinq hommes, quatre-vingts chevaux et quatre canons. Partie de Saint-Louis le 10 septembre 1878, elle arrivait le 22 septembre devant la citadelle nègre. Un violent combat s'engagea. Il dura cinq heures, et se termina par la prise et la destruction de Sabouciré. Niamody fut tué dans la bataille, et à ses côlés tombèrent cent cinquante Toucouleurs, sans compter ceux qui se noyèrent dans le fleuve. Nous avions eu treize tués, dont deux officiers, et cinquante et un blessés. Cette exéculion sommaire rétablit notre crédit compromis, mais la victoire nous coûta bien cher; car " les troupes s'élaient à peine embarquées sur nos avisos pour rejoindre Saint-Louis que la fièvre jaune s'élait aballue, sombre el 
implacable, sur les officiers et les soldals qu'avaient épargnés Jes balles des Malinkés ou les fièvres du Logo. Les bateaux s'arrêtaient sans cesse pour permettre de creuser sur la berge les tombes des victimes, ensevelies dans de simples toiles de hamac. " (Rapport du capilaine Gallieni.)

En résumé, grâce à ces énergiques manifestations, tous les États riverains du Sénégal sont aujourd'hui ou directement administrés par nos agents ou soumis à notre influence. C'est un immense progrès qui a élé réalisé en peu d'années.

Nos gouverneurs ne se sont pas contentés d'annexer ou do réduire à l'obéissance les États riverains du Sénégal. Ils ont également cherché à étend:e les possessions françaises sur toutes les contrées baignées par les fleuves parallèles au Sénégal qui s'étendent entre Gorée et Sierra-Leone. C'est ainsi que les vallées de la Casamance, du Rio-Nunez, de Rio-Pongo, de la Mellacorée, etc., ont été successivement ajoutées à notre domaine colonial; mais c'est surtout dans la vallée du haut Sénégal et dans celle du Niger, c'est-à-dire dans le Soudan, que s'est exercée notre activilé. De là un double courant d'opérations de guerre ou d'entreprises commerciales qu'il importe d'exposer avec quelque détail, car nous assistons depuis peu à une vigoureuse reprise en avant du mouvement colonial; ct comme de nouvelles contrées s'ouvrent aux ardentes investigations de nos soldats et de nos négociants, il est nécessaire de présenter avec quelque développement ces épisodes, dont la portée économique et politique n'échappera à aucun de nos lecteurs.

\section{$\mathrm{X}$}

VOYAGES DE PENTRATION AU SOUDAN

L’idée de joindre le Sénégal au Niger par une série de posles à la fois commerciaux et politiques, et de faire rayonner au loin dans le Sahara, et par conséquent dans l'Afrique centrale, l'influence et la civilisation françaises, n'est pas une idée nouvelle. André Brue, au dernier-siècle, avait 
déjà essayé de la réaliser. Le général Faidherbe, dès qu'il eut triomphé des difficultés de la première heure et assis sur des bases désormais inébranlables la domination de la métropole, s'empressa de reprendre le grand projet qui était en quelque sorte le couronnement de ses entreprises antérieures. «Il nous faudrait, écrivait-il à Mage le 7 août 1863, une ligne de postes distante d'une trentaine de lieues entre Médine et Bamakou, ou tout autre point du haut Niger qui paraîtra convenable pour élablir un centre commercial sur le fleuve. " C'est seulement dans les dix dernières années que du domaine théorique ce projet passa dans la réalité, et qu'une succession d'explorations hardies et de campagnes heureuses non seulement nous a conduils sur les bords du Niger, mais encore nous a permis de fonder en pleine Afrique un véritable empire et a ouvert aux légitimes espérances de nos économistes et de nos hommes d'État un champ pour ainsi dire illimité. Si, en effet, nous savons nous servir du merveilleux instrument de renaissance coloniale que notre bonre fortune met en ce moment entre nos mains, c'est sur les bords du Niger et dans la direction du Soudan que nous trouverons nos Indes africaines.

Nous ne saurions oublier les ouvriers de la première heure, ceux de nos compatriotes qui ont frayé la voie aux dépens de leur santé, parfois de leur vie, et qui, de gaieté de cœur, se sont exposés, pour la plus grande gloire de la patrie, aux hasards ou plutôt aux dangers d'une exploration à travers des pays ennemis ou barbares. Parmi ces héroïques pionniers de la civilisation brille au premier rang René Caillié. Nul aussi bien que lui ne mérite une place à part parmi les voyāgeurs, tant il a déployé de courage, tant il a su, sans atlache officielle, faire avec simplicilé de grandes choses.

René Caillié ${ }^{1}$ naquit à Mauzé, dans les Deux-Sèvres, le 19 novembre 1799. Il appartenait à une humble famille. Son père élait boulanger, et encore le perdit-il de bonne heure, ct fut-il obligé de gagner sa vie en devenant, à l'âge de onze ans, apprenti cordonnier. Le vicil instituteur qui lui avait appris

1. René G.ıIluÉ, Journal d'un voyjage à Temboctou et à Jenné, dans l'Afrique centrale, précédé d'observations faites chez les Maures Braknas, les Nalous et d'autres peuples, pendant les annćes 1824 à 1828; 3 vol. in-80, Paris, 1830. 
à lire exerça sur lui une incroyable influence en lui racontant, à la veillée, les exploits des conquistadores espagnols et les voyages de Cook et de Lapérouse. Il brûlait déjà du désir de les imiter, et se passionnait pour leurs aventures. La lecture de Robinson Crusoé fit sur lui une impression profonde. "Je brûlais d'avoir des aventures, a-t-il écrit plus tard; déjà même je sentais naître dans mon cœur l'ambition de me signaler jar quelque découverte importante. "Aussi se prépara-t-il de bonne heure à chercher fortune hors de France. Malgré les représentations de sa famille, il s'embarqua à Rochefort, à l'âge de seize ans, ayant en poche pour toute fortune soixante francs qu'il avait économisés à grand'peine et en se privant de tout plaisir.

La gabare la Loire, sur laquelle était embarqué Caillié, marchait de conserve avec la Méduse, de sinistre mémoire. C'était un fàcheux début. A peine arrivé à Saint-Louis, Caillié apprend qu'une expédition anglaise, commandée par le major Gray, est à la veille de partir pour le Niger. Il se met aussitôt en route pour la rejoindre en Gambie, et n'hésite pas à s'engager à pied dans les solitudes sablonneuses du Cayor. Cette première course fut très douloureuse, à cause de l'extrême fatigue et surtout du manque d'eau. Elle fut, de plus, inutile, car, à peine arrivé à Dakar, Caillié apprenait le départ de la caravane anglaise et était obligé de revenir à SaintLouis. Il quilla celte ville presque aussitôt et alla à la Guadeloupe, où il ramassa quelque argent; mais la lecture de la relation de voyage de Mungo-Park exerça sur lui une telle fascination, qu'il renonça à sa naissante fortune et ne songea plus qu'à se lancer sur les traces de l'héroïque Écossais.

Dès 1818 nous retrouvons Caillié au Sénégal. Il s'engage dans la caravane Partarrieu, qui allait rejoindre le major Gray. Ceile fois encore le voyage échoua, et les souffrances endurées le furent en pure perte. "On m'a dit depuis que j'avais les yeux hagards, que j'étais haletant, que ma langue pendait hors de ma bouche. Pour moi, je me rappelle qu'à chaque halte je tombais par terre, épuisé, et n'ayant pas même la force de manger. " Arrivés à Bakel, les explorateurs furent obligés de descendre le fleuve et de retourner en France. 
Malgré ce double échec, Caillié était toujours possédé par la passion des voyages. Après un court séjour aux Antilles, il revenait une troisième fois à Saint-Louis, à titre d'employé dans les bureaux de la direction de l'artillerie (1824); mais il rêvait toujours de s'enfoncer dans le centre inconnu du continent africain. Le point lumineux qui l'attirait était Tombouctou, cette ville légendaire, ce rendez-vous mystérieux des caravanes, dont aucun Européen n'avait encore aperçu les monuments, et que les géographes ne connaissaient que par les trafiquants arabes. Pénétrer jusqu’à Tombouclou était le rêve qui tourmentait Caillié. Plusieurs voyageurs, tous des Anglais, avaient déjà tenté de le réaliser, MungoPark, Denham, Oudney, Clapperton, Gordon-Laing. Seuls Denham et Clapperton étaient revenus en Europe, mais après des efforts surhumains et sans avoir pu satisfaire leur curiosité. Ces Anglais avaient eu l'appui de leur gouvernement; ils s'étaient fait accompagner d'escortes chèrement recrutées; ils apportaient avec eux de riches présents pour payer leur passage. Caillié, bien que traité avec égards par le gouverneur d'alors, baron Roger, n'avait pour toute ressource que deux mille francs, produit de ses économies personnelles. Il était seul, sans autre secours de la part de ses compatriotes que celui de M. Castagnet, riche négociant français établi à Kakondy. Mais il avait pour lui une invincible opiniâtreté, un courage à toute épreuve et une présence d'esprit sans laquelle il lui eût été impossible de sortir des mauvais pas qu'il rencontra si souvent sur son chemin. De plus, il savait très bien la langue arabe et n'hésita pas à se lier avec des négociants nègres, des Mandingues, venus à Kakondy avec de la poudre d'or. Pour se concilier leur confiance, il inventa une fable qui réussit parfaitement près de ses nouveaux amis.

"Un jour, d'un air mystéricux, lisons-nous dans sa relation, je leur révélai, sous.le sceau du secret, que j’étais né en Égypte de parents arabes, et que j'avais été emmené en Europe dès mon plus bas âge, par des Français faisant partie de l’armée qui avait conquis l'Égypte; que depuis j'avais été conduit au Sénégal pour y faire les affaires commerciales de mon maître, qui, satisfait de mes services, m'avait affranchi. "Maintenant, 
"ajoulai-je, libre d'aller où je reux, je désire nalurellement "rclourner en Égyple pour y retrouver ma famille et repren" dre la religion musulmane. " $\mathrm{Si}$, au premier abord, mes auditcurs purent nourrir quelques doutes à l'égard de mon histoire et de mon zèle religieux, ils n'en conservèrent aucun dès qu’ils m’entendirent réciter par cœur plusieurs passages du Coran, et qu'ils m'eurent vu chaque soir faire le salam arec eux. Ils finirent par se dire l'un à l'autre que j'étais bon musulman. C'est celte fable, répétée chaque fois que j'en ai cu besoin, qui m’a servi de passeport de Kaliondy à Timé, de Timé à Tombouctou et de là à Tanger ${ }^{1}$."

Ce fut donc sous le couvert d'une apostasie simulée que Caillié put accomplir son merveilleux voyage. D'autres l'araient essaré aussi, et n'araient pas réussi, notamment Walt et Winterbaltone, qui, en 1794 , avaient pénétré jusqu’à Timbo déguisés en chérifs, mais qui, reconnus pour chrétiens, avaient élé trop heureux d'en ètre quiltes pour être ignominieusement chassés. Caillié connaissait donc le danger de son déguisement; mais il arait fait de la langue, de l'écriture et des usages musulmans une étude si scrupuleuse, qu'il put prolonger liillusion jusqu'au bout, et se faire accepter par tous comme un derriche mendiant. Le plus difficile pour lui pendant tout son royage devait être de prendre des notes. Il arait imaginé d'emporter des feuillets de Coran en arabe, imprimés sculement sur le recto. Il s'écarlait de ses compagnons, et, sous prétexte de lire le livre sacré, prenait en hâte toutes scs notes. "Elles seraient devenues contre moi, a-t-il écrit, une pièce de conviction inexorable, si j'arais été surpris traçant ¿'es caraclères étrangers, et dévoilant aux blancs les mystères de ces contrées. Je portais toujours dans mon sac mon arrêt te mort. et combien de fois ce sac a dù être confié à des mains ennemies! " En outre, Caillié n'avait reçu qu'une insIruction très élémentaire, et, comme instruments de précision, il n'emportait arec lui que deux boussoles de poche, un bâton qui arait juste un mètre de longueur, deux ou trois cordons arec un fil à plomb et des crayons. Pourtant il recueillit par- 
tout des renseignements très précis, et il s'était habitué à évaluer, rien qu'en marchant, les distances avec une telle exactitude, qu'on a pu dresser la carte et retracer l'itinéraire de son voyage.

Le 19 avril 1827, Caillié partait de Boké, sur le Rio-Nunez, plein d'espérance dans la réussite de ses projets. Après vingt jours de marche, il arrivait en plein massif du Fouta-Djallon. Il lui fallut trois mois pour franchir ce massif, jusqu'alors inconnu aux Européens. Dans ces petites républiques mandingues, chez ces Foulahs, pâtres ou laboureurs, Caillié n'eut pas toujours à se louer de l'hospitalité des habitants. Aussi arriva-t-il à Timé harassé de fatigue, affaibli par les privations et le manque de soins. Une blessure au pied l'obligea même à un repos que ses forces épuisées rendaient nécessaire. Loin de pouvoir profiter de celte halte, il fut pris par uno fièvre maligne qui lui enleva le reste de ses forces et le relint longtemps chez une vieille négresse, qui se montra pleine de complaisance et d'égards à son endroit. Grâce aux bons soins de celte pauvre femme, Caillié finit par se remettre. Après un mois de convalescence, il se trouva assez forl pour continuer son voyage, et se diriger sur Jenné, ville importante située sur les bords du Niger.

Il allait parlir et n'altendait plus qu'une occasion favorable, quand un nouveau malheur vint le frapper. Le scorbut l'atlaqua et le conduisit aux portes du tombeau. "Que l'on s'imagine ma position, écrivait-il : perdu dans l'intérieur d'une contrée sauvage, couché sur la terre humide, n'ayant d'autre oreiller que le sac de cuir qui contenait mon bagage, sans autres soins que coux que m'accordait la bonne vieille mère Baba. Je fus bientôt réduit à l'état de squelette. Je perdis loute mon énergie. Le mal seul absorbait mes idées. Il no me restait que deux pensées, celles de la mort et de Dieu ${ }^{1}$. "

Certes il était dur pour un homme aussi vigoureusement trempé de se voir mourir, emporté par une lente maladie, sans secours, loin des siens, au milieu de cette ténébreuse - Afrique, et cela quand il élait en si bon chemin et avait l'as-

1. Journal, t. II, p. 23. 
surance de terminer heureusement son voyage. Telle élait pourtant sa résolution que même la perspective d'une mort prochaine ne pouvait triompher de son obstination. "J'aimais mieux mourir, écrit-il, que retourner sur mes pas sans avoir fait de plus grandes découvertes, sans avoir navigué sur une partie encore inexplorée du Niger et avoir touché à Tombouctou, celte ville mystérieuse, but principal de mon entreprise $^{1} . "$

Heureusement pour lui, une vieille femme, amie de son hôtesse, connaissait un remède à son horrible maladıe. Touchée de compassion, elle prit à tâche de le guérir. Le traitement fut énergique, mais efficace. Peù à peu Caillié reprit ses forces. Une lente convalescence le rétablit tout à fait, et la telle saison qui revint acheva de lui rendre la santé. Alors, sans attendre davantage, profitant d'une caravane qui venait des montagnes du sud, Caillié se mit en route pour Jenné (9 janvier 1828), non sans avoir fait à ses bienfaitrices les cadeaux que lui permettait son dénuement.

La caravane passait par le Bambara. Pendant les longues journées du voyage, Caillié eut le loisir d'examiner les contrées pittoresques qu'il traversait, et d'étudier les mours indigènes, souvent curieuses pour un Européen. Quoique la défiance de ses compagnons de route l'empêchât la plupart du temps de prendre des notes, et que diverses circonstances l'aient privé plus tard de presque toutes celles qu'il avait recueillies, sa mémoire était si grande qu'à son retour il put écrire une relation détaillée et fort exacte de son voyage. Il avait tout remarqué et n'avait rien oublié. Aussi son ouvrage contient-il les renseignements les plus intéressants et les plus variés. On y trouve, avec des aperçus historiques et ethnologiques, tout ce qui intéresse le commerce, l'agriculture, les coutumes domestiques. Il décrit les fêtes auxquelles il a assisté, les danses et les modes féminines. Il se rappelle avec gaieté les ornements bizarres qui font l'orgueil des beautés bambaras, les grelots qui sonnent à la ceinture, les draperies bleu foncé qui cachent les cheveux, et la botoque, mor- 
ceau d'étain pointu qui traverse la lèvre inférieure et la force à se pencher peu gracieusement. "Souvent, ajoute Caillié, je fus tenté de rire en pensant à l'étrange effet que cet ornement ferait sur les lèvres blanches et vermeilles de nos jolies Françaises. "

Depuis Timé, la caravane mit deux mois à atteindre Jenné. C'est une place de commerce importante; les caravanes de tous pays s'y croisent, y vendent leurs marchandises et en prennent de nouvelles. La ville était alors au pouvoir d'un prophète fanatique, Sego-Ahmadou. Caillié n'était pas sans quelque appréhension en pénétrant sur le territoire de ce convertisseur par le sabre. Heureusement Caillié avait emporté avec lui un modeste parapluie. Le prophète, émerveillé par cet instrument de la civilisation européenne, pria avec inslance le voyageur de le lui céder. Caillié y consentit et devint aussitôt personna grata. Non seulement il fut directement protégé, mais encore il reçut une leltre de recommandation pour Tombouctou. En outre, les marchands de Jenné lui firent bon accueil. Toute sa pacotille européenne fut échangée contre des produits indigènes, et il fut défrayé de toutes ses dépenses; puis on l'embarqua pour Tombouctou, le 22 mars 1828.

De Jenné à Tombouctou le voyage fut pénible pour Caillié. La chaleur était accablante, l'air manquait, et, de plus, le patron de la barque qui portait notre compatriote était un véritable tyran. "Non seulement il me fit jeûner plus que de droit et, m'interdisant l'intérieur de la pirogue, me força à coucher sur le pont, où les atteintes du serein et les intempéries de la nuit altérèrent profondément ma santé, mais il ne négligea aucune occasion de m'insulter grossièrement et d'exciter contre moi par son exemple les gens de l'équipage, ct jusqu'aux esclaves, malheureux toujours prêts à imiter les défauts de leurs maîtres ${ }^{1}$. " La navigation sur le Niger était lente et pénible. Les grandes barques qui composaient la flottille élaient extrêmement lourdes et, n'ayant pas de voiles, ne pouvaient avancer en temps de calme; d'un autre côté, elles étaient si fragiles que le moindre vent menaçait de les faire 
chavirer. Les matelots bambaras tiraient ces barques avec des cordes, ou, lorsque la nature des rives rendait impossible ce moyen primitif de locomotion, se servaient de perches pour pousser en avant leurs embarcalions. Les rives du fleuve ne présentaient rien de pittoresque ni d'attrayant. Le Niger coulait dans une immense plaine, sans qu'aucun accident de terrain vînt réveiller l'attention du voyageur. Parfois il était obligé de se cacher à fond de cale pour éviter les visites intéressées des Touaregs Sourgous, voleurs sans scrupules, tout disposés à piller également chrétiens ou musulmans.

Ce fut dans ce triste équipage que Caillié descendit le Niger, traversa le lac Debou, belle nappe d'eau que tous les matelots saluèrent de coups de fusil et du cri de "Salem! salem! " passa devant Sâ, riche port commerçant, et, le 19 avril 1828, arriva à Cabra, port de Tombouctou, situé à dix milles de cette ville. Le lendemain, au coucher du soleil, il réalisait son rêve et faisait son entrée à Tombouctou, entouré d'une brillante escorte que lui avait envoyée l'hôte auquel il avait été recommandé par le chérif de Jenné. "Ję voyais donc cette capitale du Soudan qui depuis si longtemps était le but de tous mes désirs. En entrant dans cette cilé mystérieuse, objet des recherches des nations civilisées de l'Europe, je fus saisi d'un sentiment inexprimable de satisfaction; je n'avais jamais éprou vé une sensation pareille et ma joic était extrême. Mais il fallut en comprimer les élans. Ce fut au sein de Dieu que je confiai mes transports; a vec quelle ardeur je le remerciai de l'heureux succès dont il avait couronné mon entreprise! Que d'actions de grâces j'avais à lui rendre pour la protection éclatante qu'il m'avait accordée, au milieu de tant d'obstacles et de périls, qui paraissaient insurmontables ${ }^{1}$. $"$

Revenu de son enthousiasme, Caillié ne tarda pas à trouver que le spectacle qu'il avait sous les yeux ne répondait pas à son attente. Pour une cité bâtie au milieu des sables, Tombouctou est une belle cité, mais fort triste, car elle est entourée par d'immenses plaines de sables mouvants, d'un blanc tirant sur le jaune, et d'une aridité désespérante. Les maisons 
sont grandes, mais peu élevées. Il n'entre dans leur construction ni pierres ni fer; les murs sont en briques roulées dans les mains et séchées au soleil. On y comptait jusqu'à sept mosquées, mais fort délabrées et d'une architecture rudimentaire. Le fond de la population est formé par les Nègres Sonrays. Les Maures y jouent le même rôle que les Européens dans les colonies, et servent de correspondants aux marchands du Maroc, du Tafilet, et mème du littoral méditerranéen.

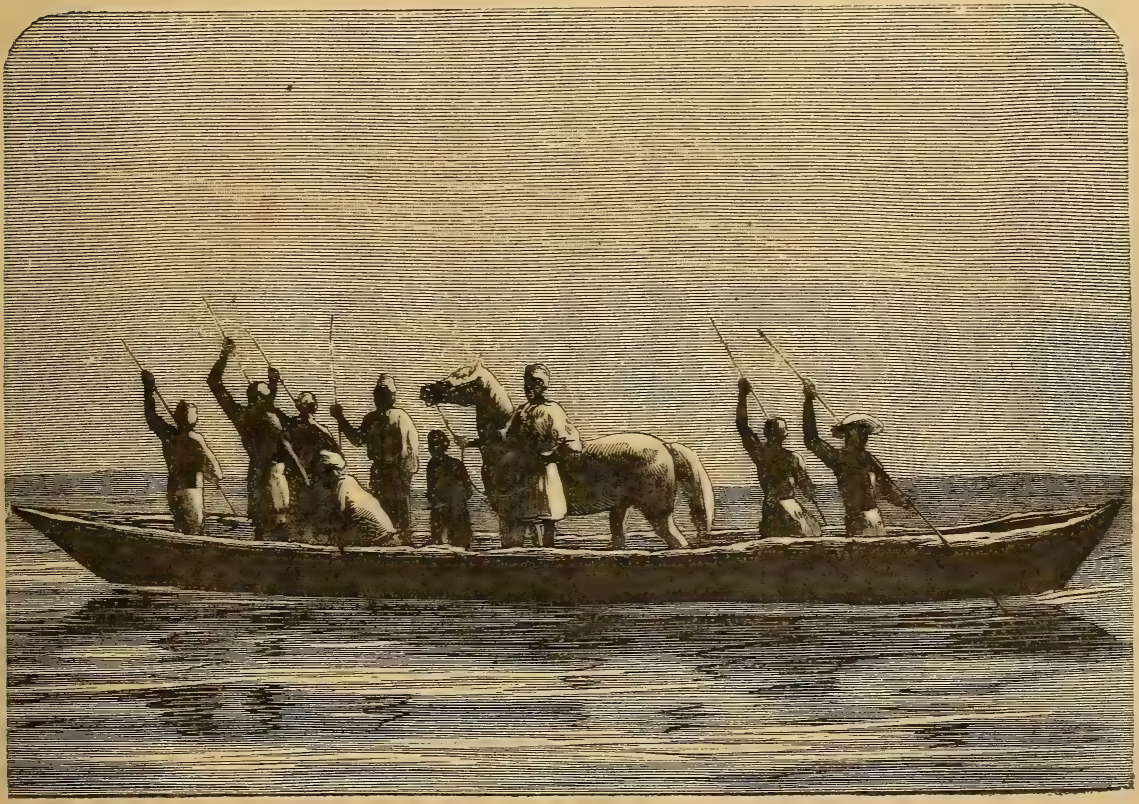

Navigation sur le Niger.

Quoique le commerce soit moins important à Tombouctou qu'à Jenné, les Maures y font rapidement de belles affaires; et quand ils se jugent assez riches, ils quittent la ville pour aller jouir de leur fortune dans leur pays natal.

L'hôte de Caillié, Sidi Abdalhah Chébri, fut plein de prévenances et de soins pour lui. Il était doux et tranquille. Sa réserve surlout plaisait fort à Caillié, car il comprenait que si on arrivait à connaître sa véritable origine et sa véritable religion, il serait immédiatement massacré. Aussi résolut-il de hâter son départ. Son hôte le pressait de rester à Tom- 
bouctou. Il lui proposait même de l'intéresser à quelque affaire commerciale et de lui fournir les moyens de faire fortune : "Les craintes que j'avais d'être découvert, jointes au désir de revoir ma patrie, m'engagèrent à refuser ces généreuses propositions ${ }^{1}$. D'ailleurs mon départ pour l'intérieur de l'Afrique, n'étant point connu authentiquement, tomberait dans l'oubli si je venais à périr, et les observations que j'avais pu faire seraient perdues pour mon pays. "

Une occasion se présenta bientôt. Une caravane allait se rendre au Tafilet par le Sahara. Caillié hésitait à s'engager dans ce désert immense; mais le désir de revoir sa patrie et la crainte d'être découvert le décidèrent à tout braver. La bienveillance de son hôte pourvut à ses besoins. Il lui assura un guide, un chameau et sa nourriture pour toute la traversée du Sahara. Il le recommanda même à son correspondant d'El-Arouan. "Le convoi destiné pour cetle ville, et dont je faisais partie ${ }^{2}$, écrit Caillié, devait se mettre en route le 4 mai au lever du soleil. Mon hôte fut debout de si bonne heure, qu'il eut le temps avant le départ de m'emmener déjeuner chez lui avec du thé, du pain frais et du beurre. C'est sous l'impression agréable de ce repas peu africain que je quillai Tombouctou, où j'avais passé qualorze jours (4 mai). "

La traversée du Sahara fut longue et dangereuse pour Caillié : tempêtes de sable brùlant, solitudes désolées, railleries ou mépris des Maures grossiers et ignorants de la caravane, rien ne lui fut épargné. Le manque d'eau surtout fut pénible. On fut obligé de boire l'eau qui avait servi à panser les plaies des animaux, et de tuer un chameau pour se partager la boisson conservée dans son estomac. L'espoir du retour le soutenait. Ce n'était plus à Tombouctou qu'il songeait, mais à la France, à la France qui allait l'acclamer.

Après avoir traversé les territoires de Drah et d'El-Harib, où il éludia les mœurs des Berbers, Caillié franchit les passes de l'Atlas, visita Fez, Mequinez, Rabat, et arriva enfin à Tanger. Là encore il était entouré de sectaires qui lui auraient fait payer cher son déguisement, s’ils l'avaient soupçonné.

1. Journal, t. II. p. 333.

2. Journal, t. II, p. $33 \%$. 
Il lui fallut user de la plus grande prudence pour échapper à leur altention. Il réussit enfin à se jeter chez notre consul, Delaporte, qui lui facilita les moyens de s'embarquer pour Toulon, où il arriva le 8 octobre.

Caillié avait donc accompli, avec un bonheur presque miraculeux, cet audacieux voyage du Sénégal au Maroc par Tombouctou. Il avait parcouru un chemin énorme au milieu de contrées jusqu'alors inconnues. Le premier parmi les Européens qui avaient pu parvenir dans la cité mystérieuse, il était assez heureux pour apporler au monde savant les résultats de son voyage. Après un moment d'hésitation ou plutôt de surprise, la France le reçut en triomphateur. Il obtint le prix de dix mille francs proposé par la Société de géographie à celui qui le premier reviendrait de Tombouctou. Il fut accablé d'autant d'honneurs qu'il avait subi d'épreuves. Il aurait certes pu se poser en héros d'aventures. Il préféra rentrer dans la vic privée, et acheta d'abord à Beurlay, dans la Charente-Inférieure, puis à la Badère, une propriété qu'il se mit à cultiver lui-même. De temps à autre son ardeur se réveillait. Il aurait voulu aller à Bamakou, puis explorer les mines du Bouré; mais sa famille le relenait. Une attaque de paralysic l'emporta, le 17 mai 1838. Des monuments ont été élevés en son honneur à Mauzé et à Pont-l'Abbé, où il fut enterré, ainsi qu'une colonne à Boké, sur le Rio-Nunez, d'où il partit pour son grand voyage, et une plaque commémorative dans l'enceinte du lycée Fontanes, à Niort. La France a le droit de s'enorgueillir de ce succès. Aussi bien, n'est-ce pas à Caillié qu'elle doit d'être, encore aujourd'hui, la seule nation qui entretienne avec Tombouctou des relations quelque peu suivies?

Le lieutenant de vaisseau Mage et son compagnon le docteur Quintin sont les successeurs immédiats de René Caillié, ct encore leur voyage n'eut-il lieu qu'en 1864, trente-six ans seulement après celui de Caillié. Le général Faidherbe fut le promoteur de cette importante expédition. Ainsi qu'il l'écrivait en 1863 dans l'Avenir du Sahara, "relier le Sénégal à l'Algérie à travers au moins quatre cents lieues de désert, quelle que soit la route que l'on suive, c'est chose impossible ou qui du moins n'aurait pas de conséquences sérieuses, par 
suite des frais énormes du transport à dos de chameau. Pour s'emparer du commerce si important du Soudan, el particulièrement du coton qui, au dire des voyageurs, s'y trouve en grande abondance et à vil prix, il faut s'emparer du haut Niger en établissant une ligne de postes pour le rallacher au Sénégal entre Médine et Bamakou. " Le lieutenant Mage fut chargé de préparer l'exécution de ce projet hardi en allant reconnaitre le pays et en signant, si faire se pouvait, un trailé d'alliance avec notre ancien adversaire de Médine, Al-HadjiOmar, le nouveau possesseur de Ségou. Mage était l'homme de la situation. Il avait déjà vécu cinq ans au Sénégal et deux sur le lilloral. Il avait été chargé de diverses missions, qu'il avait toutes remplies arec honneur et profit. Il venait de passer neuf mois à Makhana, entre Bakel et Médine, au milieu des noirs du haut fleuve, et s'était familiarisé avec leur langue et leurs usages. Il s'élait même fait aimer par eux en les prolégeant, avec sa canonnière la Coulevrine, contre les bandes d'Omar, qui tenaient encore le pays. D'un courage à toute épreuve, plein de foi dans l'œuvre qu'il entreprenait, il avait toutes les qualités nécessaires pour réussir. Son compagnon le docleur Quintin, froid, mais résolu, peu brillant, mais solide, le secondait à merveille. Il eut en outre la bonne fortune d'ètre escorté par des servileurs indigènes très braves, très dévoués, très fiers d'avoir été choisis entre beaucoup pour accompagner les deux officiers blancs.

Faidherbe leur avail donné comme instructions de reconnaître la route de Médine à Bamakou par Bafoulabé, afin d'y créer un courant commercial entre le Soudan et les possessions françaises, de négocier un traité de commerce et au besoin une alliance avec le maître de Ségou, et de revenir, suivant les circonstances, soit en descendant le Niger jusqu'à son embouchure, soit en regagnant Tunis, Alger ou le Maroc. Ce programme ne put être exécuté de point en point; mais l'œurre de nos explorateurs fut suffisamment grande, et il faut leur savoir gré de ne pas avoir connu un instant de défaillance au milieu des épreuves qui les attendaient.

Nous ne pouvons suivre ce voyage dans tous ses délails'.

1. Relation, p. 30. 
Il nous suffira de rappeler que, partis de Saint-Louis le 12 ociobre 1863, Mage et Quintin arrivaient à Ségou seulement le 28 février 1864 . Chemin faisant, ils prenaient des renseignements précis sur les ressources locales, sur les besoins commerciaux, sur les chances qu'avait la France d’ètre bien accueillie. Le grand trafic élait celui des esclares, surtout des captifs de guerre, dont le nombre arait singulièrement augmenté depuis les grandes dévastations d'Omar. Les caplifs élaient mème devenus comme une monnaie courante. Un cheval, un bœuf élaient estimés un esclave, un demi-esclave, etc., et nos compatriotes furent mème obligés de cheminer quelque temps arec un trafiquant de chair humaine. "Possesseur d'une petite fortune, lisons-nous dans la Relation, cet homme s'était mis en marche, achetant d'abord une esclave dont il avait fait sa femme, et qui, lui ayant donné un enfant, sétait élevée au rang de femme libre. Un fort captif portait l'enfant, puis trois autres jeunes filles, éclopées par la longue route qu'elles venaient de faire, les jambes enflées, suiraient, s'aidant d'un bâton. Outre cela, un malheureux enfant de trois à quatre ans, aux membres maigres, courait entre les jambes des cheraux, faisant des marches de cinq à six lieues; le docteur avait pris cet enfant en amitié et souvent il le mettait devant lui à cheval. Quant aux femmes, quelque endurci que je fusse, je ne pouvais voir ces malheureuses au moment du départ, les membres engourdis, trop faibles pour se lever; sourent leur maitre arrivait, les frappait, et une larme coulait silencieusement le long de leurs joues. Sans doute elles pensaient au lieu de leur naissance, à la case de leur mère, et lentement, péniblement, elles se mettaient en marche. "Tout en déplorant cet abaissement de la dignité humaine, Mage et Quintin ne pouraient s'empêcher d'admirer les types superbes qüils rencontraient de temps à autre. Sauf le front bombé à l'excès et les pommeltes saillantes, tel de ces indigènes aurait pu rivaliser pour la beauté accomplie des formes arec les modèles de l'art ancien. Nos explorateurs admiraient aussi les magnificences de la nature : La plaine splendide du Natiaga se déroulait au loin, et allait se perdre dans des gorges étroites, surmontées de pics nombreux.. Je ne pourais me lasser d'ad- 
mirer ce pays où la Providence a semé ses biens arec une prodigalité peu commune. La terre y est d'une richesse incroyable; l'eau y abonde et y fournit des poissons succulents. L'or est à quelques pas du défilé que je vois à ma gauche; le fer partout. Le fleure abonde en chutes dont la force molrice serait incalculable; mais la main des hommes n'a rien fait de ce monde de richesses; les indigènes n'ont pas su seulement tirer de quoi se rêtir proprement ${ }^{1}$. »

Lorsque Mage et Quintin arrivèrent à Ségou, iḷs n'y rencontrèrent pas Omar, qui était parti pour la conquète du Iacina, mais son fils Ahmadou, auquel il avait délégué tous ses pouvoirs. Des bruits de défaite et même de mort commençaient à circuler : ils n'étaient que trop fondés, puisque Omar venait en effet d'ètre tué à Hamdallahi; mais son fils affectait une imperturbable confiance, et, sous prétexte que les envoyés français n'avaient été accrédités qu'auprès de la personne de son père, il les retint à Ségou. Ressentait-il la confiance dont il se targuait, et attendait-il récllement des nouvelles du théâtre de la guerre, ou bien redoulait-il que nos envoyés, s'il les relâchait, ne fussent trop vite au courant de la vérité? Cédait-il encore à un sentiment de méfiance auquel le poussait un de ses conseillers intimes, ou obéissait-il à ce fatalisme musulman qui aime à reculer les décisions importantes? Toujours est-il que les représentants de la France royaient les mois s'ajouter aux mois, et qu'on les retenait à Ségou, prisonniers arec les apparences de la liberté, et mème cntourés d'honneurs, mais prisonniers. Ahmadou leur proposa même de le suivre dans les expéditions qu'il préparait contre des rebelles. Cédant aux ennuis de l'inaction, nos envoyés crurent pouroir se départir de la neutralité que leur commandaient les fonctions dont ils étaient investis, et acceptèrent les offres du maitre de Ségou.

De toutes ces campagnes africaines, les plus dramaliques furent marquées par la bataille de Toghou et par le siège de Sansandig.

Ln prince africain, Mari, s'élait rérolté, et arait poussé 
jusqu'à huit lieues de la capitale, jusqu'au village fortifié de Toghou. Ahmadou se contenta d'envoyer contre lui une simple division, commandée par un certain Tierno Alafane; mais elle fut dispersée, et l'insurrection prit tout à coup un caractère inquiétant. Ahmadou concentra aussitôt quatre nill'e cavaliers et six mille fantassins, et, à leur tête, marcha contre les rebelles. Avant d'engager le combat, il ordonna, suivant le rite introduit par son père, une confession générale et publique, la fameuse cérémonie des liouloulous ${ }^{1}$, ou restitution des objets pillés à la guerre et soustraits au parlage général : "Cette opération fut longue; nul soldat ne se décidait à commencer; enfin, lentement, très lentement, on en vit se lever : l'un restituait un peigne, l'autre une outre en peau de bouc, un couteau, un chapelet; enfin l'un avoua qu'il avait vendu un fusil cinq mille cauris, disant que, s'il était tué, il avait un esclave qui représentait plus que cette valeur; un autre confessa le détournement d'un captif, dont il avait dissipé le prix. "

Pendant ce temps les révoltés avaient pris leurs dispositions pour résister; mais Ahmadou avait ordonné à ses soldats de ne tirer qu'à bout portant. L'effet produit par celte décharge sur une foule compacte fut incroyable. En un clin d'œil toute l'armée ennemie fut enfoncée et rejetée aux portes de Toghou, où ils tombèrent en rangs serrés les uns sur les autres. On n'eut plus que la peine de les tuer avec des fusils chargés de douze à quinze balles. Mage et Quintin, qui avaient pris part à la bataille, pénétrèrent dans Toghou en même temps que les vainqueurs, mais ils en rapportèrent une impression profonde de répugnance: "Dans les maisons, dans les rues, les cadavres étaient étendus dans toutes les positions. Au réduit où l'on s'était si longtemps défendu, chaque case était transformée en un charnier infect. Les toitures, enflammées par le haut, avaient brùlé des centaines de malheureux, dont les cris sourds avaient seuls révélé l'agonic. Dans quelques cases on s'était pendu de désespoir. A une des portes de la ville, plus de cinq cents cadavres étaient couchés les uns sur les autres :

1. Relation, p. 90 . 
c'était la porte attaquée par les talibés. Plus tard j'allai dans les broussailles. Le sol n'y était, comme celui du village, qu'une litière de morts, et le lendemain, lorsque de dessous les décombres enflammés on eut retiré ces cadavres à demi brûlés et qu'on les eut traînés dans la plaine, l'odeur infecte qui s'en exhalait empestait l'air à une grande distance ${ }^{1}$. ")

Les scènes de vengeance ou de pillage qui suivirentla victoire furent plus odieuses encore. Tous les prisonniers furent froidement égorgés. Après un interrogatoire sommaire, on les conduisait au bourreau, un nègre de taille gigantesque, à la figure bestiale, qui d'un seul coup de sabre enlevait la tête de la victime. Mage remarqua que presque tous les cadavres avaient la figure souriante. "Leurs yeux avaient une inexprimable expression de douceur. Peut-être ces victimes du despotisme et de la barbarie, qui n'ont jamais été mises en contact avec une religion plus élevée, et dont le bon sens repousse l'islamisme, ont-elles eu conscience. au moment de la mort, d'une seconde vie meilleure; peut-être un horizon lumineux leur est-il apparu. " Quant au pillage, il fut exécuté avec conscience. Les vainqueurs emportèrent tout, jusqu'aux chandeliers du pays, tiges en fer munies de coquilles, où brûle, trempée dans de l'arachide ou du beurre de karité, une mèche de coton. Les femmes réduites en esclavage, vieilles ou jeunes, furent chargées de leurs propres dépouilles, et ce bétail humain prit le chemin de Ségou. Toutes celles qui manifestaient la moinde velléité de mécontentement ou la moindre fatigue étaient aussitôt assassinées. "Je fus témoin d'un acte de ce genre, écrit $\mathrm{Mage}^{2}$, et il me fallut rester calme et ne pas faire sauter la lête du misérable qui venait de le commettre. Nos laptots et quelques talibés même en étaient indignés; mais ils formaient l'exception, et la masse passait, ne donnant à la victime qu'un signe de dédain, accompagné de celte exclamation, qui devait être sa seule épitaphe: "Keffir! "

Le siège de Sansandig fut fécond en épisodes plus dramatiques encore. Pendant soixante-douze jours les assiégeants campèrent sous les murs de la ville, qui était en proie à toutes

1. Relation, p. 94.

2. Relation, p. 94 . 
les horreurs de la famine; car les habitants furent réduils à se nourrir de peaux de bœuf et de chevaux crevés, exposés à des pluies tropicales el décimés par la peste. "Sur le fleuve dérivaient, à demi cousus dans des nattes, les cadavres venus de la ville, et dont le nombre augmentait tous les jours. De quelque côté que vînt la bise, elle nous apportait des odeurs nauséabondes et des miasmes putrides. Ces cadavres empestaient le camp, et semblaient chargés de venger les souffrances de leurs compatriotes. Néanmoins tout le monde dans l'armée dévorait Sansandig des yeux, comme une proie qu'on tenait enfin. " Plusieurs assauts furent livrés, tous sans résultat, à cause des fautes stratégiques d'Ahmadou. "Ses irrésolutions laissèrent toujours échapper les occasions favorables d'altaquer l'ennemi, et sa barbarie implacable, qui n'épargnait aucun prisonnier, quelle que fût son origine, retrempa toujours, au moment décisif, dans la haine et le désespoir, la résolution ébranlée de ses adversaires aux abois. "Survint une armée de secours, qui remporta sur les troupes d'Ahmadou un succès inespéré, mais ne sut pas profiter de la victoire. Le sultan de Ségou se décida pourtant à battre en retraite, mais fièrement et sans se laisser entamer.

Pendant ce temps le bruit de la mort d'Omar à Hamdallahi prenait de la consistance. Ahmadou était certainement informé de cette catastrophe, qui réduisait sa puissance ; mais il ne voulait rien laisser paraître de sa déception, surtout aux yeux des Français. D'un autre côté, il ne pouvait indéfiniment les retenir auprès de lui. Prétextant le retour des serviteurs nègres de Mage, qui étaient revenus de Saint-Louis et annonçaient que Faidherbe rappelait auprès de lui ses envoyés, Ahmadou se détermina, malgré la prétendue absence de son père, à signer avec eux un traité et à leur rendre la liberté. Voici les termes de cette convention, le premier instrument diplomatique régulier que la France ait signé avec un des maîtres du Soudan.

Traité passé entre MII. Mage et Quintin, envoyés du gouverneur du Sénégal, et S. M. Ahmadou, fils de Cheich-El-Hadji-Omar, roi de Ségou.

I. - La paix est faite entre tous les pays respectifs où demeurent les deux chefs. 
II. - Les hommes du gouverneur du Sénégal pourront circuler librement dans tous les pays où commande Ahmadou, dans tous ceux où il pourra commander plus tard, et y seront protégés, qu'ils viennent pour commerce, missions ou simple curiosité.

III. - Lne fois qu'ils auront payé le droit d'un dixième auquel sont soumises toules les caravanes entrant dans les États d'Ahmadou, les duilas ou marchands du Sénégal n’auront plus rien à payer à qui que ce soit pendant tout leur séjour.

IV. - Ahmadou promel d'ourrir toutes les routes du pays qu'il commande vers nos comptoirs.

V. - Le gouverneur du Sénégal promet que la roule du Fouta aur pays d'Ahmadou sera ouverte et que les hommes ou femmes pourront y circuler librement sans qu'aucun chef puisse les arrêter.

VI. - Les hommes envoyés par Ahmadou à Saint-Louis pourront y acheter ce dont ils auront besoin, et recevront dans la route protection contre tous ceux qui voudraient les maltraiter.

VII. - Tous les marchands venant du Sénégal dans un pays où commande Ahmadou payeront le droit d'entrée dans le chef-lieu qui sera le but de leur royage, Dinguiray, Koundian, Mourgoula, Kouniakary, Niuro, Diolo, Tambacara, Diangouté, Farabougou ou Ségou-Sikoro.

Telle fut cette première exploration officielle de la France dans le Soudan. Certes, rien encore n'annonçait ni même ne faisait prévoir la future prise de possession de celte immense contrée par la France; mais un puissant souverain · indigène s'était engagé par un acte solennel, et la porte était ouverte sur le mystérieux continent. Restait à compléter ce premier et grand résultat, si rapidement obtenu, en se lançant résolument à la conquête pacifique de la région.

Bien des années pourtant devaient encore s'écouler avant que les successeurs de Faidherbe aient songé à profiter des clauses du traité de Ségou. C'est un simple particulier qui, presque sans ressources, osa s'aventurer de nouveau dans ce pays ou trop oublié ou trop dédaigné, et, comme autrefois Caillié, força le gouvernement à sortir de son indifférence systématique. Ce nouveau pionnier de la civilisation lest Paul Soleillet, qu'une mort prématurée vient d'enlever à la science, qüil honorait, et à sa patrie, qu'il adorait. Ce fut un grand cœur et un noble esprit. Nous avons eu l'honneur de compter au nombre de nos amis cet héroïque découvreur. On nous pardonnera de ne rappeler son souvenir qu'avec une sympathique émotion. Jamais nous n'oublierons sa parole chaude 
ct vibrante, ses gestes simples et nobles, et son patriolisme convaincu. Ce n'était pas un chercheur de mots, un entasseur de périodes ronflantes : il racontait ce qu'il avait fait, mais que de grandes choses il avait faites! C'est par l'Algérie qu'ii commença à altaquer le mystérieux continent qui semble s'ouvrir avec tant de peine à nos investigations. En 186 , 1866 et 1867, il parcourut dans tous les sens notre belle colonie. En 1872, il visita successivement les oasis du Sahara algérien, les Ksours du Djebel-Amour, la ville sainte d'Aïn-Madhi, le Mzab et le pays des Chambâas. Dans ce dernier voyage il acquit la conviction qu'un simple particulier, n'appartenant ni au gouvernement ni à l'armée, pouvait, tout en conservant sa qualité de Français et de chrétien, voyager dans tout le Sahara, pourvu qu'il acceptât les mœurs et coutumes des indigènes et se présentât à eux sans escorte. En effet, dès l'année suivante il se mettait en marche pour Insalah, avec l'espoir de gagner de là Tombouctou et le Sénégal. Les Insaliens ne voulurent pas le recevoir dans leurs murs, bien qu'il fût arrivé en vue de la mystérieuse cité, et il fut obligé de rentrer précipitamment en Algérie. Il n'avait fait, comme il l'a dit plus tard, qu'entrevoir la terre promise; mais son voyage ne fut cependant pas stérile. Il en rapporta une foi profonde dans la possibilité d'établir un chemin de fer à travers le Sahara, et de joindre par conséquent l'Algérie au Sénégal. Seulement, au lieu de s'obstiner à rester en Algérie, il changea tout à coup de plan; et résolut de porter vers le Sénégal toute l'aclivité et tout le dévouement dont il se sentait capable.

Le 8 avril 1878, Soleillet débarquait à Saint-Louis, bien déterminé à gagner Alger en passant par le Niger. "Un inconnu le prie de lui écrire un mot en souvenir de son départ, et Soleillet trace sur un chiffon de papier celle phrase qui se passe de tout commentaire: "Si je ne réussis pas, je recommencerai ${ }^{1}$. " Il partait sans autre escorte qu'un tirailleur sénégalais, accompagné de trois bœufs pour transporter son bagage. Aucune arme, au moins apparente. Aucun

1. Gravier, ouvrage cité, p. 25. 
appareil. Il poussait la simplicité jusqu'à adopler le costume du pays, persuadé que la confiance qu'il lémoignait aux indigènes en venant ainsi au milieu d'eux flatterait leur amourpropre et faciliterait la tâche qu'il s'était imposée. Ses prévisions se réalisèrent. Partout il reçut un accueil empressé, même de la part de populations notoirement hostiles, même dans des contrées qui ne reconnaissaient pas notre suprématie. On se pressait aulour de lui, on le consultait, car tous les nègres croient à la supériorité médicale des Européens. Au moins ce docteur improvisé n'eut-il à se reprocher aucune ordonnance maladroite. Il n'opérait qu'à coup sûr, et ses prescriptions étaient uniquement hygiéniques. Les nègres se montraient reconnaissants el subvenaient à tous ses besoins. Ils lui servaient même de guides et le recommandaient à leurs amis d'un village à l'autre. Un seul jour, le 6 août, dans le village de Dziongo, il fut brutalement repoussé par le chef indigène, qui ne voulut ni lui fournir une case ni lui donner des vivres. Soleillet, avec une grande présence d'esprit, se dirige aussitôt vers le tata du chef récalcitrant, y choisit une case qui lui paraît en bon état, donne l'ordre de la balayer et s'y installe. Le chef, surpris, se dirigea vers lui, et dès ce moment se montra plein de prévenances ${ }^{1}$. " Cet Européen, raconlait-il plus tard aux notables, est un chef; vous l'avez vu, sans armes, agir comme s'il était chez lui, sans se fâcher, sans crier. Nous avons eu tort envers lui, et cependant il m'a bien reçu. "

Malgré la faligue du voyage, malgré la fièvre qui brisait ses forces, malgré les lenteurs qui entravaient sa marche, Soleillet se rapprochait chaque jour de Ségou. "J'avoue, a-t-il écrit $^{2}$, qu'il me faut résister aux conscils de la bête, qui déjà m'a fait faire bien des sotlises. Elle voudrait aller passer quelques jours à Médine, pour aller se faire soigner par le bon docteur. L'autre lui répond: "Mademoiselle, vous êtes une " douilletle. Vous ne pensez qu'à vos aises. A Ségou, ma belle, " et vite! " Le 30 seplembre Soleillet arrivait sur le Niger, à Yamina, et s'embarquait aussitôt pour descendre le fleuve. Le lendemain il était en vue de Ségou. "Je me préparai avec

1. Gravier, ouvrage cité, p. 211.

2. Gravier, ouvrage cité, p. 172. 
émotion, écrit Soleillet, à entrer dans celte grande ville. Je crus que le moment était venu de déployer le drapeau de la France sur un fleuve où aucun pavillon européen n'a encore été vu... Je fis donc arborer à l'arrière de ma barque un drapeau tricolore que mon interprète avait confectionné. On tire un coup de fusil pour le saluer, et je m'incline avec respect el altendrissement devant le pavillon national. " Le sultan de Ségou, Ahmadou, prévenu de son arrivée, envoya aussitôt,

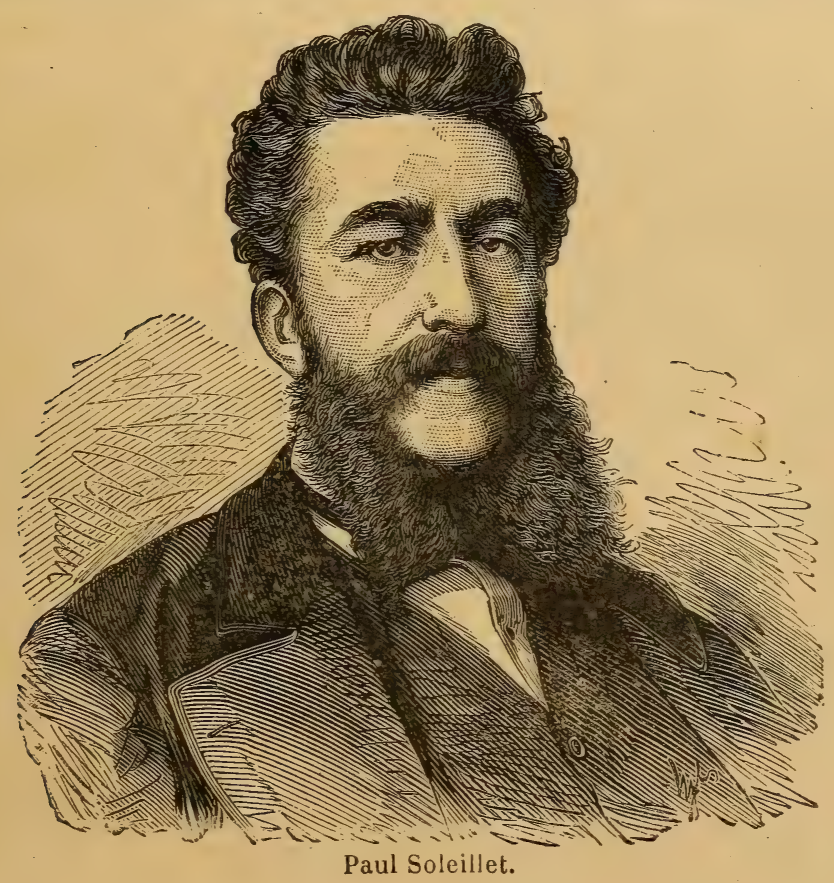

" pour faire honneur au drapeau ", douze à quinze cents soldats, qui le saluèrent en déchargeant leurs armes et en poussant des cris.

Ce bon accueil dura les cent douze jours du séjour de notre voyageur à Ségou. Il est vrai qu'Ahmadou, jaloux de conserver dans tout le Soudan oriental le prestige que lui donnaient ses relations avec la France, ne voulut pas lui permettre de pousser jusqu'à Tombouclou; mais il le laissa librement circuler dans ses Étals, prendre des notes, recueillir des 
observalions et former avec ses sujets des relations qui ne pourront être, un jour ou l'autre, que très utiles à nos négociants. Soleillet, en effet, est revenu de son voyage à Ségou avec le même succès, mais bien persuadé que rien n'était plus facile que d'établir un courant d'affaires entre le Sénégal et lo Niger. Peut-être élait-il trop affirmatif, ou, si l'on préfère, trop plein d'illusions; mais la route indiquée par lui n'en est pas moins tracée aujourd'hui, et ce n'est plus à l'arrière d'une humble pirogue, mais dans un fort gardé par une garnison française et défendu par des canons français, que flotte sur le Niger le pavillon tricolore. Soleillet a donc été un précurseur, et c'cût été la pire dès injustices que de l'oublier dans un livre destiné à remettre en lumière ceux de nos compatriotes qui ont bien mérité de la patrie ën Afrique.

Aussi bien, la relation du voyage de Soleillet, composée sur ses manuscrits par un de ses amis les plus dévoués, Gabricl Gravier, achève de nous faire aimer l'homme et apprécier le citoyen. Il est peu de récits aussi atlachants dans leur simplicité. Il en est peu qui nous inilient davantage aux détails d'une civilisation si différente de la nôtre. Soleillet fut en effet doué du talent d'observation, et ses études de mœurs présentent un côté humoristique qui les grave dans l'esprit. Avec lui on assiste aux danses nationales, la makoudrais, pas de caractère dans le genre noble; la simonkam, pas comique, charge de la précédente, et le diumfollo ou danse des csclaves, provocante et lubrique. On écoute les griots battre leur tambour, le tama, qui se place sous le bras gauche et se joue soit avec les doigts de la main gauche, soit avec un bâton recourbé et de la main droite; le ndiounndioun, espèce de tambourin que l'on frappe avec des instruments qui ressemblent à des castagneltes, et le tantango ou grosse caisse. On voit les jeunes filles s'occuper de leur toiletle et se frotter les dents, pour les conserver, avec des morceaux de bois tendre d'essence aromatique, ou se percer les gencives avec de petites aiguilles, ce qui les rend bleuâtres. Soleillet les suit à la pêche, et s'étonne de leur façon de procéder: "Elles sont assises dans l'eau et altendent que les poissons passent à leur portée. Elles étendent 
les bras, et, parait-il, ce procédé n'est pas sans réussir. " Il a grand soin de noter au passage les coutumes originales: "Quand un caplif est mécontent de son maître, il coupe un morceau de l'oreille au fils ainé de l'homme auquel il reut appartenir. Par le seul fait de cette mutilation, il passe de suite, et pour la vie, dans la famille de l'enfant, sans que son ancien maîle puisse s'y opposer. Les captifs ne recourent à cet expédient que pour entrer dans de grandes maisons, pour appartenir à des chefs honorés et puissants. Pour cette raison, les chefs noirs du Fouta sont très fiers d'aroir des bouts d'oreille en moins, et le roi Ismaël est fort orgueilleus d'en avoir perdu une presque tout entière. "

Il serait facile de multiplier les citations, de montrer notre voyageur au milieu des captifs, aux souffrances desquels il compâtit, entouré de malades auxquels il distribue sans rire d'inoffensifs médicaments. Ce quai se dégage de cette lecture, c'est une impression de sympathie profonde pour l'homme et pour l'écrivain. Soleillet était un vrai Français, qui fit partout sur son passage aimer le nom de la France, et qui n'eut qu'un tort, celui de ne pas vivre assez pour récolter ce qu'il avait semé.

On eût dit que Soleillet avait le pressentiment de sa fin prochaine, car, à peine arrivé à Saint-Louis, il entreprenait un nouveau voyage, toujours avec l'arrière-pensée d'ouvrir cntre nos colonies de nouveaux débouchés. Il voulait cette fois gagner Tombouctou, non plus par la vallée du Sénégal, mais par les oasis d'Adrar, de Tichit et de Oualata. Repoussant toute intervention officielle, toute escorte armée, il se contenta de quelques lettres de recommandation que lui donnèrent le gouverneur du Sénégal et le marabout Bou-el-Moghdad, le chancelier de la légation de France à Tanger, Hecquart, et Crémieux, le président de l'alliance israélite universelle pour les communautés juives du Sahara central. Il s'était également muni d'un sauf-conduit du chérif de la Mecque et d'un passeport délivré par le chérif d'Ouazzan, le grand maître de la puissante confrérie de Mouley-Taïeb.

Parti de Saint-Louis le 16 février 1850, Soleillet arrivait sans encombre dans le pays des Maures Trarzas, dont le 
chef, notre allié Ely, le reçut très cordialement, et lui donna même l'hospitalité dans sa tente. Elle était fort grande, de couleur noire, en épaisse étoffe de laine et poil de chameau, doublée à l'intérieur de peau tannée avec des dessins noirs et rouges. Soleillet fut même présenté à la reine, belle Nauresque, affligée d'un énorme embonpoint; mais elle en tirait vanité, car la beauté suprême consiste à ne plus pouvoir se mouvoir à force d'obésité. Lorsqu'une fille maure est sur le point de se marier, elle reste plusieurs mois sous la tente, chaudement couchée, et, de gré ou de force, avale des boulettes de beurre et boit du lait du matin au soir. Ely vivait en patriarche au milieu de sa famille et de ses domestiques. Il accabla Soleillet de ses protestations de fidélité, et le pria de le considérer comme un compatriote.

Un marabout très respecté, Saad-Bou, fit également un très bon accueil à notre voyageur. Saad-Bou avait organisé une sorte de couvent de talibés, jeunes étudiants tout à sa dévotion. On lui attribuait des pouvoirs extraordinaires. II passait pour lire dans les yeux les plus secrètes pensées. Il voyait en dormant ce qui se passait sur toute la terre, et n'élait pas soumis aux lois de la physique, car il marchait sur les eaux. Saad-Bou ayant déclaré à sa première entrevue avec Soleillet " qu'il avait lu avec attention dans ses yeux, qu'il n'avait trouvé que du bien en lui, et qu'on devait le traiter avec les mêmes égards et le mème respect que les membres de sa famille ", des relations intimes s'établirent tout de suite entre eux. Soleillet lui exposa ses vues économiques, et le marabout s'y associa, mais en lui conseillant d'attendre quelques mois, car la route n'était pas sûre. Notre voyageur négligea ce prudent avis, et il eut tort, car à peine s'était-il remis en route pour gagner l'oasis d'Atar, d'où il lui aurait été facile de se joindre à des caravanes qui l'auraient conduit en ringt jours à Tombouctou, qu'il fut altaqué par une bande d'Ouled-Dlim, et dépouillé de tout ce qu'il possédait. Soleillet aurait pu se défendre, mais il aurait été massacré. Il se résigna donc et fit bien, car deux des frères de Saad-Bou accoururent à son aide, et obtinrent des pillards non seulement qu'ils respecteraient sa vie, mais encore qu'ils 
lui rendraient tous ses instruments, ses papiers et ses collections. Soleillet eut un moment de désespoir : "Le matin à mon réveil,-a-t-il écrit, en voyant ainsi détruit un voyage dont le succès me paraissait assuré, et surtout en réfléchissant que, si la chance m'avait servi deux jours de plus, j'étais à Atar, dans la famille de Saad-Bou, dans des régions dont les chefs vivent en bonne intelligence avec la France, que si j'avais pu atteindre Atar, je serais revenu au moins de Tombouctou, je me trouve dans un état de prostration complète, sans volonté, sans force, sans énergie. " Sur cette âme énergique le découragement n'avait pas de prise. Réconforlé par la restitution de ses papiers et de ses collections, Soleillet relourna auprès de son ami, qui lui promit de l'accompagner lui-mème au prochain hivernage. Il se décida alors à reprendre le chemin de Saint-Louis, où il arriva le 12 avril, et pria le gouverneur de nommer une commission afin de juger sa conduite. On lui rendit pleine et entière justice. Le témoignage le plus favorable fut donné par un de ses serviteurs, Mohammed-Moljar : "J'ai élé surpris de l'énergie dont il a fait constamment preuve, et de sa sobriété, qui dépasse tout ce que l'on saurait imaginer. Je ne l'ai jamais entendu se plaindre ou demander un arrêt quelconque. On est étonné qu'il ait pu vivre avec deux galettes de biscuit par jour, du lait et un peu de thé. Je ne croyais pas qu'un chrétien pût se contenter de si peu." "

Dans ce voyage, qui dura cinquante-cinq jours, Soleillet avait parcouru onze cent soixante-quatre kilomètres. Il rapporlait quarante-quatre échantillons géologiques et quarante échantillons botaniques, dont un, la gomme de fernan, semble appelé à devenir très important. Le fernan est un figuier sans feuillage, dont les branches sont remplies d'un suc laileux très abondant, qui, lorsqu'il coule des branches incisées, a l'apparence et la consistance du caoutchouc. Les Maures de la côte d'Arguin s'en servent pour calfater leurs barques. Soleillet avait également signalé le tauriza, arbuste à fleurs violettes, dont le fruit, plus gros que le poing, contient de la soie végétale. Son voyage n'avait donc pas été inutile, et d'ailleurs il était tout prêt à le recommencer. 
Le ministre des travaux publics venait de meltre vingt mille francs à sa disposition, et le chargeait officiellement de se rendre à Tombouctou pour y frayer la voie à nos négociants. Soleillet reprit aussitôt son bâton de voyage. Tout semblait annoncer cetle fois le succès définitif. Ici se place un épisode qui n'a pas encore été suffisamment débrouillé. On apprit tout à coup que le gouverneur du Sénégal, Brière de l'Isle, ordonnait au commandant de Médine d'arrêter Soleillet, de se faire remettre par lui tout le matériel qui était en sa possession, et de le renvoyer à Saint-Louis. Cette mesure sévère étail, paraît-il; molivée par la publication en France d'une lettre dans laquelle le personnel militaire de la colonie était assez durement apprécié. Que Soleillet ait été coupable d'imprudence, nous le reconnaîtrons avec lui, mais il est facile de plaider les circonstances atlénuantes. Cette lettre était adressée à un ami intime et n'a été publiée que parøsuite d'une indiscrétion. D'ailleurs il n'eût pas été hors de propos de traiter avec quelque ménagement un homme qui depuis quinze ans était sur la brèche pour l'exploration de l'Afrique. Une observation aurait suffi, et non pas un brusque rappel en France. Solcillet n'eut pas de peine à faire accepter sa justification, mais il ne devait jamais revenir au Sénégal : c'est dans une autre direction, en Abyssinie, qu'il allait désormais concentrer ses efforts.

René Caillié, Mage et Quintin, Paul Soleillet, tels furent les hommes qui préparèrent les voies à l'action française dans le Soudan. Aussi bien, il était temps que le gouvernement prît la haute direction de l'entreprise et indiquât résolument, non plus par des tentatives isolées et par des promesses, mais par des actes énergiques, qu'il voulait étendre l'influence et au besoin la domination française dans la vallée du Niger. Continuer ce qui avait été si bien commencé, c'est-à-dire étudier soigneusement le terrain pour construire une route entre Médine et un point à déterminer sur le Niger, tel fut dès lors le projet favori de nos gouverneurs du Sénégal. Bientôt même ce ne fut plus une simple route, mais une voie ferrée qu'ils voulurent construire. En se précisant, le projet prit de l'extension. Ce ne fut plus seulement entre 
Médine et le Niger, mais entre Dakar et Saint-Louis d'un côlé, éntre Saint-Louis et le Niger de l'autre, qu'on songea à construire le chemin de fer. De là diverses explorations, dont quelques-unes fort importantes, et que nous allons essayer de résumer.

Dans la voie projetée on distinguait trois sections : la première de Dakar à Saint-Louis (deux cent soixante kilomètres), la seconde de Saint-Louis à Médine (cinq cent quatre-vingts kilomètres), et la troisième de Médine au Niger (cinq cent vingt kilomètres). Toutes les trois furent étudiées séparément.

Saint-Louis est la capitale du Sénégal et la ville la plus importante de notre colonie. Il semble donc, au premier abord, assez étrange qu'on n'ait pas choisi cette ville comme tête de ligne. Voici pourquoi. Le Sénégal, en se jelant à la mer, forme, juste en face de Saint-Louis, une barre mobile qui gène beaucoup la navigation. Le passage de celte barre peut

- n'être qu'un jeu pour les bateaux à vapeur, mais il est d'une extrême difficulté pour tous les navires à voiles. Il faut les décharger et leur apporter des marchandises de retour; mais, sans parler de la perte de temps résultant de l'attente, il y a doubles frais pour le chargement et le déchargement des marchandises en avant de la barre. Aussi un commerce sérieux ne s'établira jamais dans de pareilles conditions. C'est pour parer à ces inconvénients qu'on a songé à Dakar.

Dakar se trouve dans une grande rade, protégée contre les vents du nord et de l'ouest par une île célèbre dans notre histoire coloniale, Gorée. Dakar est de création récente. Elle n'a été fondée qu'en 1859. Deux jetées artificielles, défendues par des batteries qui croisent leurs feux avec la citadelle de Gorée, prolègent l'entrée du port. De nombreux phares et des balises permettent d'y entrer à toute heure, avantage inappréciabile sur une côte encore mal connue. Aussi Dakar a-l-elle pris une grande importance, et c'est avec raison que le gouverneur du Sénégal l'avait désignée comme tète de ligne du futur chemin de fer. Seulement, vul'importance de Saint-Louis, on décida qu'on chercherait tout d'abord à unir Dakar à SaintLouis. Une difficulté se présentait. Le chemin de fer projeté traversait le Cayor, et le souverain de cette province était 
notre ennemi secret ou déclaré, le damel Lat-Dior. Comme il avait conservé l'amer ressentiment des défailes que lui avait autrefois, et à plusieurs reprises, infligées Faidherbe, il élait à craindre qu'il s'opposât à la construction d'une voie ferrée sur son territoire. En effet, il feignit d'abord de se rendre aux raisons que lui présenta un vieux Yolof ami de la France, Bou-el-Moghoad, et promit non seulement de nous céder gratuitement le terrain, mais encore de faire abattre les arbres nécessaires à la construction, et de nous prêter des travailleurs. A peine les chantiers étaient-ils ouverts que Lat-Dior était subitement pris de scrupules théologiques, et entrait en campagne Il fallut diriger contre lui plusieurs expéditions. Il devint même nécessaire de le détrôner, et de lui donner pour successeur un de ses rivaux, Samba-Laobé, qui, lui non plus, ne resta pas fidèle à ses promesses : mais Lat-Dior et Samba-Laobé ont disparu, et le chemin projeté à travers le Cayor a été rapidement achevé. Les communications par voie ferrée sont aujourd'hui régulières entre Dakar et Saint-Louis.

La seconde section devait joindre Saint-Louis à Médine. De Saint-Louis à Mérinaghen, aucune difficulté : le tracé était tout indiqué; mais à partir de Mérinaghen plusieurs directions étaient proposées, et il fallait toutes les étudier avant de se décider. Trois missions, dirigées par nos officiers, partirent donc de Mérinaghen. La première, commandée par les lieutenants Pietri et Marchi, parcourut la région plate, fertile, boisée, qui sépare Mérinaghen de Dagana. Bien accueillie par les tribus riveraines, elle exécuta sans peine le travail qui lui avait été confié. La seconde mission, commandée par le lieutenant Jacquemart, était chargée de côtoyer, sur la rive gauche du Sénégal, la limite extrême des inondations, afin de savoir où l'on pourrait sans inconvénient poser les rails, de façon à n'avoir rien à craindre du fleuve, tout en s'en éloignant le moins possible. Jacquemart a distingué dans la vallée trois sortes de villages : les premiers, sur les bords du fleuve, sont absolument inhabitables; les seconds, sur la crête des petiles collines riveraines, sont habités toute l'année; les autres sont en arrière, sur des plateaux, et habilés seulement en temps d'hiver M. Jacquemart aurait voulu 
que le chemin de fer suivît la ligne des villages bâtis sur les collines. Il y aurait sans doute quelques travaux d'art à exécuter, mais la ligne présenterait l'immense avantage de parcourir un pays accessible en toute saison, et surtout d'ètre assurée d'un trafic constant, car la région est très habitée. Jacquemart fut partout bien accueilli : il ne rencontra d'opposition que chez les tribus toucouleurs, qui nous détestent cordialement, d'abord parce qu'elles sont fanatisées par les prédications des missionnaires musulmans, et plus encore parce qu'elles ont gardé le ressentiment des défaites que nous avons infligées à leur chef vénéré, Omar-al-Hadji. Lorsqu'il entra sur le territoire des tribus toucouleurs, un de leurs chefs, Abdul-Bou-Beker, défendit à Jacquemart de pénétrer plus avant. Celui-ci ne tint aucun compte de sa défense; mais le Toucouleur lui déclara qu'il était prêt à émigrer avec toute sa tribu, soit sur la rive droite du Sénégal, soit dans les possessions anglaises, le jour où l'on poserait le premier rail. Ce ne sont pas là de vaines menaces. Les Toucouleurs reculent devant notre civilisation. Plutôt que d'accepter nos J)ienfaits, ils sont disposés à nous céder la place. Soit! qu'ils nous la cèdent! Une troisième expédition, commandée par les lieutenants Monteil et Sorin, partit encore de Mérinaghen, mais en traversant une région inexplorée, le Ferlo. C'est un immense désert, qui forme une forêt continue de gommiers acacias. Depuis Mollien, qui le parcourut en 1818, aucun Européen ne s'était aventuré dans ses solitudes. Ce sont des bètes féroces, et surtout des éléphants, qui fréquentent la région. Le pays est plat, les eaux rares et saumâtres. Le seul avantage que présenterait un tracé par le Ferlo serait d'abréger la voie, mais cet avantage ne compense pas la pauvrelé du pays traversé, l'absence des matériaux de construction, el le petit nombre des habitants.

En résumé, depuis Saint-Louis jusqu'à Bakel, le meilleur tracé paraît être celui de M. Jacquemart. De Bakel à Médine, aucune difficulté. On n'aura qu'à suivre la vallée du Sénégal, et les riverains, habitués à notre domination, ne demanderont pas mieux que de voir créer une voie ferrée qui donnera une plus-value considérable à leurs produits, tout en 
leur permettant de s'approvisionner à moins de frais des produits variés de notre industrie.

La troisième section va de Médine au Niger. A partir c'e Médine on entrait en pays inconnu, ou du moins à peine entrevu. C'est dans cette direction que se concentrèrent les efforts de l'administration, et c'est là qu'on obtint les résultats les plus complets et les plus inattendus.

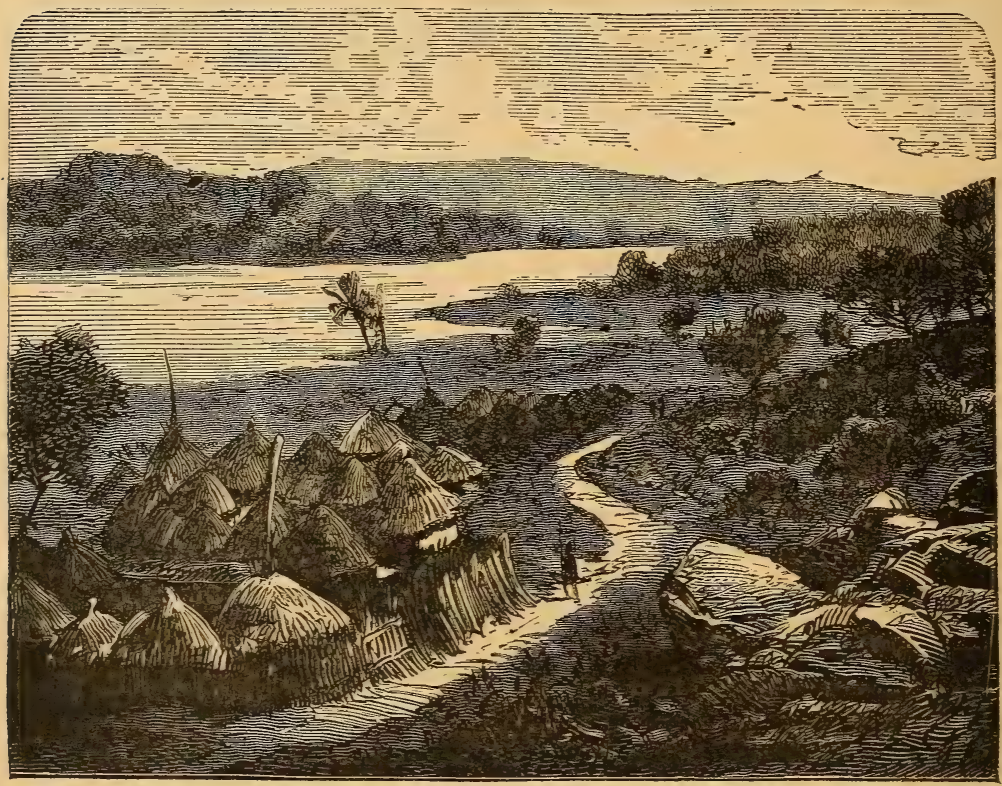

Village dans le haut fleuve.

Tout d'abord quelques mots sur la région qui s'étend de Médine au Niger. Depuis la mort d'Omar-al-Hadji, qui avait réussi à maintenir sous sa domination la contrée tout entière (1864), ses fils s'étaient partagé ses domaines; mais les héri tiers de cet autre Charlemagne ne surent pas garder entre eux la concorde nécessaire pour consolider un empire aussi rapidement improvisé. Pendant qu'Ahmadou, le fils aîné du prophète, se maintenait à Ségou, sur le Niger, son neveu Tidiani s'installait dans le Macina, et ses autres enfants se taillaient des principautés à leur fantaisie. La guerre civile était en permanence, et la guerre religieuse compliquait encore la situa- 
tion, car les néophytes musulmans poursuivaient de leur haine ceux de leurs compatriotes qui élaient restés fidèles au fétichisme. Aux horreurs qu'entraîne toujours à sa suile le fanatisme surexcité se joignaient les haines de race et les animosités locales. C'est dans cette mêlée confuse de religions et de nationalités que nous allions nous engager, sans seulement connaître nos amis et nos ennemis. En effet, le plus puissant de ces souverains indigènes, Ahmadou, nous accablait de ses protestations d'amitié et ne négligeait aucune occasion de faire savoir à Saint-Louis combien il nous était dévoué; mais au fond il nous détestait, et comme musulman et comme Toucouleur, et cherchait sous main à nous nuire. En 1878, bien qu'il se soit défendu de toute intervention contre la France, c'est bien lui qui avait excité contre nous une dangereuse sédition dans la province du Logo. Il avait fallu envoyer contre Sabouricié, la principale cité de la région, une colonne expéditionnaire sous le commandement des colonels Raymond et Bourdiaux. Sabouricié fut pris et détruit, et le chẹ du Logo périt dans la lutte. Ahmadou n'avail pas bougé, mais il avait suivi les péripéties de la lutte avec un intérêt qui dénonçait ses véritables sentiments. Il ne faut donc tenir aucun compte de l'alliance du maître de Ségou. Ce n'est qu'un ennemi caché. D'un autre côté, tous les chefs indigènes restés fidèles au fétichisme détestent Ahmadou, leur persécuteur. Ils devraient être nos alliés naturels; mais ils se défient de nos relations avec le maître de Ségou, et se tiennent sur une réserve qui, d'un jour à l'autre, peut se convertir en hostilité. Il était donc fort difficile de savoir quelle politique adopter. Haines mal dissimulées des uns, défiances des autres, à vrai dire la France avait tout le monde contre elle. N'importe! le temps était venu de l'action. On se décida à aller de l'avant. 


\section{I \\ CONQUETE DU SOUDAN FRANCGAS}

Il s'agissait, avant tout, de trouver plus loin que Médine un nouveau poste, d'où rayonnerait notre influence dans tous les sens, où nous pourrions concentrer nos moyens d'action, et, au besoin, de résistance, et qui deviendrait en un mot une nouvelle étape dans la conquête pacifique de la région. On se décida pour Bafoulabé, au confluent du Bafing et du Bakoy, à peu près à mi-chemin entre Médine et le Niger. Le capitaine d'infanterie de marine Gallieni fut chargé de cette délicate mission (1879). Gallieni devait, sur son chemin, pacifier les tribus du Lago et du Natiaga, tâcher de conclure avec leurs chefs des traités avantageux et étudier le prochain emplacement de la voie. Le 12 octobre il arrivait à Bafoulabé et y trouvait tous les chefs malinkés de la région, assemblés pour assiéger le château d'Ouliba, où s'était renfermé le renégat Tiecoro, vassal d'Ahmadou. Gallieni pria ces chefs de venir le trouver. Ils répondirent à son appel. Le capitaine leur exposa ses projets. Les chefs malinkés acceptèrent avec empressement sa double proposition de construire un poste fortifié à Bafoulabé et d'établir un chemin de fer à travers leur pays. Aussitôt Gallieni signa avec eux une série de traités, en vertu desquels, le 21 décembre 1879, commencèrent les travaux de construction d'un fort à Bafoulabé. Ils furent poussés avec tant d'activité, que le 30 janvier 1880 tout était prêt, c'est-à-dire que les fossés étaient creusés, les murailles debout, ainsi que les magasins et les casernes. Bafoulabé, en un mot, pouvait résister à une attaque de vive force. C'était une prise de possession complèle, et, par celte rapide occupation, nous nous trouvions déjà à mi-chemin du Niger.

Restait à assurer les communications entre la nouvelle citadelle française et Médine. Un des auxiliaires de Gallieni, le lieutenant Vallière, avait déjà soigneusement examiné le 


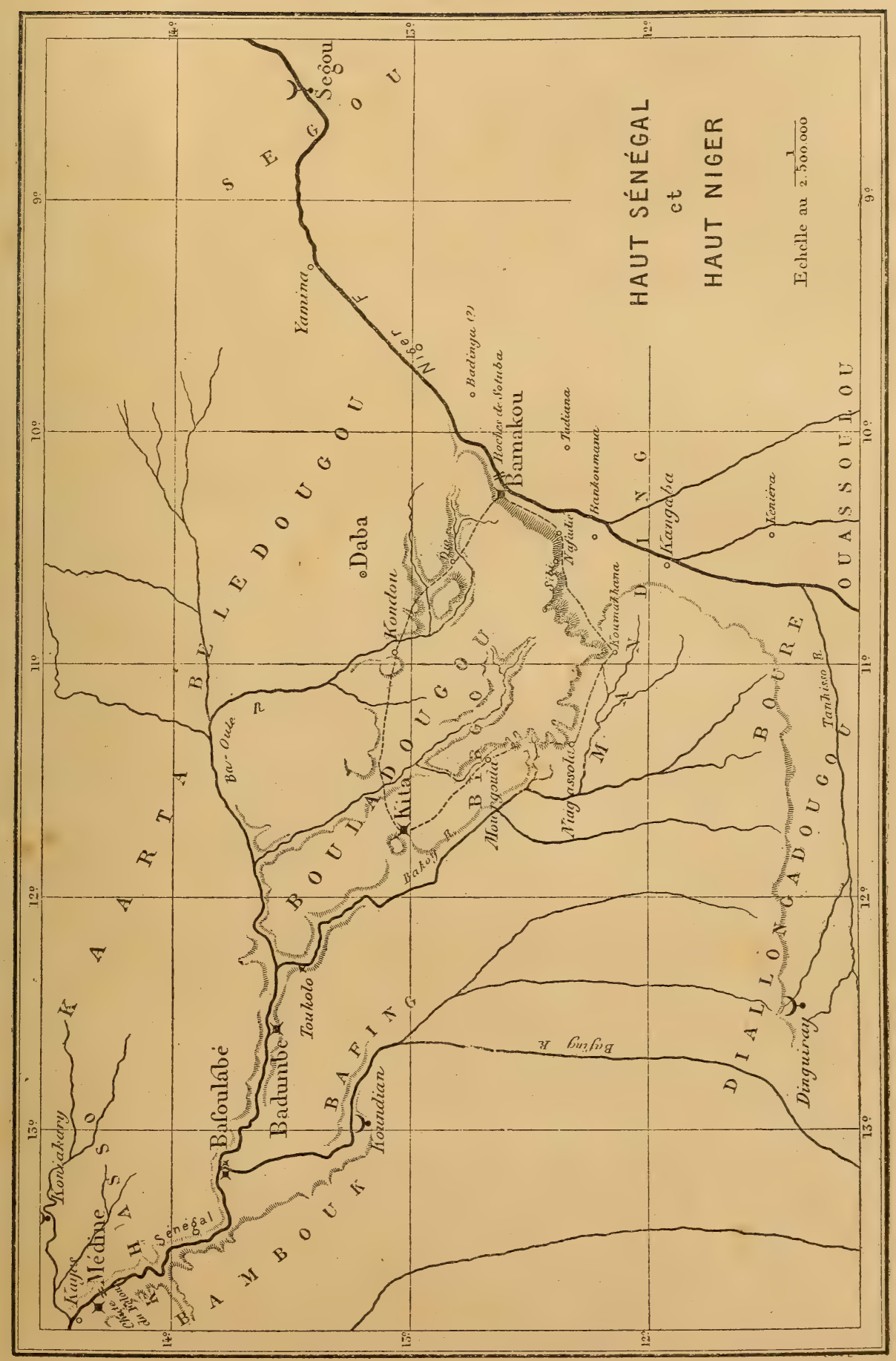



terrain en vue de la prochaine corstruction soit d'une voie ferrée, soit d'une ligne télégraphique. Il était difficile d'improviser la première, car les bras manquaient, mais plus aisé de planter en terre des poteaux et les relier par des fils électriques. Cette campagne fut rapidement conduite, et bientôt on put expédier des dépêches de Saint-Louis à Bafoulabé. C'était un premier résultat obtenu, qui frappa d'admiration les indigènes, et servit plus à consolider notre jeune domination que ne l'auraient fait plusieurs expéditions victorieuses.

Il s'agissait maintenant de gagner le Niger, et, sur le Niger, le point le plus rapproché, Bamakou. Gallieni avait si bien réussi dans sa première mission, qu'on n'hésita pas à lui en confier une seconde. MM. Pietri et Vallière, officiers qui avaient déjà fait leurs preuves au Sénégal, les docteurs Bayol et Tautain, vingt tirailleurs et sept spahis lui furent adjoints. En outre, un nombre assez considérable d'indigènes furent chargés de porter les bagages et, au besoin, de frayer la route. L'expédition comptait en tout cent cinquante personnes. Le capitaine Pietri préparait le terrain, le lieutenant Vallière dirigeait l'ilinéraire topographique, le docteur Bayol était chargé de la météorologie, et le docleur Tautain de l'astronomie. Le but de la mission était d'explorer le pays entre Bafoulabé et Bamakou, de créer, autant que possible, une nouvelle station fortifiée, et d'établir des relations pacifiques avec les chefs indigènes, surtout avec Ahmadou.

Le 30 janvier 1880, départ de Saint-Louis; le 22 mars, arrivée à Médine; quelques jours après, à Bafoulabé. Les chefs malinkés ne paraissaient pas mécontents de l'établissement du fort. Tous signèrent des traités par lesquels ils se soumettaient au protectorat exclusif de la France. A partir de Bafoulabé on entra en pays inconnu. A cause de la guerre qui la ravage depuis si longtemps, la contrée offrait peu de ressources; néanmoins les populations se montraient sympathiques, et partout nos compatriotes étaient bien accueillis. Chemin faisant ils étudiaient le futur tracé de la voie, et signaient des traités avec les petits rois indigènes, ceux de Fangalla (10 avril), de Gouniokoro (14 avril), de Makadambougou (19 avril). Sur le parcours on retrouvait les traces et 
le souvenir de l'expédition de Mungo-Park en 180د. Dans un de ces villages, le chef réclama un cadeau à Gallieni, sous prétexte que son père en avail jadis reçu un de l'illustre Écossais. Or c'était tout le contraire, comme Gallieni le découvrit en lisant l'itinéraire de Mungo-Park. Aussi les indigènes étaientils stupéfaits de voir nos compatriotes si bien renseignés.

Le 20 avril on arriva à Kita. C'est un poste stratégique et commercial, le point de convergence des routes de caravane cntre Je haut Niger, le haut Sénégal et le Sahara. Elle est bâtie sur un plateau assez élevé, dont la température ressemble à s'y méprendre à celle de la France. Or, le principal obstacle à notre domination dans le Sénégal ayant été jusqu'à présent la rigueur du climat et la difficulté pour nos fonctionnaires et pour nos soldats de résister aux ardeurs dévorantes du soleil, il sera facile de transporter nos malades à Kita, surtout si le chemin de fer était construit. Un simple changement d'air les guérira sur-le-champ. C'est ainsi que les Anglais établis dans l'Hindoustan parviennent à s'y maintenir en bonne santé en se transportant, dès qu'ils ressentent les premières atteintes de la maladie, dans les fraîches vallées de l'Himalaya ou des Vindhya. Kita pourrait de la sorte devenir le grand hôpital de la colonie. De plus, à cause de sa siluation géographique, il sera facile d'y établir des marchés et des foires. Ce sera une ville de transit. Nous en ferons le centre de notre système de défense et d'approvisionnement dans la région. Kita marquera en outre une nouvelle étape sur la route du Soudan. Ces considérations déterminèrent Gallieni à obtenir du chef de Kita la cession d'une partie de son territoire pour y construire un fort et une station. Après force palabres, un traité de cession fut en effet conclu ( $2 \%$ avril 1880), et aussitôt commencèrent les travaux d'installation, aussi rapidement menés qu'à Bafoulabé.

A partir de Kita, on entrait dans le Bambara, région barbare dont les habitants avaient jusqu'alors repoussé toutes nos avances. Gallieni aurait voulu atteindre le Niger en passant par le Nioro, mais le pays était déchiré par la guerre civile : il lui fallut alors se rabattre vers le sud-est et se frayer un chemin dans la vallée du Bandingo. La population est en 
grande partie composée de fétichistes, très altachés à leurs superstitions, et qui ont eu beaucoup à souffrir des musulmans et de leurs derniers chefs Omar et Ahmadou. Or les Nègres, ainsi que toutes les races primitives, n'admettent ni tempéraments ni accommodements. Qui n'est pas pour eux est contre eux. Ces Français qui entraient ainsi sur leur territoire en se prétendant leurs amis, et pourtant avouaient que le but de

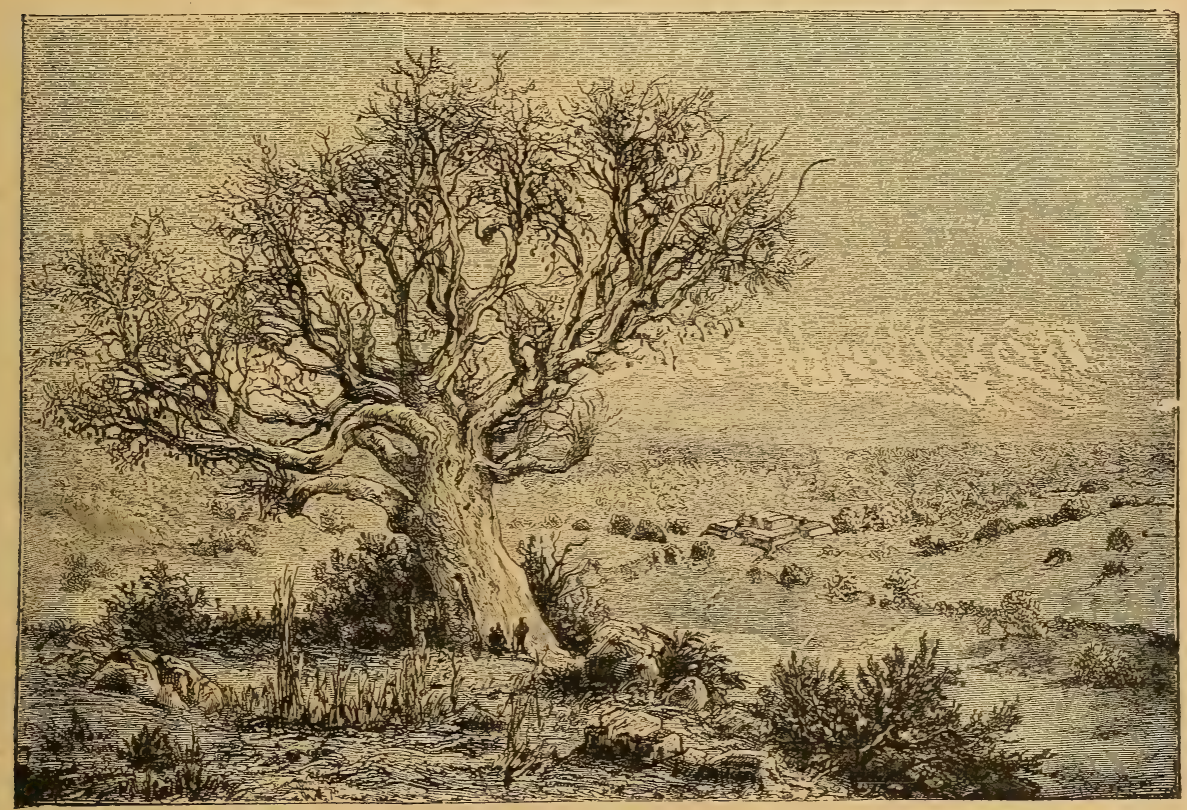

Kita.

leur voyage était la capitale du sultan abhorré, fallait-il ajouter foi à leurs déclarations? Était-il possible d'être à la fois l'ami des Nègres et l'ami d'Ahmadou? Ces étrangers n'étaient évidemment que des espions ou des traîtres, et, malgré leurs armes redoutables, malgré leur tactique savante, il fallait à tout prix s'en débarrasser. Anssi de jour en jour l'attitude des indigènes devint hostile. Le 5̆ mai, à Guisoumalé, ils ne consentirent à fournir des vivres que parce que le docteur Bayol leur donna des consultations gratuites et excita leur étonnement par les décharges d'une pile électrique. Le lendemain 6 , 
à Ouoloni, l'accueil élait froid et embarrassé. Le chef refusa des guides, et sur le soir une rixe éclata entre les habitants du village et l'arrière-garde, commandée par le docteur Tautain. Le 7 il fallut camper dans une forêt. Le 8, à Guinina, femmes et enfants avaient disparu. Seuls restaient les hommes, et ils étaient tous armés. Sans la ferme attitude de nos compatriotes, ils auraient élé attaqués pendant la nuit.

Le 11, les Français, de plus en plus mal accueillis, et serrés de près par des in digènes dont le nombre grossissait d'heure en heure, venaient de quilter le village de Dio et de s'engager dans un terrain fourré. Le guide marchait en avant, mais on remarquait que, contrairement à l'usage des nègres, qui vont toujours droit devant eux, il faisait souvent changer de direction à la colonne. De plus, un sourd grouillement sortait des villages, et les herbes s'agitaient. Tout à coup, sur les derrières des Français, alors espacés sur une longueur de six à sept cents mètres, éclate nne vive fusillade. C'étaient les gens de Dio, d'Ouoloni, de Guinina et de vingt autres villages qui nous attaquaient, dans l'espoir de nous exterminer et de piller nos bagages. Le premier choc fut rude. Le docteur Tautain, qui commandait l'arrière-garde, réussit à se réfugier dans des ruines, y organisa la résistance, parvint à rallier tout son monde et bientôt à rejoindre Gallieni; mais quatorze hommes manquaient à l'appel, et presque tous les autres étaient blessés. On les hissa, au détriment des bagages, sur les bêtes de somme, et on précipita la marche dans la direction du fleuve. On en élait éloigné de soixante et dix kilomètres, et la retraite n'était pas aisée dans un pays accidenté et peu connu. Par bonheur, les indigènes ne se battent que pendant le jour; mais ils suivirent la colonne jusqu'au moment où elle aperçut le Niger, et cela sans cesser de tirailler. Gallieni ne fut sauvé que par le dévouement de ses tirailJeurs sénégalais, qui, à diverses reprises, le couvrirent de leur corps. Pietri et Vallière, qu'il avait envoyés à l'avance, étaient déjà arrivés à Bamakou. Ils coururent à la rencontre du chef de l'expédition, et réussirent à opérer leur jonction. La colonne expéditionnaire présentait alors un aspect peu triomphal. On n'avait plus de médicaments, plus de vêtements de 


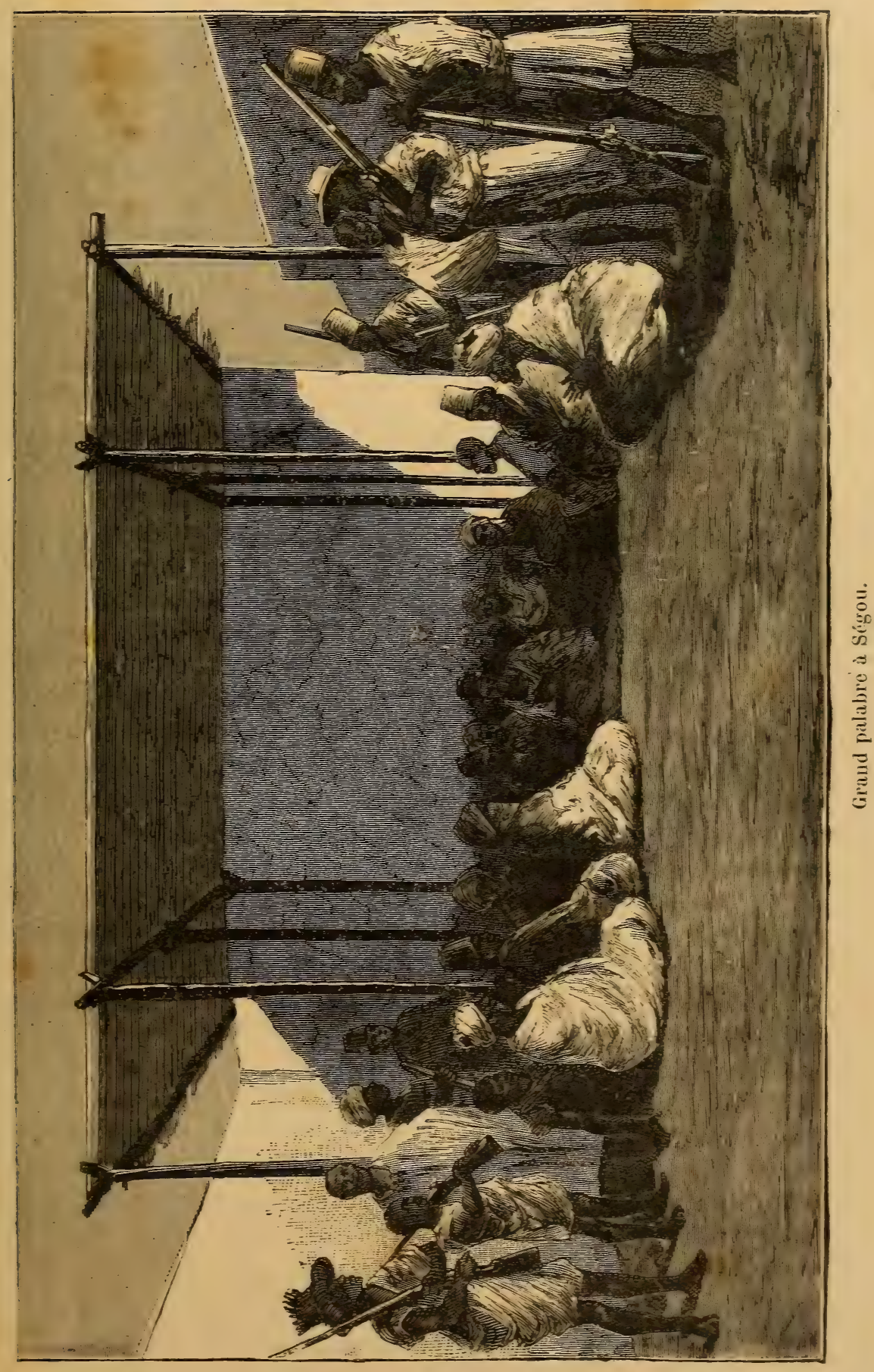



rechange, plus de cadeaux à distribuer. Il ne restait au docteur Bayol, pour ses opérations chirurgicales, qu'un mauvais canif. Il élait donc nécessaire de hâter la marche sur Ségou, afin de rentrer au plus vite à Saint-Louis. Aussi bien, malgré la débandade de Dio, l'expédition n'avait pas élé infructueuse. Kita avait accepté notre protectorat, les affluents du haut Sénégal avaient été reconnus, et jusqu'au dernier moment les Français, ainsi qu'ils l'avaient promis, n'avaient pas fait usage de leurs armes, et s'étaient présentés en pionniers de la civilisation.

Le 15 mai le Niger était franchi, non loin de Nafadié. C'est alors un beau fleuve, de sept cent cinquante mètres de large, rempli d'îles et bordé sur les deux rives de belles plaines. Gallieni espérait arriver rapidement à Ségou; mais Ahmadou était prévenu contre lui. Ne lui avait-on pas fait croire que le capitaine avait le mauvais œil? L'entrée de la capitale fut donc interdite au jettatore inconscient. Au moins lui donna$t$-on tout ce dont il avait besoin, et fut-il nourri, lui et ses hommes. On ne lui refusa que du papier, car Ahmadou ne voulait pas que les Français prissent des notes ou des levés de terrain. Nos compatriotes passèrent dans le village de Nango tout l'hiver, et il fut terrible, à cause des fièvres et du dénuement général. Enfin, après quatre mois d'hésitation, apprenant que les Français s'établissaient décidément à Kita, Ah madou se décida à signer avec notre représentant un traité qui doit opérer une révolution dans la nature de nos relations avec les peuples du Niger. En voici les clauses principales: $1^{\circ}$ les Français auront le droit, à l'exclusion de toutes les nations européennes, de s'établir et de fonder des comptoirs dans tout l'empire de Ségou; $2^{\circ}$ ils pourront améliorer les routes et ouvrir des voies commerciales vers le haut Niger; $3^{\circ}$ le Niger est placé sous le protectorat exclusif de la France, depuis ses sources jusqu'à Tombouctou; $4^{\circ}$ les Français auront seuls le droit de naviguer et de créer des établissements sur le Niger; $5^{\circ}$ après le payement de la première annuilé de la rente, la France pourra, s'il lui convient, entretenir à Ségou un résident, représentant du protectorat français. D'un autre côté, nous donnons à Ahmadou quatre canons de cam- 
pagne, mille fusils à picrre et une rente d'environ vingt-cinq mille francs.

C'est là un fait important, et qui favorisera singulièrement notre influence et nos intérêts dans cette partie de l'Afrique. "C'est seulement guidés par l'intérêt du pays que nous avons pu franchir le Niger, s'écriait Gallieni dans la première conférence qu'il fit sur son voyage, à Bordeaux, en juin 1881. C'est en n'ayant en vue que la patrie que nous avons pu rendre nos efforts utiles. " Certes, le capitaine a bien mérité de la patrie, et ce ne sera que justice si la reconnaissance nationale conserve son nom.

Dans celte première exploration du pays, on n'avait en quelque sorte fait qu'ébaucher les grandes lignes. Il était nécessaire de compléter cette prise de possession, d'abord en étudiant avec soin la région soumise à notre influence, puis en faisant respecter partout et en toute circonstance le drapeau national. De là deux sorles d'entreprises : les unes, d'un caractère plus scientifique, destinées à étendre le champ de nos connaissances, et à préciser nos renseignements sur les ressources de la contrée; les autres, d'un caractère plus politique, destinées à augmenter le respect dù à la France, et à l'imposer au besoin.

Lespremières opérations ont été particulièrement heureuses. Elles ont été en général confiées à des officiers qui s'étaient pour ainsi dire acclimatés, et qui portaient à leur patrie d'adoption une affection toule filiale. En 1880, une mission topographique fut organisée sous la direction du commandant Derrien. Elle comprenait trois officiers de marine, MM. de Kersabiec, Sorrin, Hue; six officiers de l'armée, MM. Sever, de Sourdeval, Delanneau, Rivals, Delcroix, Brosselard, et le docteur Colin. Elle commençait ses opérations à Médine, étudiait le cours de Bakoy, arrivait à Kita ${ }^{1}$, mais ne pouvait poursuivre ses opérations jusqu'au Niger, à cause d'une révolte des indigènes. Six feuilles à l'échelle du cent millième

1. Itinéraire de Kayes à Kita. - Environs de Médine, Bafoulabé, Kita, Mourgoula, Sitakoto, gué de Mahina, Toukoto, Maya. - Plans de Médine, Sabouciré, Fatafi, Koubakoto, Koumakana, Bahé, Médina, Niantemso, Guignagné Goubanko, Sita-Kotu. 
ont été dressées par elle, ainsi que de nombreux plans et levés. Une seconde mission topographique, sous la direction des capilaines Henri et Delanneau ${ }^{1}$, a, de 1881 à 1882, complété ces premières éludes par de nouveaux renseignements. Une troisième mission topographique ${ }^{2}$, sous la direction du capilaine Bonnier, a cetle fois poussé jusqu’à Bamakou, et dressé sept feuilles à l'échelle du cent millième et une à celle du cinquante millième. Ces travaux ont élé difficiles, dangereux même, non pas tant à cause de l'hostililé des indigènes que parce que nos officiers ont souvent opéré, sous un soleil de feu, tantôt gravissant des pentes à travers des fourrés impénétrables, tantôt stationnant des heures entières sur des rochers dénudés, afin d'élablir une triangulation exacte. Les conquêtes de la science sont moins brillantes que celles de la guerre, mais aussi pénibles et toujours plus profitables.

Aussi bien, la France ne renonçait pas à établir son prestige par les armes. N'était-il pas nécessaire de rappeler à ces impressionnables tribus indigènes que nous gardions le souvenir du guet-apens de Dio et des lenteurs calculées du sultan Ahmadou? Le moment semblait bien choisi pour l'intervention française. La domination des Toucouleurs était en pleine décadence. Les talibés d'Omar et d'Ahmadou, après avoir ravagé les provinces conquises, après les avoir épuisées jusqu'à la moelle, s'étaient rapprochés de Ségou. Ils ne tenaient plus garnison que dans les tatas de Dinguiray, de Mourgoula et de Koundian. Les vaincus commençaient à relever la tête et à espérer une prochaine délivrance. Précipiter la décadence des Toucouleurs, grouper autour de la France les tribus nègres, qui avaient déjà la plus haute idée de nos ressources militaires et de nos richesses, se les attacher par les liens si multiples de la reconnaissance et de l'intérêt, et ne pas hésiter à briser toutes les résistances que nous rencontrerions, telles ont été les grandes lignes de la politique suivie au Soudan dans ces dernières années, tels ont été les principes aux-

1. Itinéraires de Bakel à Kayes par Sénoudébou et par le Sénégal, de Kita à Koundou, au Baoulé et à Keniera. - Envirous de Kita. - Bakoy entre Koniakary et Bafoulabé.

2. État de Bamakou. États de Kita, Sedian, Kondou, Bélédougou, Robado, FataG, Kobokoto. 
quels nous avons rigoureusement subordonné tous nos acles, et qui nous ont valu une série de victoires, sans doute peu retentissantes, mais glorieusés néanmoins, et dont on ne connaît pas encore toutes les conséquences.

Le colonel Borgnis-Desbordes fut chargé en 1880 de conduire dans le haut Sénégal une reconnaissance militaire. Cette expédition présentait de grandes difficultés. On ne croyait pas à sa réussite. Les uns prélendaient que nos soldats n'iraient mème pas jusqu'à Médine. Les plus optimistes assuraient qu'ils ne dépasseraient pas Bafoulabé. Les débuts furent en effet malheureux. Le colonel, gravement indisposé, fut obligé de s'arrêter à mi-chemin, à Saldé, |et la colonne expéditionnaire, décimée par la fièvre typhoïde, mit cinquante jours à parcourir la route entre Saint-Louis et Médine (11 novembre-27 décembre 1880). Il est vrai que les navires sur lesquels nos soldats devaient remonter le Sénégal ne purent dépasser Matam à cause de la baisse des eaux, et qu'il fallut s'entasser sur de lourds chalands traînés à la cordelle. Enfin, après bien des fatigues, la concentration s'opéra tạt bien que mal à Médine. Le colonel Borgnis-Desbordes, remis de son indisposition, put reprendre le commandement. Il termina les approvisionnements, et ce n'était pas aisé, car il fallait tout cmporter avec soi dans les misérables contrées qu'on allait traverser; il répartit le maléricl sur un convoi de douze conts ânes indigènes, excellents animaux qui rendirent de grands services, et donna enfin le signal du départ ( 9 janvier $1 S 81$ ).

La colonne expéditionnaire arrivait à Bafoulabé le 17 janvier 1881. Elle traversait aussitôt le Bafing sur des pirogues, difficile transbordement qui demanda quatre jours, passait le Bakoy au gué de Toukôto le 22 du même mois, et arrivait au rocher de Kita le 9 février. On dirait un immense quadrilatère, sur les côtés duquel se dressent sans ordre des blocs à forme bizarre, tantôt masses compactes, tantôt gradins, semblables aux marches d'un gigantesque escalier. Au sommet s'étend un vaste plateau qui descend en pente douce vers un point central, sorte d'entonnoir échancré qui donne passage aux eaux. Tout le massif est couvert d'une régétation rabou- 
grie qui donne asile à des milliers de singes. Ces animaux virent arriver les Français avec peine. Ils troublèrent à diverses reprises nos travaux. Leur instinct était merveilleux pour découvrir et détruire les signaux géodésiques. On eût dit qu'ils défendaient un des sanctuaires de leur race.

C'est sur cette importante position stratégique que le colonel Borgnis-Desbordes résolut d'installer une nouvelle étape sur le chemin de Saint-Louis au Niger. Depuis le traité signé

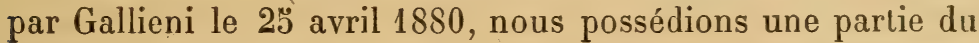
territoire. Nos soldats s'improvisèrent ouvriers, et la construction d'un fort fut rapidement menée. Pour ceux qui nient les aptitudes merveilleuses de notre race au labeur dur et ingrat de la colonisation, il suffirait de les renvoyer aux prodigieux travaux accomplis par nos soldats à Kita. Ils transformèrent des affùts de canon en voitures pour le transport des matériaux; ils enlevèrent les fers des chevaux et des mulels pour fabriquer les instrumenis qui leur manquaient; ils débitèrent avec des outils minuscules d'énormes pièces de charpente. Aussi Kita devint-elle rapidement une importante forteresse, qui assurait à nos soldats une retraite en cas d'insuccès, et qui leur permettait de pousser plus avant dans la direction du Niger.

Les indigènes avaient d'abord fait bonne figure; mais, excilés sous main par les émissaires d'Ahmadou, et surtout encouragés à la résistance par un chef dont nous ne soupçonnions encore ni les projets ni la puissance, un certain Samory, le nouveau maître du Ouassoulou, ils ne tardèrent pas à couper les convois de vivres et à engager les hostilités. C'étaient surtout les gens de Goubanko, village fortifié à dix kilomètres au sud de Kila, qui se signalaient par leur audace. A Goubanko s'élaient réfugiés un ramassis de pillards peuls, bambaras ou mandingues, déjà compromis par leur attitude à l'égard de la mission Gallieni. Non seulement ils avaient déclaré qu'ils ne voulaient avoir aucune relation avec les Français, mais encore avaient pris l'iniliative de la déclaration des hostilités. Suivant l'usage africain, leur chef avait fait hisser sur un très grand arbre un poulet avec une pierre au cou, annonçant que tous les Français qui dépasseraient cette 
limite auraient le même sort. Un exemple devenait nécessaire. Le 11 février, Borgnis-Desbordes marchait contre Goubanko à la tête de soixante-dix ouvriers, cent quatre-vingts tirailleurs, vingt-cinq spahis et quatre pièces de quatre. Le feu commençait à sept heures du matin et durait jusqu'à midi. Nous n'avions plus que trois coups à tirer, lorsque enfin la brèche fut ouverte, et le village emporté. C'était la première fois que le canon français retentissait si loin dans le Soudan. Aussi l'effet produit par la chute de Goubanko fut-il considérable. Non seulement tous les chefs du voisinage firent leur soumission, mais Ahmadou, qui n'avait pas encore signé avec Gallieni le traité de Nango, et qui le retenait auprès de lui à Ségou, s'empressa de terminer les négociations et de renvoyer les représentants de la France. Les travaux de construction à Kita furent en outre très rapidement menés, et, grâce à la prise de Goubanko, celte première campagne se termina de la sorte tout à notre avantage.

Il n'était que temps d'affirmer la résolution et de prouver la puissance de la France, car, au moment où les soldats de Borgnis-Desbordes s'aventuraient ainsi en plein Soudan, un grand danger les menaçait. Ils furent coupés de leurs communications avec Saint-Louis. Un chef du Bosséa, AbdoulBoubakar, s'était jeté sur une de nos colonnes engagée dans le Fouta. Il n'avait pas, il est vrai, réussi à l'entamer, grâce à l'héroïque résistance de quelques spahis à N'da-Boyan, mais il avait arrêté la marche de la colonne. En outre, il avait barré le Sénégal entre Bakel et Médine. Négociants, approvisionnements, soldats de renfort, rien ne pouvait passer. La colonie était comme coupée en deux tronçons : d'un côté SaintLouis et Bakel, de l'autre Médine, Bafoulabé et Kita. Aussi l'inquiétude était-elle fort grande à Saint-Louis, et à Kita surtout, dans l'autre moitié de la colonie ; la situation empirait de jour en jour, car on n'avait plus rien à manger, et, devant la perspective de mourir de faim, on agita sérieusement la question de faire sauter la nouvelle citadelle et de revenir en arrière. C'eùt élé pour la France un recul lamentable et la destruction de tous nos projets d'avenir dans le Soudan. Le gouverneur du Sénégal, Delanneau, compril la né- 
cessilé d'agir. Il envoya vers Abdoul-Boubakar (27 avril 1881) le capitaine Rémy et quelques-uns des principaux nègres de Saint-Louis, le menaçant de marcher contre lui avec toutes les forces dont il disposait, s'il ne renonçait pas immédiatement à la lutte. Le chef du Bosséa prit peur et accepta toules nos conditions. Aussilôt les passages du fleuve redevinrent libres, les caravanes circulèrent de nouveau, Kita put respirer, et la France, reprenant ses projets contre le Soudan, organisa une seconde expédition.

Le colonel Borgnis-Desbordes fut de nouveau désigné pour la conduire. Il s'agissait cette fois de pénétrer jusqu'au Niger, et de faire pour la région comprise entre Kita et le grand fleuve ce qui venait de si bien réussir pour la région entre Kita et Bafoulabé. Or les indigènes ne cachaient pas leur mauvais vouloir, et nous allions nous heurter, presque sans nous en douter, contre un puissant empire improvisé dans ces dernières années, et contre un homme auquel n'ont manqué ni le courage du conquérant ni les talents de l'administrateur. Cet empire africain est le Ouassoulou, et notre nouvel adversaire se nommait Samory.

Les notions précises sur le Ouassoulou ne dépassent pas l'année 1840. Un certain Mahmadou, de Kankan, lieutenant d'Al-Hadji-Omar, s'élait initié, sous la direction du prophète, à la tactique et en même temps à la science du gouvernement. Il le quitta aussitôt après le siège de Dinguiray, et résolut de reprendre, mais pour son propre compte, ce qui avait si bien réussi à 0 mar. Il réunit sans peine de nombreux volontaires, et fonda sur la rive droite du Niger un État indépendant dont Kankan fut la capitale. Un Bambara, le roi Dieri, mécontent de ce voisinage, lui déclara la guerre et vint l'assiéger dans sa capitale. La place allait succomber lorsqu'il fut tué dans un assaut. Son armée se dispersa aussitôt. Mahmadou réunit aux siens les plus braves de ses soldats, et se trouva le maître incontesté de toute la région. Pendant dix ans il régna en paix, et trouva le temps, tout en propageant l'Islam, de consolider sa puissance et de donner à son empire des instilutions très remarquables. Son fils Dianaboufarina Modi lui succéda. Il n'avait ni l'intelligence ni la fermeté de 
son prédécesseur. De nombreuses révolles éclatèrent, el la dislocatioñ du royaume de Kankan parut imminente. C'est à ce moment que Samory entra en scène ${ }^{1}$. Il n'était que le fils d'un dioula ou marchand de Sanankorô, ce qui était fort mauvais pour ses projels ultérieurs, car les tribus soudaniennes sont très fières de la pureté de leur race, et ne tien nent qu'en très médiocre estime les dioulas. Mais Samory était brave et déterminé. Il commença par faire la gucre sous les ordres du marabout Sori Ibrahima, qui s'était taillé une principauté aux dépens de Dianaboufarina Modi, puis passa au service d'un autre vassal rebelle, Bitike Souané; mais il ne tarda pas à supplanter son nouveau maître et à travailler pour son propre compte. Bientôt il fut rejoint par les meilleurs soldats, qui comprenaient qu'ils avaient tout à gagner sous un chef entreprenant et sans scrupule. A leur lête, il marche contre sa ville natale, Sanankorô, s'en empare après un siège de six mois, et conquiert, moitié par violence, moitié par ruse, la belle province du Ouassoulou; c'est à ce moment que le maître légitime de la contrée, Dianaboufarina Modi, réduit aux dernières extrémités par ses sujets révoltés, et assiégé dans la dernière place qui lui restait, dans sa capitale Kankan, appela Samory à son aide. Ce dernier accepta cette proposition inattendue. Les nouveaux alliés réussirent en effet à débloquer Kankan, et à reprendre quclques-unes des provinces usurpées. Mais Samory se fit la part du lion, et Dianaboufarina Modi ne tarda pas à comprendre qu'il avait fait un marché de dupe. Il est probable que c'est lui qui excita sous main le marabout Sori Ibrahima à déclarer la guerre à son ancien lieutenant. Samory, conformément au traité qui le liait au possesseur de Kankan, demanda son concours. On le lui refusa. Samory dissimula sa colère, feignit d'accepter les excuses de Dianaboufarina Modi, battit les généraux de Sori Ibrahima, puis, se retournant brusquement contre son ancien allié, le somma de se déclarer son vassal.

1. Voir, sur les commencements de Samory, la curieuse notice, rédigée par un traitant mandingue, Nohammed-Saufo, et transmise à la Société de géographie de Marseille (1888) par F. Bohn, directeur de la Compagnie française de l'Afrique occidentale. 
Aussitôt le roi de Kankan appelle à son aide Sori Ibrahima; mais les deux souverains sont baltus, et Kankan ouvre ses portes après dix mois de siège.

Après cette victoire décisive, Samory, maître incontesté de tout le bassin du Niger supérieur, et de la région qui s'étend de l'Atlantique et du Fouta-Djallon au Sénégal et au Soudan, prend le titre d'almamy du Ouassoulou et d'émir al moumenin. Il se donne une cour, il organise ses États et fait continuer les conquêtes par ses lieutenants. Le Ouassoulou forme aujourd'hui un vaste empire de trois cent cinquante à quatre cent mille kilomètres carrés, peuplé d'environ dix-huit cent mille à deux millions d'habitants, Peuls, Mandingues, Malinkés, Bambaras, Soussous et Soninkés, tous violemment rapprochés par la conquête, n'ayant de lien commun que le souvenir des dangers courus et des victoires remportées ensemble. A cheval sur la ligne de partage des eaux du Niger et des fleuves de l'Allantique, en contact à l'ouest avec la république de Libéria, Sierra-Leone, le Sénégal et le Fouta-Djallon, au nord avec le Soudan français et le royaume de Ségou, à l'est et au sud avec un État indigène qu'on ne connait encore que très imparfaitement, le Canadougou, le nouvel empire forme un vaste plan incliné, dont l'arête supérieure suit la crête des monts du Loma et du FoutaDjallon, et dont les gradins sont constitués par des étages successifs. Bien qu'il soit difficile d'avoir des détails précis sur le Ouassoulou, attendu que les sujets de Samory se savent surveillés et craignent d'être punis de leurs indiscrétions, on sait que l'empire compte cent soixante provinces, et dix grands commandements, disposés en secteurs autour de quatre provinces centrales. Samory s'est réservé l'administration directe de ces quatre provinces, qui sont exemptes d'impôt et soumises à la seule obligation d'héberger les troupes de passage. Les dix grands commandements sont confiés soit à des princes de la famille de Samory, soit à ses généraux. Ils sont assistés d'un conseil de chefs de gucre, de marabouts et de griots, dont les décisions sont valables dans l'étendue du gouvernement. La justice est rendue par les assemblées de village, de province ou de gouvernement, et 
par Samory en personne. Ce dernier ne s'occupe que des crimes d'État ou des causes qui l'intéressent.

L'armée a été l'objet des suins tout particuliers du conquérant. Elle comprend des levées temporaires, astreintes à un service dont la durée est indéterminée, et des soldats d'élite, les sofas, captifs dressés à la guerre dès leur jeune âge, ou volontaires libres. Chaque gouverneur a sa garde particulière de sofas. Samory les réunit et les commande lui-même en cas d'expédition sérieuse. Ils sont armés de fusils à pierre achelés aux Anglais de Sierra-Leone, et de sabres grossiers. Samory a en outre une garde personnelle d'environ mille fanatiques, les seuls qui portent un uniforme, sarreau et pantalon noirs, ceinture et chechia rouges. Ce sont eux qui fournissent des cadres aux levées temporaires. Une quarantaine d'entre eux, les plus braves et les plus habiles, ont des armes à tir rapide ou des espingoles de douanier. Samory ne s'est inquiété ni des marches, qui se font en désordre, ni des bivouacs, qui se dressent au hasard; mais il paraît avoir inventé une manœuvre de combat dont l'effet doil être irrésistible. Ses hommes se rangent en trois, six ou douze lignes de profondeur. La première ligne, quand elle a tiré, démasque la seconde, qui tire à son tour, puis va se reformer en arrière et recharger ses armes, en sorte que le feu n'est jamais interrompu. Les sofas savent même exécuter des feux de salve. En temps de paix, Samory fournit aux besoins de ses soldats; en temps de guerre, ils vivent aux dépens de l'ennemi. Celte tactique barbare, mais supérieure à tout ce qui existait en Afrique, explique les succès rapides remportés par les soldats du Ouassoulou.

Samory et les principaux de ses lieutenants pratiquent l'islamisme, mais défiguré par mille jongleries absurdes. Les marabouts ne sont que des sorciers, mais dont le pouvoir occulte est considérable. Quelques-uns d'entre eux, plus intelligents et plus instruits, ont rompu avec ces pratiques ridicules, et s'efforcent de ramener le peuple à la stricte observation des préceptes du Coran. Ils sont bien vus par Samory, qui leur accorde sa confiance, écoute volontiers leurs conseils et leur confie l'éducation de ses enfants. On prétend même 
que, nouveau Charlemagne, il ne dédaigne pas de suivre leurs leçons, et s'exerce à écrire. Les jeunes talibés, instruils par ces marabouts, deviendront les plus fermes soutiens du Ouassoulou, et reconnaîtront par les services qu'ils sont appelés à rendre tout le prix de l'éducation qu'ils ont reçue.

Tel est cet empire improvisé dans l'Afrique centrale, et dont les progrès ont été si élonnants ; mais il semble arrivé à son apogée. Sans doute à l'est et au sud s'étendent devant lui de mystérieuses contrées où il peut encore grandir, mais à l'ouest il se heurte contre la république de Liberia, contre les Anglais de Sierra-Leone, contre le Fouta-Djallon. Au nord-est, les talibés du royaume de Ségou ne veulent pas se laisser déposséder. Au nord-ouest enfin la France est là, dont les progrès sont incessants, et qui ne veut pas laisser grandir dans son voisinage un empire africain fortement constitué. Il est vrai que nous ne soupçonnions pas l'imporlance du Ouassoulou lorsque nos avant-postes rencontrèrent les sofas de Samory. Aux premiers coups de fusil on reconnut de part et d'autre que la partie qui s'engageait était redoutable et que c'élait la suprématie dans l'Afrique occidentale qu'allaient se disputer les deux peuples. Aussi des deux côtés s'y prépara-t-on avec ardeur et passion.

Samory entra le premier en campagne. Il lança contre Kita un de ses alliés, Abdallah, l'almamy de Mourgoula, et vint mettre le siège devant la forte place de Keniera, sur la rive droite du Niger. Un lieutenant de tirailleurs sénégalais, AllaKamessa, lui fut envoyé, pendant l'hiver de 1881, afin de le décider à abandonner le siège de Keniera. Samory non seulement ne tint aucun compte de ses menaces, mais le retint prisonnier et parla de le décapiter. Alla-Kamessa ne parvint à s'échapper qu'après une dure captivité de plus de deux mois. Il ne restait plus qu'à faire parler la poudre, ainsi que disent les Orientaux.

Le colonel Borgnis-Desbordes était parti de Saint-Louis le 17 octobre 1881. Il arrivait à Kayes le 20 décembre, imposait des contributions aux chefs rebelles ou brûlait leurs villages, ct, après avoir soumis les tribus dont nous avions besoin pour assurer le ravitaillement entre Bafoulabé et Kita, en- 
trait dans Kita le 9 janvier 1882. Poursuivant aussitôt ses avantages, il entrait en campagne contre Samory, et, bien que ses instructions lui enjoignissent de ne pas dépasser Kila, n'hésitait pas à marcher au secours de Kenera. C'était une entreprise bien hardie. Il n'amenait avec lui que deux cent vingt combaltants et deux canons. Aucun secours à espérer des indigènes. Ils élaient comme hébétés par la terreur. Le colonel ayant dil à un de leurs chefs qu'il allait enrôler leurs femmes pour l'aider à les défendre: "Tu as raison, lui répondit-il, nos femmes sont plus braves que nous. " Puis s'adressant au docteur : "As-tu un médicament, lui demanda-t-il, qui puisse nous donner du courage à moi et à mes hommes? "Il ne fallait pas compler sur de pareils auxiliaires : ils n'auraient été dangereux que si nous eussions battu en retraile. Le colonel Borgnis-Desbordes connaissait trop bien les tribus soudaniennes pour ignorer que l'inaction était périlleuse. Aussi se décida-t-il à marcher au secours de Keniera, malgré la faiblesse de son effectif et bien que le pays à traverser fût inconnu sur le plus long parcours.

Le 11 février 1882, la pelite colonne se mettait en marche. Elle traversa Mourgoula, Niagassola, Diassa, et arriva le 2o février à Falama, sur le Niger. En deux heures le grand fleuve élait franchi, et nos soldats précipitaient leur marche dans al direction de Keniera, espérant qu'ils arriveraient à temps pour sauver la ville et prévenir un affreux massacre. Ils rencontrèrent bientôt les premiers cavaliers de Samory. En quelques minutes l'aclion devint générale. Comme aux temps homériques, on vit les hommes des deux partis se provoquer et s'injurier. Entre tous se signalait le lieutenant Alla-Kamessa, qui apostrophait en langue malinké ses ennemis, et l'interprète Mahmadou-Alpha, qui galopait au-devant de l'armée, tout en exécutant une fantasia désordonnée. Effrayés par l'élan de notre attaque, et par le bruit du canon et l'effet de la mitraille, les soldals de Samory ne tinrent nulle part. Ils nous abandonnèrent le champ de bataille, et s'enfuirent au delà de Keniera.

Il était trop tard. La ville venait d'être prise, quelque temps avant l'arrivée des Français, et l'exéculion tant redou- 
tée avait eu lieu. "Enfin on voit la plaine de Keniera et les ruines fumantes du village ${ }^{1}$. Le spectacle de loin était lésolant: à mesure qu'on s'approchait, il devenait horrible. Dans la plaine, autour du village, on voyait des cadavres et des têtes coupées; un peu plus loin s'élevait un bûcher, amoncellement de cendres, de tisons encore brûlants et d'ossements noircis, où le prophète avait jeté nombre de victimes, lorsque les puits du village avaient été pleins de cadavres. Il variait ainsi les genres de supplice, et le bùcher n'empêchait pas qu'on ne coupâl des tètes. Nos soldats trouvèrent même des malheureux ràlant encore, portant des blessures difformes, et que leurs bourreaux n'avaient pas eu le temps d'achever. Toutes ces horreurs n'étaient pas encore aussi navrantes que la vue des faméliques tout nus, décharnés, vrais squeletles que l'on aurait pu prendre pour de vivantes statues de la Faim, et qui tendaient lés bras vers nos soldats à leur approche. Les vieilles femmes, les enfants surtout, gisaient sans force, exténués, continuant encore leur plainte de la veille et demandant à manger. C'étaient des aveugles ou des infirmes, que l'ennemi ne pouvait utiliser comme captifs, et qu'il laissait ainsi mourir de faim. "

Le vainqueur n'aurait pas mieux demandé que de poursuivre à outrance Samory, mais la colonne expéditionnaire n'était pas assez nombreuse. La retraite sur Kita fut donc ordonnée, et même elle nẻ s'opéra que fort lentement, car notre arrière-garde élait sans cesse attaquée. Nous n'en avions pas moins, par notre énergique intervention, arrêté les progrès de Samory, et nettement démontré à toutes les tribus soudaniennes que nous songions à les délivrer, et non pas à les conquérir.

Une troisième campagne fut préparée dans l'ćlé de 1882. On était cette fois résolu à pousser jusqu'au Niger, afin de consolider notre protectorat sur le haut Sénégal et de profiter du traité conclu par Gallieni avec Ahmadou. Le colo-

1. Pietri, les Français au Niger, p. 233. - Cf. Delaxiseau, Conférence à la Société de griographie de Douai: "Nous avous pu voir des trous profonds, dans lesquels plusieurs centaines de ces malheureux araient été jetés pieds et poiugs liés, pêle-mêle arec de la paille et des fagots enflammés." 
nel Borgnis-Desbordes, chargé pour la troisième fois du commandement, eut beaucoup de peine à former sa colonne cxpéditionnaire. Presque tous les chevaux moururent d'une épizootie, et la plupart des spahis se trouvèrent démontés. La petite armée ne put entrer en campagne que le 22 novembre 1882. Ce n'élait point contre Samory qu'elle se dirigeait, ni contre Ahmadou, mais contre une des citadelles qui obéissaient encore à ce dernier, contre Mourgoula, la capilale du Birgo, à mi-chemin entre Kita et le Niger, dont les habitants n'avaient pas caché leurs sentiments hostiles à l'égard de la France. Abdallah, le maître de Mourgoula, avait réuni autour de lui tous les bandils toucouleurs restés disponibles après les grandes guerres d'Omar et d'Ahmadou. Très dévoué à son maître Ahmadou, il ne se maintenait que par la terreur et les exactions. Il avait fait le vide autour de lui. Des cinquante villages que l'on comptait dans le Birgo avant l'arrivée des Toucouleurs, huit seulement restaient encore debout, et ils élaient en ruine. Mourgoula était même presque démantelée. Des trois enceintes qui entouraient jadis cette forteresse, la première, de forme pentagonale, était en fort mauvais élal; la seconde, de forme rectangulaire, flanquée aux angles de quatre grosses tours, était plus soignée; la troisième, qui comprenait une grosse tour et le palais d'Abdallah, était seule en état de résister; mais deux cents soldats seulement défendaient la place, et il en aurait fallu plus de mille rien que pour la première enceinte. Abdallah ne se dissimulait aucun des dangers de la situation. Isolé au milieu des populations hostiles, inquiété par le voisinage et par les progrès des Français, il était résolu à défendre jusqu'à la dernière extrémité le poste d'honneur qu'on lui avail confié, mais il se sentait vaincu à l'avance. Il avait déjà fait part de ses craintes d'avenir au capitaine Vallière, qui lui avait été envoyé par Gallieni, mais ne lui avait pas caché sa détermination de rester fidèle jusqu'au bout au sultan de Ségou. Borgnis-Desbordes ne pouvait laisser en arrière un ennemi aussi résolu et une citadelle où, en cas d'insuccès, tous les ennemis de la France auraient couru l'attendre au passage. L'expédition fut menée avec vigueur et dans le plus grand secret. En sept 
jours furent franchis les cent trente kilomètres qui séparaient Kita de Mourgoula. La citadelle toucouleur ouvrit presque aussitôt ses portes. C'était un coup droit porté contre Ahmadou, un véritable défi de la France. Avec Mourgoula démantelée disparaissait la puissance des Toucouleurs dans le Birgo. La France n'avait plus qu'à pousser droit au Niger.

Une autre forteresse indigène nous barrait encore le passage, Daba, où s'était retiré le Bambara Nampa, celui qui avait organisé le pillage de la mission Gallieni. Très fier de son succès, il avait laissé sous les murs de sa ville les deux pierriers et les deux espingoles enlevés dans la déroute, et, une fois possesseur de ces armes fatidiques, qui assuraient la victoire, il se vantait d'exterminer les blancs assez hardis pour s'approcber du Niger ${ }^{1}$.

Daba était bien fortifié. "Un mur en banko, haut de trois mètres cinquante à quatre mètres, large de cinquante centimètres en moyenne, fait tout le tour de la ville et n'est interrompu que par les portes en bois, qui sont dissimulées dans des renfoncements; il està peu près circulaire, mais présente de nombreuses sinuosités. Des maisons en terre, avec poutres ct solives en bois, recouvertes d'argile, sont appuyées à celte enccinte sur la presque totalité de son pourtour, en sorte que l'on peut abaltre une grande partie du mur sans avoir pour cela d'accès dans la ville. Toutes les maisons sont de forme carrée et reliées les unes aux autres par une petite muraille d'un mètre cinquante de hauteur. Il n'y a pas de grande rue, mais seulement des sentiers sinueux qui suivent les murs, crénclés sur tout leur parcours. On ne trouve pas de réduit principal, mais chaque maison peut offrir une résistance sérieuse. On se rend facilement compte de la difficulté de prendre d'assaut une ville ainsi construite; on ne peut y meltre le feu avec l'artillerie, les obus mêmes produisent des dégâts insignifiants. Les Bambaras n'ont, heureusement, que des fusils sc chargeant par la bouche, en sorte que, leur coup tiré, ils sont à la merci des assaillants. "

Daba ne se rendit pourtant qu'après avoir subi un siège en

1. De Pour, Campagne sur le haut Niger, de 1881 à 1883 (Nouvelle Revue, 18S6). 
règle. Un parlementaire fut tué, et les neuf cents à mille défenseurs de la place dirigèrent un feu meurtrier contre nos artilleurs. Ce n'est qu'au deux cent qualorzième coup de canon que la brèche fut ouverte, et que la colonne d'assaut, conduite par le capitaine Combes, put enfin pénétrer dans la ville. Encore fallut-il faire le siège des maisons. Les Bambaras se firent bravement tuer. Le vieux Nampa, son frère Gouong et toute sa famille donnèrent l'exemple, et périrent les armes à la main. Nos pertes furent cruelles. Presque tous les officiers qui avaient pris part à l'assaut furent blessés, l'un d'entre eux, le lieutenant Piquart, mortellement. On rendit aux morts, le soir même de la vicloire, les honneurs suprêmes. Le bois des cases écroulées forma le bûcher où l'on jeta les cadavres, afin de leur épargner une insulte suprême, car on les aurait délerrés après notre départ, les os des blancs passant pour communiquer aux amulettes une vertu toute particulière.

Les survivants de Daba s'étaient enfuis dans les villages roisins. Le capilaine Combes fut envoyé à leur recherche. Terrifiés, les indigènes de Soguierna-Bongou, de Siro-Corobougou et de Tourodo firent aussilôt leur soumission. Un des prisonniers se signala par son courage. Il refusa obstinément d'indiquer la retraite où se cachait un chef échappé au carnage. Menacé de mort, et conduit devant un mur avec un peloton de tirailleurs, il resta inébranlable, et ne sourcilla pas devant les fusils qui s'abaissaient. Relâché par BorgnisDesbordes, qui rendait hommage à son grand cœur, il avoua quelques jours plus tard qu'il connaissait la retraite de son chef, mais qu'il serait mort avant de l'indiquer. De pareils trails honorent les Bambaras. Ce ne sont pas des adversaires indignes de la France, et ils pourront derenir d'utiles alliés. Les Bambaras, en effet, sont nos alliés nalurels Maintenant que leur orgueil a élé humilié, il est probable non seulement que nous n'aurons plus rien à redouter de leur part, mais encore qu'ils se rapprocheront de nous.

La prise de Daba produisit un grand et salulaire effet dans foute la région. Nous ne devions plus rencontrer de résistance jusqu'au Niger. Ouoloni, Guinina, Dio, Diako et tous les 
villages dont les habitants avaient pris part au pillage de la mission Gallieni n'essayèrent même pas un simulacre de résistance. Ils rendirent tous les objets volés restés en leur possession, présentèrent de très humbles excuses, et se soumirent à nos réquisitions. Il est vrai que le colonel Borgnis-Desbordes, fidêle à son système de douceur, ne fut pas trop sévère dans ses revendications. C'est ainsi que la colonne arriva le $1^{\text {er }}$ février à Bamakou, sur le Niger, sans être inquiétée.

Deux tribus rivales se disputaient alors Bamakou, les Soumanas et les Niarés. Les premiers sont de pure race bambara. Cultivaleurs et guerriers, ils conservent la suprématie donnée par l'origine et par l'antique possession du sol. Bien qu'assez actifs, ils aiment à se pavaner dans de belles étoffes, et à humer d'abondantes prises de tabac, allongés sur des nattes au-devant de leurs cases. Ils sont menteurs pour l'amour du mensonge. "A quoi me șcrvirait d'avoir menti? " répondait un jour un chef soumana à un de nos officiers qui l'accusait de s'être fait payer deux fois le même objet. Au demeurant, accessibles aux sentiments élevés, peu sanguinaires, et disposés à bien accueillir les Français. Les Niarés, au contraire, mélangés de Maures et de Soninkés, sont surtout des commerçants. Le principal objet de leur négoce est la traite des esclaves. Aussi ne voyaient-ils qu'avec peine arriver les Français, et leurs vœux secrets étaient pour Ahmadou. Ils n'osaient cependant se prononcer trop ouvertement, et se contentaient d'instruire de nos faits et gestes non seulement leur maître, le sultan de Ségou, mais aussi notre redoutable ennemi Samory, le maître du Ouassoulou. Ils essayèrent aussi de nous prendre par la famine, et refusèrent de nous céder des vivres en échange de nos monnaies, que pourtant ils connaissaient bien. Le colonel passa outre, et se contenta de les menacer de réquisitions. Le service des subsistances fut aussitôt assuré.

Bamakou n'avait plus la même importance qu'au temps où Mungo-Park la visita. Depuis une vingtaine d'années, la guerre avait fermé tous ses débouchés et tari ses sources d'approvisionnement. Un marché rival, espèce de village neutre bâti sur la rive gauche du fleuve, Koubkoro, lui faisait une concurrence désastreuse. Il est vrai que Bamakou occupe 
une position stralégique importante, au point de croisement de routes nombreuses, à l'endroit où le Niger commence à être navigable. Ces considérations engagèrent le colonel BorgnisDesbordes à s'établir à Bamakou, et à y fonder notre premicr établissement sur le Niger. Le 7 février, entouré de tout le corps expéditionnaire, il posait la première pierre d'un fort, et prenait possession au nom de la France de toute la région environnante. "Nous tirerons onze coups de canon, avait-il dit à ses compagnons, pour saluer les couleurs françaises flollant sur les bords du Niger. Le bruit que font nos petites bouches à feu ne dépassera pas les montagnes qui sont à nos pieds; et cependant, soyez-en convaincus, on en entendra l'écho bien au delà du Sénégal. Tous les Français qui mettent au-dessus de tout la grandeur et l'honneur de leur pays, applaudiront sans réserve à ccux de leurs compatrioles qui, à force d'énergie, d'abnégation, de courage, de discipline, se sont montrés, malgré toules les difficultés qu'ils ont rencontrées, à la hauteur de la grande ouvre de civilisation dont l'exécution, décidée par le Parlement, leur a été confiée. "

En 1879, Soleillet, tout seul, descendait le Niger. En février 1883, une petite armée française campait sur les bords de l'immense fleuve; que de progrès accomplis en quatre années! Et quel n'est pas en effẹt l'avenir réservé à la France dans l'Afrique centrale, si, celte fois du moins, nous ne laissons pas échapper le merveilleux instrument de prospérité et de renaissance coloniale que notre bonne fortune met de nouveau entre nos mains!

L'arrivée des Français à Bamakou eut un grand retentissement. Le sultan de Ségou, tremblant pour lui-même, n'osa pas protester; mais il excita sous main nos ennemis, surtout l'insaisissable Samory, et forma contre nous une véritable coalition. Les marchands maures de Bamakou étaient de connivence avec nos ennemis. Ils les renseignaient sur tous nos mouvements. Afin de faire cesser ce dangereux espionnage, le colonel fit saisir trois des plus compromis, et leur annonça qu'ils seraient mis à mort à la première attaque du chef nègre. Ces marchands restèrent impassibles. Ils protestèrent même de leurs sympathies pour la France. On vit pourtant leurs faces 
noirâtres bleuir légèrement sous le coup de l'émotion, lorsqu'on les conduisit en prison. Il n'était que temps de prendre ces précautions, car Samory avait déjà filé sur nos derrières, coupant les fils télégraphiques et menaçant nos communica-

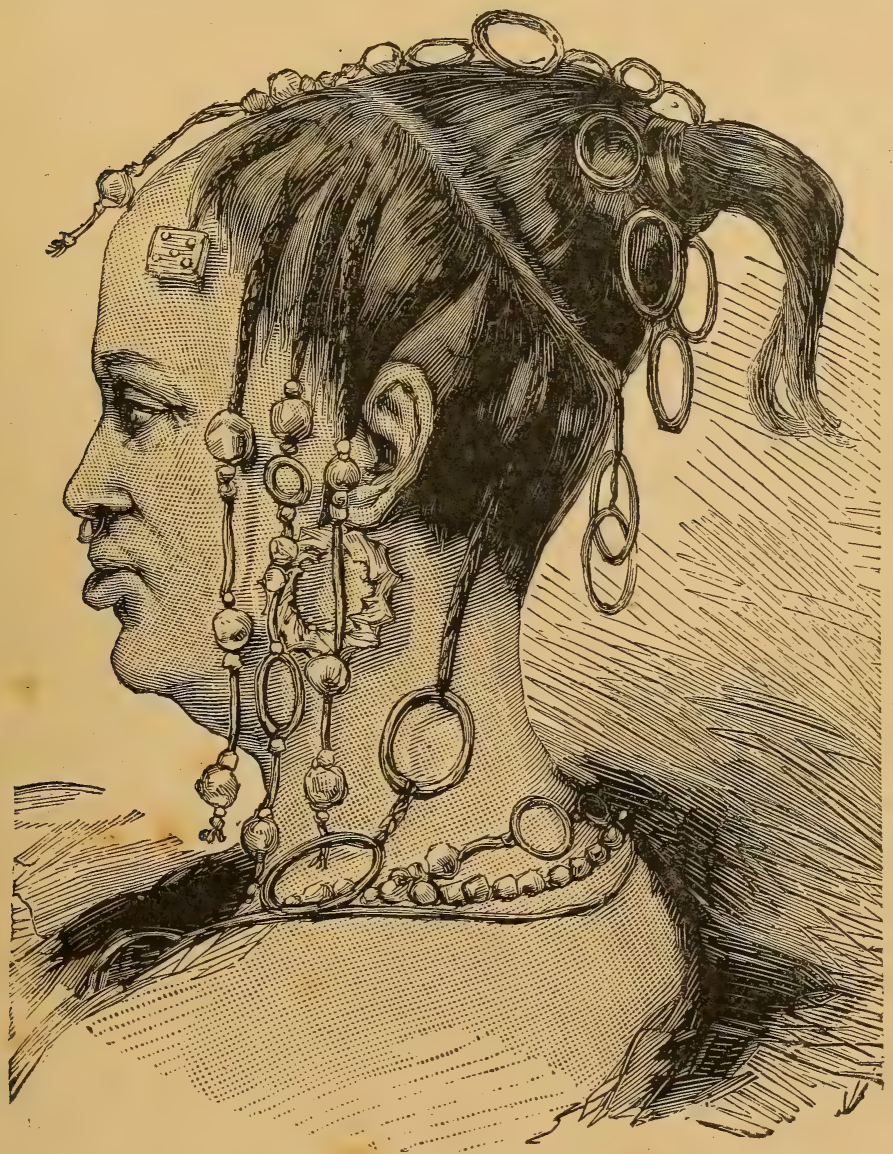

Femme de Ségou.

tions. Deux de ses lieutenants eurent même l'audace de nous provoquer et vinrent nous attaquer presque sous les murs de Bamakou.

Le 2 avril, des spahis envoyés en reconnaissance furent vivemenl ramenés en arrière par des masses compactes d'ennemis. Avec leurs chevaux fatigués, s'ils avaient eu l'impru- 
dence de fuir, ils étaient perdus, et ce premier succès aurait augmenté la confiance des soldals du Ouassoulou; mais ils tinrent bon, et n'opérèrent leur retraite que lentement, et toujours en bon ordre, jusqu'à ce qüils fussent secourus par une colonne sortie de Bamakou. Dès le lendemain une vraie bataille s'engageait à Ouejako. Les Français n'étaient en tout que cent. Ils furent aussitôt tournés et enveloppés. Obligés de se former en carré, leur situation fut un instant critique. "Plus d'un se préparait à rendre chèrement sa vie, a écrit l'un d'eux, M. de Pols, et je ne crois pas exagérer en disant que chacun de nous pensait déjà à se réserver une balle de revolver, pour ne pas tomber vivant entre les mains de sauvages qui n ïgnorent aucun des raffinements de la cruauté. " Malgré les feux de salve, malgré les décharges de la mitraille, les gens de Samory tenaient bon. Les Français furent obligés de battre en retraite. Sans l'énergie des officiers, sans le dérouement des spahis, celte retraite se serait convertie en désastre, car nos fantassins étaient épuisés de fatigue. Bon nombre d'entre eux avaient mème quitté le carré, et attendaient la mort. Ils furent tous ramenés par les spahis, et purent enfin arriver jusqu’à un marigot, où il était plus facile d'organiser la défense. Les pertes de l'ennemi étaient effroyables. Le sol était jonché de cadarres, mais les Français araient reculé. C'était pour Samory un véritable succès.

Pendant quelques jours notre situation fut très précaire. Les communications étaient interceptées. Les conrois de vivres n'arrivaient plus. Toutes nos reconnaissances étaient repoussées. Enfin, d'un instant à l'autre, il fallait s'attendre à lirruption dans nos lignes des soldats d'Ahmadou. Le colonel Borgnis-Desbordes comprit qu'il fallait risquer le tout pour le tout, et prit hardiment l'offensive.

Le 12 arril, la colonne expéditionnaire entrait en campagne. Elle brùlait sur son passage de nombreuses hultes en paille, déjà construites par l'ennemi en prévision de la prochaine occupation de Bamakou, et sur tous les points refoulait les soldats de Samory. A la nouvelle de ces succès inespérés, plusieurs centaines de Bambaras auxiliaires venaient grossir nos rangs, pillards plutôt que combaltants, mais néanmoins 
utiles auxiliaires pour garder nos communications et assurer nos subsistances. A près chaque affaire, on les voyait se jeter sur les objets abandonnés par l'ennemi. Ils s'acharnaient surtout après les chiens assez nombreux que traînaient à leur suite les gens du Ouassoulou. Ils les égorgeaient sans pitié, et en faisaient le plat de résistance de leurs festins du soir. La chair de ces chiens, nourris de glands frais, est en effet assez savoureuse, et plusieurs de nos hommes partagèrent sans répugnance les plaisirs gastronomiques de nos auxiliaires improvisés.

Le 19 avril, grand combat à Nafadié et victoire des Français ; le 22, incendie du village de Diougou-Fara; le 23, du village de Samaco. Les gens du Ouassoulou étaient décidément refoulés, et les armes françaises avaient retrouvé leur preslige. Borgnis-Desbordes put rentrer à Bamakou sans être inquiétẻ, et s'occupa tout aussitôt de rétablir notre ligne de ravitaillement. Kassaba, Dilbouroula, Donabougou, furent successivement repris. On installa même un poste nouveau à Koundou, et dans toutes les directions non seulement nous fùmes dégagés, mais encore libres de nous porter sur tous les points menacés. Aussi l'impression de ces victoires mullipliées fut-elle extraordinaire. Notre domination sur le haut Niger se trouvait assurée. Bon nombre d'indigènes se rapprochaient de nous, et de nos deux principaux ennemis, les maîtres du Ouassoulou et du Ségou, l'un, Samory, se retirait de la lutte, l'autre, Ahmadou, craignant pour sa propre sûrelé, bien qu'il ne fût pas entré en campagne, abandonnait sa capitale et se retirail à Yamina.

En résumé, quels étaient les résultats de ces trois campagnes? Nous venions de nous emparer d'un terriloire égal en superficie au tiers de la France. Trois forts avaient été construits, à Bafoulabé, à Kita et à Bamakou. Les deux cent quatre kilomètres qui séparenl Bafoulabé de Kita, et les deux cent vingt-deux qui s'étendent entre Kita et Bamakou étaient reliés par des itinéraires soigneusement étudiés. Deux tronçons de route étaient même commencés entre Bafoulabé et Kita d'une part, entre le gué de Toukoto et Kita de l'autre. Enfin une ligne télégraphique de sept cent dix kilomètres, 
desservie par dis bureaux, reliait Bakel à Bamakou, le Sénégal au Niger, la France au Soudan. Le drapeau national avait été victorieusement promené à travers toule la région, et les indigènes, horriblement foulés depuis longues années par tous les ambitieux et tous les bandits de l'Afrique occidentale, s'habituaient à la pensée d'accepter la domination réparatrice et la protection efficace de la France. C'étaient là d'heureux débuts, et d'un excellent augure pour l'arenir.

Tout cependant n'est pas encore fini. Dans cette marche rapide de Médine à Bamakou, bien que les stations intermédiaires les plus importantes soient entre nos mains, la distance est tellement longue qu'il est à peu près impossible de maintenir sur tout le parcours une sécurilé absolue. On est obligé d'expédier, à des intervalles assez rapprochés, des colonnes de ravitaillement. C'est ainsi qu'en 1884 le colonel Boilère alla de Saint-Louis à Kita sans rencontrer de résistance, et par une route assez large pour que quatre-cavaliers pussent y passer de front. Dans celte quatrième campagne on décida la construction du fort de Koundou, à cent dix kilomètres de Kiita et à cent vingt de Bamakou. C'est une bâtisse de médiocre importance, moitié en terre, moitié en pierre, mais placée sur une belle position et commandant la route ct la rivière de Baoulé. Le grand inconvénient, c'est que le fort n'a que des cilernes pour sa provision d'eau. En cas de siège ou mème d’investissement, la garnison serait fort exposée.

En 1883 , nouvelle campagne de ravitaillement. Le 31 mai, le capitaine Louvel repoussait les bandes de Samory entre Niagassola et Siguiri, et le 22 juin le commandant Combes remportait une victoire à Sitakoto. On décidait en outre la construction d'une forteresse à Niagassola, non loin du Niger, poste d'observalion de haute importance contre le Oouassoulou et ses remuants soldats. Ce n'est encore qu'une grosse maison, à peine entourée par un mur de terre sèche, mais elle est défendue par une petite garnison. Deux canons protègent ses abords, et une ligne télégraphique, passant par Mourgoula, la relie déjà à Kita.

Chacune des campagnes du Niger marquait de la sorte une 
étape nouvelle dans la prise de possession du pays. D'année en année augmentait le nombre de nos ciladelles, et les indigènes, se groupant sous la protection de nos canons, shabituaient à se considérer comme nos clients.

\section{XII}

CONSOLIDATION DE LA PUISSANCE FRAYCAISE AC SÉXÉGA ET $A U$ SOLDAX

Le moyen le plus pratique daffermir à tout jamais notre domination dans ces contrées encore si pleines des souvenirs de leur indépendance, serait de les traverser de part en part par cette fameuse voie ferrée dont la construction avait été décidée dès l’année 1850. En effet, le ă férrier 1880, l’amiral Jauréguiberry, alors ministre de la marine, avait demandé un crédit de cinquante-quatre millions cent quatre-vingt-trois mille francs pour la consiruction immédiate de la ligne entre Médine et Bamakou. $\mathrm{La}$ demande parut prématurée, et on ne rota qu'un million trois cent mille francs pour études préparatoires. L'amiral Cloué, le successeur de Jauréguiberry, ne s'est pas tenu pour battu par le rejet de cette première demande. Dans la séance du 13 novembre 1880 il réclama aux députés, et obtint, dans la séance du 21 férrier 1881, un crédit de huit millions cinq cent cinquante-deus mille sept cent cinquante francs pour amorcer la roie ferrée entre Médine et Bafoulabé. Les traraus ont immédiatement commencé. Ils n'ont pas abouti d'abord, parce que les ouvriers indigènes, dont on arait essaré d'utiliser les loisirs, sont d'une indolence inouie. On a calculé que soixante et onze journées de travail exécuté par des indigènes ralaient à peine une journée de travail exécuté par un Européen. Après une campagne de six mois, on n'arait réussi à construire que quatro mille huit cents mètres de route. En second lieu, les études préparatoires ont élé par trop négligées. Le tracé définilif na a pas élé détcrminé, et on a follement gaspillé des sommes impor- 
tanles. Bref, il a fallu fermer les chantiers, et depuis lo mois de seplembre 1884, la construction de la voie ferrée du haut fleuve est abandonnée. Il paraitrait, mais les renseignements sur ce point manquent de précision, que l'aulorilélocale aurait continué les travaux grâce à certains crédits disponibles. II y a là, comme bonne administration financière, une irrégularité certaine; mais combien serait-il à souhaiter que nos dépulés, sans se laisser arrèter par des dépenses dont l'utilité présente n'est pas démontrẹe, mais qui engagent et assurent l'avenir, revinssent sur leur décision! A défaut de chemins de fer à grande traction, serait-il donc impossible d'établir une voie ferrée d'après le srslème Decauville analogue au chemin qui relie aujourd'hui Kiairoan an littoral, et qui nous a déjà rendu tant de services en Tunisie? C'est là un desideratum bien modeste, et pourtant cette voie de pénétration de la France dans literique centrale ouvrirait à notre forlune coloniale des peŕspectives indéfinies.

Si le chemin de fer avait été créé, nous naurions pas eu lant de peine à triompher des insurrections qui, en $1856 \mathrm{et}$ 1887, ont failli compromelle notre situation non pas seulement sur le Niger, mais mème au Sénégal. Ce n'est pas du Ségou ou du Ouassoulou que celle fois s'est déchaînée la tempête, c'est au Sénégal même, et c'est un Sénćgalais qui s'est cru un moment à la veille de réaliser le rève jadis formé par Al-Hadji-Omar ou par Samory. Ce nouvel adversaire de la France vient de succomber, mais il a vaillamment lutté, et nos officiers ont eu bien de la peine à le réduire.

Mahmadou-Lamine était un Sarakolé. c'est-à-dire quii appartenaif à une race très fière de son intelligence et de la supériorilé qu'elle s'arroge. Il naquit près de Kayes, vers 1837, et partit de très bonne heure pour la Mecque. Pendant de longues années, il parcourut le monde musulman, séjourna à Constantinople, et ne revint en Afrique quarec un trésor d'expérience ct de connaissances chèrement acquises. Résolu à fonder un empire sur les ruines de celui d'-1l-Hadji-0mar et d'Alimadou, il eut le tort de dévoiler trop tôt ses secrets desscins, car lo maitre de Ségou lo retint six ans dans une demicaptivité. Malımadou-Lamine, à peine rulâché, tourna aussilòt 
son activité contre les provinces directement soumises à la France. Grand, de mise imposante, éloquent, fort instruit pour un nègre, il recruta sans peine de nombreux adhérents, et se posa tout de suite comme un marabout inspiré et comme un fondateur d'empire. Rusé dans sa propagande, très actif, il aimait à raconter aur noirs quilil avait, à la Mecque. couché à côté du corps de Mahomet, et n'arait que deux doigls de moins que le Prophète. Il insinuait par là que son rùle serait presque aussi grand que le sien. Déjả mème il avait fait des miracles. Il rassemblait sas prosélrctes autour d'un bassin rempli d'eau, et faisait défier à leurs reux surpris, grảce à des images d'Épinal collées dans la paume de ses mains, toute une série d'uniformes français. On agitait alors le bassin, et le tableau se brouillait. "C"est ce que nous ferons de l'armée française! "s s'écriait alors le prophète dun ton convaincu, et il se retirait aussitôt, sans doute pour laver sss mains et ne pas s'exposer à êlre accusé de jonglerie. Ces grossiers stratagèmes valurent à Mahmadou-Lamine une immense réputation. Les mécontents se groupèrent autour de lui. Jeunes gens avides de pillage, bandils de toute prorenance, fanaliques et exaltés lui promirent leur concours. Les bateliers du fleuve, qui ne nous aiment guère, bien que nous les fassions vivre, s'engagèrent à le rejoindre au premier signal. Le marabout ne s'était pas encore compromis, et il était déjà redoutable.

En novembre 1885, le colonel Frêy, qui conduisait au Niger une colonne de ravitaillement et exécutait une sixième campagne, rencontra Mahmadou-Lamine à Kayes. Le marabout protesta de son dérouement, et il élait peut-ètre sincère, car les agitateurs nègres n'ont pas été jusqu à présent très heureux contre nous. Il annonęa mème son intention d'aller razzier les paiens de la Gambie: mais à peine le colonel Frey arait-il poussé sa pointe en arant que Mahmadou-Lamine. profitant de l'éloignement de la colonne française et de la mort soudaine de notre vieil allié Boubakar-Saada, l'almamy du Bondou, prêchait la guerre sainte, s'emparait par surprise de Sénoudébou et lançait ses avant-postes jusqu’à Kouguel, à sis kilomètres seulement de Bakel. Il avait des intelligences 
dans la place. Liinterprète, Alpha-Séga, lui était tout dévoué. Ce fut sur les instigations de ce traître que, dans une sortie imprudente, nous perdîmes dix tués, vingt-cinq blessés et un canon. Aussitôt, avec la mobilité d'impression qui caractérise ces peuples primitifs, les Africains se soulèvent en masse. A Bakel même, la moitié des indigènes se déclarent contre nous, et la garnison du fort ne parvient à se maintenir qu'après un sanglant combat dans les rues de la petite ville.

Averti par le télégraphe, le colonel Frey s'empressa d'accourir. Dès le 2 avril 1886, il arrivait à Kayes avec quatrevingts soldats blancs et près de quatre cents tirailleurs et spahis. Se heurter avec celte poignée d'hommes contre les quinze à vingt mille hommes que le marabout avait groupés autour de lui eût été bien imprudent. Le colonel adopta une taclique plus sûre. Il se décida à aller ravager successivement tous les villages qui avaient envoyé leurs contingents à Mahmadou-Lamine. Alors commence une campagne de six semaines, très intéressante à suivre dans ses détails, à cause des marches forcées, des surprises et des embuscades dont clle est toute remplie.

Le Gindimacko, province dépendant du sultan de Ségou, fut le premier puni de sa défection. A Bokkoro, où s'étaient réfugiés les révoltés avec force butin, s'engagea un violent combat. Les femmes prirent part à l'action. On les entendit, toute la nuit qui suivit la défaite, appeler à grands cris le prophète à leur secours. Mahmadou-Lamine ne se décida à interrompre le blocus de Bakel que lorsqu'il apprit que la colonne Frey venait de remporter de nouveaux succès à Guemou et à Bambella. Il vint présenter la bataille à son habile adversaire, le 19 avril, à Tambouckhané. Ce fut une action chaudement disputée. Le porte-drapeau de Mahmadou-Lamine vint tomber percé de coups à vingt mètres seulement de nos lignes. Les noirs se dispersèrent après avoir subi de grandes pertes. Les contingents désolés regagnèrent leurs villages, et le prophète s'enfuit dans le Bondou, serré de près par nos soldats lancés à sa poursuite.

Deux colonnes, commandées par le colonel Frey et son licutenant lo commandant Combes, venaient en effet de comm- 
mencer contre le marabout une poursuite sans trêve ni merci. La première de ces colonnes, pour couper au plus court et lui barrer le passage, n'hésita pas à traverser le désert qui s'étend entre Sénoudébou et Makhana. Les souffrances furent extrèmes. Il fallut marcher quatorze heures de suite. Aussi plusieurs auxiliaires moururent-ils de soif et d'épuisement. Mahmadou-Lamine venait d'arriver au village de Kydira. Son tam-tam de guerre retentissait dans les rues, appelant les indigènes au secours. Tout à coup éclatent des coups de fusil. Le marabout, croyant à un engagement sans importance arec les nègres, haussait les épaules de mépris; mais bientôt aux détonations isolées succèdent des feus de salve. Il s'enfuit aussitôt vers Sénoudébou. Par bonheur pour lui, le gué de Naé restait libre. Nos hommes, furieux de leur déconvenue, enlèvent le tata où les partisans du marabout essayent un simulacre de résistance, et font un immensc butin. Près de six cents femmes, un troupeau innombrable, des bagages et la bibliothèque de Mahmadou tombèrent entre leurs mains. Cette bibliothèque, à la possession de laquelle le marabout attachait une sorte de respect superstitieux, se composait de plusieurs centaines d'exemplaires du Coran, manuscrits ou imprimés, très richement reliés, qu ill arait achetés dans ses vorages ou qui lui avaient été donnés en présent par les princes musulmans.

Pendant que le nouvel Abd-el-Kader, privé de sa smalah, s'enfuyait d'abord à Sénoudébou, puis dans le Dioka, nos soldals victorieux couraient au secours de Baliel toujours assiégé. Une première bataille s'engageait à Manahel, une seconde à Guemou, et une troisième à liemandao. Les indigènes, persuadés que nous ne leur accorderions aucune grâce, nous opposèrent une résistance désespérée. Ils avaient même recouru à des pratiques superstitieuses, en égorgeant des moutons à proximité des sentiers choisis pour nous tendre des embuscades. Un des conjurateurs fut tué au moment mème où il lançait contre nous les paroles sacramentelles.

A la fin de mai non seulement Bakel était délivré et tous les villages révoltés réduits à l'obéissance, mais le marabout semblait hors d'état de jamais rentrer en campagne. Près de 
trois mille nègres avaient payé de leur vie celle folle équipéc. P'eu de campagnes avaient été plus meurtrières. Le renom de la France grandit d'autant plus que le danger avait ćlé plus sérieux.

Tous les périls n'étaient pas encore conjurés, et MahmadouLamine n'avait pas renoncé à la lutte. Lentement et péniblement il reconstituait ses forces. Installé à Dianah, la capitale du Diaka, il y avait improvisé une ciladelle redoutable, et, persuadé que la France n'irait jamais le chercher à deux cent cinquante kilomètres de Bakel, continuait ses prédications et ses agitations. Il avait même l'audace d'ènvahir le Bondou, où il surprenait et décapitait notre vieil allié Oumar-Penda. Pcu à peu se formait contre nous un orage menaçant.

Depuis septembre 1886, le nouveau commandant du Soudan français était le colonel Gallieni, le héros de la grande reconnaissance de 1880 . Très au fait des pratiques indiggènes et pénétré de la nécessité d'arrêter par un retentissant exemple toute velléité d'insurrection, Gallieni résolut de prendre l'offensive en opérant une marche convergente sur Dianah. Deux colonnes furent donc organisées qui, partant d'Arondon, en aval de Kayes, et de Diamon, en amont, devaient, malgré les cent cinquante kilomètres qui les séparaient, se réunir à jour fixe sous les murs de Dianah. L'opération était difficile, car on s'engageait dans un pays à peu près inconnu et sans route; mais Gallieni apporta les soins les plus minutieux à la préparation de l'entreprise, Tous les Européens furent montés. On leur assura une distribution journalière de soixante-quinze centilitres de vin, et du pain à discrétion. En outre, la Société des dames de France leur envoya des légumes conservés, du chocolat, du sucre, etc.

Quand tout fut prêt, le 12 décembre 1886, les deux colonnes s'enfoncèrent en pays ennemi, diminuant chaque jour la distance qui les séparait. Mahmadou-Lamine avait annoncé qu'il écraserait successivement les deux colonnes. C'était en effet la seule tactique à suivre; mais il ne sut prévenir leur jonction. Le 24 décembre, la colonne qui avait traversé le Bondou se trouvait à Pétéboki, dernière étape désignée avant Dianah, quand elle entendil le canon de la seconde colonne, 
celle qui venait du Bambouck et altaquait le village de Saroudian. Nos soldats coururent aussitôt au secours de leurs camarades. Les parlisans du marabout, pris en queue et sur le flanc, n'eurent bientôt plus d'autre ressource que de s'enfuir en désordre dans la brousse. Les deux colonnes opérèrent leur jonction sur le champ de bataille, et, désormais réunies, marchèrent sur Dianah. Elles arrivèrent sous les murs de la place le 2 o décembre, au jour précis qu'avaient prévu les instruclions de Gallieni. Le prophète n'essaya même pas de résister, et s'enfuit avec ses derniers fidèles dans la direction des territoires anglais de la Gambie.

Aussitôt commença la poursuite. Les ennemis s'arrêtèrent sur un plateau découvert, dont les pentes tombaicnt sur un marigot à fond vaseux, le marigot de Kaguibé. Les abords de la position étaient couverts par une végétation très dense, favorable aux embuscades. Nos spahis, lancés en éclaireurs, furent reçus par une fusillade à bout portant, et vivement ramenés sur le gros de la colonne, qui se forma aussitôt en carré et reprit l'offensive. Les bords du marigot et les abor 's du plateau furent défendus avec énergie; mais nos soldats balayèrent par des feux de salve les clairières, et l'on vit bientôt s'enfuir dans toules les directions les partisans du prophète. Quelques-uns d'entre eux, à l'arrière-garde, se firent bravement tuer pour donner à leur chef aimé le temps de s'enfuir. En effet, celte fois encore notre insaisissable ennemi réussit à s'esquiver; mais il ne trouva un refuge que chez les Sarakolès de Tebekouta, dans le Niani, qui confine aux possessions anglaises. Gallieni ne s'acharna pas à sa poursuite. Il rentra à Dianah et ordonna la destruction de cette place. Les voisins, épouvantés par cetle exécution et croyant aux vengeances françaises, s'enfuirent avec leurs femmes et leurs troupeaux dans les bois. On voyait dans la nuit, tout aulour de Dianah, des feux de bivouac qui allestaient leur présence. Cerles Gallieni pouvait user du droit de la guerre, brûler les villages, couper les récoltes sur pied, et transformer le pays en désert. Il préféra la douccur. Des émissaires, choisis parmi nos alliés, furent envoyés dans les bois, porteurs de paroles de clémence. Ils furent écoulés, et, 
les uns après les autres, les gens de Nieri, de Tiali, de Gamon rentrèrentdans leurs villages et acceptèrent notre protectorat.

Comprenant que rien ne serait terminé tant que MahmadouLamine tiendrait la campagne, Gallieni s'empressa d'écrire à tous les chefs de la contrée pour les menacer des vengeances françaises s'ils donnaient asile au marabout. C'est ainsi que nos généraux africains, à l'époque où ils poursuivaient $\mathrm{Abd}$ cl-Kader, avaient défendu aux chefs arabes ou marocains de recevoir l'émir. Les ordres impératifs de Gallieni furent exéculés. Un des fils de Mahmadou-Lamine, Soybou, avait essayé d'insurger le Guidimaka. Il fut pris les armes à la main au gué de Dikokori, et passé par les armes avec les plus compromis de ses compagnons. Cet acte vigoureux n'augmenta ni le nombre ni la puissance des partisans du marabout. En effet, Mahmadou-Lamine était à son tour chassé de Tébékouta, altaqué et ballu en rase campagne par les indigènes du Ouli, et finalement obligé de se réfugier, dénué de tout, à Darsalanné, près du poste anglais de Mac-Carthy. Ne se trouvant 'pas en sûreté, il se retrancha à Baracounda, sur la rive droile de la Gambie, à environ quatre-vingts lieues de la mer. C'est là qu'une colonne commandée par le capitaine Fortin, partie de l'embouchure de la Falémé, est venue l'atteindre, après une marche de plus de deux cents kilomètres à travers un pays inconnu. Le 8 décembre, Baracounda était pris, et Mahmadou-Lamine tué. Cet événement considérable nous vaut tout le bassin supérieur de la Gambie.

Les conséquences de celle septième campagne furent très importantes. Au point de vue militaire, il était démontré qu'on pouvait ravitailler une colonne engagée au Soudan fort loin de sa base d'opérations, et par conséquent ne pas se contenter de disperser, mais poursuivre à outrance et détruire tous les agitateurs nègres qui voudraient recommencer la lulte. Au point de vue politique, la frontière était reportée à trois cent cinquante kilomètres au sud du Sénégal; la fertile province du Bondou élait rattachée à notre influence, et nous nous rapprochions du Fouta-Djallon, qui doit devenir le foyer de notre puissance au Soudan. Enfin nous occupions un pays fertile, bien arrosé, peuplé d'habitants laborieux, intelligents, 
très susceptibles de progrès. Des voies commerciales nourelles étaient ouvertes vers Bakel et Médine, et il est à présumer que les caravanes reprendront leurs anciennes traditions.

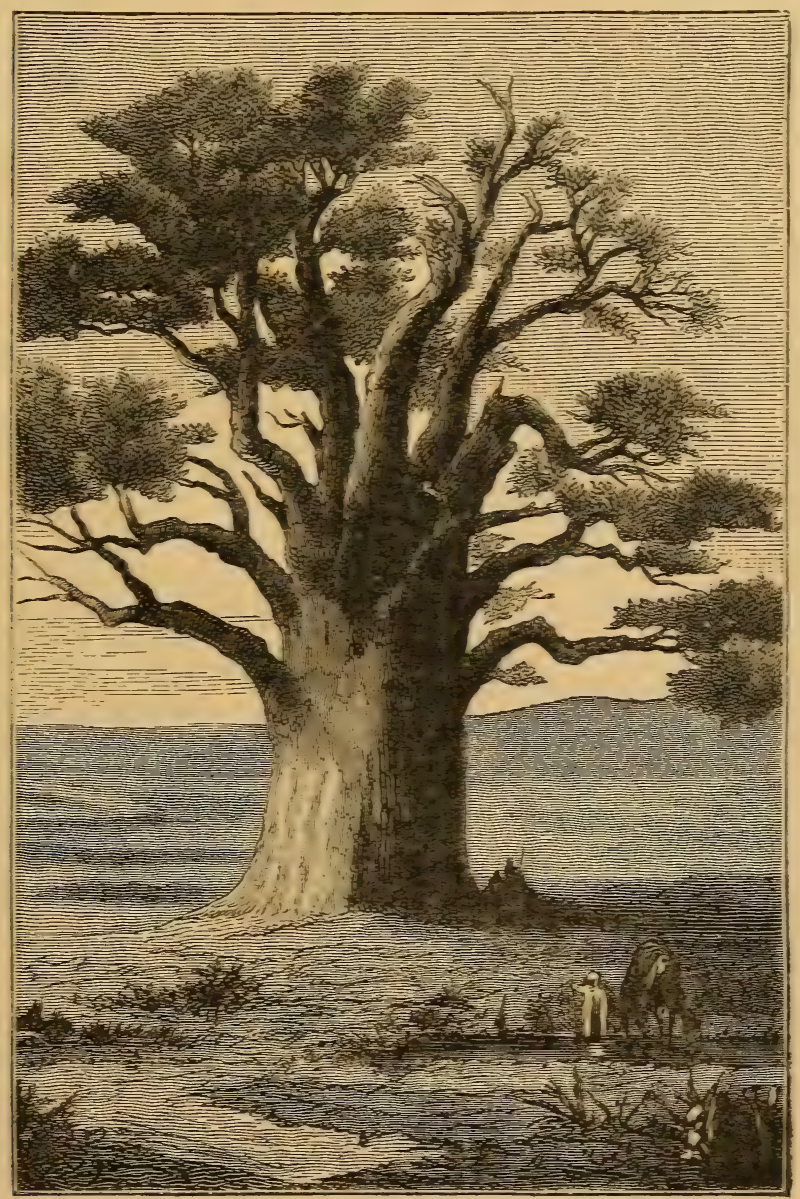

Baobab.

Deux événements importants ont encore marqué l'année 1887. Le premier est la signature d'un traité avec Samory, le second esl la prise de possession du Niger par la marine française.

Dès l’année 1886, des négociations avaient été enlamécs 
arec Samory. Trop intelligent pour ne pas comprendre qu'il avait tout à gagner à des relations de bon voisinage arec la France, le maître du Ouassoulou avait signé d'assez bonne grâce un premier traité avec le capilaine Tournier; mais ce n'étaient en quelque sorte que les préliminaires de la paix, car bien des questions n'araient élé qu'effleurées. Gallieni résolut de dissiper toutes les équiroques et organisa une nouvelle mission. La direction en fut confiée au capitaine Peroz, déjà connu de Samory, qui devait être assisté par le lieutenant Plat et le docteur Fras, chargés le premier de dresser la carte du pays, et le sccond de ramasser des collections scientifiques. Afin de préparer le terrain, on cnvoya en arant un des fils de Samory, le prince Karamolio, jeune homme qui nous avait été confié par son père et qui revenait d'un voyage en France, plein de reconnaissance pour le bou accueil qu'il arait reçu, et pénétré d'admiralion et de respect pour les merveilles de notre civilisation.

La mission partit de Dianiou le כ̊ décembre 1886. Elle arrivait à Damlio, sur le Niger, le 19 janvier 1887, mais ne recerait que le 28 du même mois l'autorisation de continuer sa marche. Arrivé à Kanlian, l’ancienne capitale, le capitaine Peroz eul l'heureuse inspiration d'accorder une récompense à la famille indigène qui, en 1827, avait bien accueilli notre compatriote René Caillié. Celte générosité rétrospective produisit une excellente impression, et nous valut de nombreuses sympathies. Les Français arrivèrent bientôt à la nouvelle capitale, Bissandougou. Ce n'est qu'une réunion de cabanes semblable à tous les villages nègres, mais très propre et bien aérée. Au centre est bâlie la résidence de Samory. Elle se compose d'un double rang de cases défendues par un rempart percé de trois porles. Au centre, dominant le tout, se dresse, comme un donjon féodal, une vaste lour carrée, où résident les farorites et où l’on a ménagé une raste salle de réception. On remarque encore une mosquée couvrant quatre cents mètres de superficie, et surmontée par un toil en charpente ingénieusement agencé. En arant de la mosquée s’étend une place rectangulaire, plantée d’arbres, où chaque vendredi Samory donne audience ou assiste à des fantasias. 
Les négocialions furent rondement menées. Ln instant tout sembla compromis, car Samory ne voulait accorder ancune concession. Grâce au bon vouloir du prince haramolio. ct surtout à l'énergie de Gallieni, dont les instructions élaient formelles, la glace finit par se rompre, et un Iraité définitif fut signé le 23 mars 1857. Samory acceptait comme limite de ses Élats le Tankisso, affluent de la rive gauche du Niger, et plaçait tout le Ouassoulou sous notre protectorat : c'est-à-dire que la France acquérait du jour au lendemain une situation prépondérante dans le Soudan occidental, et que notre ennemi de la veille devenait le plus utile des alliés. Or, ce qui semblerait indiquer que Samory est disposé à exécuter la nouvelle convention, c'est quil en a fait connaitre les conditions dans les contrées de la rive gauche du Niger qui lui étaient jadis soumises, et qu'il a comblé de prérenances et de bons offices tous les Franęais qui depuis lors se sont aventurés dans le Ouassoulou. Nous ne pourons que souhailer la continuation de ces bons rapports, car Samory est un organisateur de premier ordre; et sül consentait à devenir le porte-drapeau de la France dans le Soudan, nos progrès seraient rapides.

Il est rrai que les couleurs nationales sont aujourd hui portées dans le grand fleuve soudanien par deux canonnières françaises, le Niger et le Mage. La première de ces embarcations mesure dix-huit mètres soixante de long sur deux mètres soixante et dix de large. Son poids est de sept mille cinq cent cinquante kilogrammes, et elle a coutté soirante-sept mille francs. Elle fut transportée morceau par morceau de Médine à Bamakou, mais au prix de faligues inonies. L'enscigne Froger, chargé du transport, déploya de rares qualités d'énergie et de persévérance, car il n'avait pour auxiliaires que des nègres indolents, ct le royage dura quatre longs mois. Arrivé à Médine, il saperçut que des pièces importantes avaient été égarées. On remonta néanmoins l'embarcation, on remplaça par des tuyaulages provisoires les morceaux qui manquaient, et la canonnière fut enfin mise à l'eau. Elle ne put aller que jusqu'à Kioulikoro, à quarante kilomètres en aval de Bamakou. Ce n'en était pas moins un prenier succès d'un bon augure pour l'arenir. 
La construction d'une seconde canonnière avait été décidée, mais celle fois, pour éviter les frais de transport, le chantier devait être installé à Bamakou même. En effet, sous la direction du licutenant de vaisseau Caron fut rapidement construit un nouveau baleau de vingt-cinq mètres de long et de cinq mètres de large, jaugeant cent tonneaux. Le 4 avril 1887 , Gallieni présidait au baptême de la canonnière, à laquelle il donnait le nom prédestiné de Mage. "Honneur à vous, disaitil, mes chers compatriotes, qui avez reçu la mission, enviée de lous, d'aller montrer les couleurs de la République sur le Djoliba, aux villes inconnues qui en bordent le cours. Nos vœux les plus ardents vous accompagnent dans votre voyage, et nos cœurs de patriotes se réjouiront quand nous recevrons la nouvelle de votre arrivée au but tant désiré. " Le vœu de Gallieni s'est réalisé. Le Niger est arrivé jusqu'au port de Tombouctou, et désormais le grand fleuve africain est soumis à notre influence depuis Siguiri, au confluent du Tankisso et du Niger, jusqu'à la mystérieuse cilé où si peu d'Européens ont encore abordé.

Ce fut le $1^{\text {er }}$ juillet 1887. que le lieutenant Caron partit, avec le Mage, de Manambougou, à quarante kilomètres au-dessus de Bamakou. Il arriva sans incident à Diafarabé, où l'on célèbre joyeusement l'anniversaire du 14 juillet, et se dirigea sur Mopti afin de déboucher dans le lac Dhéboé. Le Mage pénétrait alors dans le Macina, territoire soumis à Tidiani, neveu d'Al-Hadji-Omar, un des adversaires les plus déterminés de la politique française. Caron n'hésita pas à prévenir de son arrivée le chef toucouleur, et lui demanda l'autorisation d'aller lui rendre visite dans sa capitale Bandiagara. Tidiani déteste la France, mais il n'osa pas repousser les ouvertures de son repr'sentant. Caron se dirigea donc sur Bandiagara, une des dernières citadelles du fanatisme musulman, et y arriva, après un voyage des plus pénibles, le 24 juillet. Le chef toucouleur pourvut à tous ses besoins, mais l'accueillit avec une grande froideur, et répondit à ses propositions d'alliance par un refus mal déguisé. Il est évident que les Toucouleurs redoutent notre intervention. Ils ne règnent dans le Macina qu'en s'imposant par la tcrreur, el ils craignent qu'à notre 
contact les Bambaras et les Peuls opprimés ne se révoltent en recourant à notre protectorat. Après une semaine de pourparlers inutiles, le lieutenant Caron se décida à quitter Bandiagara, et rejoignit sa canonnière.

De Bandiagara au lac Dhéboé, le Niger arrose un pays inhabité. Aussi l'équipage de la canonnière avait-il la plus grande peine à trouver le bois nécessaire au chauffage de la machine. On n'avait, en effet, emporté que huit tonnes de char-

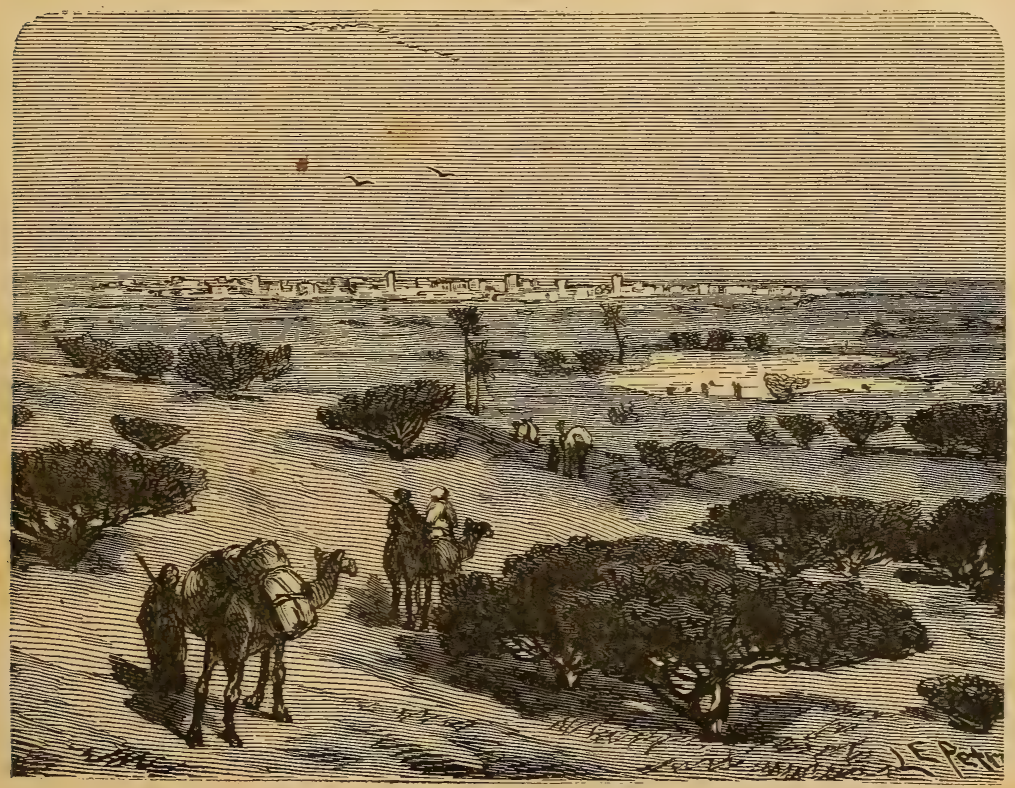

Tombouctou.

bon, et il fallait chaque jour descendie à terre pour couper du bois, au risque de s'altirer une mauvaise affaire avec les riverains, excités contre nous par Tidiani. Le 9 ju' let, les Français arrivaient dans le lac Dhéboé, nappe d'cau magnifique, sur les rives de laquelle se pressent de nombreux villages; mais Tidiani avait mis partout les populations en éveil, et jamais les Peuls ou les Bambaras ne purent approcher de nos compatriotes ou écouter leurs paroles pacifiques.

Le 15 août, les Français, en sortant du lac Dhéboé, entrèrent dans un pays soumis depuis peu aux Touaregs. Le chef 
de ces Touaregs, Alimsar, avait délégué son autorilé à un cerlain Rhiaīa, qui sétait installé à Tombouclou et faisait peser sur les indigènes une intolérable tyrannie. Aussi les nègres n'auraient-ils pas mieux demandé que d'entrer en relations arec le licutenant Caron; mais ils étaient surveillés, et les Touaregs se montrèrent nettement opposés à notre intervention. Ils prirent mème une attitude menaçante. De nombreux détachements de Touaregs armés de lances se montraient dans la plaine. Des captifs, conducteurs d'ânes, stalionnaient au bord du fleuve, comme s'ils n'altendaient quiun signal pour emporter le bulin. Caron, qui ne roulait pas tomber dans un guet-apens semblable à celui qui avait causé, quelques années auparavant, la catastrophe du colonel Flalters, rompit toute communication avec la terre, et refusa de laisser monter aucun Touareg à bord de la canonnière. Les chefs de Tombouctou lui arant fait savoir qu'ils ne voulaient pas que la France intervint dans leurs affaires, le licutenant se disposa à partir. Le 17 septembre, après un voyage fort pénible, et dans lequel il fallut se résigner à brùler le chaland qui suivait la canonnière, afin d'alimenter la machine, car les inondations empèchaient de faire à terre la provision de combustible, l'expédilion rentrait à Diafarabé, et le 6 octobre à Mamanbougou. Partout elle recevait un accueil enthousiaste. Les riverains apportaient des vivres et félicitaient les voyageurs. Aussi bien il était grand temps darriver. Les barreaux des grilles seétaient effondrés et le bois brûlait sur les cendriers. Quant à l'équipage, Européens et indigènes élaient exténués.

Les résultats de l'expédilion élaient forl importants. La latilude de Tombouctou a élé délerminée avec précision, et clle est plus au sud d'un degré environ, et plus à l'est de trente minutes que celle que l'on fisait d'habitude. Près de huit cents kilomètres ont élé lerés, qui sont entièrement noureaux. Le lac Dhéboé ne ressemble plus au lac tel qu'il figurait sur les anciennes cartes. De nombreux pays, jusqu'alors complètement inconnus, ont élé indiqués pour la première fois. En un mot, c'est toute une révélation géographique. Les explorateurs rapportent en oulre une ample moisson de 
renseignements sur le commerce de la région, la faune, la flore, le régime des eaux; ct, malgré les défiances de Tidiani, malgré les provocations des Touaregs, ils ont rempli leur mission sans tirer un coup de canon.

En résumé, voici quelle serait, aux premiers jours de 1889, la situation de la France dans le Soudan. Du Sénégal au Niger sont jetés les postes de Bafoulabé, Kila, Koundou et Niagassoula. Sur le Niger, nous possédons Bamakou, et, depuis peu, Siguiry. Celle nouvelle citadelle, sur lacuelle s'appuieront les communications entre les Rivières du Sud et le haut Niger, se trouve au confluent du Niger et du Tankisso, au cour du Bouré, le vrai pays de l'or. Sa garnison comprend une compagnie de lirailleurs avec cent mille carlouches el des vivres pour un an. Elle peut résister à toules les armées nègres de l'Afrique centrale. Samory est notre allié. Ahmadou nous déteste, mais feint de nous aimer. Mahmadou-Lamine vient d'être tué. Il scmble que de longs jours de prospérité nous sont promis, et que, de la période des conquêtes, nous entrons dans la période de l'occupation pacifique.

Déjà les licutenants de Gallieni se sont mis à l'œuvre pour reconnaître le pays. MM. Forlin et Lefort ont exploré le Niéri el le Bondou; Quiquandon, le Tiali et le Bambouck méridional; Berhemberg, la haute Falémé, le Koukandougou et le Bambougou; Oberdorf, le Niokolo, le Djallon-Kadougou el le Dinguiray. C'est par ces pays que passe la route la plus direcle pour se rendre d'un côlé aux oasis du sud algérien, et de l'autre aux fleuves qui sortent du Foula-Djallon. L'exploration qui paraît avoir été la plus féconde en résultals inattendus est celle du capitaine Binger ${ }^{1}$. Cet officier voulait combler la grande place blanche qui dans les cartes se trouve encore dans la boucle du Niger entre Siguiry, Tombouctou, Sag et la mer. Il désirait relier les travaux ct les levés exécutés sur la rive droite du grand fleuve par nos officiers avec les ilinéraires de Caillié et de Barth. Le 150 mai 1887 il partait de Kayes, et sculement en septembre de Bamaliou; car notre allié Samory, prélextant la guerre qu'il soutenait con-

1. X., Exploration du capituine Binger (Revue franfaise de l'étranger el des colonies, février 1859). Cf. Revue des Déux Mondes du ler février 1890. 
tre son voisin de l'est, le roi Ticba, avait jusqu'alors refusé de le laisser passer. Le 26 scplembre, Binger arrivait à Sikasso, qu'assiégeait alors Samory. Le pays qu'il venait de traverser élait ravagé. "Les deux premiers jours qui ont suivi mon départ de Tenetou, a-t-il écrit dans son journal de marche, j'ai complé sept et dix cadavres sur le chemin mème, sans parler de ceux qui se trouvent dans la brousse à une certaine distance, mais que l'on devine par l'odeur infecle quills répandent dans l'air. Aujourd'hui je ne les compte plus. Il y a sur la roule depuis le squelette blanchi au soleil jusqu'au moribond; les malheureux qui reviennent de la colonne ont le rictus de l'agonie sur les lèvres en me saluant; ils savent qu'ils ne, regagneront jamais leurs villages, et mon peu de vivres ne me permet pas de les secourir. Dans les rares villages où il $\mathrm{y}$ a quelques habitants, on les chasse pour ne pas être encombré par les cadarres. Beaucoup meurent sur les bords des cours d'eau, n'ayant pu les traverser à la nage... Toules les ruines sont encombrées de cadavres. ")

Binger aurait voulu jouer le rôle de médiateur; mais les chefs africains élaient résolus à continuer la guerre. Samory avait juré de prendre Sikasso, dût-il rester plusieurs années sous les murs de la place, et Tieba était résolu à prolonger la résistance. Le capilaine, ne pouvant triompher de leur obstination et risquant, par ses démarches, de s'altirer la défiance des deux partis, crut prudent de rebrousser chemin, afin de rendre comple de ses observations au colonel Gallieni.

Le 16 octobre il se remeltait en marche, mais n'arrivait que le 17 janvier 1888 dans les Élals de Tieba, et le 3 février dans la ville de Kong. C'est une agglomération de dix mille noirs, divisés en sepl grands quartiers et quelques faubourgs. Elle est placée sous la suzeraineté de la famille Ouattara, qui a réussi à maintenir dans la région un calme relatif. Aussi Kong est-il rapidement devenu un centre important de commerce. Accueilli d'abord avec défiance par la population, qui voyait en lui un émissaire de Samory, Binger se mit sous la proteclion des marabouts, qui forment la classe dirigeante. Dès lors sa sécurité fut assurée, et il put à son aise explorer. 
le pays et rcgagner la côte. On ne connaît pas encore le détail de cette belle et féconde exploration.

Aussi bien, les différents chefs africains paraissent avoir renoncé à leurs sentiments hostiles contre les Européens, et spécialement contre les Français. Ainsi que l'écrivait un de nos plus vaillants explorateurs, le docteur Colin, "la sécurité de l'Européen dans le Soudan occidental est aujourd'hui absolue. Je m'en irais sans hésitation, avec une canne pour toute arme, de Bakel au Niger, par les bords du fleuve, par le Bambouck, par le Gangaran, peu importe. Je suis persuadé que j'y serais non seulement respecté, mais encore bien accueilli. "

Les Indes africaines s'ouvrent donc à nous. Il y a un siècle, nous avons perdu l'occasion de nous emparer de l'Hindoustan. Espérons que nous profiterons des leçons du passé, et que nous saisirons l'occasion inespérée qui s'offre à nous de réparer nos pertes, et de fonder la grandeur coloniale de la France en Afrique. 



\section{TABLE DES MATIÈRES}

I. - Géographie physique du Sénégal...............

II. - Géographie économique..................... 19

III. - Géographie politique...................... 38

IV. - Histoire du Sénégal depuis les origines jusqu'à l'année 1815. 71

V. - Histoire du Sénégal de 1815 à $1854 \ldots \ldots \ldots \ldots \ldots \ldots \ldots . \ldots 2$

VI. - Conquête du Oualo. - Refoulement des Naures. - Expéditions du Sine et du Saloum. - Guerres du Cayor..... 101

VII. - Guerres contre le prophète Al-Hadji-Omar et ses successeurs. 120

VIII. - Réformes administratives du général Faidherbe........ 138

IX. - Le Sénégal de 1864 à nos jours.................. 148

X. - Voyages de pénétration au Soudan............... 158

XI. - Conquête du Soudan français................... 190

XII. - Consolidation de la puissance française au Sénégal et au Soudan.................................. 221 


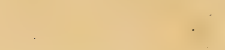


$x+2$ 


